\title{
SPECTROSCOPICALLY EVALUATED RATES AND ENERGIES \\ FOR PROTON TRANSFER AND BJERRUM DEFECT \\ MIGRATION IN CUBIC ICE
}

\author{
By \\ WILLIAM BRIDGMAN COLLIER \\ Bachelor of Science \\ Oral Roberts University \\ Tulsa, Oklahoma \\ 1977 \\ Master of Science \\ Oklahoma State University \\ Stillwater, Oklahoma \\ 1981
}

Submitted to the Faculty of the Graduate College of the Oklahoma State University

in partial fulfillment of the requirements

for the Degree of

DOCTOR OF PHILOSOPHY

December, 1983 


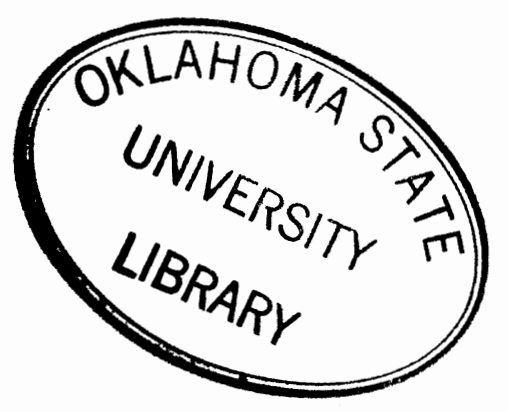

SPECTROSCOPICALLY EVALUATED RATES AND ENERGIES

FOR PROTON TRANSFER AND BJERRUM DEFECT

MIGRATION IN CUBIC ICE

Thesis Approved:

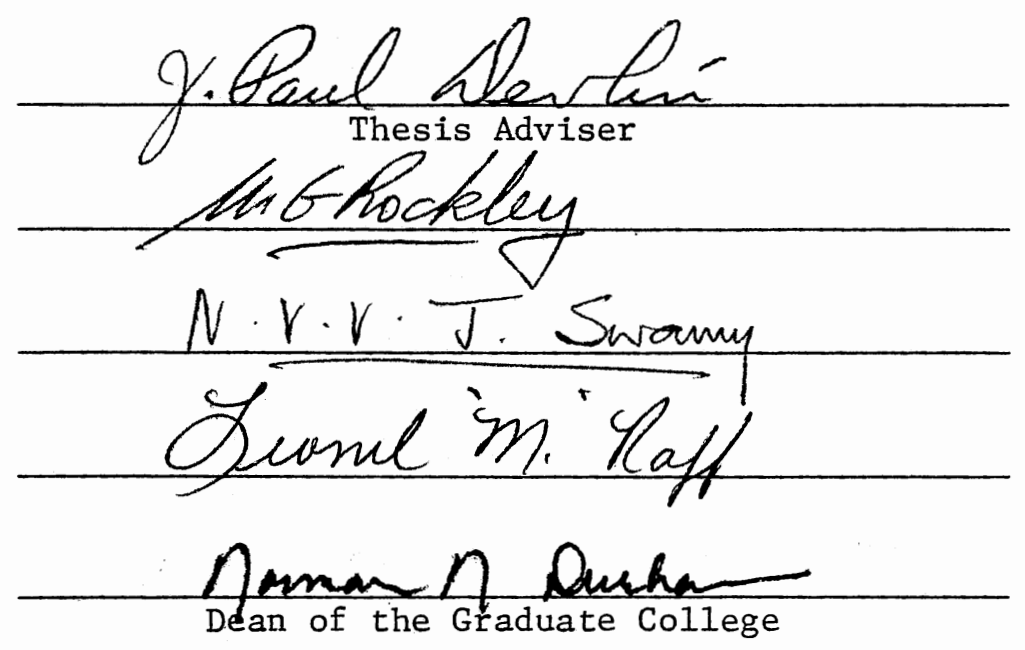




\section{ACKNOWLEDGMENTS}

Science and its advancement depends heavily on the support of fellow researchers and the labors of scientists long past. Truly no research work is the product of one individual, but rather a team. I would like to take this opportunity to acknowledge a small part of that team.

A very special thanks goes to my research adviser, Dr. J. Paul Devlin, for his insight, patience, and encouragement, especially during the more frustrating moments of the project. Thanks go to Dr. G. J. Mains, Dr. Mark G. Rockley, Dr. Lionel M. Raff, and Dr. N. V. V. Swamy for consenting to serve on my committee and rendering needed advice. Financial support from the National Science Foundation and the Oklahoma State University Chemistry Department are gratefully acknowledged.

Much of the joy of learning and research come from interactions with faculty, fellow students, and fellow workers. To the following I would like to give thanks for friendship, helpful discussions, and constructive criticisms: Gary Ritzhaupt, Hugh Richardson, and Keith Consani, in-house members of Dr. Devlin's research group. A special thanks goes to Gary for laying the experimental groundwork for this thesis, and collecting some data for me during a summer's absence. Jim Thompsen and Dennis Fine are to be thanked for encouragement, friendship, and constructive criticism from an analytical chemistry viewpoint. 
To my parents, John R. and Carrie M. Collier, goes a debt of gratitude for love, patience, and help, above and beyond all call of duty. Without their support this work would never have materialized. And lastly goes honor and gratitude to Almighty God, the author of all original thought, and creator of ice in the first place. 
TABLE OF CONTENTS

Chapter

Page

I. LITERATURE REVIEW . . . . . . . . . . . . . . . 1

Introduction . . . . . . . . . . . . . 1

Pure Ice Spectra . . . . . . . . . . . . . 7

Matrix Isolated Decoupled Ice Spectra . . . . . . 15

Theory of Ice Spectra . . . . . . . . . . . . 18

Proton Transfer in Ice . . . . . . . . . . . 21

Presentation of Problem............. 29

II. EXPERIMENTAL PROCEDURES AND RESULTS . . . . . . . . . 31

Matrix Isolation Methods . . . . . . . . . 31

Metal Cell Technique .. . . . . . . . . . 31

Glass Cell Apparatus ... . . . . . . . . . 35

Procedure . . . . . . . . . . . . . . 42

III. DATA TREATMENT AND THEORY DEVELOPMENT . . . . . . . . 49

Resolution of the Kinetic Spectral Data... . . . 49

Determination of Relative Molar Absorptivities . . . 71

Mode1 Development . . . . . . . . . . . . 81

Determining Rate Constant Relationships . . . . . . 86

Solution and Data Analysis of the Models . . . . . 100

IV. RESULTS AND CONCLUSIONS . . . . . . . . . . . 106

Spectral and Concentration Data .......... 106

Nonlinear Least Square Strategy . . . . . . . . . 110

Transfer and Rotational Activation Energies . . . . 141

Discussion of Activation Energies . . . . . . . . 145

Summary . . . . . . . . . . . . . 147

REFERENCES ...................... 150

APPENDIX A - FORTRAN PROGRAM REMOLE . . . . . . . . . . . 1.53

APPENDIX B - INPUT INSTRUCTIONS TO FORTRAN SUBROUTINE DGEAR • • • 165

APPENDIX C - FORTRAN PROGRAM NLLSQ1 • . . • . . . . . . . 175

APPENDIX D - SAS PROGRAM ACTIV . . . . . . . . . . . . 189 


\section{LIST OF TABLES}

Table

Page

I. Collection Parameters Used for Collecting Kinetic

Data . . . . . . . . . . . . . 4 47

II. Absorbances and Scaling Factors for Resolved OD

Stretch Multiplets . . . . . . . . . . . 64

III. Relative Molar Absorptivities . . . . . . . . . 77

IV. Relative Concentrations Determined from Absorbance

Data ................... 78

V. Relative Probability Factors for Transfer Migration . . . 89

VI. Relative Probability Factors for Rotational Migration . • 93

VII. Least Square Calculated Rate Constants for One and Two Equilibrium Models . . . . . . . . . . . 111

VIII. Transfer and Rotational Activation Energies . . . . . . 142 
LIST OF FIGURES

Figure $\quad$ Page

1. Oxygen Lattice Structure of Hexagonal Ice . . . . . . . . . 3

2. Possible Hydrogen Configuration in Ice Ih . . . . . . • . . 3

3. Ice Crystal Lattice Defects . . . . . . . . . . . . . 6

4. Oxygen Lattice Structure of Cubic Ice . . . . . . • . • . $~ .8$

5. Free $\mathrm{H}_{2} \mathrm{O}$ Normal Modes of Vibration . . . . . . . . . . . . 9

6. $\mathrm{D}_{2} \mathrm{O}$ Spectral Changes with Isotopic Exchange . • . • . • . 26

7. (HOD) 2 Spectral Changes with Isotopic Exchange . • • • • • • 27

8. Air Products CS-202 Displacer/Expander Module with Tip and Sample Deposition Window . . . . . . . . . . . 32

9. Brass Vacuum Shroud for Displacer/Expander Module • • • • • 33

10. Glass Cryostat Cell for Vapor Deposition • • • • • • • • • 36

11. Expanded $\mathrm{D}_{2} \mathrm{O}$ Decoupled in $\mathrm{H}_{2} \mathrm{O}$ Ice $v_{3}$ Bandshapes . • • • • •

12. Nitrogen Gas Cooler System for Glass Cryostat Ce11 • • • • • 40

13. Spectral Changes Occurring between Amorphous and Cubic

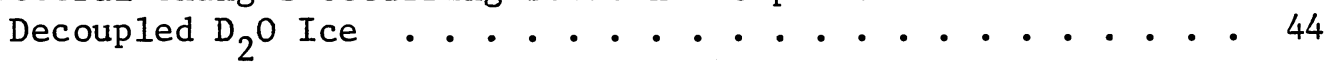

14. $\mathrm{D}_{2} \mathrm{O}$ Decoupled in $\mathrm{H}_{2} \mathrm{O}$ Cubic Ice Infrared Spectrum • • • • • • 45

15. OD Stretch Multiplet of $\mathrm{D}_{2} \mathrm{O}$ Decoupled in $\mathrm{H}_{2} \mathrm{O}$ Ice • • • • • • 50

16. Time Variation of OD Stretch Multiplet with Proton

Exchange . . . . . . . . . . . . . . . . 51

17. 7-Azaindole Doped $\mathrm{D}_{2} \mathrm{O} / \mathrm{H}_{2} \mathrm{O}$ Ice Deposit Spectral Resolution $• \quad 54$

18. Pure Component $\mathrm{D}_{2} \mathrm{O} \nu_{3}$ Bandshapes from Glass Cell • • • • • • 55

19. Subtraction of $\mathrm{H}_{2} \mathrm{O}$ Combination Shoulder from OD Multiplet . 56

20. Subtraction of $\mathrm{D}_{2} \mathrm{O}$ Component from OD Multiplet • • • • • • 58 
21. Subtraction of Uncoupled HOD Component from HOD Multiplet . . 59

22. Subtraction of HOD Multiplet from OD Multiplet . . . . . 61

23. $\mathrm{D}_{2} \mathrm{O}$ Scaling Factor Deviation Effects on Coupled HOD

Bandshapes .................. 62

24. REMOLE Dataset Coverage and Analysis . . . . . . . . 75

25. a) Hydrogen Bonded Chain in Cubic Ice; b) Possible Proton Transfer Positions; c) Example $2 \mathrm{HOD}_{\mathrm{nm}}$ Configurations • • 82

26. $\mathrm{D}_{2} \mathrm{O}_{11}$ to $2 \mathrm{HOD}_{\mathrm{nm}}$ Migration Mechanism . . . . . . . . 84

27. Proton Transfer Steps for Deuterium Migration . . . . . 88

28. Proton Transfer Steps for Deuterium Migration . . . . . . 91

29. Proton Rotational Steps for Deuteron Migration . . . . . . 94

30. Proton Rotational Steps for Deuteron Migration . . . . . 95

31. Coupled HOD Absorbance Spectrum of $145 \mathrm{~K}$. . . . . . . 107

32. a) Possible Coupled Configurations in Cubic Ice Lattice;

b) Amorphous Induced Bands in Coupled HOD Bandshapes . . . 109

33. Experimental and One Equilibrium Model Calculated Relative Concentration Curves for 6/7/82 $150 \mathrm{~K}$ Data . . . . . . 113

34. Experimental and Two Equilibrium Model Calculated Relative Concentration Curves for 2/2/82 $150 \mathrm{~K}$ Data . . . . . 116

35. Experimental and Two Equilibrium Model Calculated Relative Concentration Curves for 6/7/82 $150 \mathrm{~K}$ Data . . . . . . 117

36. Experimental and Two Equilibrium Model Calculated Relative Concentration Curves for 6/9/82 $150 \mathrm{~K}$ Data . . . . . . 118

37. Experimental and Two Equilibrium Model Calculated Relative Concentration Curves for 1/29/82 $145 \mathrm{~K}$ Data . . . . . . 119

38. Experimental and Two Equilibrium Model Calculated Relative Concentration Curves for 5/10/82 $145 \mathrm{~K}$ Data . . . . . 120

39. Experimental and Two Equilibrium Model Calculated Relative Concentration Curves for 5/24/82 $145 \mathrm{~K}$ Data . . . . . . 121

40. Experimental and Two Equilibrium Model Calculated Relative Concentration Curves for 6/3/82 $145 \mathrm{~K}$ Data . . . . . . . 122 
Figure

41. Experimental and Two Equilibrium Model Calculated Relative Concentration Curves for 5/4/82 $140 \mathrm{~K}$ Data . . . . . . . 123

42. Experimental and Two Equilibrium Mode1 Calculated Relative Concentration Curves for 5/25/82 $140 \mathrm{~K}$ Data . . . . . . 124

43. Experimental and Two Equilibrium Model Calculated Relative Concentration Curves for 5/15/83 $140 \mathrm{~K}$ Data . . . . . . 125

44. Experimental and Two Equilibrium Model Calculated Relative Concentration Curves for 5/26/82 $135 \mathrm{~K}$ Data . . . . . . 126

45. Experimental and Two Equilibrium Model Calculated Relative Concentration Curves for 6/11/82 $135 \mathrm{~K}$ Data . . . . . . 127

46. Calculated $\mathrm{D}_{2} \mathrm{O}_{11}$ and $2 \mathrm{HOD}_{\mathrm{nm}}$ Configuration Concentration Curves for $272 / 82150 \mathrm{k}$ Data . . . . . . . . . . 129

47. Calculated $\mathrm{D}_{2} \mathrm{O}_{11}$ and $2 \mathrm{HOD}_{\mathrm{nm}}$ Configuration Concentration Curves for $677 / 82150 \mathrm{k}$ Data . . . . . . . . . . 130

48. Calculated $\mathrm{D}_{2} \mathrm{O}_{11}$ and $2 \mathrm{HOD}_{\mathrm{nm}}$ Configuration Concentration Curves for 6/9/82 $150 \mathrm{~K}$ Data . . . . . . . . . . . 131

49. Calculated $\mathrm{D}_{2} \mathrm{O}_{11}$ and $2 \mathrm{HOD}_{\mathrm{nm}}$ Configuration Concentration Curves for $1 / 29 / 82145 \mathrm{~K}$ Data . . . . . . . . . . . 132

50. Calculated $\mathrm{D}_{2} \mathrm{O}_{11}$ and $2 \mathrm{HOD}_{\mathrm{nm}}$ Configuration Concentration Curves for 5/10/82 $145 \mathrm{~K}$ Data . . . . . . . . . . 133

51. Calculated $\mathrm{D}_{2} \mathrm{O}_{11}$ and $2 \mathrm{HOD}_{\mathrm{nm}}$ Configuration Concentration Curves for 5/24/82 $145 \mathrm{~K}$ Data . . . . . . . . . 134

52. Calculated $\mathrm{D}_{2} \mathrm{O}_{11}$ and $2 \mathrm{HOD}_{\mathrm{nm}}$ Configuration Concentration Curves for 6/3/82 $145 \mathrm{k}$ Data . . . . . . . . . . 135

53. Calculated $\mathrm{D}_{2} \mathrm{O}_{11}$ and $2 \mathrm{HOD}_{\mathrm{nm}}$ Configuration Concentration Curves for 5/11/82 $140 \mathrm{~K}$ Data . . . . . . . . . . 136

54. Calculated $\mathrm{D}_{2} \mathrm{O}_{11}$ and $2 \mathrm{HOD}_{\mathrm{nm}}$ Configuration Concentration Curves for 5725/82 $140 \mathrm{~K}$ Data . . . . . . . . . . 137

55. Calculated $\mathrm{D}_{2} \mathrm{O}_{11}$ and $2 \mathrm{HOD}_{\mathrm{nm}}$ Configuration Concentration Curves for 5/15/82 $135 \mathrm{~K}$ Data . . . . . . . . . 138

56. Calculated $\mathrm{D}_{2} \mathrm{O}_{11}$ and $2 \mathrm{HOD}_{\mathrm{nm}}$ Configuration Concentration Curves for 5/28/82 $135 \mathrm{~K}$ Data . . . . . . . . . 139

57. Calculated $\mathrm{D}_{2} \mathrm{O}_{11}$ and $2 \mathrm{HOD}_{\mathrm{nm}}$ Configuration Concentration Curves for $6 / 11 / 82135 \mathrm{~K}$ Data . . . . . . . . . 140

58. Transfer and Rotational Rate Constants Arrhenius Plots . . . 143 
CHAPTER I

\section{LITERATURE REVIEW}

\section{Introduction}

Ice is a peculiar solid. Its unique properties have fascinated scientists for decades but surprisingly its behavior and structure is still often ambiguous. The importance of ice to chemistry, physics, geophysics, atmospheric science, hydrology, cryobiology, molecular biology, and other fields has grown and with it an immense volume of published research. Any review of ice must be necessarily selective and the present work is no exception. The main focus will be the areas of ice research related to the spectroscopy of ice with special emphasis on proton transfer.

Ice can exist in several solid phases. The low pressure forms are amorphous or vitreous ice (ice $\mathrm{Ia}$ or Iv), cubic ice (ice Ic), and the naturally occurring hexagonal ice (ice Ih). Sometimes cubic and hexagonal ice mixtures or hexagonal ice alone is referred to as polycrystalline ice I. The presently known high pressure polymorphs are ice II-VII and are accessible at pressures in the kilobar range. As early as 1917 (1) x-ray diffraction studies on ice were pursued. In 1922 Bragg (2) deduced that each oxygen atom is located at the center of gravity of its four neighboring oxygen atoms for hexagonal ice. Since then modern $x$-ray and electron diffraction data (3) have confirmed that hexagonal ice is composed of tetrahedrally 
coordinated oxygen atoms stacked such that it gives a hexagonal crystal structure. Figure 1 gives the oxygen lattice structure of hexagonal ice with its dimensions. Notice that the oxygen atoms can be grouped into a series of rough planes called basal planes that are normal to the crystal c-axis. By looking parallel to the c-axis the hexagonal holes of ice Ih are readily seen. This open structure gives hexagonal ice its lower than liquid water density.

Since each oxygen atom has two bonded hydrogen atoms, the oxygen lattice must somehow accommodate these hydrogens. One early suggestion by Barnes (4) was to put the hydrogens midway between each oxygenoxygen link. This would preserve the symmetry and stoichiometry of the crystal. However this arrangement was ruled out since the water molecule would be ionized into $\mathrm{H}^{+}$and $\mathrm{O}^{2-}$ ions, and water is a poor electrical conductor. Bernal and Fowler (5) suggests that the hydrogens were distributed between the oxygen-oxygen bonds but displaced such that a given hydrogen atom was about 1 angstrom from one oxygen atom and 1.76 angstroms from the other with the arrangement of hydrogen atoms in the complete lattice such that each oxygen atom has two hydrogens chemically bonded at 1 angstrom and two hydrogen bonds to two adjacent water molecules with the hydrogen at 1.76 angstroms. Figure 2 illustrates Bernal and Fowler's suggestion. A closer examination of this model reveals a water subunit with a $\mathrm{HOH}$ angle of approximately $109^{\circ}$ compared with the gas phase value of approximately $105^{\circ}$. The $\mathrm{OH}$ bond length is 1 angstrom compared with .97 angstrom for the gas phase. Thus the distortion of a water molecule transcending the gas to ice transition is slight. Some researchers have even suggested that the $\mathrm{H}_{2} \mathrm{O}$ subunit retains its gas phase angle in the hexagonal phase ice such that the 


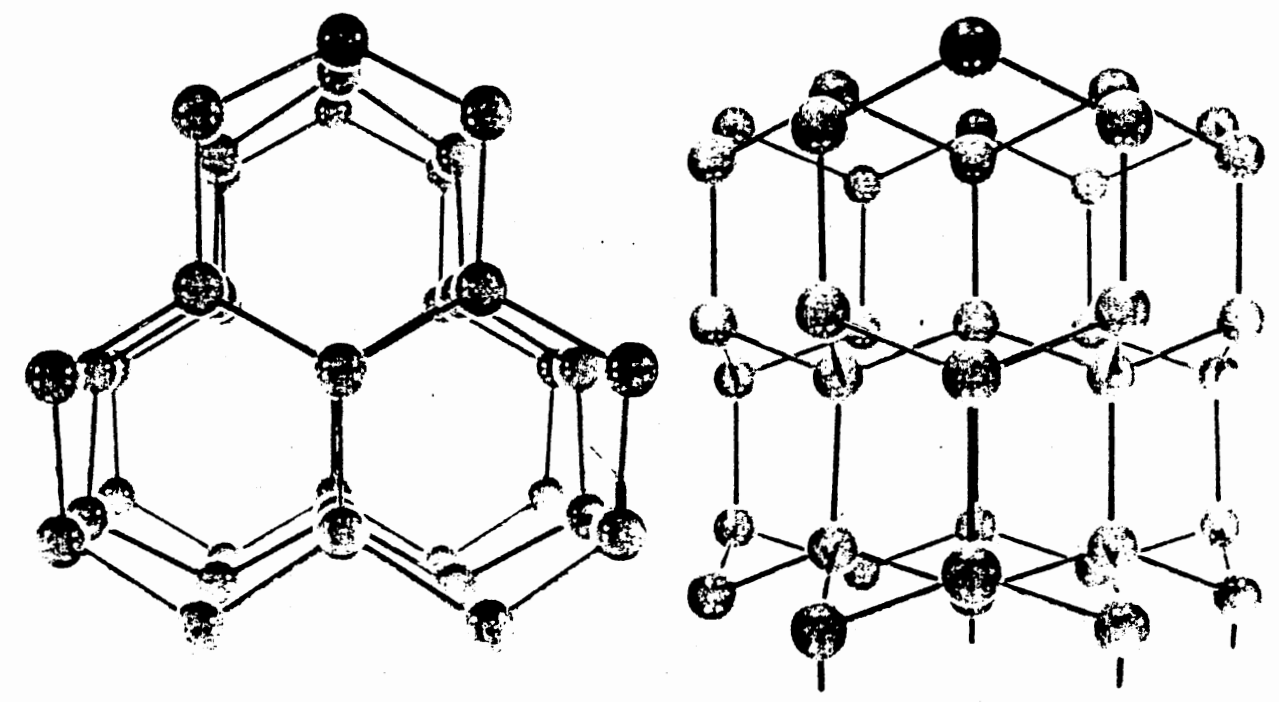

Figure 1. Oxygen Lattice Structure of Hexagonal Ice
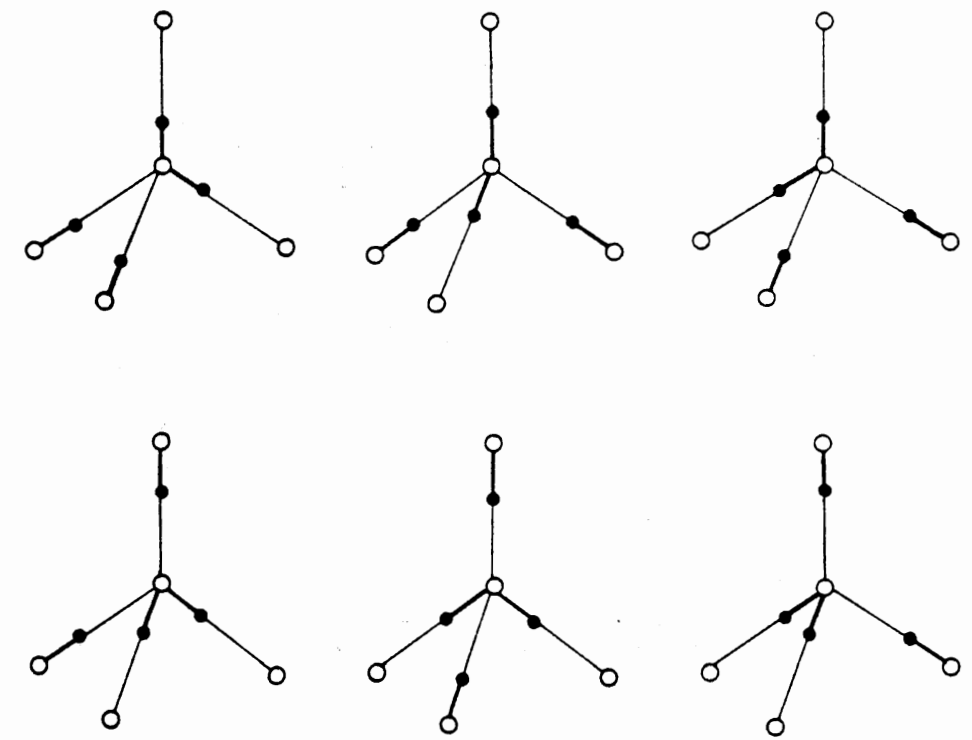

Figure 2. Possible Hydrogen Configuration in Ice Ih 
hydrogens lie slightly off center of the 0-0 lines.

One interesting implication of the Bernal and Fowler model is that around any given oxygen atom there are six possible configurations of hydrogens as Figure 2 illustrates. Thus even at $0 \mathrm{~K}$ ice Ih may freeze into a number of different possible hydrogen configurations leaving ice with a nonzero thermodynamic probability and hence a nonzero residual entrophy at $0 \mathrm{~K}$. This led Pauling (6) to propose a statistical model for ice Ih with the following assumptions.

(1) Each oxygen atom has two hydrogen atoms attached at distances of about 0.95 angstroms, thus forming a water molecule.

(2) Each water molecule is oriented so that its two hydrogen atoms are directed approximately towards two of the four oxygen atoms which surround it tetrahedrally.

(3) The orientations of neighboring water molecules are such that one hydrogen atom normally lies between each pair of oxygen atoms.

(4) Under normal conditions ice Ih can exist in any one of a large number of configurations, each of which corresponds to a particular hydrogen atom distribution among the oxygen lattice. (p. 2680).

These four assumptions are of ten called the Bernal and Fowler rules and ice crystals which follow them are called ideal crystals.

Bjerrum (7) in 1951 proposed ice crystal defects that could facilitate proton transfer. These defects named Bjerrum defects are created when the third Bernal and Fowler rule is violated. A D defect is formed when two hydrogen atoms occupy an 0-0 bond and an $\mathrm{L}$ defect is formed when an $0-0$ bond is left vacant. In conjunction with ionization defects, these could allow positive and negative ionic charges to migrate through the ice crystal. If a hydrogen ion in an ideal hexagonal ice crystal shifts from one $\mathrm{OH}$ bonded position to the $\mathrm{OH}$ 
bonded position of the adjacent oxygen, i.e. a movement of approximately .24 angstroms of a hydrogen to the adjacent hydrogen bonded oxygen, then two ion defects will be formed. One will be the $\mathrm{H}_{3} \mathrm{O}^{+}$ion about the oxygen the defect moved toward, the other a hydroxyl $-\mathrm{OH}$ ion left behind. Figure 3 illustrates these defects.

As mentioned earlier, there are presently two other known low pressure phases of ice, amorphous ice (ice Ia or Iv) and cubic ice (ice Ic). If water vapor is condensed on a substrate below $130 \mathrm{~K}$ ice Ia is formed. If the temperature is above $130 \mathrm{~K}$ and below approximately $170 \mathrm{~K}-190 \mathrm{~K}$ then cubic ice is formed. Above $190 \mathrm{~K}$ hexagonal ice tends to form, though it should be noted that the exact temperatures are disputed.

Amorphous ice has a disordered structure associated with it since the energy of the substrate is not sufficient to allow a deposited water molecule to reorient itself to a more energetically favorable position. Because of the lack of structural order amorphous ice has been studied as a possible model for liquid water structure.

Cubic ice can be made in situ by direct vapor deposition, or by warming amorphous ice to above the cubic ice transition temperatures as noted by Honjo et al. (8). The oxygen lattice of cubic ice is almost identical to the hexagonal lattice except that every alternate basal plane is rotated $60^{\circ}$ about the crystal c-axis relative to the adjacent nonrotated basal planes. This preserves the tetrahedral oxygen lattice but removes the hexagonal holes along the c-axis. Honjo and Shimaoko (9) investigated the possible hydrogen atom positions of cubic ice using electron diffraction and found that the cubic equivalent of Pauling's statistical model of ice Ih still holds. 


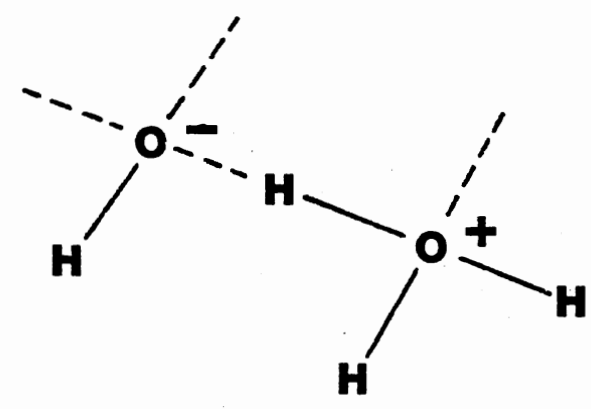

ION PAIR DEFECT
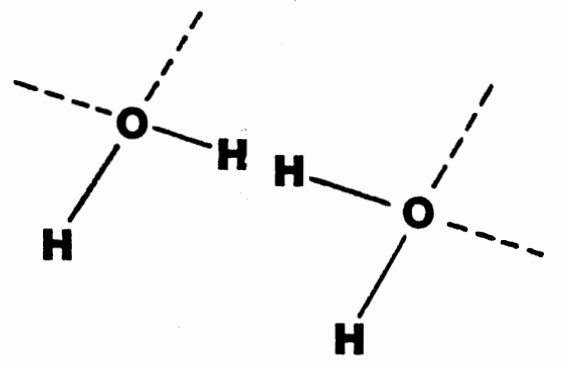

D ROTATIONAL DEFECT

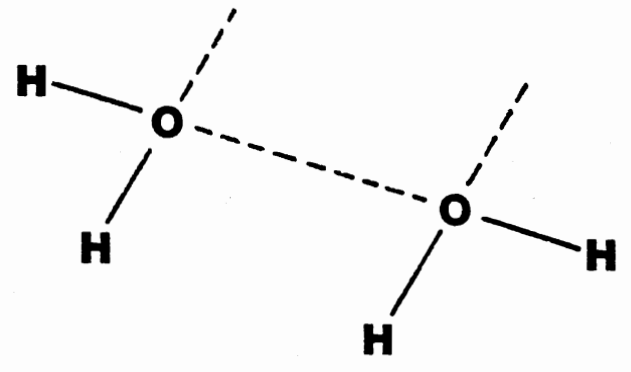

L ROTATIONAL DEFECT

Figure 3. Ice Crystal Lattice Defects 
Further evidence of the cubic hydrogen atom positions comes from infrared spectroscopy where, to date, no definite difference has been detected between the cubic and hexagonal ice IR spectra. Likewise it appears that the Bjerrum and ionization defects of hexagonal ice also apply to cubic ice. The oxygen lattice structure of cubic ice is shown in Figure 4.

The $\mathrm{H}_{2} \mathrm{O}$ molecule possesses a $\mathrm{C}_{2 \mathrm{~V}}$ symmetry with three normal modes of vibration as shown in Figure 5 . The $v_{3}$ vibration is the asymmetric stretch belonging to the $B_{1}$ irreducible representation and occurs in the $3000-3500 \mathrm{~cm}^{-1}$ region for $\mathrm{H}_{2} \mathrm{O}$ and $2200-2600 \mathrm{~cm}^{-1}$ for $\mathrm{D}_{2} \mathrm{O}$. The $\nu_{1}$ vibration is the symmetric stretching mode belonging to the $A_{1}$ irreducible representation, and has a wavenumber range similar to $v_{3}$. The $v_{2}$ bending vibration also belongs to the $\mathrm{A}_{1}$ irreducible representation and usually is found around $1500-1800$ $\mathrm{cm}^{-1}$ for $\mathrm{H}_{2} \mathrm{O}$ and $1100-1300 \mathrm{~cm}^{-1}$ for $\mathrm{D}_{2} \mathrm{O}$. In ice and liquid water $\nu_{3}$ and $\nu_{1}$ are found in the $\mathrm{OH}$ stretching region as a very broad almost featureless band whose width has traditionally been attributed to hydrogen bonding. Certain lattice modes are found below $v_{2}$ and their combinations with other modes are often interspersed among the fundamentals.

\section{Pure Ice Spectra}

The spectra of pure ice has been studied for many years. Bertie and Whalley have figured significantly in the early characterizations of the ice IR spectra.

In 1968 Bertie, Labbe', and Whalley (10) examined the absorptivity of ice $I$ in the 4000 to $30 \mathrm{~cm}^{-1}$ range. True absorptivity profiles of 

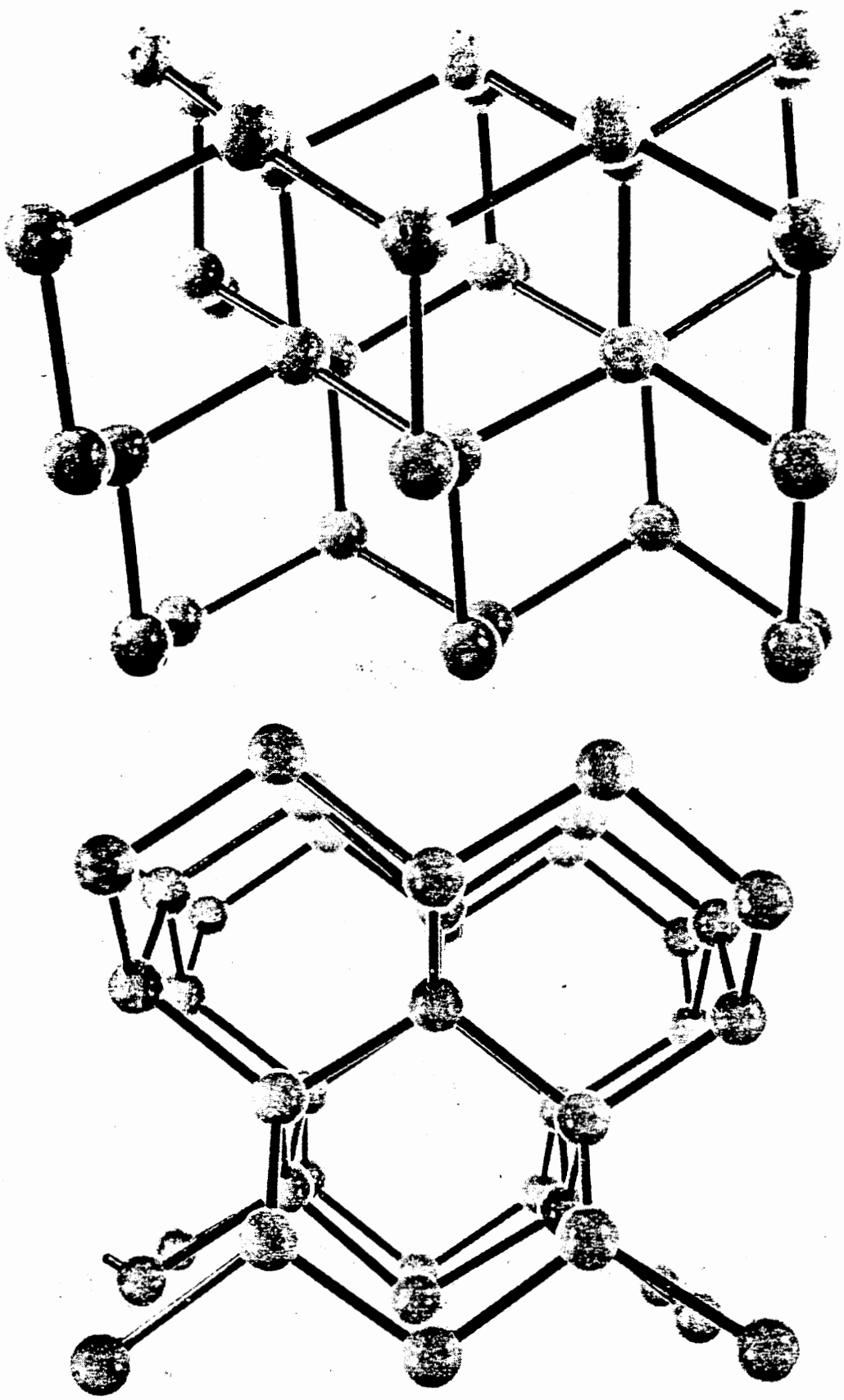

Figure 4. Oxygen Lattice Structure of Cubic Ice 
$\nu_{1}$ Symmetric Stretching Mode
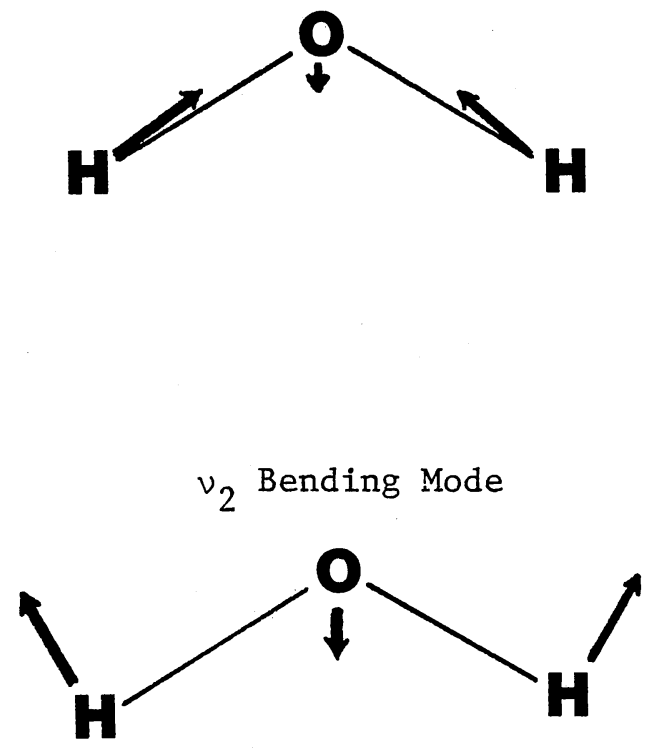

$\nu_{3}$ Asymmetric Stretching Mode

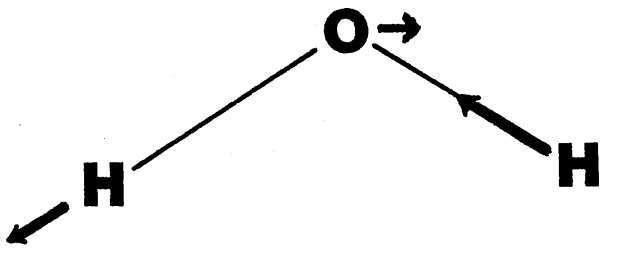

Figure 5. Free $\mathrm{H}_{2} \mathrm{O}$ Normal Modes of Vibration 
solid state ice can be difficult to obtain, especially near large absorptivities where the infrared index of refraction changes dramatically. Therefore a true absorptivity profile that accounted for reflection and scattering losses would facilitate interpretation of ice spectra.

The vitreous to cubic ice I phase transition was studied by Hardin and Harvey (11) by monitoring the bandshape changes of several bands over a 92 to $210 \mathrm{~K}$ temperature range. They reported the well known sharpening of the vitreous ice bands upon transformation to the cubic phase. One exception noted was the vitreous ice $v_{2}$ bending mode whose half-height bandwidth was reported as $350 \pm 10 \mathrm{~cm}^{-1}$ in the amorphous phase but $365 \pm 10 \mathrm{~cm}^{-1}$ in the cubic phase. The transition for this band was between $123 \pm 5 \mathrm{~K}$ and $137 \pm 5 \mathrm{~K}$. However the $800 \mathrm{~cm}^{-1} \nu_{\mathrm{r}}$ showed a $-25 \mathrm{~cm}^{-1}$ decrease in bandwidth at $92 \mathrm{~K}$ as expected. Ice Iv transformed over a $120 \pm 5$ to $135 \pm 5 \mathrm{~K}$ temperature range. They concluded that vitreous (or ice Iv or $\mathrm{Ia}$ ) ice is stable up to $120 \pm 5 \mathrm{~K}$ and undergoes an irreversible transformation to cubic ice between 120 and $140 \mathrm{~K}$. Hardin and Harvey felt confident that their spectra represented cubic ice and did contain some small discernable differences from the spectra of hexagonal ice.

In $1973 \mathrm{Li}$ and Devlin reported the glassy water Raman spectra from a trapped laser beam. Both polarized and depolarized spectra in the 3570 to $2950 \mathrm{~cm}^{-1}$ region were reported where $v_{1}$ was located at $3110 \mathrm{~cm}^{-1}$ and $2 v_{2}$ at approximately $3250 \mathrm{~cm}^{-1}$. In 1975 Narten, Venkatesh, and Rice (13) obtained x-ray diffraction data on amorphous $\mathrm{H}_{2} \mathrm{O}$ and compared it with neutron diffraction data. They suggested a high density $10 \mathrm{~K}$ ice and a low density $77 \mathrm{~K}$ ice amorphous ice phase 
to explain their data. Their model predicted a randomized ice I structure, with interstitial molecules, having a density of 1.1 grams $/ \mathrm{cm}^{3}$. Their model was also consistent with the predictions of supercooled water; with no structural changes other than a contraction of the 0-0 separations. Thus Narten et al. suggested that the low temperature phase of amorphous ice may serve as a model for liquid water.

Whalley (14) studied the spectra of ice Ic and Ih and presented a detailed assignment based on the spectrum of ice VIII. Whalley noted that assignments can be difficult because the vibrations can not be treated as arising from a single molecule, but due to the strong intermolecular coupling that exists in ice, the coupled crystalline lattice. He split the ice $I v_{1}$ mode into in-phase and out-of-phase components at $3083 \mathrm{~cm}^{-1}$ and $3420 \mathrm{~cm}^{-1}$, respectively and the $v_{3}$ band into the TO and LO components of $3209 \mathrm{~cm}^{-1}$ and 3323 $\mathrm{cm}^{-1}$, respectively. Whalley contended that there should be strong similarities between the spectra of ordered and disordered ice Ic, and that the spectra of ice Ic and Ih are identical.

Scherer and Snyder (15) measured the Raman intensities of a single crystal of ice Ih at various crystallographic orientations. Their analysis suggested that the hydrogen bonds parallel to the crystallographic c-axis are more linear than the equatorial ones. They disagreed with Whalley's (14) $3209 \mathrm{~cm}^{-1}$ TO $v_{3}$, and 3420 out-of-phase $v_{1}$ assignments, but instead preferred assignments using various combinations of $\nu_{1}, \nu_{3}$, and $\nu_{t}$.

The reduced vibration (RVM) model for describing the amorphous and polycrystalline ice Ih spectra was introduced by Bergren, Schuh, 
Sceats, and Rice (16). They claimed that the inter and intramolecular coupling of $\mathrm{OH}$ oscillators is almost equal, thus any vibration of the condensed phase does not necessarily have a one-to-one parentage with vibrations of the free molecule. From their data Bergren et al. determined the optical constants of $\mathrm{H}_{2} \mathrm{O}$ and $\mathrm{D}_{2} \mathrm{O}$ polycrystalline ice Ih and amorphous ice.

Sivakunar, Rice, and Sceats (17) examined the Raman spectra of the $\mathrm{OH}$ stretching region of low density amorphous water and polycrystalline ice Ih. They found that the low temperature amorphous phase is stable at $10 \mathrm{~K}$ for at least two months. The spectra support a structure derived from ice Ih which is created by introducing a distribution of 0-0-0 angles. This angle and separation dispersion is partly responsible for the observed spectral width of the bands. Scherer (18) published an extensive review on the vibrational spectroscopy of water. Early in the review, Scherer discussed the importance of Fermi resonance and the formation of Evans holes. Much controversy has resulted from whether or not there is Fermi resonance between $v_{1}$ and $2 v_{2}$ in the liquid and condensed phases of ice. Scherer pointed out that Fermi resonance between two vibrational states is not as simple as a frequency displacement between two interacting states. Often the magnitude of the interaction constant and the bandshapes of the interacting states can combine to give unusual bandshapes. When a broad band Fermi interacts with a narrow band, the resultant is often a broad band with a spike or hole (Evans hole) that is not a simple sum of the two component bands. This can complicate the interpretation of the possible $\nu_{1}$ and $2 \nu_{2}$ Fermi interaction.

He pointed out that many liquid water bandshape analyses and 
bandfitting attempts are based on false assumptions because the ice data and widths of infrared bands do not support a spectral breadth arising from a small number of molecular species, but from a broad distribution of $\mathrm{OH}$ bonds strengths, a disorder in the hydrogen bonding environment, and intermolecular coupling.

Scherer stated that the ice Ic to Ih transition seems to be dependent on the thermal history of the particular sample, and lies between $-120^{\circ} \mathrm{C}$ and $-63^{\circ} \mathrm{C}$. He also raised the question over how much does the disorder from true oxygen tetrahedral coordination widens the $\mathrm{OH}$ stretch band versus intermolecular coupling. Ice II which has an ordered proton structure yields four sharp crystallographically distinct $\nu_{O D}$ bands. Scherer explained the wide $\mathrm{OH}$ stretch region of ice as follows: an uncoupled $\mathrm{OH}$ or $\mathrm{OD}$ ice oscillator is split under the intramolecular coupling into two vibrations that would be equivalent to $\nu_{3}$ or $\nu_{1}$ in the gas phase in their in-phase and out-of-phase character. Strong intermolecular coupling present in the ice lattice would further split each of these into two more components yielding a total of four or more components that could be further broadened by the proton disorder induced broadening effect of hexagonal, cubic, or amorphous ice; and complicated by Fermi resonance between $2 \nu_{2}$ and a smeared $v_{1}$ vibrational state. Since intermolecular coupling increases with decreasing temperature, and the ice $\mathrm{OH}$ and $\mathrm{OD}$ bandwidths remain essentially unchanged with temperature, Scherer claimed that disorder must play a role in the $\mathrm{OH}$ or $\mathrm{OD}$ stretch width at higher temperatures. In conclusion Scherer (18) stated:

(1) Fermi resonance between $\mathrm{OH}$ stretching and $2 v_{2}$ states has been observed. 
(2) Band fitting procedures that approximate the Evans hole with two bands are invalid.

(3) Intermolecular coupling between adjacent water molecules is important in ice, amorphous ice, and liquid water.

(4) Isobestic regions in the Raman spectra of water can not be interpreted as evidence for different molecular species.

(5) Disorder is responsible for the bandwidth in liquid water and amorphous ice.

(6) Liquid water at low temperatures is similar to ice near the melting point or amorphous ice at $-180^{\circ} \mathrm{C}$.

(7) There is evidence for non-tetrahedral HOH valence angles in ice, with some orientational preference for the c-axis hydrogen atoms to form more linear hydrogen bonds. (p. 211).

Rhim, Burum, and Elleman (19) studied the proton anisotropic shift in single crystal hexagonal ice and confirmed the Pauling model of ice but could not confirm or reject any possible proton ordering of ice. No hydrogen motion was observed at the liquid nitrogen temperatures used.

Recently Hagen, Tielens, and Greenberg (20) performed an extensive temperature study on the ice Ia to Ic transition between 10 and $140 \mathrm{~K}$. They found the transition to occur between 130 and $140 \mathrm{~K}$; with a 45 minute duration at $140 \mathrm{~K}$, and 90 minute duration at $135 \mathrm{~K}$. By monitoring the interference of a laser beam through the deposit Hagen et al. were able to measure the thickness of the sample. They calculated a $\mathrm{d} v / \mathrm{dRo}-\mathrm{O}=6700 \mathrm{~cm}^{-1}$ (where Ro-o is the oxygen-oxygen lattice separation) and noted that the amorphous to cubic ice transformation was dependent on the thermal history of the sample. 
Matrix Isolated Decoupled Ice Spectra

One of the first matrix isolated systems to be studied was water isolated in solid nitrogen by Thiel, Becker, and Pimentel (21). By obtaining infrared spectra at various water to nitrogen ratios $(\mathrm{M} / \mathrm{A}=$ 1000 to 10; where $M=$ moles matrix gas and $A=$ moles water) Pimente1 et al. distinguished between monomer, dimer, and possibly trimer bands of water. The bands at $3725 \mathrm{~cm}^{-1}$ and $3627 \mathrm{~cm}^{-1}$ were assigned to the $\nu_{3}$ and $\nu_{1}$ stretch of monomeric water and the $3691 \mathrm{~cm}^{-1}$ and $3546 \mathrm{~cm}^{-1}$ $\mathrm{OH}$ stretches to the dimer species. Because of the low number of dimer bands observed Pimental et al. claimed the water dimer had a cyclic structure. They also noted a tenfold increase in the absorption coefficient of polymeric water relative to monomeric water.

In 1960 Haas and Hornig (22) published a benchmark paper in the study of ice. The spectra of HOD mixed with either a $\mathrm{H}_{2} \mathrm{O}$ or $\mathrm{D}_{2} \mathrm{O}$ matrix at $-80^{\circ} \mathrm{C}$ or $-190^{\circ} \mathrm{C}$ were recorded. The coupled $\mathrm{H}_{2} \mathrm{O}$ and $\mathrm{D}_{2} \mathrm{O}$ fundamentals and combinations were assigned, and interestingly, they were able to observe and assign the corresponding isotopically decoupled HOD modes. The HOD OD stretch was observed at $2416 \mathrm{~cm}^{-1}$ in a predominately $\mathrm{H}_{2} \mathrm{O}$ matrix, and the $\mathrm{HOD} O \mathrm{OH}$ stretch at $3275 \mathrm{~cm}^{-1}$ in a predominately $\mathrm{D}_{2} \mathrm{O}$ matrix. An unusual facet of the HOD OD stretch was the appearance of two distinct sidebands at $2393 \mathrm{~cm}^{-1}$ and $2442 \mathrm{~cm}^{-1}$ symmetrically placed about the $2416 \mathrm{~cm}^{-1}$ oD stretch. The bands start appearing at HOD concentrations above 10 percent HOD in the ice matrix. Haas and Hornig attributed these sidebands to the coupling of adjacent or near neighbor OD oscillators producing an in and outof-phase OD coupling at $2393 \mathrm{~cm}^{-1}$ and $2442 \mathrm{~cm}^{-1}$ respectively. The 
narrow bandwidth of the HOD stretches in the presence of strong hydrogen bonding suggested that the large breadth of $\mathrm{OH}$ and $\mathrm{OD}$ stretches in ice spectra were due not to hydrogen bond variation but intermolecular coupling. The overtone $2 v_{\mathrm{OH}}$ was assigned to $6300 \mathrm{~cm}^{-1}$ with a remarkably wide $60 \mathrm{~cm}^{-1}$ bandwidth even at 1ow HOD concentrations where intermolecular coupling is absent. The large $2 v_{\mathrm{OH}}$ width along with the greater $\nu_{\mathrm{OH}}$ width compared with $\nu_{\mathrm{OD}}$ suggested that a mass dependent phenomena such as tunneling was responsible for the $2 v$ width. They postulated that since the hydrogen can occupy two symmetric sites on a given oxygen-oxygen bond that a given proton could tunnel from one side of the oxygen-oxygen double well potential to the other. The presence of the $2 v_{\mathrm{OH}}$ band also suggested that the thermal activation energy must be above $18 \mathrm{kcal}$ but below $27.5 \mathrm{kcal}$ if the brief Haas and Hornig calculations are accepted.

Tursi and Nixon (23) studied the water dimer in solid nitrogen. The $\mathrm{H}_{2} \mathrm{O}, \mathrm{D}_{2} \mathrm{O}$, and $\mathrm{HDO}$ isotopes were isolated in $\mathrm{N}_{2}$ matrices at $20 \mathrm{~K}$ and $4 \mathrm{~K}$. The sample to matrix ratios were varied and M/A plots as in Pimentel's paper were constructed. They observed a lack of the $\mathrm{OH}$ stretch in the HOD dimer implying that the deuterium hydrogen bond was stronger than the $\mathrm{H}$ hydrogen bond; thus producing a lack of these species in the matrix. Murby and Pullin (28), Bentwood, Barnes, and Orville-Thomas (29), and Barnes and Suzuki (30) have recently reinvestigated the self-association of matrix isolated water and concurred with Tursi and Nixon (23) that there seemed to be a preference for HOD to form OD hydrogen bonds rather than $\mathrm{OH}$ hydrogen bonds.

The decoupled frequencies of $\mathrm{OH}_{2}$ and $\mathrm{OD}_{2}$ oscillators in ice were 
highly desired as appropriate starting points from which to build a coupled model of ice vibrations. In a series of papers $(24,25,26)$ Devlin et al. elucidated these frequencies and assigned the vibrational frequency pattern of the isotopic ices. Ritzhaupt and Devlin (24) published the $v_{3}-v_{1}$ OD stretch region of $D_{2} O$ isolated and decoupled in a glassy $\mathrm{H}_{2} \mathrm{O}$ matrix at $90 \mathrm{~K}$. By simultaneous $1 \mathrm{y}$ depositing a small amount of $\mathrm{D}_{2} \mathrm{O}$ vapor with a large quantity of $\mathrm{H}_{2} \mathrm{O}$ vapor they were able to obtain the sample with virtually no HOD contamination in the OD stretch region of isolated $\mathrm{D}_{2} \mathrm{O}$ and with little isotopic scrambling at $90 \mathrm{~K}$.

In a latter paper Ritzhaupt, Thornton, and Devlin (25) developed the simultaneous deposition technique so that $\mathrm{D}_{2} \mathrm{O}$ spectra decoupled and isolated in cubic $\mathrm{H}_{2} \mathrm{O}$ could be realized. They deposited a 0.1 micron film of $\mathrm{H}_{2} \mathrm{O}$ (Ic) at $180 \mathrm{~K}$, prior to the codeposition of dense $\mathrm{H}_{2} \mathrm{O}$ and dilute $\mathrm{D}_{2} \mathrm{O}$ vapors on a substrate held at $135 \mathrm{~K}$. The expitaxial layer insured the ice deposit would be cubic, and the $135 \mathrm{~K}$ temperature that no deuteron or proton exchange occurred in the sample preparation period. The ice Ic $D_{2} O$ stretching frequencies were identified as $v_{1}=$ $2367 \mathrm{~cm}^{-1}$ and $\nu_{3}=2444 \mathrm{~cm}^{-1}$ for $\mathrm{D}_{2} \mathrm{O}$ in $\mathrm{H}_{2} \mathrm{O}$. The bending modes $\left(\nu_{2}\right)$ were $1220 \mathrm{~cm}^{-1}$ for $\mathrm{D}_{2} \mathrm{O}$ in cubic ice and $1230 \mathrm{~cm}^{-1}$ for amorphous or glassy ice. Both of these bending mode frequencies were high enough to discount any significant Fermi resonance interaction between $2 \nu_{2}$ and $v_{1}$ in $\mathrm{D}_{2} \mathrm{O}$ decoupled ice spectra. By raising the sample temperature to 140 to $160 \mathrm{~K}$ they were able to initiate proton-deuteron exchange as evidenced by the growth of the HOD band and decay of the $\mathrm{D}_{2} \mathrm{O}$ bands. The ability to measure the exchange rates at different temperatures presented the opportunity of measuring the activation energy of the 
exchange process. This they found to be approximately $10 \mathrm{kcal}$; well within the range suggested by Haas and Hornig (22).

By 1980 Ritzhaupt, Collier, Thornton, and Devlin (26) were using the expitaxial method of cubic ice deposition to unravel the uncoupled $\mathrm{H}_{2} \mathrm{O}$ ice Ic frequencies. About 5 percent $\mathrm{H}_{2} \mathrm{O}$ was codeposited with a $\mathrm{D}_{2} \mathrm{O}$ matrix at $135 \mathrm{~K}$. By allowing the sample to warm to $155 \mathrm{~K}$ the growth and decay of the appropriate isotopic exchange bands were observed. Both Raman spectra with polarization measurements and FTIR spectra were obtained. The use of digitilized FTIR spectra allowed for the subtraction and scaling of different isotopic exchange spectra such that the change and identification of fundamental $\mathrm{H}_{2} \mathrm{O}$ modes was enhanced. Ritzhaupt et a1. placed the decoupled $\mathrm{H}_{2} \mathrm{O}$ cubic ice $\nu_{3}$ at $3270 \mathrm{~cm}^{-1}, \nu_{1}$ at $3200 \mathrm{~cm}^{-1}$, and $\nu_{2}$ at $1732 \mathrm{~cm}^{-1}$. Likewise the HOD $\nu_{\mathrm{OH}}$ was assigned to $3270 \mathrm{~cm}^{-1}$, $\nu_{\mathrm{OD}}$ to $2418 \mathrm{~cm}^{-1}$, and $\nu_{2}$ to $1510 \mathrm{~cm}^{-1}$ for a $\mathrm{D}_{2} \mathrm{O}$ matrix and $1465 \mathrm{~cm}^{-1}$ for a $\mathrm{H}_{2} \mathrm{O}$ matrix. Sceats, Stavola, and Rice (27) from their theoretical calculations suggested that Fermi resonance of $2 v_{2}$ with $v_{1}$ actually pushed $v_{1}$ and $v_{3}$ bands into coincidence with the $\nu_{\mathrm{OH}}$ band yielding a single absorption. Ritzhaupt et al. showed that the coincidence of the cubic ice $\nu_{3}$ and $\nu_{\mathrm{OH}}$ was correct but the Fermi resonance of $2 v_{2}$ with $v_{1}$ actually increased the $\nu_{\mathrm{OH}}{ }^{-\nu_{1}}$ separation. With all the observed decoupled isotopic cubic ice frequencies available, Ritzhaupt et al. were able to perform overlay normal mode calculations for the calculated decoupled frequencies and quadratic force constants.

\section{Theory of Ice Spectra}

Much of the recent theoretical work done on coupled and decoupled 
ice spectra has been done by Rice and Sceats who developed a method for predicting vibrational modes in highly intermolecularly coupled systems that is called the reduced vibrational model or RVM that greatly simplifies calculations.

McGraw, Madden, Bergren, Rice, and Sceats (31) used the RVM model to build a 64 molecule ice Ih cell in which the symmetry, ice rules, and zero net dipole moment were met. Like Whalley et al. (10) and Haas and Hornig (22), they contended that strong intermolecular coupling had to be accounted for before any realistic assignments could be made about the ice I stretching region. In examining their results they found that long range coupling between molecules not directly hydrogen bonded served to make features more diffuse but not to greatly affect the spectral distribution. In addition, the intermolecular coupling was predicted to be of the same magnitude as the intramolecular coupling. Rice et al. found that the modes predicted by the 64 molecule cell were complex mixtures of molecular motions such that identification of regions of the ice Ih stretching IR and Raman spectra with isolated molecular modes was not useful, but the predicted spectra agreed well with the observed spectra. In a follow-up paper Madden, Bergren, McGraw, Rice, and Sceats (32) extended the theory and model to the $\mathrm{OH}$ stretching region of amorphous ice. Interestingly they found that the random orientation required of the new model cell had little affect on the predicted spectra but changes in the oxygen-oxygen lattice distances had a sizable one. They concluded that a distribution of force constants such as would result for oxygen-oxygen lattice changes rather than a change from the regular crystalline topology of ice Ih was 
responsible for the infrared spectral changes between hexagonal and amorphous ice. This could lead to some interesting conclusions regarding the spectra of 1iquid water.

Sceats and Rice (33) utilized the overtone spectrum of ice I to develop an intramolecular potential. They assumed the intramolecular potential could be accurately described by a hydrogen bond dependence of the diagonal harmonic stretching force constant and the stretchstretch interaction force constant. All other harmonic and diagonal anharmonic force constants were presumed to remain independent of hydrogen bond perturbations and hence could be derived from gas phase values or other sources. The results of their potential analysis of the ice overtone region indicated that the breadth of the $2 \nu_{\mathrm{OH}}$ overtone may be due to intermolecular coupling rather than tunneling as suggested by Haas and Hornig (22).

The experimental work of Ritzhaupt et al. (24,25) prompted Sceats, Stavola, and Rice (34) to extend their models to reproduce the stretching spectrum of $\mathrm{D}_{2} \mathrm{O}$ in $\mathrm{H}_{2} \mathrm{O}$ and $\mathrm{H}_{2} \mathrm{O}$ in $\mathrm{D}_{2} \mathrm{O}$ in both amorphous and crystalline ice $I$. They interpreted the amorphous $\mathrm{D}_{2} \mathrm{O}$ decoupled in $\mathrm{H}_{2} \mathrm{O}$ such that Fermi resonance of a near coincident $2 v_{2}$ with $v_{1}$ pushes $v_{1}$ further away from $v_{3}$ thus increasing what should have been a smaller $\nu_{1}^{-\nu_{2}}$ splitting and increasing the width of $\nu_{1}$ with the shifted $2 v_{2}$ state.

In cubic ice the situation is similar but the coincidence of $2 v_{2}$ and $v_{1}$ is not as great and hence the resultant Fermi splitting gives a component on the high frequency side of $\nu_{3}$. For $\mathrm{H}_{2} \mathrm{O}$ decoupled in $\mathrm{D}_{2} \mathrm{O}$ they calculated a spectra with a very small $v_{1}-v_{3}$ splitting such that Fermi resonance of $2 v_{2}$ with $v_{1}$ produces a single peak centered 
around the $\mathrm{HDO} O \mathrm{OH}$ decoupled stretching frequency. In a later paper by Ritzhaupt et al. (26) this was confirmed except that the $v_{1}$ frequency was assigned to a much lower frequency rather than coincident with $\nu_{3}$ and $\nu_{\mathrm{OH}}$ as predicted by Sceats, Stavola, and Rice. Morse and Rice (35) compared different pair potentials suggested by researchers for computer simulations of ice and water. Since the structures of ice I, II, III, IV, V, VI, and VII are known, the accuracy with which these structures could be predicted by the pair potentials would be a sensitive test of their validity. They tested several potentials in predicting a proton ordered ice Ih structure and found the ab initio pair potential calculated by Matsuoka, Clementi, and Yoshimine (36) succeeded best.

\section{Proton Transfer in Ice}

Proton transfer has been studied in many systems by widely varying techniques. Much of the earlier work on proton transfer in ice and liquid water was accomplished through conductance studies. One noteworthy theoretical and experimental study was that of Conway, Bockris, and Linton (37). They developed a theory of proton conduction in liquid water that broke the conduction into two processes, one quantum mechanical tunneling of a hydrogen from one molecule to another and then, two, rotation of the molecule breaking the surrounding solvent cage bonds to transfer the hydrogen or proton to the other side of the cage. By such a series of transfers and rotations a proton could be transported through the liquid. Conway et al. claimed that the tunneling transfers occurred rapidly and the classical rotations much slower and thus the rotational step was rate determining. They 
predicted from Morse potential curves that the classical proton transfer activation energy in liquid water was $3.85 \mathrm{kcal}$ for hydrogen and 5.81 kcal for deuterium and the predicted proton to deuterium transfer rate ratio was $6: 1$. The rotational activation energy was found to be quite costly energetically and dependent on the mode of rotation. They calculated that the proton spends 1 percent of its time undergoing quantum mechanical tunneling transfers. In a note Conway and Bockris (38) suggested that if their theory was applied to ice the concentration of defect formed protons might be low enough that water molecule rotation may no longer be the rate determining step and hence the tunneling process could become rate determining and hence the mobility of the proton would increase until it was limited by the now faster rate determining tunneling transfer step.

Kim and Schmidt (39) developed a theory of proton transport in ice that suggested the mobility is limited not by barrier hopping but lattice scattering. One of the implications of this particular theory is that the mobility is predicted to increase with decreasing temperature.

Conductivity measurements of ice have been studied over several decades with widely varying results and much controversy. However by the mid 1960's much of the discrepancy was resolved and the problem traced to the use of two terminal conductivity cells which gave conductivities and resulting activation energies that were a mixture of bulk and surface ice conductivities. The use of guarded or three terminal conductivity cells or holders lead to more consistent measurements among researchers. Durand, Deleplanque, and Kahane (40) utilized ion exchange membranes for electrodes in conductivity measurements. The 
temperature of the ice was kept between $-20^{\circ} \mathrm{C}$ and $-100^{\circ} \mathrm{C}$ to prevent surface conductivity effects thus negating the need for a third guard electrode. They measured a conductivity thermal activation energy of about $9 \mathrm{kcal} / \mathrm{mole}$ between $-30^{\circ} \mathrm{C}$ and $-70^{\circ} \mathrm{C}$ and a $13 \mathrm{kcal} / \mathrm{mole}$ activation energy between $-90^{\circ} \mathrm{C}$ and $-100^{\circ} \mathrm{C}$.

In another similar conductivity measurement Bullemer, Eise1, Engelhardt, Rieh1, and Seige (41) determined the bulk and surface conductivity of ice at $-10^{\circ} \mathrm{C}$. They found an activation energy of $8.5 \pm 0.5 \mathrm{kcal} / \mathrm{mole}$ for the bulk conductivity and $26-30 \mathrm{kcal} / \mathrm{mole}$ for surface conductivity using a three terminal guarded potential probe method.

An alternate theoretical view of proton conduction in ice has been advanced by A. von Hippel et al. (42) in a series of papers describing their experimental and theoretical technique. A. von Hippel postulated that the Bjerrum $D$ and $L$ defects were formed in a single asymmetric stretch and bend combination photon excitation that did not require a molecular rotation that broke three hydrogen bonds. The calculated activation energy was about $13 \mathrm{kcal}$. Furthermore he predicted that Bjerrum defects would be the current carriers in the free volume of the crystal with ionic defects only playing a role near the electrodes. The movement of defects in the free volume was expected to be in polaronic fashion, and in rapidly expanding drift ellipsoids when under the influence of an externally applied electrical field. This is in contrast to the theory of Jaccard (43) who claimed that $D$, L Bjerrum defects were the majority current carriers but ionic defects also played a role and had a 400 times higher mobility which was explained by proton tunneling. Experimentally A, von Hippel et al. 
measured a surface conduction activation energy of about $33 \mathrm{kcal} / \mathrm{mole}$ between $0^{\circ} \mathrm{C}$ and $30{ }^{\circ} \mathrm{C}$ which could be reduced to $20 \mathrm{kcal} / \mathrm{mole}$ by enclosing the sample in a vacuum. The bulk conductivity activation energy was about $12 \mathrm{kcal} / \mathrm{mole}$ with a three terminal holder. Below $-35^{\circ} \mathrm{C}$ both two and three terminal holders gave consistent results of about $12 \mathrm{kcal} / \mathrm{mole}$. Previously measured zero activation energies were claimed to result from measurements made in the initial millisecond time range where a stable conductive state had not yet been reached. Ice crystal age was also found to affect conductivity emasurements. A. von Hippel did not feel the need to invoke proton tunneling to explain proton mobility in ice.

Hubmann (44) extended Jaccard's theory to accept the complementary action of ionic defects and Bjerrum $D$, $L$ defects in proton migration in ice.

Evidence for proton tunneling and c-axis order in ice th was found by Lumpkin and Dixon (45). They measured the ${ }^{17} 0$ quadrupole resonance of ice Ih at 4.2 and $1.3 \mathrm{~K}$ using a double resonance technique and found only two resonances consistent with the explanation offered.

Ritzhaupt and Devlin (46) took the thin layer techniques developed in references 25 and 26 and isolated $\mathrm{D}_{2} \mathrm{O}$ in cubic $\mathrm{H}_{2} \mathrm{O}$ at $130 \mathrm{~K}$. Two bands at $2444 \mathrm{~cm}^{-1}$ and $2367 \mathrm{~cm}^{-1}$ were assigned to the $D_{2} 0 \nu_{3}$ and $\nu_{1}$ respectively. Upon warming the sample to $165-180 \mathrm{~K}$ the $\mathrm{D}_{2} \mathrm{O} v_{3}$ and $v_{1}$ bands lost intensity while a band at $2418 \mathrm{~cm}^{-1}$ attributed to the OD stretch of HOD grew in and gained intensity representative of the following exchange reaction.

$$
\mathrm{D}_{2} \mathrm{O}+\mathrm{H}_{2} \mathrm{O} \rightarrow 2 \mathrm{HOD}
$$

Ritzhaupt and Devlin obtained FTIR spectra at several time 
intervals during the exchange reaction at elevated temperatures. By subtracting the appropriate scaled pure HOD $2418 \mathrm{~cm}^{-1}$ component band from the $\mathrm{D}_{2} \mathrm{O}$-HOD exchange band complex the time dependence of $\mathrm{D}_{2} \mathrm{O}$ loss could be followed by the $\mathrm{D}_{2} \mathrm{O}$ band intensities after HOD subtraction or by the scaling factors used to scale the original $2418 \mathrm{~cm}^{-1}$ HOD band used in the subtraction. Figure 6 illustrates the spectral changes accompanying deuterium-hydrogen exchange. Over the temperature range of $165 \mathrm{~K}$ to $181 \mathrm{~K}$ the activation energy was found to be $9.3 \mathrm{kcal}$. They noted that this value was close to half the formation energy of ion pair defects (18.6 kcal) found by Bullemer et al. (41). This was considered indicative of the thermally activated proton tunneling mechanism suggested by Haas and Hornig (22) where a thermally activated $\mathrm{H}_{3} \mathrm{O}^{+}$ion defect is mobilized by proton tunneling. Such a process should reflect an Arrhenius type behavior. It was also suggested that such thermal activation would involve a ground to excited state stretching mode vibration whose energy of about $9.2 \mathrm{kcal} /$ mode is amazingly close to the measured activation energy.

In a subsequent paper Ritzhaupt and Devlin (47) discovered that the previous samples of $\mathrm{D}_{2} \mathrm{O}$ isolated in cubic $\mathrm{H}_{2} \mathrm{O}$ discussed in reference 46 had been contaminated with minute quantities of aromatic compounds desorbing from the cell walls. As the contamination was slowly cleared up in subsequent experimental runs it was found that the rate of exchange reaction increased considerably with a new transitory peak at $2396 \mathrm{~cm}^{-1}$ slowly appearing as the reaction proceeded and then losing intensity as the exchange neared completion. Figure 7 shows the $\mathrm{D}_{2} \mathrm{O}$ $2444 v_{3} \mathrm{~cm}^{-1}, 2367 v_{1} \mathrm{~cm}^{-1}$, and $2396 \mathrm{~cm}^{-1}$ intermediary band spectral changes with time after interfering $\mathrm{H}_{2} \mathrm{O}$ and HOD bands have been 


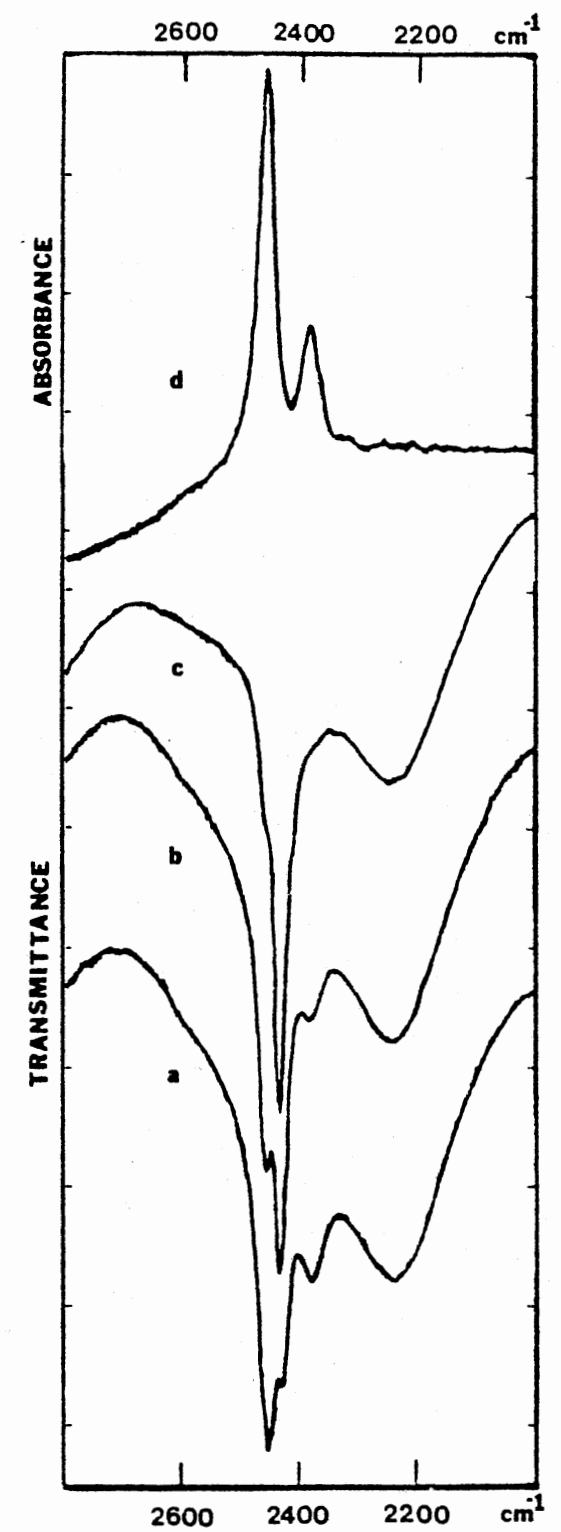

Infrared curves for $\approx 2 \% \mathrm{D}_{2} \mathrm{O}$ in $\mathrm{H}_{2} \mathrm{O}$ ice $\mathrm{I}_{\mathrm{c}}$ : (a) original deposit warmed to $165 \mathrm{~K}$; (b) same sample after two hours at $165 \mathrm{~K}$; (c) same sample $(165 \mathrm{~K})$ after seven hours at $165 \mathrm{~K}$ and following brief annealing at $185 \mathrm{~K}$ and (d) $\mathrm{D}_{2} \mathrm{O}$ absorbance spectrum from curve (b) using curve (c) to remove HOD absorbance.

Figure 6. $\mathrm{D}_{2} 0$ Spectral Changes with Isotopic Exchange 


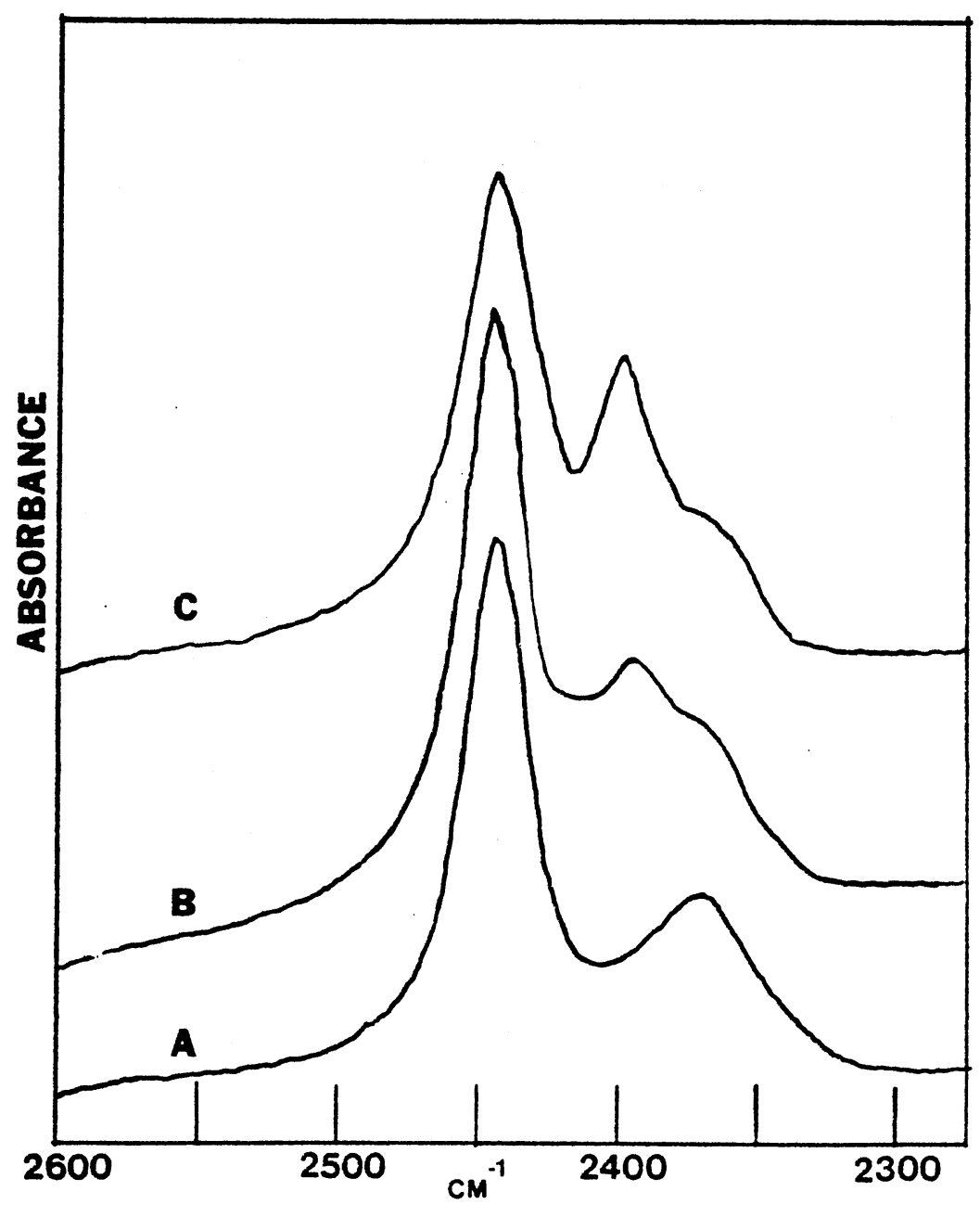

Figure 7. (HON), Spectral Changes with Isotopic Exchange 
digitally subtracted. The $2396 \mathrm{~cm}^{-1}$ band could clearly be identified with the $2393 \mathrm{~cm}^{-1}$ dimer HOD coupled in-phase oD stretch assigned by Haas and Hornig (22). The $2442 \mathrm{~cm}^{-1}$ out-of-phase coupled oD oscillator stretch should be obscured beneath the more intense $D_{2} O v_{3}$ vibration at $2444 \mathrm{~cm}^{-1}$. This suggested the following exchange reactions.

$$
\begin{gathered}
\mathrm{D}_{2} \mathrm{O} \text { (isolated) }+\mathrm{H}_{2} \mathrm{O} \stackrel{\mathrm{k}_{1}}{\rightarrow} \text { (HOD) } 2 \text { (coupled) } \\
\quad \text { (HOD) } 2 \text { (coupled) } \stackrel{\mathrm{k}_{2}}{\longrightarrow} 2 \mathrm{HOD} \text { (isolated) }
\end{gathered}
$$

Devlin et al. attributed the first step to a proton transfer which would produce a coupled HOD unit and the second step to a Bjerrum defect migration by a molecular rotation which decouples or destroys the coupled HOD producing two isolated HOD subunits. They explained the behavior of the doped and pure ice systems as follows. The doped system inhibited the transfer process enough that $k_{2}>k_{1}$ and hence the $(\mathrm{HOD})_{2}$ concentration was a very small steady state value and not spectrally observed. Hence the overall rate was slower and higher temperatures were needed to initiate the exchange. As the dopant was removed and $k_{1} \approx k_{2}$ the steady state situation was removed with a corresponding increase in (HOD) 2 concentration and greater overall exchange rates. The dopant appeared to have no effect on the rotational step. Rough calculations on the $k_{1}$ rate or proton transfer process indicated an activation energy of 8.5 to $10.5 \mathrm{kcal}$. This suggested the dopants affected the proton transfer rate by trapping ion pair defects rather than altering the activation energy for defect formation. Devlin et al. suggested the possibility existed for elucidating the activation energy for both the ion pair defect formation and Bjerrum rotational defect migration.

In a recent note Kunst and Warman (48) used a microwave conduc- 
tivity pulse radiolysis technique to find the mobility of protons and deuterons in ice. The proton virtual mobility in $\mathrm{H}_{2} \mathrm{O}$ ice was determined to be $.0064 \mathrm{~cm}^{2} / \mathrm{V} \cdot \mathrm{s}$ at $-5^{\circ} \mathrm{C}$ and the deuteron virtual mobility in $\mathrm{D}_{2} \mathrm{O}$ ice to be $.0024 \mathrm{~cm}^{2} / \mathrm{V} \cdot \mathrm{s}$ at $-5^{\circ} \mathrm{C}$ with a deuteron mobility to proton mobility ratio of 375 .

Presentation of Problem

Ritzhaupt and Devlin (47) presented their analysis of the infrared $\mathrm{D}_{2} \mathrm{O}$ stretching region of $\mathrm{D}_{2} \mathrm{O}$ isolated and decoupled in cubic $\mathrm{H}_{2} \mathrm{O}$ ice at $130-180 \mathrm{~K}$. From the spectral changes observed it was concluded that proton or deuteron migration in ice followed a two fold process. The first step involved an ionic defect formation which mobilized a proton via a tunneling mechanism that allowed the defect to migrate throughout the crystal once formed. This proton transfer encountering a $\mathrm{D}_{2} \mathrm{O}$ molecular subunit in an $\mathrm{H}_{2} \mathrm{O}$ ice crystal would initiate isotopic scrambling by proton transfer; i.e. exchanging and transferring a proton for a deuteron leaving a vibrationally coupled (HOD) ${ }_{2}$ dimer. The (HOD) 2 dimer would further scramble to two vibrationally decoupled and more spatially removed HOD molecular subunits in the $\mathrm{H}_{2} \mathrm{O}$ ice crystal lattice by a molecular rotation or Bjerrum D, L defect migration.

The goal of this study is to find the best quantitative estimate of the ionic defect formation and Bjerrum D, L defect migration activation energies and examine their possible implications for proton transport in hydrogen bonded molecular networks. The study of these energies could yield possible insights into the role proton transport could have in alternate electrical control devices, and energy conversion and storage in biological systems. 
Accomplishing this study will involve developing experimental

techniques to implement the following procedures.

(1) Collection time resolved IR spectra of $\mathrm{D}_{2} \mathrm{O}-\mathrm{H}_{2} \mathrm{O}$ exchange processes over a suitable range of sampling times, time durations, samples, and experimental temperatures to perform kinetic analyses of the data obtained.

(2) Assure sample purity such that the rates obtained reflect a reasonably pure ice situation.

(3) Resolve the $\mathrm{D}_{2} \mathrm{O}-\mathrm{HOD}$ band complex obtained in each sample collection into its individual spectral components.

(4) Relate the spectral intensity of the spectral components to each component concentration.

(5) Develop a kinetic model for obtaining the proton transfer rate via ionic defect migration and Bjerrum $D$, L defect rotation rate from the spectral component concentrations.

(6) Find the proton transfer and rotational rates over as wide a temperature range as experimentally feasible and find their respective activation energies.

(7) Analyse the results for implications. 
CHAPTER II

EXPERIMENTAL PROCEDURES AND RESULTS

Matrix Isolation Methods

Matrix isolation techniques are usually used to isolate a particular molecular specie in an inert matrix. This is accomplished by directing the gaseous mixture of the molecular specie and an inert gas matrix onto a cryogenic surface where the frozen gas mixture may be examined by optical spectroscopy or other means.

For this work matrix isolation techniques were used but the matrix gas of $\mathrm{H}_{2} \mathrm{O}$ interacted significantly with the guest molecule $\mathrm{D}_{2} \mathrm{O}$. Though the electronic interaction between the matrix and guest were large, the different isotopic masses caused a decoupling of specific normal modes of vibration between the matrix and guest molecules. So the present work is better described as matrix decoupled spectroscopy.

All of the experimental work was accomplished by depositing vapors of $\mathrm{H}_{2} \mathrm{O}$ and $\mathrm{D}_{2} \mathrm{O}$ on a nitrogen gas cooled or mechanically cooled cesium iodide substrate. Two types of vapor deposition cells were used.

\section{Meta1 Cell Technique}

The first phase of the experimental work consisted of creating crystalline deposits of ice Ih with a $5 \%$ to $95 \%$ ratio of $\mathrm{D}_{2} \mathrm{O}$ to $\mathrm{H}_{2} \mathrm{O}$. Figures 8 and 9 show the experimental apparatus used for this. The heart of the cryostat is an Air Products and Chemicals, 


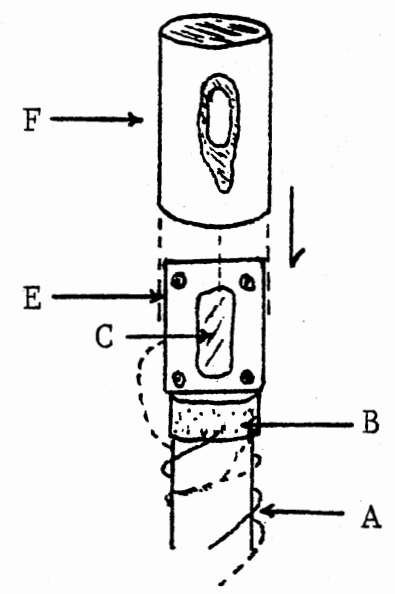

Front View

A - Electrical leads to internal resistance heater located at the cryotip

B - Cryotip

C - CsI inner window

D - Removable Cu plate

E - Cu sampling block

$\mathrm{F}$ - Cu heat shield

G - Thermocouple leads (gold-chromel $0.7 \% \mathrm{Fe}$ )

H - Mode1 CS-202 Displex ${ }^{T M}$ displacer/expander

I - Self-sealing coupling (low pressure return)

$\mathrm{J}$ - Self-sealing coupling (surge line)

$\mathrm{K}$ - Self-sealing coupling (high pressure supp1y)

L - Electrical connector

M - Flexible metal lines to compressor

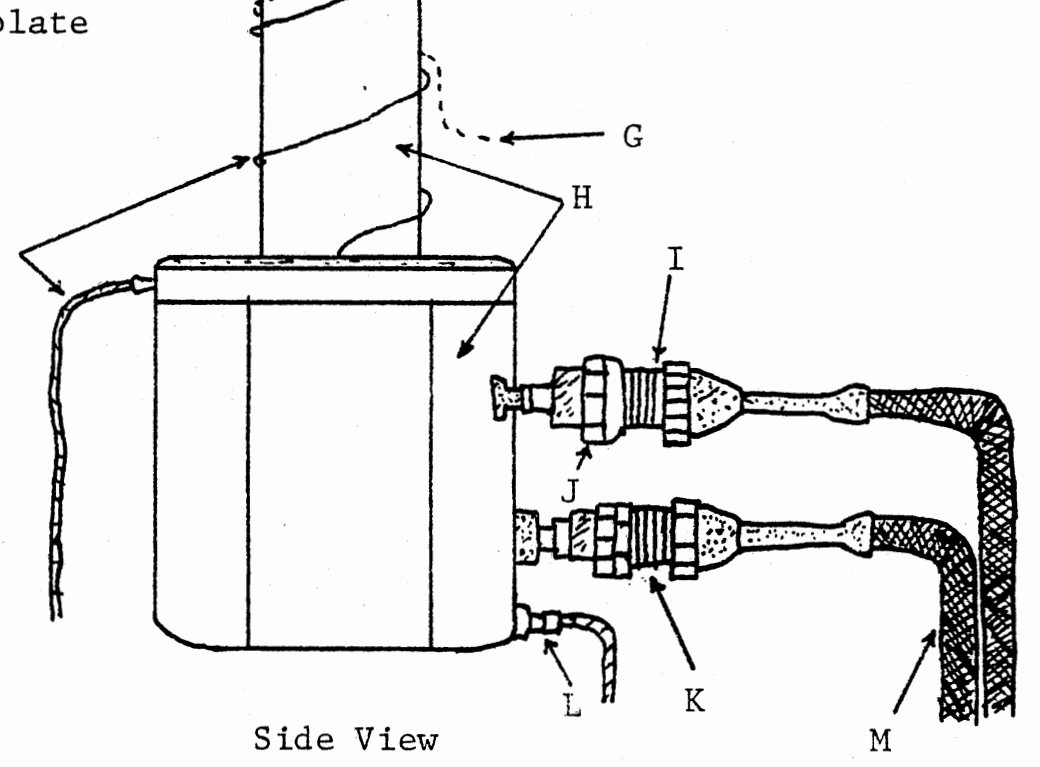

Figure 8. Air Products CS-202 Displacer/Expander Module with Tip and Sample Deposition Window 


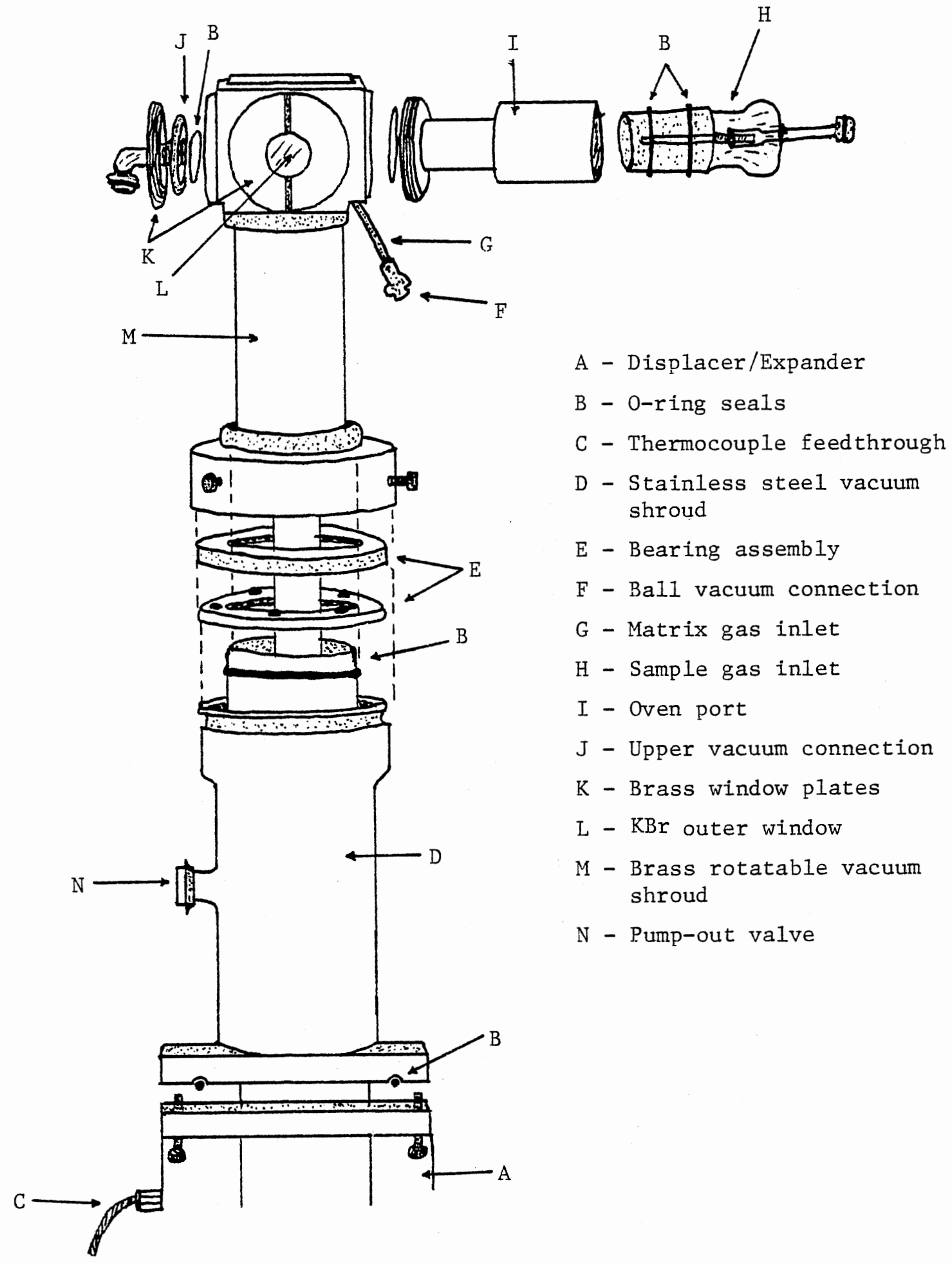

Figure 9. Brass Vacuum Shroud for Displacer/Expander Module 
Inc. Model CS-202 Displex closed cycle helium refrigerator. Included in the system is a displacer/expander module connected by flexible lines to a compressor and control panel. The displacer/expander module has a refrigerated tip on which the cesium iodide substrate window is mounted. The module may assume any orientation and has a capability of temperature to $10 \mathrm{~K}$. A small resistance heater mounted on the refrigerator tip allows temperature control from $10^{\circ} \mathrm{K}$ to $300^{\circ} \mathrm{K}$ with an accuracy of $\pm .5^{\circ} \mathrm{K}$. If an insulating vacuum of $10^{-4}$ torr is maintained around the cryotip, the cool-down time from room temperature to $10^{\circ} \mathrm{K}$ is approximately one hour. On the end of the cryotip is a copper block for mounting a cesium iodide substrate window for infrared transmission studies. Four screws and a copper backing plate holds the window to the salt plate holder. Thermal contact is assured by indium wire gaskets between the window and backing plate and copper block. Two gold $(0.7 \% \mathrm{Fe})$ chromel thermocoupler measure the cryotip and CsI window temperature. One is attached directly to the refrigerator tip with indium solder for the internal heater control; and the other is sandwiched between the CsI and copper block in the indium gasket to monitor the CsI window surface temperature on the deposition side.

To maintain the necessary vacuum for vapor deposition and cryogenic temperatures a brass vacuum shroud was available that would cover and seal the displacer/expander module allowing vacuum operation and injection of sample and matrix gasses through two injection ports (Figure 9). Also as shown in Figure 9 the shroud has the opposing potassium bromide windows and a vacuum connection. The shroud was mounted on bearings to allow rotation of the shroud while under vacuum and was 
equipped with vacuum valves so that once a good vacuum was reached, the displacer/expander module could be sealed off and removed from the vacuum pumps and removed to a FTIR infrared spectrophotometer for infrared studies of the deposit made on the cryotip cesium iodide window. The brass shroud could be rotated to bring the two shroud potassium bromide windows in line with the inner cesium iodide window for easy optical examination.

The matrix gas $\mathrm{H}_{2} \mathrm{O}$ is introduced through $\mathrm{G}$ and the sample gas $\mathrm{D}_{2} \mathrm{O}$ through $\mathrm{H} . \mathrm{D}_{2} \mathrm{O}$ vapors are sent to the cryostat from a vacuum valve sealed glass reservoir connected to a micro-flow needle valve that is connected to the sample line at $C$. The vapor pressure of $\mathrm{D}_{2} \mathrm{O}$ at $\mathrm{O}^{\circ} \mathrm{C}$ provided the necessary $\mathrm{D}_{2} \mathrm{O}$ gas for deposition. $\mathrm{H}_{2} \mathrm{O}$ vapors were likewise introduced into the cryostat. The $\mathrm{H}_{2} \mathrm{O}$ vapor flow rate is controlled by a teflon needle valve above the $\mathrm{H}_{2} \mathrm{O}$ water reservoir and monitored by a Fisher-Porter $1 / 16$ glass flowmeter inserted into the $\mathrm{H}_{2} \mathrm{O}$ sample line.

All vacuum selas in the system are made with lightly greased viton 0 -rings except for the $\mathrm{D}_{2} \mathrm{O}$ and $\mathrm{H}_{2} \mathrm{O}$ sample and matrix gas lines where the vacuum grease was omitted to prevent any possible grease contaminations in the deposits.

\section{Glass Cell Apparatus}

During the course of the investigation it was found necessary to make $\mathrm{D}_{2} \mathrm{O}-\mathrm{H}_{2} \mathrm{O}$ deposits doped with 7-azaindole. Rather than risk contamination of the metal cell where pure $\mathrm{D}_{2} \mathrm{O}-\mathrm{H}_{2} \mathrm{O}$ deposits were being made, these samples were prepared in an all glass vapor deposition cell as shown in Figure 10. This cell being very similar in function 


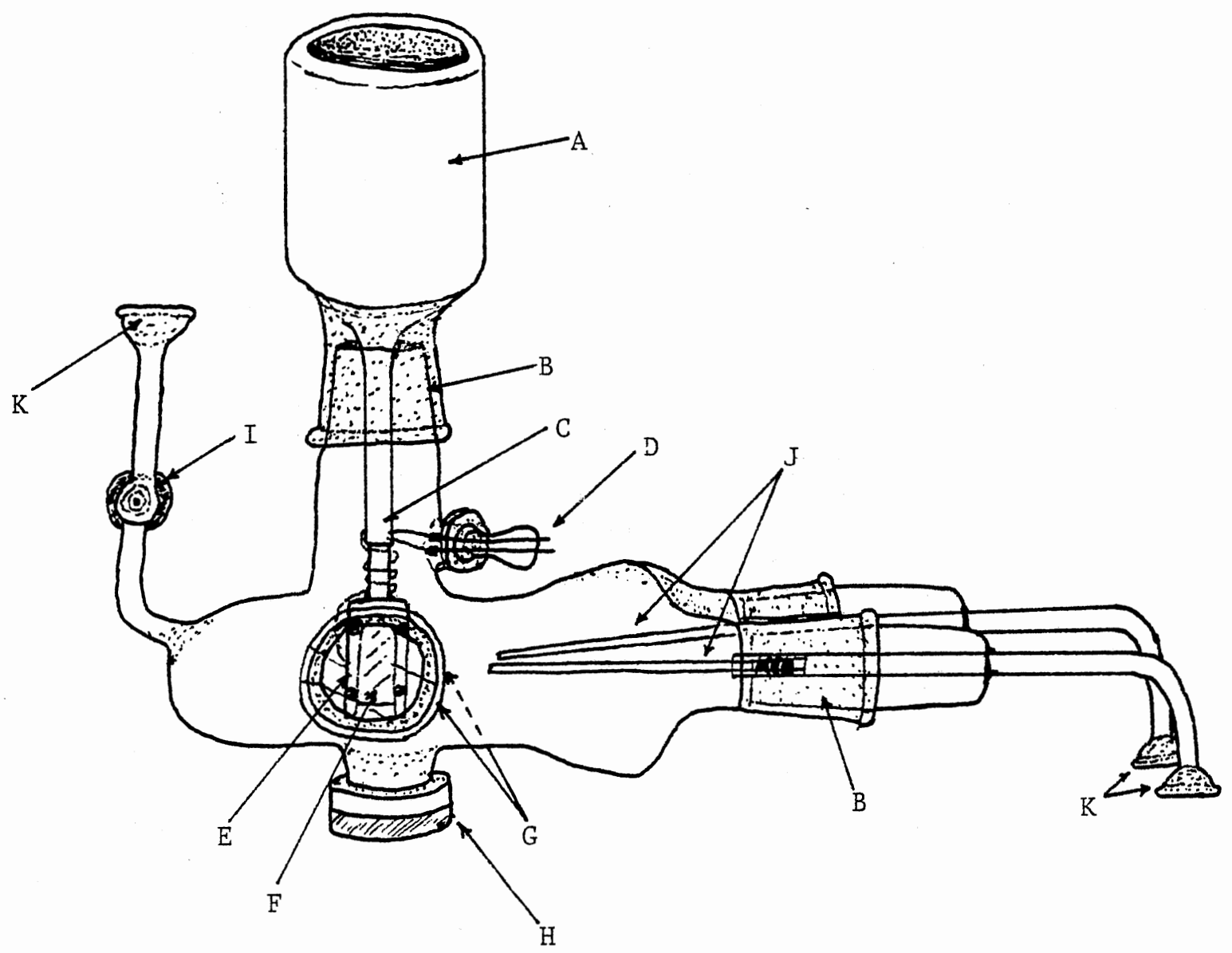
A - Liquid nitrogen dewar
$\mathrm{G}$ - Outer $\mathrm{KBr}$ windows
B - Vacuum greased taper joint
$\mathrm{H}$ - Glass window
C - Dewar stem glass-meta1 connection
D - Thermocouple wire vacuum seal
E - Cu sample block
I - Teflon vacuum valve
$\mathrm{J}$ - Sample and matrix gas inlet
$\mathrm{K}$ - Female ball vacuum connections
F - CsI window
Figure 10. Glass Cryostat Cell for Vapor Deposition 
to the closed-cycle helium refrigerator apparatus is comprised of a glass container with provisions for introducing the matrix and sample gasses through two sample lines terminating in nozzles aimed at a cesium iodide substrate window. The cesium iodide substrate window is attached to a copper holder with indium gaskets for thermal contact. The copper substrate holder is connected by a Kovar glass to metal seal to the bottom of a liquid nitrogen dewar for cooling. The dewar is attached to the glass cell by a greased glass taper joint so that the cesium iodide substrate window may be turned facing the sample gas inlet nozzles for deposition and then rotated $90^{\circ}$ for optical spectroscopy through two potassium bromide windows fastened on opposing sides of the glass vapor deposition cell. The temperature was monitored by an iron-constanton thermocouple inserted into the indium wire gasket between the copper holder and deposition side of the inner cesium window. To obtain reproducible and consistent temperature measurements and correspondence between the metal cell and glass cell deposit temperature it was found necessary to temper the glass cell thermocouple leads by stripping off the outer insulation jacket of the thermocouple wire and wrapping the two individually insulated leads at least twenty times around the dewar stem attached to the copper holder before running the thermocouple leads outside the cell for voltage measurement. A Honeywell model no. 2745 potentiometer was used for all thermocouple temperature measurements. To check the temperature correspondence between the metal and glass cell measurements a series of spectra of $\mathrm{D}_{2} \mathrm{O}$ decoupled in $\mathrm{H}_{2} \mathrm{O}$ at various temperatures were made. The $v_{3}$ asymmetric stretch bond of $D_{2} O$ was expanded so that $2^{\circ} \mathrm{K}$ temperature shift effects could be detected in 
the bandshapes as shown in Figure 11. By comparing spectra collected in the metal or glass cells with these spectra plots any temperature measurement inaccuracies could readily be detected. Both cells with different composition thermocouples were found to yield identical temperature shifted $\mathrm{D}_{2} \mathrm{O} v_{3}$ bands at a given temperature setting over the 135 to $160 \mathrm{~K}$ range to at least a $\pm 1 \mathrm{~K}$ accuracy.

The matrix and sample gasses were introduced from $\mathrm{D}_{2} \mathrm{O}$ and $\mathrm{H}_{2} \mathrm{O}$ liquid reservoirs as in the metal cell apparatus. The 7-azaindole dopant was introduced by lightly dusting a glass wool plug with small crystals of 7-azaindole and placing it in the $\mathrm{H}_{2} \mathrm{O}$ vapor sample line so that small quantities of sublimed 7-azaindole would be swept by the $\mathrm{H}_{2} \mathrm{O}$ matrix vapors into the deposit. Temperature control with the glass cell was considerably more difficult. To circumvent the invariability of the liquid nitrogen boiling point for temperature control, a pressurized cool nitrogen gas cooler was designed as shown in Figure 12. A 50 liter liquid nitrogen dewar was mounted on a movable cart with a small glassware rack. The dewar was sealed off and a needle-valve controlled insulated tygon tubing line was used to direct the vented nitrogen gas to the glass cell dewar stem for cooling. Pressurization of the 50 liter dewar was provided by inserting a nichrome wire resistance heater into the liquid nitrogen of the 50 liter dewar and running the heater leads through a pressure seal in the 50 liter dewar top to a $110 \mathrm{AC}$ variac. By controlling the heater voltage and adjusting the needle valve controlling the cool nitrogen gas flow, sufficient liquid nitrogen could be vaporized and blown into the glass cell dewar stem so that temperatures between $100 \mathrm{~K}$ and room temperature could be maintained with an accuracy of $\pm .5 \mathrm{~K}$. By mounting 


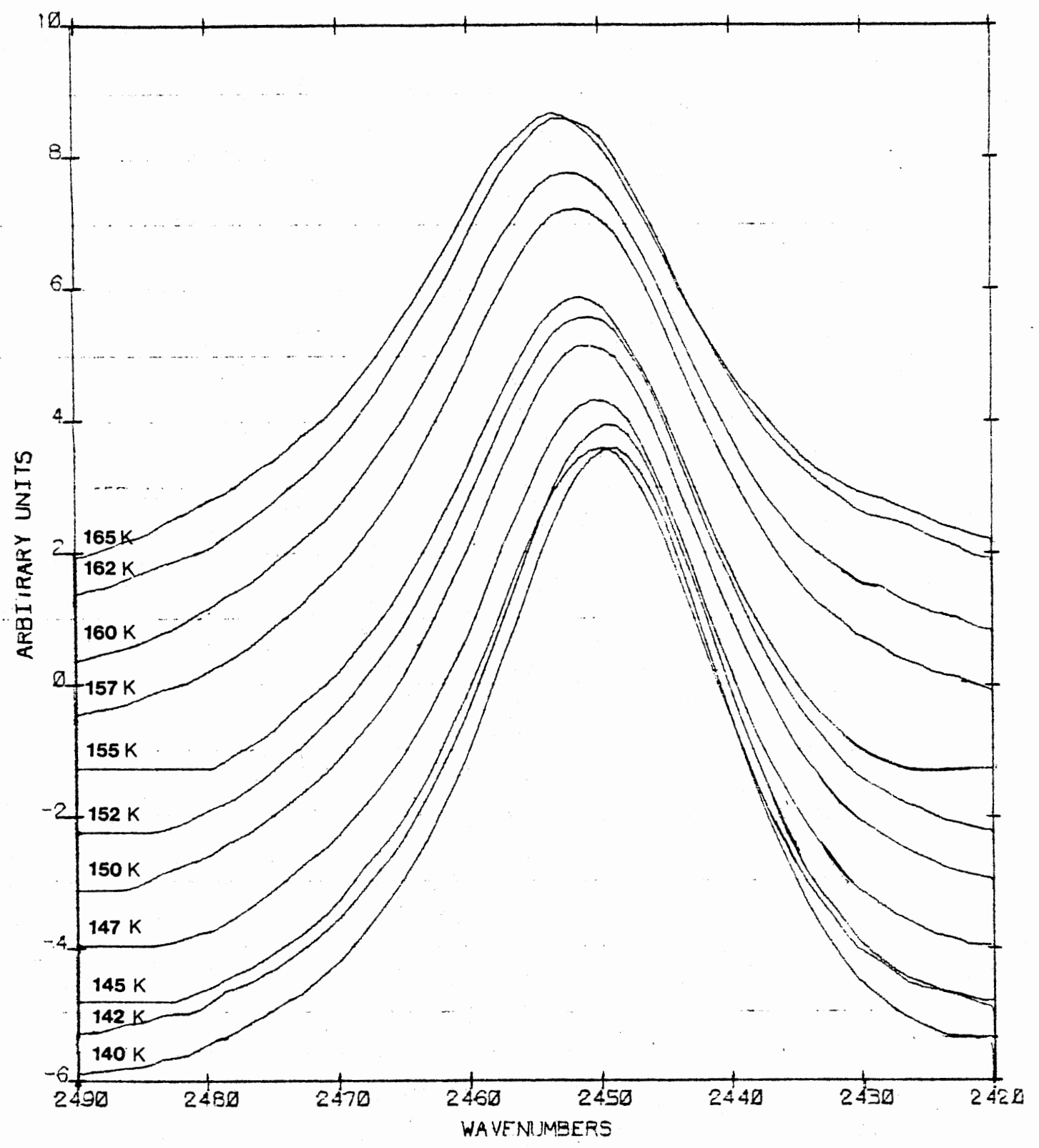

Figure 11. Expanded $\mathrm{D}_{2} \mathrm{O}$ Decoupled in $\mathrm{H}_{2} \mathrm{O}$ Ice $\nu_{3}$ Bandshapes 


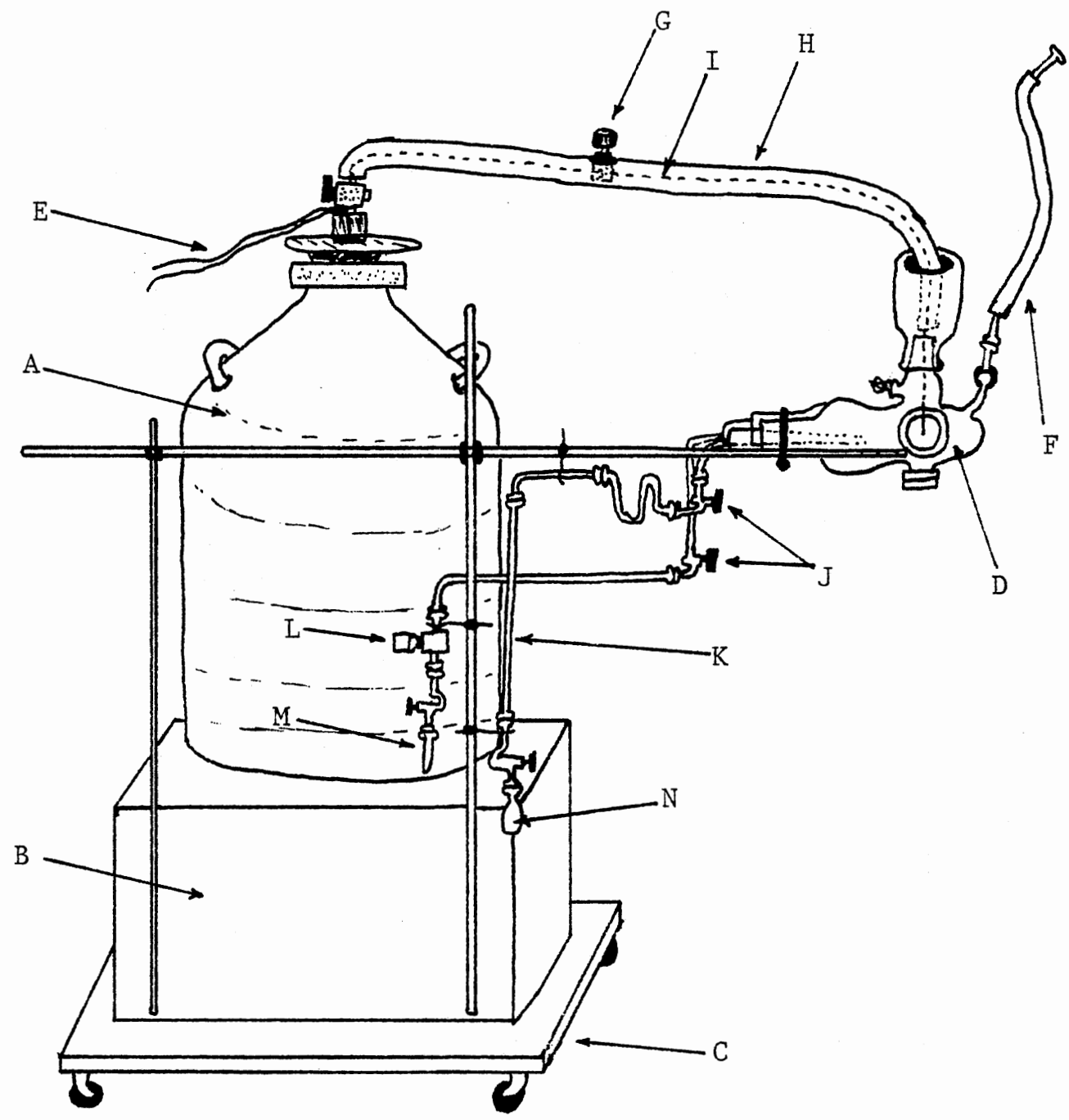
A - Liquid $\mathrm{N}_{2}$ dewar
$\mathrm{H}$ - Foam insulation
$B$ - Dewar and rack support
I - Tygon tubing
C - Rollable cart
$\mathrm{J}$ - Vacuum valves
D - Glass cryostat
K - Fisher-Porter flowmeter
E - Resistance heater leads
L - Micro-needle valve
F - Flexible vacuum line
$\mathrm{M}-\mathrm{D}_{2} \mathrm{O}$ reservoir
$\mathrm{G}-\mathrm{N}_{2}$ gas needle valve
$\mathrm{N}-\mathrm{H}_{2} \mathrm{O}$ reservoir

Figure 12. Nitrogen Gas Cooler System for Glass Cryostat Cell 
the glass dewar cell onto the 50 liter glassware rack the whole unit could be rolled to the vacuum rack for evacuation and deposition, then sealed off and disconnected from the vacuum rack to be moved to the FTIR for infrared transmission studies.

All infrared spectra were collected on a Digilab FTS-20C Fourier transform infrared spectrophotometer. This is a single beam instrument which collects digitalized interferograms via a Michelson interferometer for storage or immediate computer transform analysis to a real-time frequency infrared spectrum. All spectra can be ratioed against an earlier or later run reference spectra for background correction. The digitalized nature of the collected interferograms or computed spectra, dedicated mini-computer, and additional disk storage, allow for easy manipulation, expansion, addition and subtraction of infrared spectra. The faster collection speed, much improved accuracy, and superior quantitative features of FTIR spectroscopy were essential requirements for the completion of this work.

All spectra were collected with a triangular apodization function, a gain ranging factor (FTS-20C parameter GRR) of 40, a zero filling factor ( $\mathrm{ZFF}$ ) of 2, and detector signal sensitivities of 1 to 4 depending on the samples used and the particular experimental situation. The triangular apodization function weighs the interferogram to minimize tail fringes that may accompany Fourier transforms of infrared bands. The gain ranging factor determines the detector signal amplification changes over different parts of the interferogram to obtain the best signal to noise ratio. The zero filling factor adds additional zeroes to the end of the collected interferogram so that additional space filling points are integrated into the computed spectra. While not providing 
additional resolution it smoothes out the digitalized nature of FTIR spectra. The overall detector sensitivity was adjusted to provide maximum signal gain without overflowing the analog to digital signal converter. The number of scans that were coadded to form the final interferogram varied from 10 to 500 scans depending on the time available for the scans, and signal to noise requirements.

\section{Procedure}

A typical $\mathrm{D}_{2} \mathrm{O} / \mathrm{H}_{2} \mathrm{O}$ deposit and experimental kinetic analysis for the mechanically cooled metal deposition cell proceeded as follows.

If the cryostat's optical windows needed cleaning the cell assembly was partially dismantled, cleaned, and oven-dried to remove moisture, while the $\mathrm{KBr}$ and $\mathrm{CsI}$ windows were removed and repolished. Normally this was not required between runs, and the whole system was kept connected to the vacuum pump under a constant $5 \times 10^{-3}$ torr vacuum to minimize contamination from outside air and remove volatile contaminations from inside the vacuum systems. Several hours before a run the diffusion pump was turned on, the liquid nitrogen cold trap filled, and the system allowed to evacuate to approximately a $3 \times 10^{-4}$ torr vacuum. Next the cryostat was cooled to $170 \mathrm{~K}$ for an initial 1.5 minute deposit of $\mathrm{H}_{2} \mathrm{O}$ vapor at a flow reading of 3.0 to 3.5 on the Fisher-Porter flowmeter scale. Subsequently the cryostat was cooled to $130 \mathrm{~K}$ for the main deposit. Since the main deposit was made at the amorphous to cubic ice transition temperature, an initial deposit of cubic ice at $170 \mathrm{~K}$ was needed to induce the main deposit to form cubic rather than amorphous ice. The crystallinity of the main $\mathrm{D}_{2} \mathrm{O} / \mathrm{H}_{2} \mathrm{O}$ deposit was checked by examining the infrared spectrum in the 2800-2000 
$\mathrm{cm}^{-1}$ OD stretch region for features indicative of a crystalline or amorphous sample as shown in Figure 13. The main deposit of the $\mathrm{D}_{2} \mathrm{O} / \mathrm{H}_{2} \mathrm{O}$ vapor mixture was made at $130 \mathrm{~K}$ for 20 minutes with the $\mathrm{H}_{2} \mathrm{O}$ and $\mathrm{D}_{2} \mathrm{O}$ flow rates adjusted to a $5 \%$ to $95 \%$ ratio of $\mathrm{D}_{2} \mathrm{O}$ to $\mathrm{H}_{2} \mathrm{O}$ vapors. The flow rate of $\mathrm{H}_{2} \mathrm{O}$ on the Fisher-Porter flowmeter scale was held at approximately 7.4 while the $\mathrm{D}_{2} \mathrm{O}$ flow rate was adjusted by trial and error to give the proper ratio using a micro needle valve. Both the $\mathrm{D}_{2} \mathrm{O}$ and $\mathrm{H}_{2} \mathrm{O}$ water reservoirs were immersed in a mixture of ice and water for temperature control.

Once the deposit was completed the cryostat was sealed off and removed from the vacuum line. Next it was moved to the FTIR spectrophotometer and suspended in the FTIR sample cavity so that the IR beam would pass through the sample but yet was mechanically isolated from the interferometer to minimize vibrations from the operating displacer/ expander module. Then a $2 \mathrm{~cm}^{-1}$ resolution spectrum from $4000-500 \mathrm{~cm}^{-1}$ was collected to examine the nature of the deposit. Figure 14 shows a typical $\mathrm{D}_{2} \mathrm{O} / \mathrm{H}_{2} \mathrm{O}$ ice FTIR spectrum. In all the deposits some HOD was found initially. The HOD OD stretch would fall between the $v_{3}$ and $v_{1}$ of $\mathrm{D}_{2} \mathrm{O}$. If the HOD to $\mathrm{D}_{2} \mathrm{O}$ ratio was sufficiently small, the $\mathrm{D}_{2} \mathrm{O}$ to $\mathrm{H}_{2} \mathrm{O}$ ratio sufficiently close to an isolation ratio with little sign of dimer formation, and the sample crystalline, then a kinetic analysis was made. If not, the sample was prepared again.

To perform a kinetic analysis the cryostat was quickly warmed to the desired temperature $(135,140,145$, or $150 \mathrm{~K}$ ) to initiate isotopic exchange, and then maintained there throughout the kinetic run with an accuracy of $\pm .5 \mathrm{~K}$. Interferograms were then collected and filed at timed intervals at a $2 \mathrm{~cm}^{-1}$ resolution until exchange was complete or 


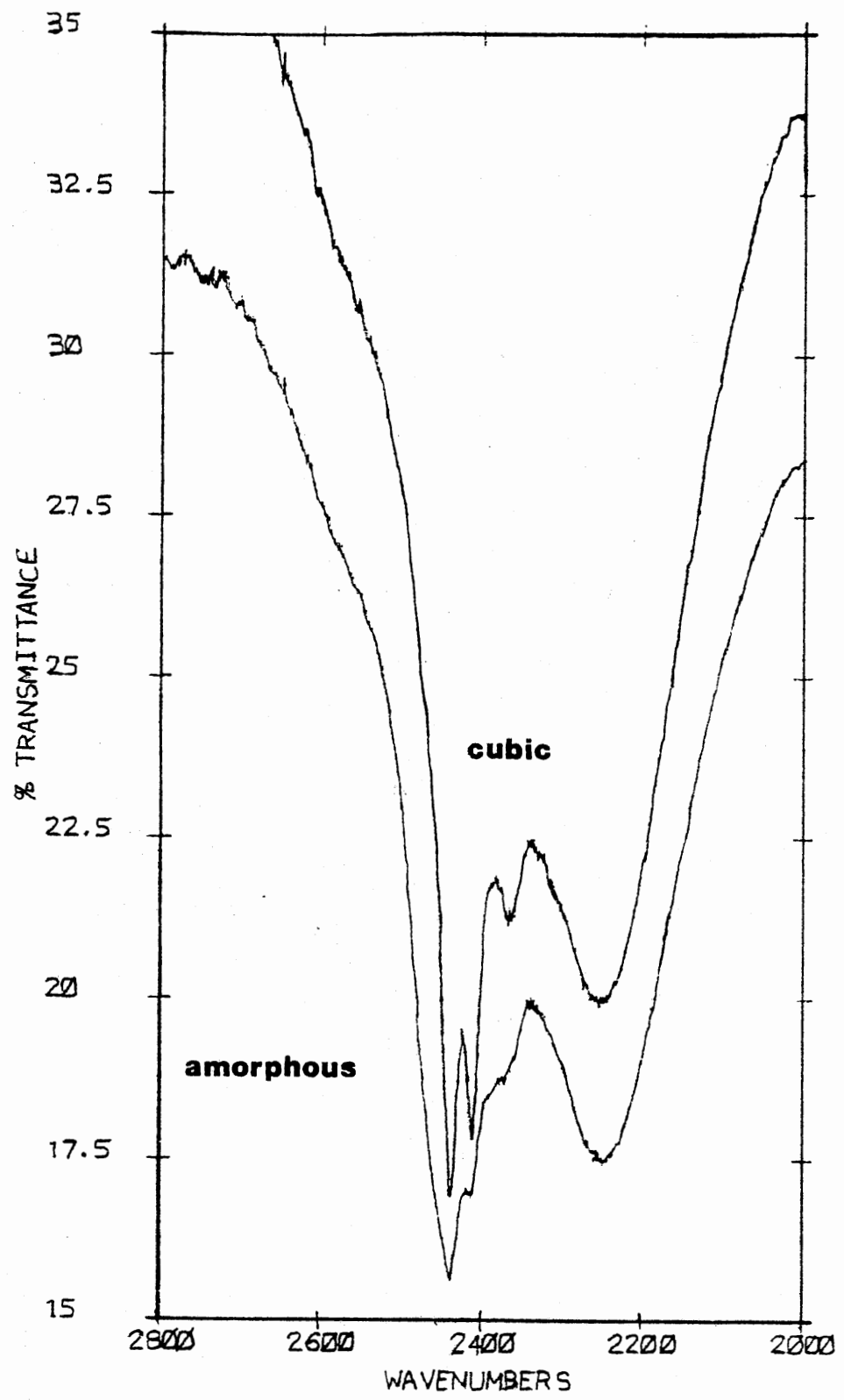

Figure 13. Spectral Changes Occurring between Amorphous and Cubic Decoupled $\mathrm{D}_{2} \mathrm{O}$ Ice 


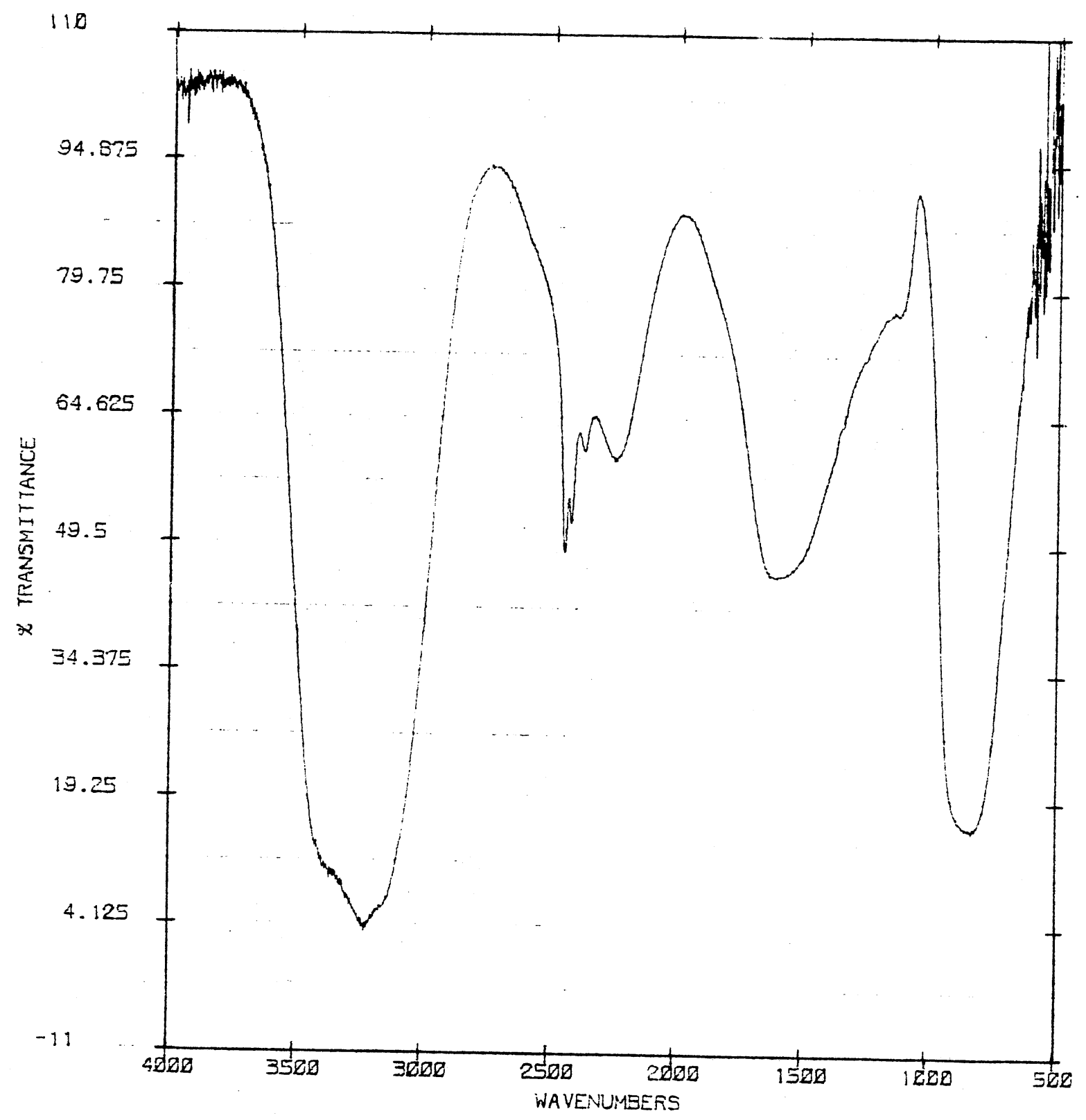

Figure 14. $\mathrm{D}_{2} \mathrm{O}$ Decoupled in $\mathrm{H}_{2} \mathrm{O}$ Cubic Ice Infrared Spectrum 
sufficiently slow to warrant stopping. The collected interferograms were stored for later transformation to frequency spectra. The sample was then warmed to approximately $170 \mathrm{~K}$ for 10-20 minutes to completely convert the sample to HOD decoupled in $\mathrm{H}_{2} \mathrm{O}$. Next the sample was cooled to the kinetic exchange temperature and a spectrum of $\mathrm{HOD}$ in $\mathrm{H}_{2} \mathrm{O}$ collected and stored. Lastly, the cryostat was reconnected to the vacuum and allowed to warm up to room temperature to vaporize and pump off the ice deposit. Thus with each sample a $130 \mathrm{~K}$ pre-kinetic run FTIR spectrum was made, a series of time correlated $\mathrm{D}_{2} \mathrm{O} / \mathrm{H}_{2} \mathrm{O}$ exchange spectra at a chosen temperature, and a final converted $\mathrm{HOD} / \mathrm{H}_{2} \mathrm{O}$ product spectra at the chosen reaction temperature.

The glass-cell 7-azaindole doped $\mathrm{D}_{2} \mathrm{O}$ in $\mathrm{H}_{2} \mathrm{O}$ deposits were prepared in a similar manner except that the deposit temperature was raised to $155 \mathrm{~K}$ to ensure crystallinity. This modification was used because doping inhibited any significant exchange at $155 \mathrm{~K}$ and affected the formation of a crystalline deposit at $130 \mathrm{~K}$.

The collected glass-cell spectra were used to produce totally resolved $\mathrm{D}_{2} \mathrm{O} \nu_{1}$ and $\nu_{3}$ bandshapes with no coupled HOD or isolated HOD band interference. These $\mathrm{D}_{2} \mathrm{O}$ bandshapes were made at 2 and $3 \mathrm{~K}$ intervals between 135 and $165 \mathrm{~K}$. Subsequently they were used to resolve the $\mathrm{D}_{2} \mathrm{O} / \mathrm{HOD} / \mathrm{H}_{2} \mathrm{O}$ spectra collected with the metal cell.

Table I shows the collection parameters used for obtaining the kinetic data from the metal cell. The sampling time shows how long it took to collect the data for an interferogram, depending on the number of scans collected. Single beam spectra of the glass and metal cells cooled to approximately $150 \mathrm{~K}$ were used as background 
TABLE I

COLLECTION PARAMETERS USED FOR COLLECTING KINETIC DATA

\begin{tabular}{lccccc}
\hline Sample & $\begin{array}{c}\text { Main } \\
\text { Deposit } \\
\text { Temp. } \\
\left({ }^{\mathrm{O}}\right)\end{array}$ & $\begin{array}{c}\text { Kinetic } \\
\text { Temp. } \\
\left({ }^{\mathrm{K}}\right)\end{array}$ & $\begin{array}{c}\text { Resolution } \\
\left(\mathrm{cm}^{-1}\right)\end{array}$ & $\begin{array}{c}\text { Scans } \\
\text { Coadded }\end{array}$ & $\begin{array}{c}\text { Sampling } \\
\text { Time } \\
(\mathrm{sec})\end{array}$ \\
\hline $2 / 2 / 82$ & 130 & 150 & 2 & 20 & 50 \\
$6 / 7 / 82$ & 130 & 150 & 2 & $10-20$ & $25-50$ \\
$6 / 9 / 82$ & 125 & 150 & 2 & $10-20$ & $25-50$ \\
$1 / 29 / 82$ & 130 & 145 & 2 & 20 & 50 \\
$5 / 10 / 82$ & 130 & 145 & 2 & 20 & 50 \\
$5 / 24 / 82$ & 130 & 145 & 2 & $10-20$ & $25-50$ \\
$6 / 3 / 82$ & 130 & 145 & 2 & 20 & 50 \\
$5 / 11 / 82$ & 130 & 140 & 2 & 20 & 50 \\
$5 / 25 / 82$ & 130 & 140 & 2 & $20-50$ & $50-120$ \\
$5 / 15 / 82$ & 130 & 135 & 2 & 20 & 50 \\
$5 / 26 / 82$ & 130 & 135 & 2 & $20-50-100$ & $50-120-240$ \\
$6 / 11 / 82$ & 125 & 135 & 2 & 20 & 50 \\
\hline
\end{tabular}


references. Also spectra of these cells at $150 \mathrm{~K}$ with 20 minute $\mathrm{H}_{2} \mathrm{O}$ deposits were used later in data manipulation. The $\mathrm{H}_{2} \mathrm{O}$ used was triply distilled and degassed under vacuum with several freeze-thaw cycles. The $\mathrm{D}_{2} \mathrm{O}$ utilized was Merck and Co., Inc. deuterium oxide "100\%" with a minimum isotopic purity of $99.96 \%$ deuterium. It was degassed under vacuum like $\mathrm{H}_{2} \mathrm{O}$. All chemical transfers were made with oven baked glassware under a dry nitrogen atmosphere. The 7-azaindole was obtained from Aldrich with a melting point of $105-107^{\circ}$, and IR and elemental analysis checks. 
CHAPTER III

\section{DATA TREATMENT AND THEORY DEVELOPMENT}

\section{Resolution of the Kinetic Spectral Data}

The initial spectroscopic work on proton transfer in cubic ice deposits was reported by Devlin et al. $(46,47)$. As a result identification of the various vibrational bands in a typical $\mathrm{D}_{2} \mathrm{O} / \mathrm{HOD} / \mathrm{H}_{2} \mathrm{O}$ deposit spectrum was readily made. Figure 15 shows the 2600 to 2250 $\mathrm{cm}^{-1}$ region of Figure 14 converted to absorbance units and expanded. Band for four distinct isotopic species are identifiable in the multiplet shown. The bands at $2444 \mathrm{~cm}^{-1}$ and $2367 \mathrm{~cm}^{-1}$ belong to $v_{3}$ and $v_{1}$ of $D_{2} O$. The strong band at $2418 \mathrm{~cm}^{-1}$ is assigned to the OD stretch of uncoupled HOD. The weak shoulder at $2396 \mathrm{~cm}^{-1}$ mentioned earlier is assigned to the in-phase coupled oD oscillator of coupled dimer HOD. Its companion out-of-phase OD stretch at $2442 \mathrm{~cm}^{-1}$ is obscured beneath the $\mathrm{D}_{2} \mathrm{O} v_{3}$ band at $2444 \mathrm{~cm}^{-1}$. The baseline slant is due to the shoulder of the $2250 \mathrm{~cm}^{-1} \mathrm{H}_{2} \mathrm{O}$ combination band.

If the $\mathrm{D}_{2} \mathrm{O} / \mathrm{HOD} / \mathrm{H}_{2} \mathrm{O}$ deposit is warmed up and allowed to exchange the changes shown in Figure 16 occur. There the 2444 and $2367 \mathrm{~cm}^{-1}$ $\mathrm{D}_{2} \mathrm{O}$ bands decrease in intensity and finally disappear, the $2396 \mathrm{~cm}^{-1}$ coupled dimer HOD band remains steady or increases to subsequently disappear, and the decoupled or isolated HOD band at $2418 \mathrm{~cm}^{-1}$ grows in intensity until eventually it becomes the sole spectral feature.

To follow the kinetics of the exchange process the multiplet 


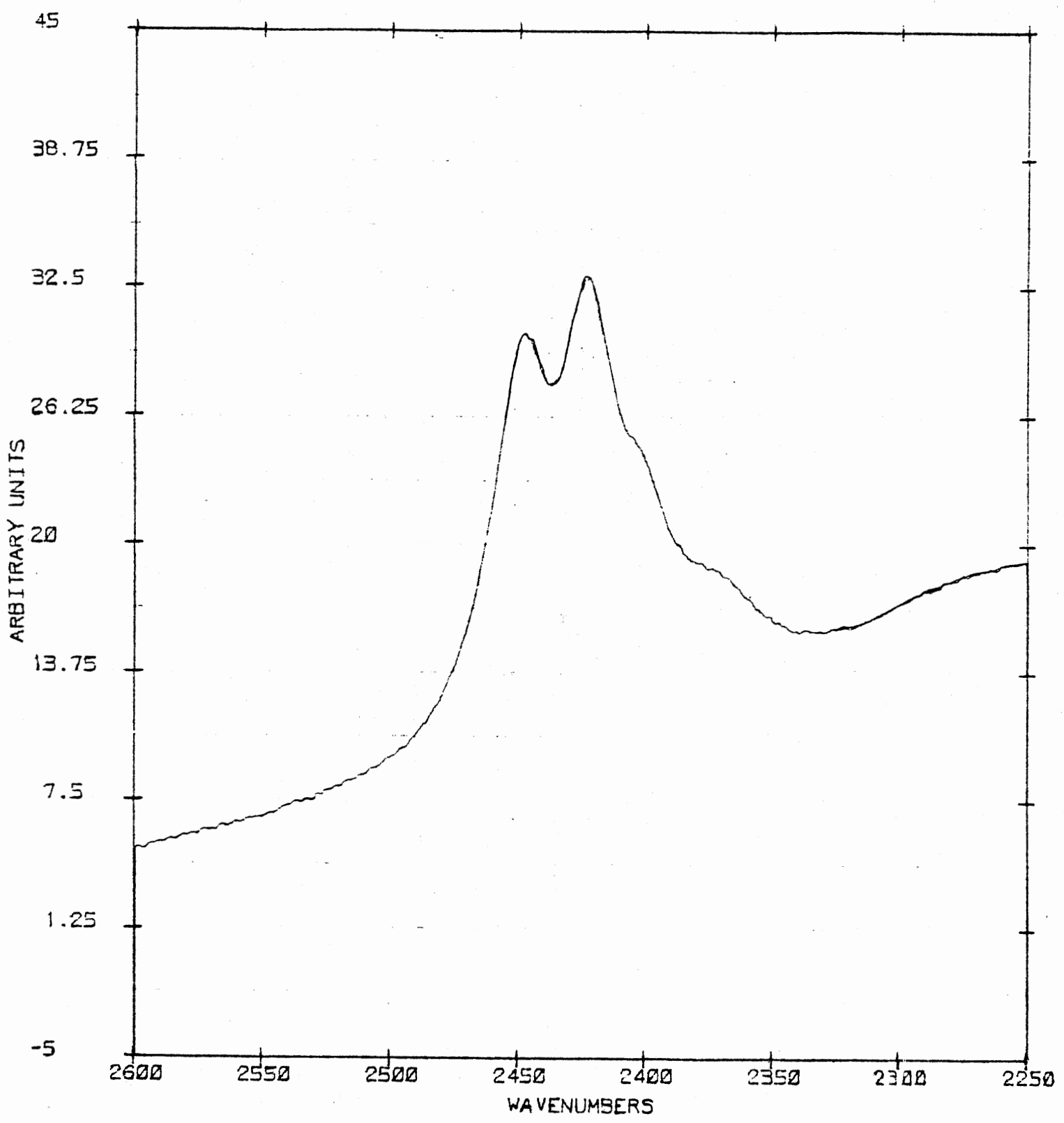

Figure 15. OD Stretch Multiplet of $\mathrm{D}_{2} \mathrm{O}$ Decoupled in $\mathrm{H}_{2} \mathrm{O}$ Ice 


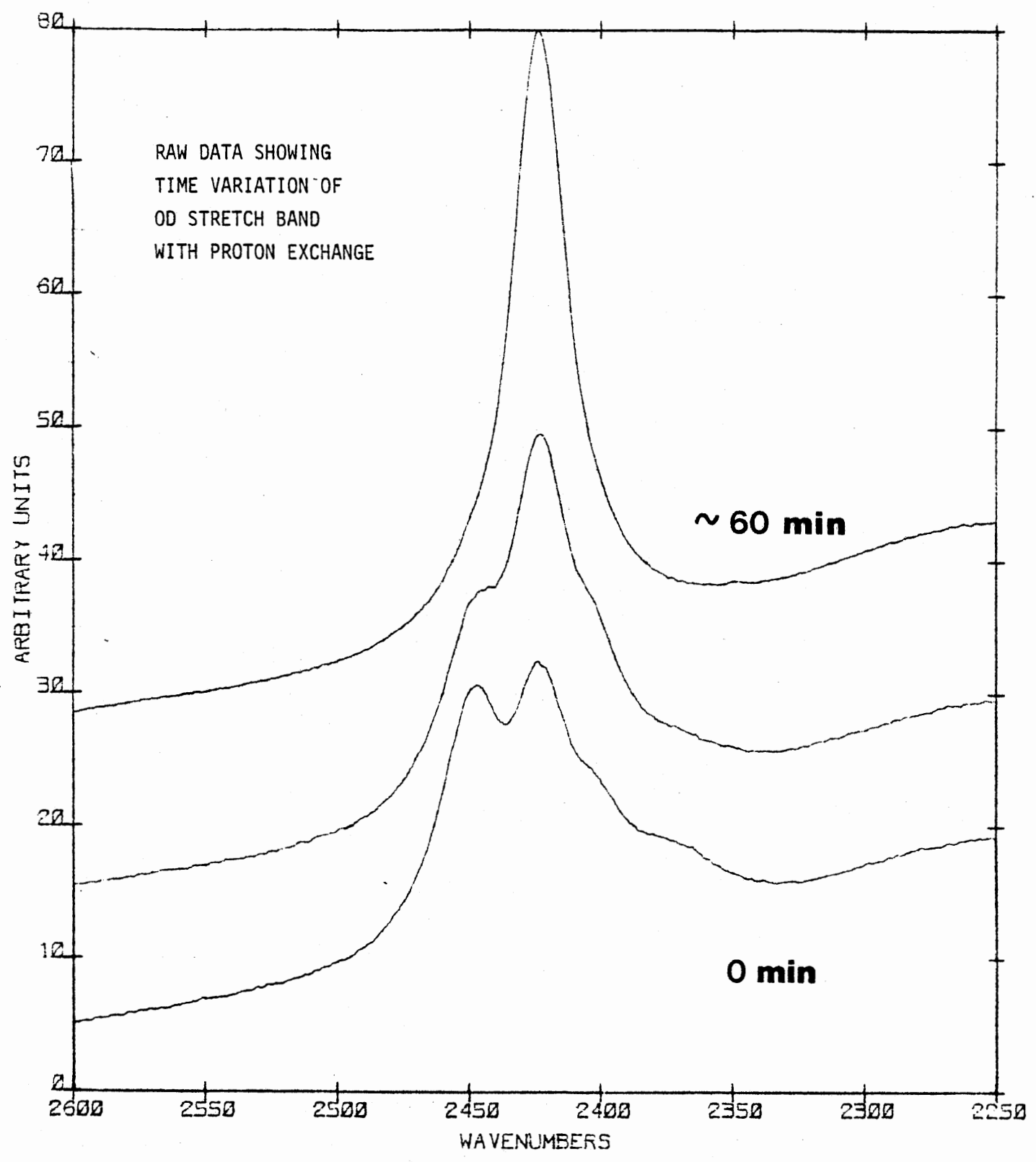

Figure 16. Time Variation of OD Stretch Multiplet with Proton Exchange 
must be resolved into the bands for the individual kinetic species for absorbance measurement. For a mixed multiplet of four distinct species this can be done if three pure component species spectra are available. There each component spectra may be scaled appropriately and subtracted from the multiplet to leave a multiplet with one less component. The process may be repeated until only the unknown component is left.

If all four pure component spectra are available, a standard least square type fitting program can be used to determine the best fit scaling constants for each component spectrum. However, in resolving the OD stretch multiplet only three pure component spectra were available. The best route to extracting the component absorbances was to extract the absorbance for three available pure components and check to see if the remaining pure component bandshape agreed with predictions. Fortunately for the $\mathrm{D}_{2} \mathrm{O} / \mathrm{HOD} / \mathrm{H}_{2} \mathrm{O}$ deposit spectra, pure component spectra are obtainable for all except the coupled dimer HOD spectrum. In addition, from Haas and Hornig (22) some information is known about the coupled HOD bandshape. There should be two bands at about $2393 \mathrm{~cm}^{-1}$ (in-phase stretch) and $2442 \mathrm{~cm}^{-1}$ (out-of-phase stretch) with approximately a 2 to 1 (in-phase to out-of-phase) intensity ratio.

The $2250 \mathrm{~cm}^{-1} \mathrm{H}_{2} \mathrm{O}$ combination band pure component spectrum was obtained by making a deposit of $\mathrm{H}_{2} \mathrm{O}$ only. The $2418 \mathrm{~cm}^{-1}$ uncoupled HOD band was obtained by allowing the $\mathrm{D}_{2} \mathrm{O} / \mathrm{HOD} / \mathrm{H}_{2} \mathrm{O}$ deposit to convert completely to uncoupled HOD at the end of each kinetic run. Obtaining pure component $\mathrm{D}_{2} \mathrm{O} \quad v_{3}$ and $v_{1}$ bands at each of the temperatures used for kinetics was considerably more involved.

From Devlin et al. (46), it is known that by introducing a dopant 
such as 7-azaindole into the ice samples the transfer rate $k_{1}$ is slowed significantly relative to the $k_{2}$ rotational rate, thus causing a very small steady state concentration of coupled HOD that is spectroscopically unobservable. Using the glass deposition cell with the glass cell procedure outlined in Chapter II, 7-azaindole doped $\mathrm{D}_{2} \mathrm{O} / \mathrm{H}_{2} \mathrm{O}$ ice deposits were made. Curve A Figure 17 shows a typical spectrum of the $2600-2250 \mathrm{~cm}^{-1}$ OD stretch region. Except for the absence of the 2396 and $2442 \mathrm{~cm}^{-1}$ coupled HOD bands the features are identical to Figure 15. By warming the deposit sufficiently, the sample could be made to convert enough to uncoupled HOD, that (see Figure 17 curve B) the converted HOD spectrum could be scaled appropriately and subtracted from the $\mathrm{D}_{2} \mathrm{O} / \mathrm{HOD}$ multiplet shown in curve $\mathrm{A}$. This left the pure component $\mathrm{D}_{2} \mathrm{O} v_{3}$ and $v_{1}$ bands at the appropriate temperature (curve $\mathrm{C}$ ). Several doped $\mathrm{D}_{2} \mathrm{O} / \mathrm{H}_{2} \mathrm{O}$ deposit spectra were collected at 2 and $3 \mathrm{~K}$ intervals from 135 to $160 \mathrm{~K}$, then warmed and converted to uncoupled HOD. After cooling the resulting spectra were collected at the same temperature as the pre-converted $\mathrm{D}_{2} \mathrm{O} / \mathrm{H}_{2} \mathrm{O}$ spectra. Thus at each temperature a $\mathrm{D}_{2} \mathrm{O} / \mathrm{H}_{2} \mathrm{O}$ multiplet and uncoupled $\mathrm{HOD}$ spectra were available for producing a pure component $\mathrm{D}_{2} \mathrm{O} v_{3}$ and $v_{1}$ spectrum. Figure 18 shows these pure $\mathrm{D}_{2} \mathrm{O} v_{3}$ and $\nu_{1}$ spectra.

Now with three pure component spectra at the same temperature as the metal cell oD stretch multiplet it is possible to subtract out each component and find its respective absorbance until only the pure coupled HOD spectrum remained. The following procedure was used. The $2250 \mathrm{~cm}^{-1}$ combination band (Figure 19 curve B) is scaled and subtracted from the metal cell ice oD stretch multiplet (curve A) to 
54

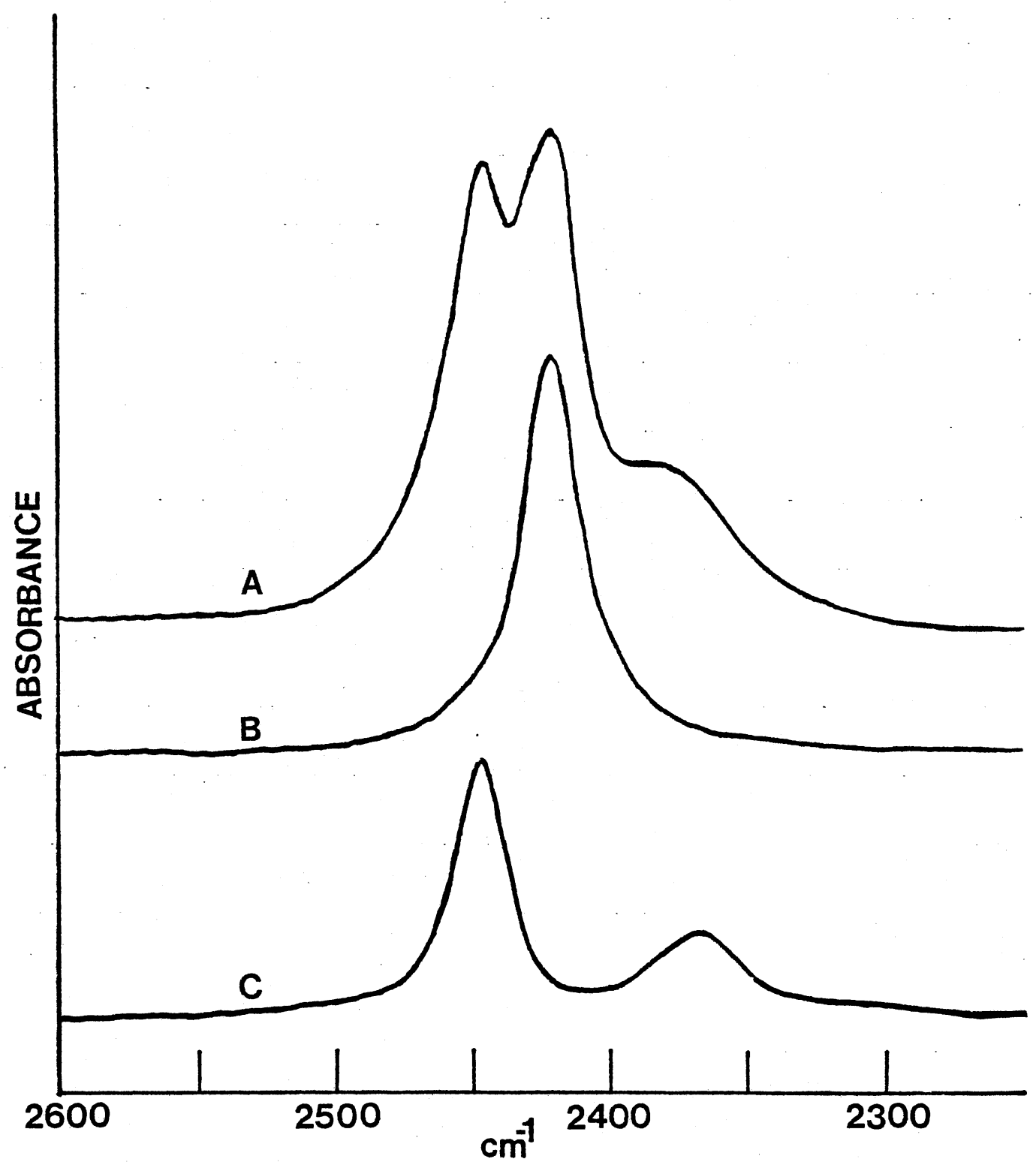

Figure 17. 7-Azaindole Doped $\mathrm{D}_{2} \mathrm{O} \mathrm{H}_{2} \mathrm{O}$ Ice Deposit Spectral Resolution 


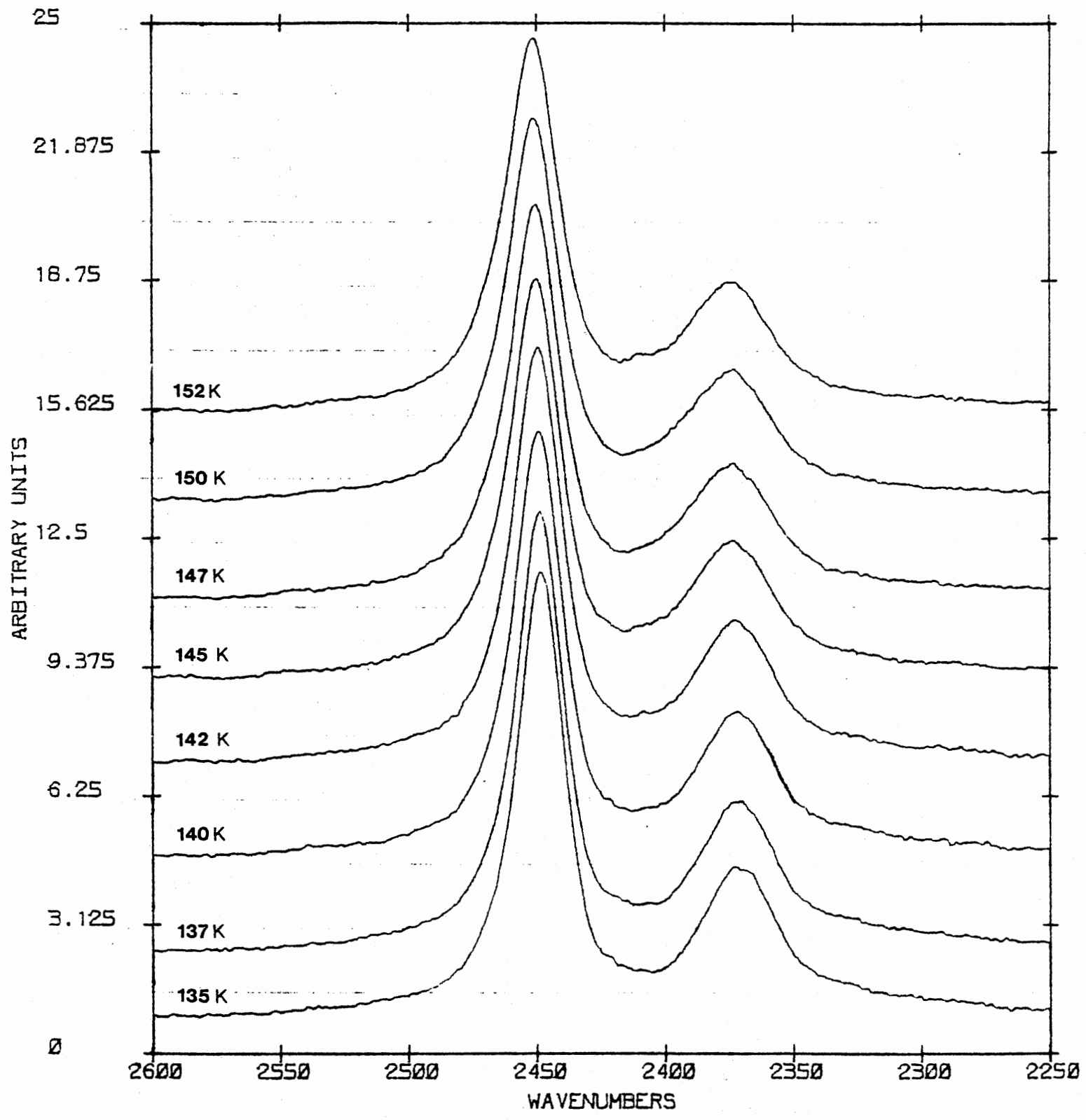

Figure 18. Pure Component $D_{2} O v_{3}$ Bandshapes from Glass Cell 


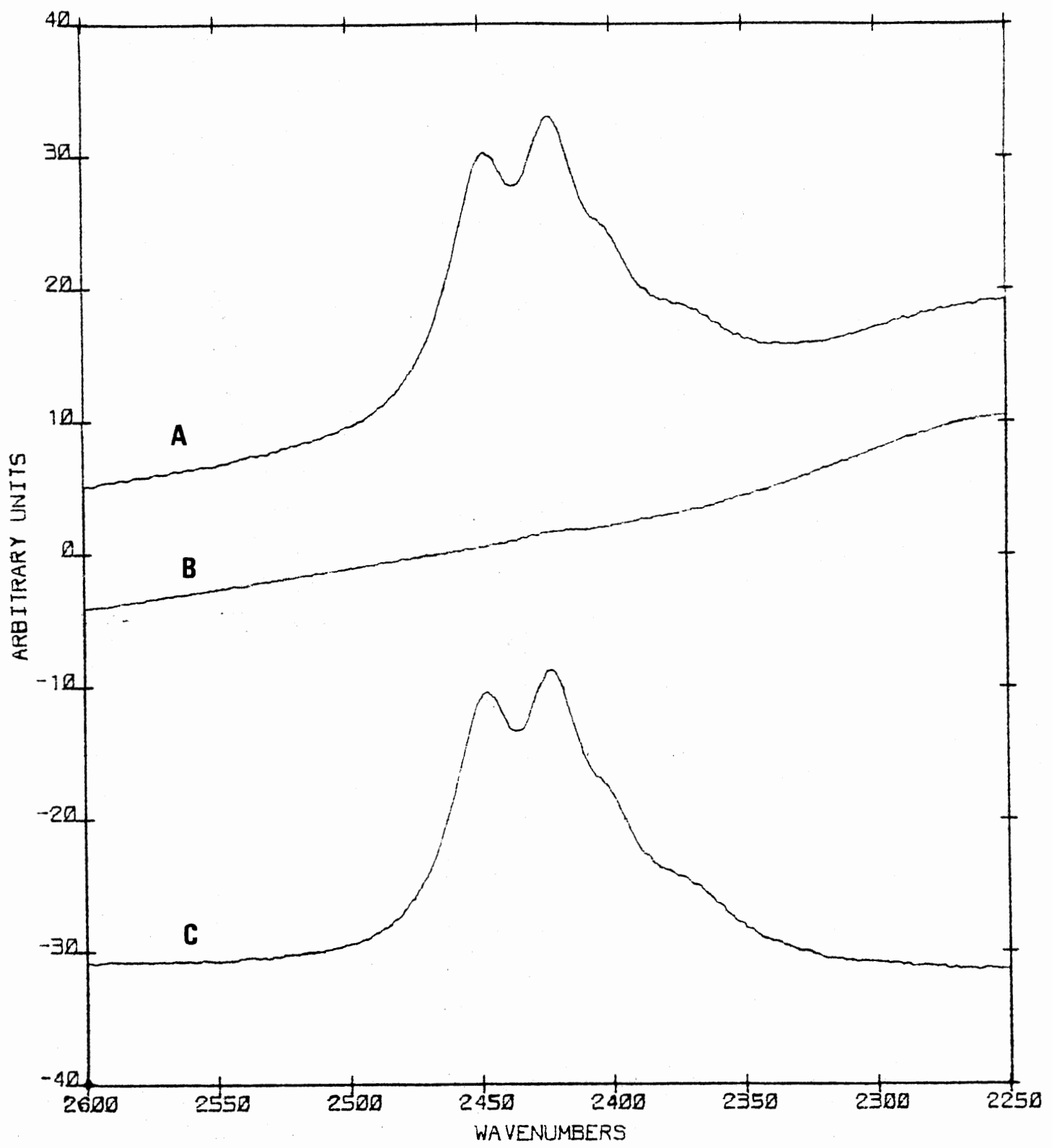

Figure 19. Subtraction of $\mathrm{H}_{2} \mathrm{O}$ Combination Shoulder from OD Multiplet 
yield the multiplet on a flat background (curve $\mathrm{C}$ ).

Next the pure $\mathrm{D}_{2} \mathrm{O}$ spectrum (Figure 20 curve $\mathrm{B}$ ), collected by the glass cell procedure at the same temperature as the OD stretch multiplet, was scaled and subtracted from the OD stretch multiplet (curve A) to yield the coupled and uncoupled HOD spectrum (curve C). Any significant over or under subtraction of the pure component $\mathrm{D}_{2} \mathrm{O}$ (curve B) spectrum left small humps or dips at 2444 and $2367 \mathrm{~cm}^{-1}$. By multiplying the particular pure component $\mathrm{D}_{2} \mathrm{O}$ absorbance by the scaling factor used, the absorbance of the $\mathrm{D}_{2} \mathrm{O}$ concentration in the ice deposition sample was found. The absorbance of the pure component $\mathrm{D}_{2} \mathrm{O}$ band was taken from the more intense $\nu_{3}$ band.

The uncoupled $2418 \mathrm{~cm}^{-1}$ HOD band (Figure 21 curve B) obtained at the end of each kinetic run was then scaled and subtracted from the previously found uncoupled and coupled HOD spectrum (Figure 21 curve A) to yield the pure component coupled HOD spectrum (curve C). The scaling factor used in the subtraction times the absorbance of the uncoupled HOD spectrum used (curve B) yielded the uncoupled HOD absorbance for that particular OD stretch multiplet. The absorbance of the coupled HOD was extracted from direct measurement of the inphase $2396 \mathrm{~cm}^{-1}$ band. Any over subtraction of uncoupled HOD (curve B) would reveal itself as too steep and negative a dip between the coupled HOD in and out-of-phase bands. Too little subtraction would show as insufficient dip or even a small residual hump between the two coupled HOD bands.

As a further check, the coupled and uncoupled spectrum (Figure 22 curve B) can be subtracted from the starting OD stretch multiplet (curve A) to yield a replica of the pure $\mathrm{D}_{2} \mathrm{O}$ component bands used in the Figure 20 


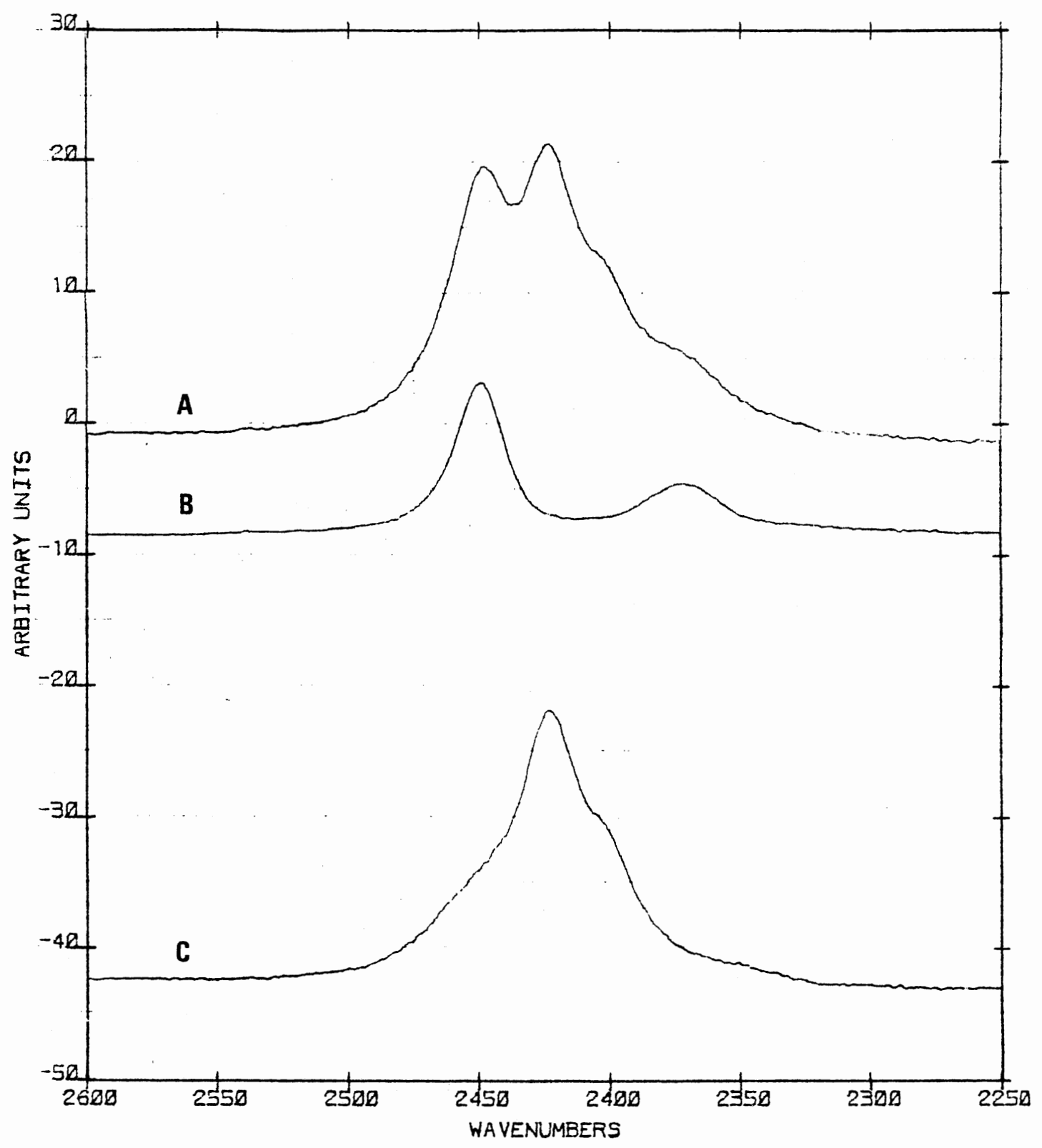

Figure 20. Subtraction of $\mathrm{D}_{2} \mathrm{O}$ Component from $\mathrm{OD}$ Multiplet 


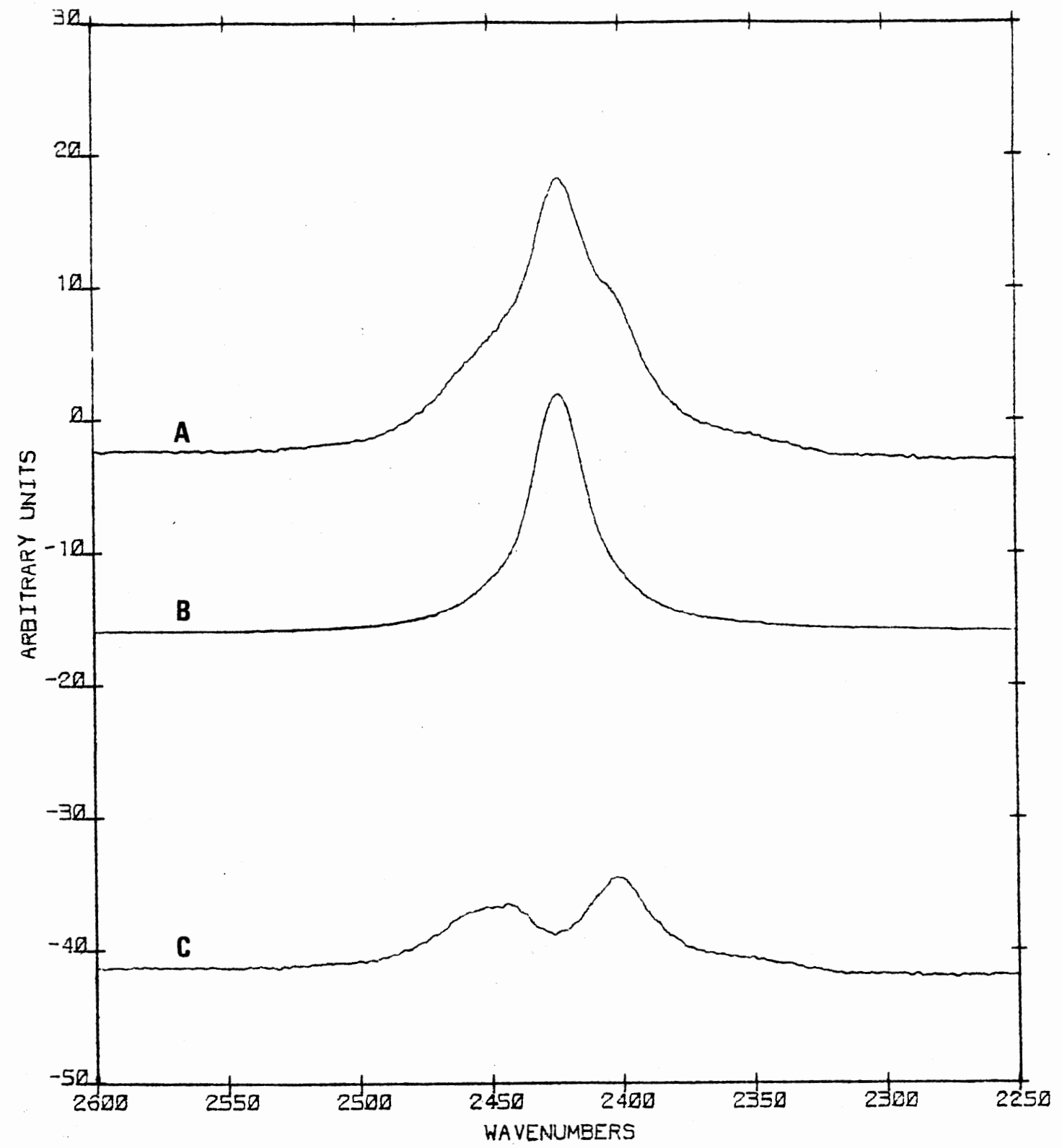

Figure 21. Subtraction of Uncoupled HOD Component from HOD Multiplet 
subtraction, except that it has been scaled by the subtraction scaling factor used in the Figure 20 subtraction. This process was repeated for all multiplet resolutions at all data collection temperatures. Usually two or three adjustments of the subtraction scaling factors were necessary before the best resolution of the pure spectral components was achieved.

Since the $\mathrm{D}_{2} \mathrm{O} v_{3}$ band at $2444 \mathrm{~cm}^{-1}$ and the coupled HOD out-ofphase band at $2442 \mathrm{~cm}^{-1}$ overlap so completely the $\mathrm{D}_{2} \mathrm{O}$ component scaling factor was not as correctly determined as the uncoupled HOD scaling factor. Figure 23 illustrates the effects of deviations of the $D_{2} O$ pure component scaling factor from the correct scaling factor, on the coupled HOD bandshapes. Additionally, when the concentration and hence intensity of the coupled HOD was small, these deviations were difficult to detect. To circumvent this problem the following reasoning was used.

Both the in and out-of-phase bands arise from the same isotopic chemical species. Thus assuming Beer's law of absorption holds over the intensity range in question, there should be a constant ratio between the in-phase band and out-of-phase band irrespective of concentration or band intensity. To experimentally find this ratio, a series of the best most intense pure coupled HOD spectra were measured to find the best absorbance ratio. The best average ratio was 0.70 for the inphase absorbance to out-of-phase absorbance. Multiplying the better determined in-phase coupled HOD band absorbance at $2396 \mathrm{~cm}^{-1}$ by 0.70 should yield a better out-of-phase $2442 \mathrm{~cm}^{-1}$ band absorbance. By subtracting this ratio determined absorbance from the spectrally measured coupled HOD out-of-phase absorbance the amount of over or 


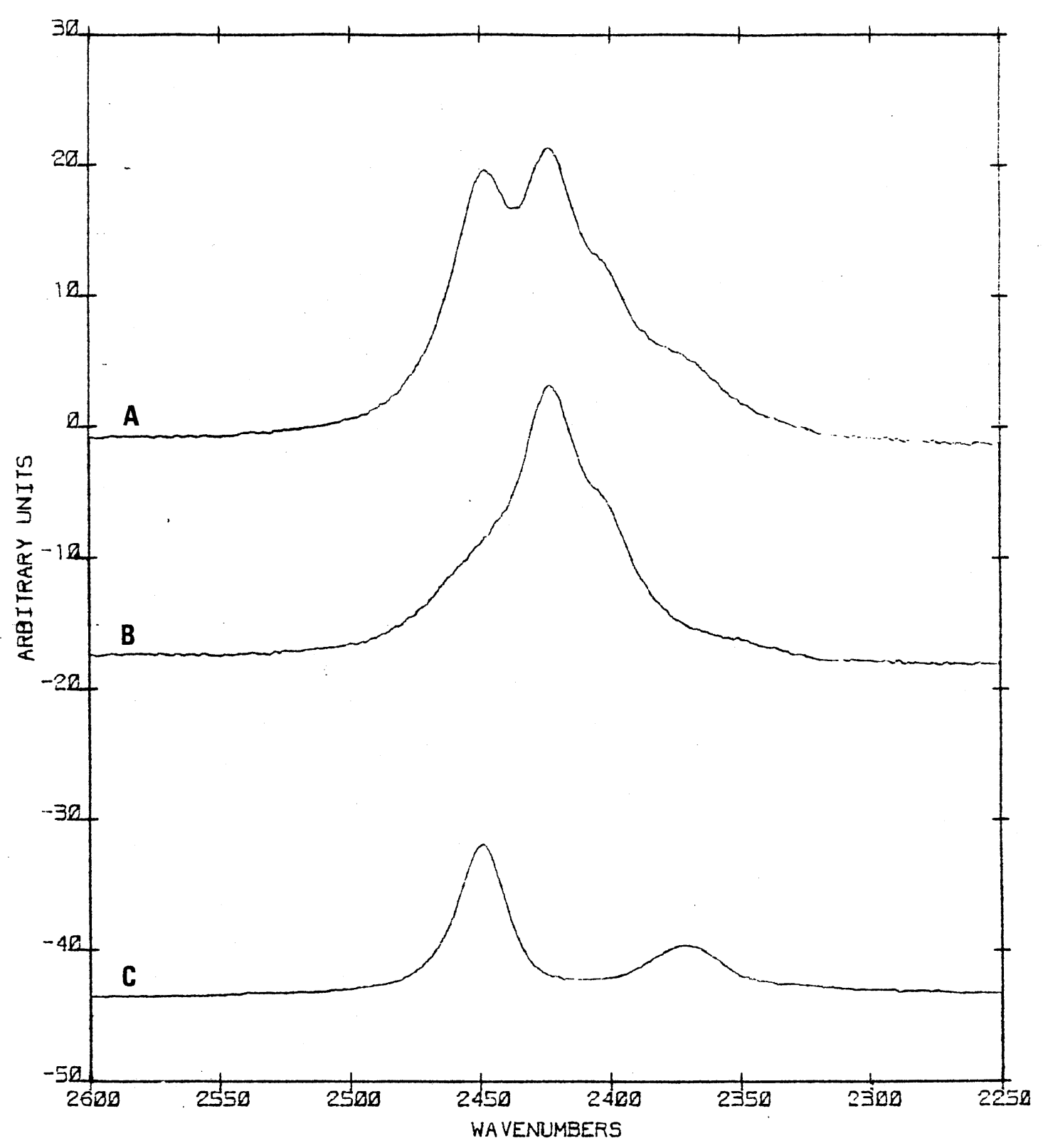

Figure 22. Subtraction of HOD Multiplet from OD Multiplet 


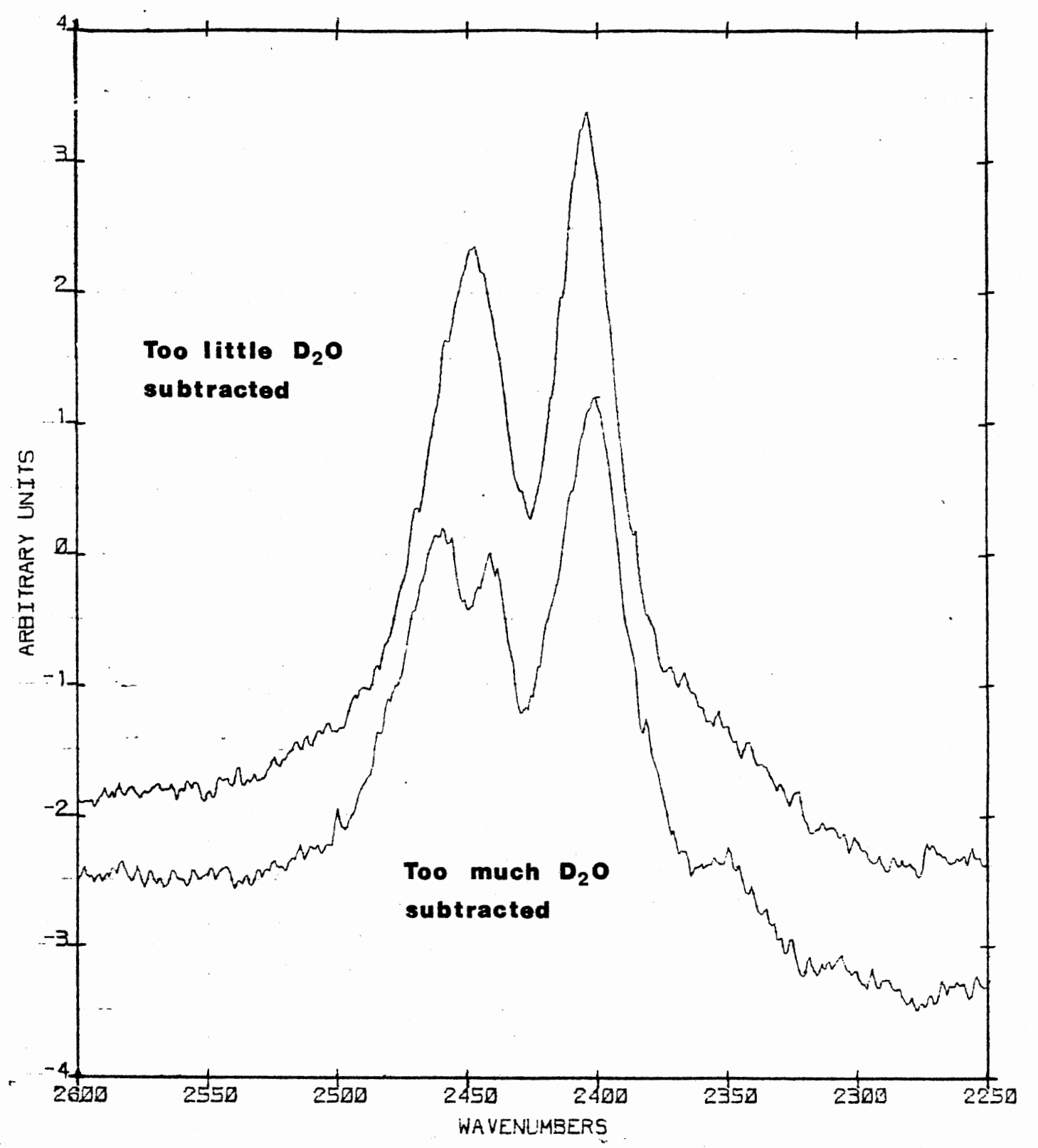

Figure 23. $\mathrm{D}_{2} \mathrm{O}$ Scaling Factor Deviation Effects on Coupled HOD 
under subtraction of the pure component $\mathrm{D}_{2} \mathrm{O}$ band from the oD stretch multiplet could be determined. This positive or negative deviation was added to the previously determined $\mathrm{D}_{2} \mathrm{O}$ component absorbance for the oD stretch multiplet being resolved. The resulting $\mathrm{D}_{2} \mathrm{O}$ absorbances are called corrected $\mathrm{D}_{2} \mathrm{O}$ absorbances. Most deviations calculated were small and served to smooth out the data of the corrected $\mathrm{D}_{2} \mathrm{O}$ absorbance values as compared to the uncorrected $\mathrm{D}_{2} \mathrm{O}$ absorbance values. Table II lists the scaling factors, corrected $\mathrm{D}_{2} \mathrm{O}$ absorbance, coupled HOD absorbance, uncoupled HOD absorbances for the kinetic data found at 135 , 140,145 , and $150 \mathrm{~K}$. Also listed are the unscaled absorbances of the fully converted uncoupled HOD bands used in subtracting out the uncoupled HOD (see Figure 21) and glass cell doped ice deposit determined pure $\mathrm{D}_{2} \mathrm{O} \nu_{3}$ bands (see Figure 20). All absorbance measurements determined from spectral plots were found by subtracting from the band peak absorbance the peak frequency absorbance of a baseline drawn tangest to the background absorption. All absorbance measurements are in Digilab's arbitrary absorbance units.

Table I shows the sampling times for the Table II data. The sampling or collection time for the interferogram is dependent on the resolution required, and number of interferometer scans coadded to form the final interferogram. For most data points the period of collection is small compared to the time interval between data points. The exceptions are the initial $150 \mathrm{~K}$ collected data. If the 2 to 4 minute interval of the $6 / 7 / 82$ dataset is examined, it is found that the greatest change occurring with the $\mathrm{D}_{2} \mathrm{O}$ absorbances are 12.639 at 2 minutes and 10.155 at 4 minutes. The Digilab FTIR takes 25 seconds to collect a $10 \mathrm{scan} 2 \mathrm{~cm}^{-1}$ resolution interferogram. Thus one quarter 
TABLE II

ABSORBANCES AND SCALING FACTORS FOR RESOLVED OD STRETCH MULTIPLETS

Dataset $\begin{gathered}\text { Time } \\ \text { (minutes) }\end{gathered} \quad \frac{\mathrm{D}_{2} \mathrm{O}}{\text { Scaling Factor Absorbance } \mathrm{a}, \mathrm{b}} \quad \frac{\text { (HOD) }_{2}}{\text { Absorbance }^{\mathrm{a}}}$ Scaling Factor Absorbance $^{\mathrm{a}}$

$2 / 2 / 82$

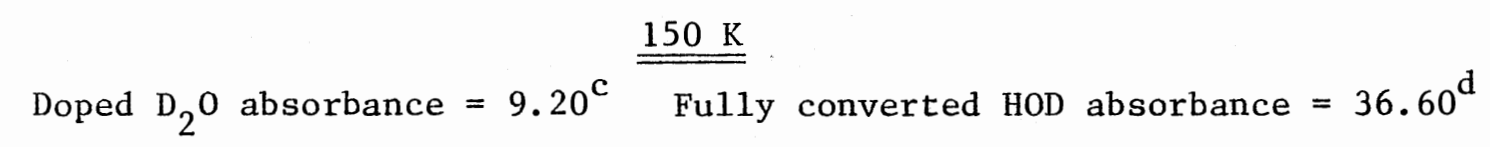

\begin{tabular}{|c|c|c|c|c|c|}
\hline 0.0 & 1.27 & $11.869^{\mathrm{e}}$ & $3.56^{\mathrm{e}}$ & 0.31 & $11.346^{\mathrm{e}}$ \\
\hline 2.0 & 0.98 & 9.281 & 5.05 & 0.35 & 12.81 \\
\hline 4.0 & 0.80 & 7.24 & 5.6 & 0.42 & 15.372 \\
\hline 6.0 & 0.65 & 5.665 & 5.45 & 0.49 & 17.934 \\
\hline 9.5 & 0.45 & 3.885 & 4.65 & 0.60 & 21.96 \\
\hline 12.5 & 0.33 & 3.041 & 3.85 & 0.67 & 24.522 \\
\hline 15.5 & 0.27 & 2.379 & 3.15 & 0.73 & 26.718 \\
\hline 20.5 & 0.19 & 1.873 & 2.25 & 0.79 & 28.914 \\
\hline
\end{tabular}

$6 / 7 / 82$

Doped $\mathrm{D}_{2} \mathrm{O}$ absorbance $=9.20 \quad$ Fully converted HOD absorbance $=38.30$

$\begin{array}{rlrlll}0.0 & 1.5 & 14.295 & 3.15 & 0.29 & 11.107 \\ 2.0 & 1.35 & 12.639 & 3.83 & 0.335 & 12.831 \\ 4.0 & 1.1 & 10.155 & 5.15 & 0.37 & 14.171 \\ 6.0 & 0.88 & 8.131 & 5.55 & 0.43 & 16.469 \\ 8.0 & 0.72 & 6.646 & 5.74 & 0.49 & 18.767 \\ 10.0 & 0.62 & 5.809 & 5.35 & 0.54 & 20.682 \\ 12.0 & 0.56 & 5.121 & 4.83 & 0.59 & 22.597 \\ 15.0 & 0.49 & 4.253 & 4.15 & 0.655 & 25.087 \\ 20.0 & 0.40 & 3.415 & 3.45 & 0.72 & 27.576 \\ 25.0 & 0.32 & 2.714 & 2.9 & 0.72 & 29.491\end{array}$


TABLE II (Continued)

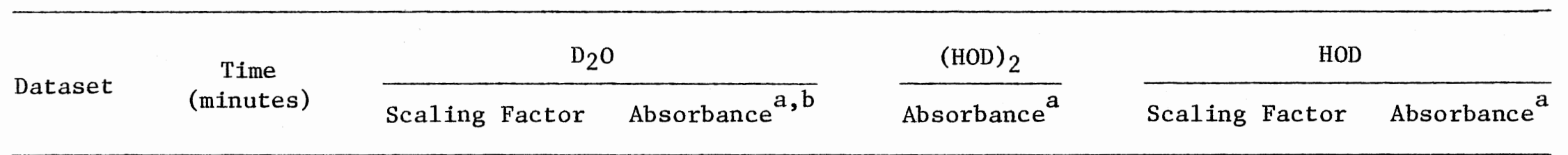

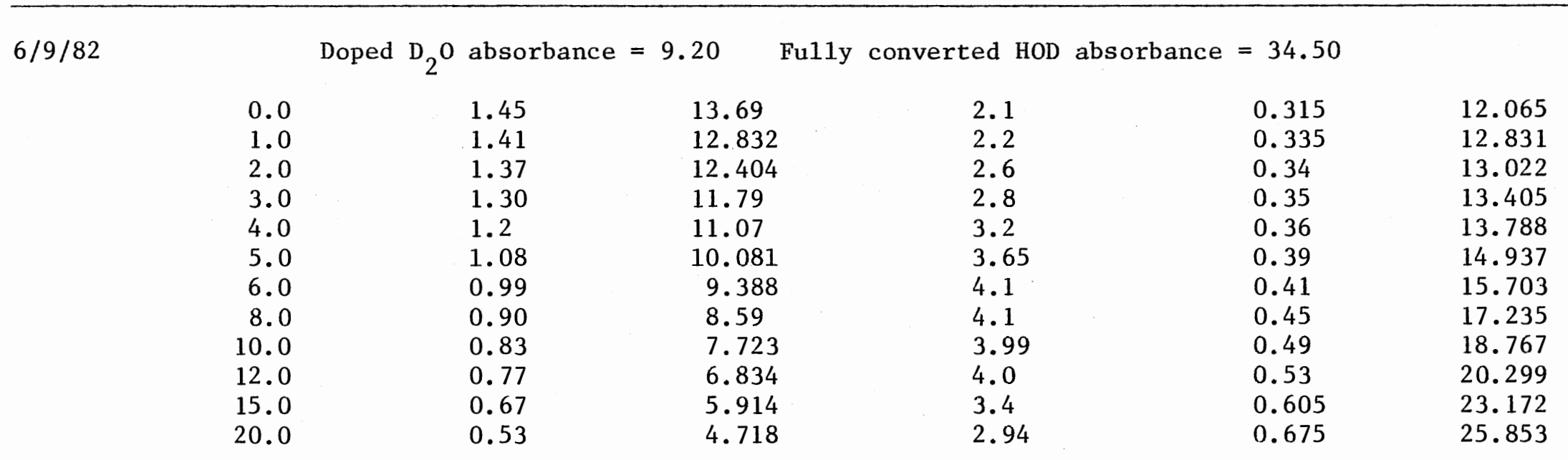

$1 / 29 / 82$

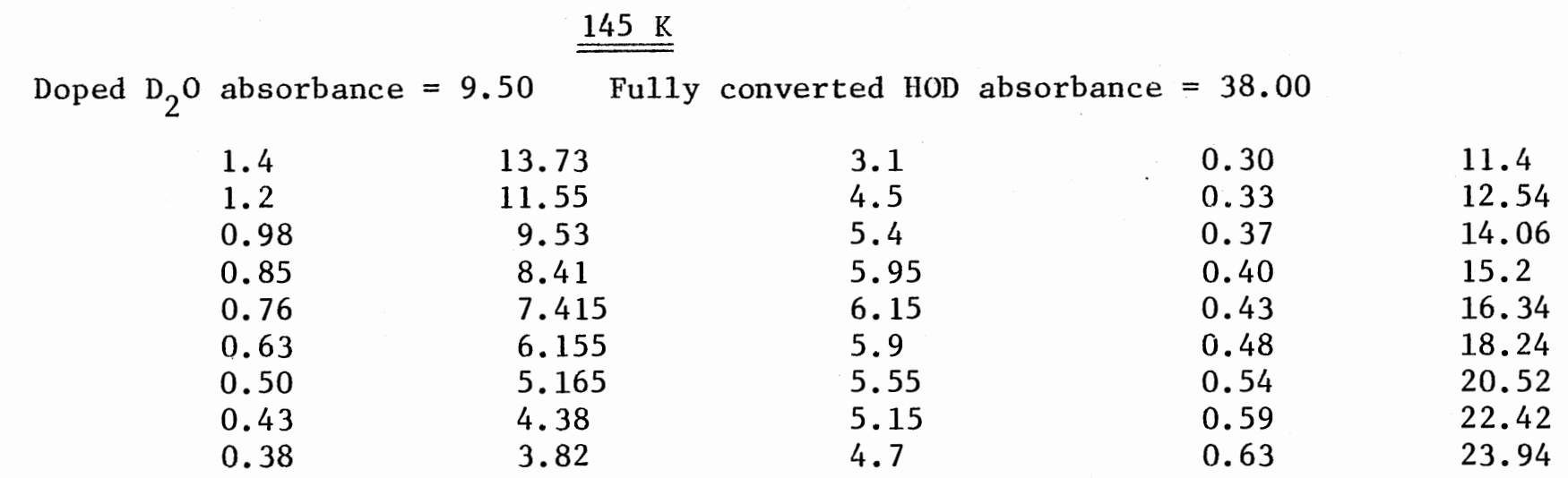


TABLE II (Continued)

\begin{tabular}{|c|c|c|c|c|c|c|}
\hline \multirow{2}{*}{ Dataset } & \multirow{2}{*}{$\begin{array}{c}\text { Time } \\
\text { (minutes) }\end{array}$} & \multicolumn{2}{|c|}{$\mathrm{D}_{2} \mathrm{O}$} & \multirow{2}{*}{$\frac{(\mathrm{HOD})_{2}}{\text { Absorbance }^{\mathrm{a}}}$} & \multicolumn{2}{|c|}{ HOD } \\
\hline & & Scaling Factor & Absorbance $a, b$ & & Scaling Factor & Absorbance ${ }^{a}$ \\
\hline & 43 & 0.30 & 3.07 & 3.9 & 0.69 & 26.22 \\
\hline & 52 & 0.26 & 2.59 & 3.4 & 0.73 & 27.74 \\
\hline & 62 & 0.22 & 2.23 & 2.8 & 0.77 & 29.26 \\
\hline & 72 & 0.18 & 2.125 & 2.55 & 0.79 & 30.02 \\
\hline
\end{tabular}

$5 / 10 / 82$

Doped $\mathrm{D}_{2} \mathrm{O}$ absorbance $=9.50 \quad$ Fully converted HOD absorbance $=35.80$

$\begin{array}{rlclll}0.0 & 1.1 & 10.367 & 3.69 & 0.36 & 12.888 \\ 3.0 & 1.0 & 9.537 & 4.09 & 0.38 & 13.604 \\ 6.0 & 0.93 & 8.805 & 4.4 & 0.40 & 14.32 \\ 9.0 & 0.85 & 7.95 & 4.65 & 0.43 & 15.394 \\ 12.0 & 0.79 & 7.675 & 4.5 & 0.445 & 15.931 \\ 17.0 & 0.70 & 6.609 & 4.63 & 0.485 & 17.363 \\ 22.0 & 0.63 & 5.947 & 4.54 & 0.52 & 18.616 \\ 27.0 & 0.58 & 5.435 & 4.25 & 0.555 & 19.869 \\ 32.0 & 0.54 & 4.821 & 4.07 & 0.59 & 21.122 \\ 47.0 & 0.41 & 3.561 & 3.32 & 0.67 & 23.986 \\ 62.0 & 0.29 & 2.895 & 2.8 & 0.72 & 25.776 \\ 77.0 & 0.22 & 2.245 & 2.35 & 0.77 & 27.566\end{array}$

Doped $\mathrm{D}_{2} \mathrm{O}$ absorbance $=9.5$ Fully converted HOD absorbance $=33.25$

$\begin{array}{rlllll}0.0 & 1.0 & 9.25 & 3.5 & 0.32 & 10.64 \\ 3.0 & 0.88 & 8.117 & 3.89 & 0.34 & 11.305 \\ 6.0 & 0.76 & 6.771 & 4.57 & 0.37 & 12.303 \\ 9.0 & 0.64 & 5.925 & 4.65 & 0.40 & 13.3 \\ 12.0 & 0.55 & 5.038 & 4.81 & 0.44 & 14.63 \\ 17.0 & 0.40 & 3.809 & 4.83 & 0.50 & 10.625\end{array}$


TABLE II (Continued)

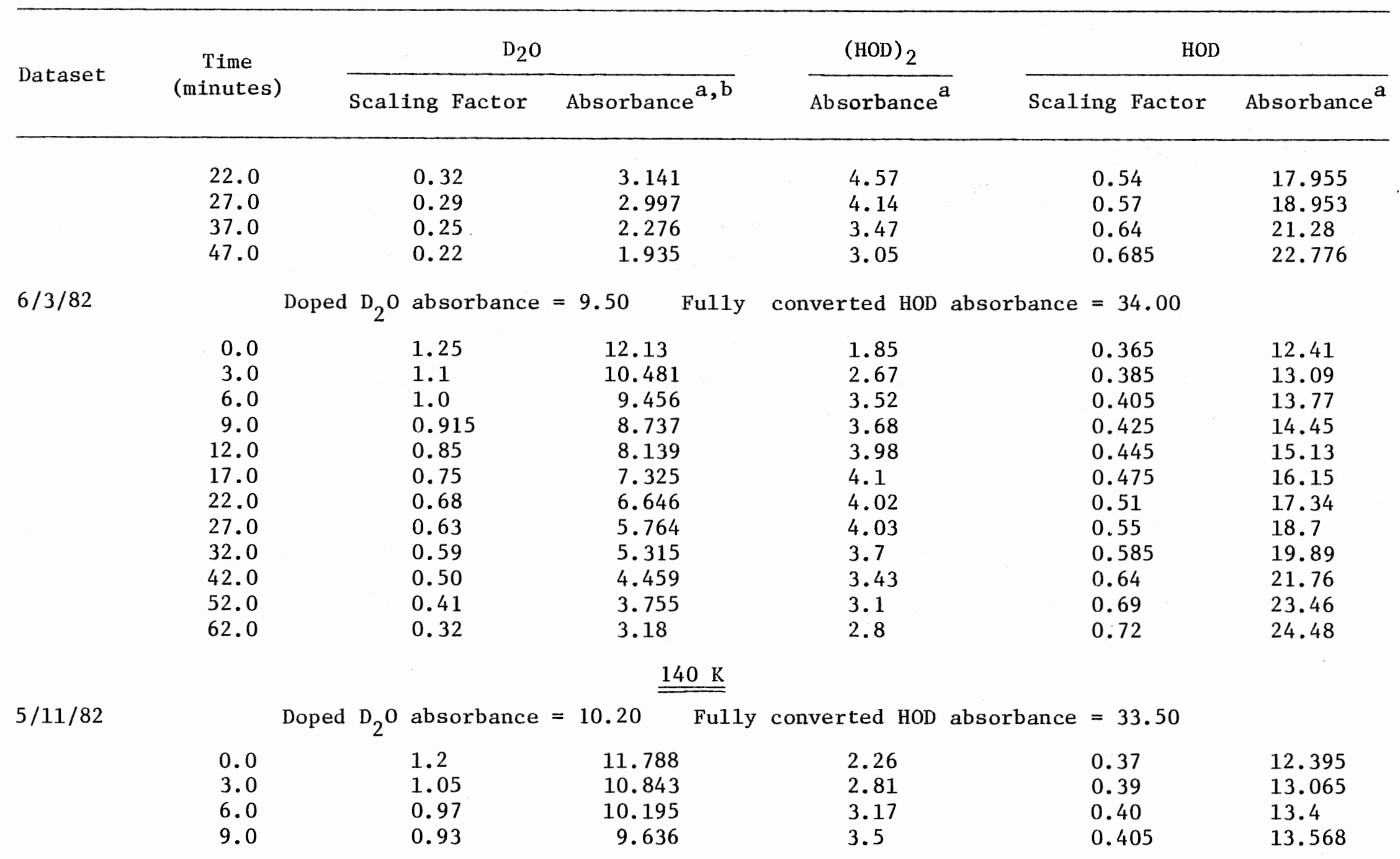


TABLE II (Continued)

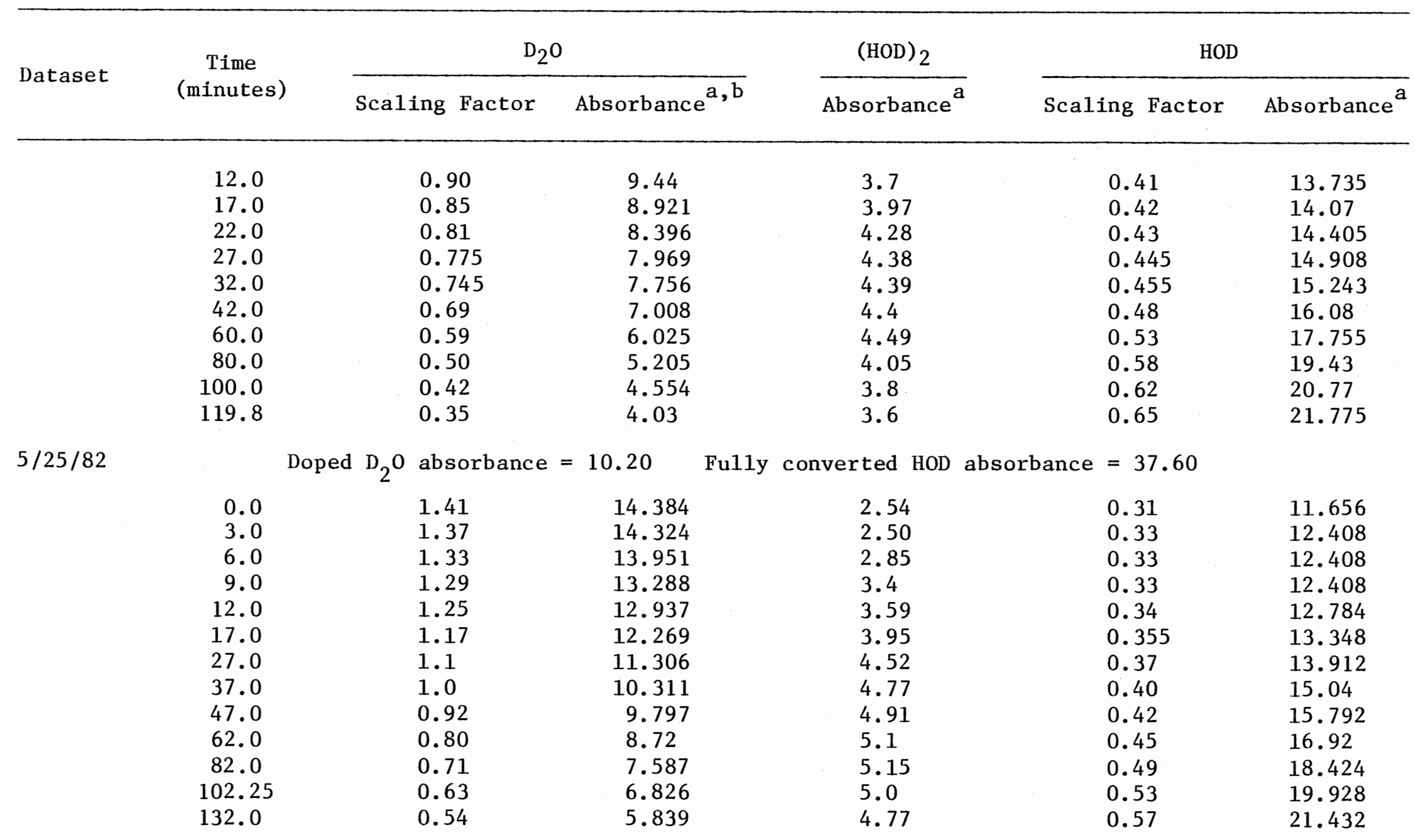


TABLE II (Continued)

\begin{tabular}{|c|c|c|c|c|c|c|c|}
\hline \multirow{2}{*}{ Dataset } & \multirow{2}{*}{$\begin{array}{c}\text { Time } \\
\text { (minutes) }\end{array}$} & \multicolumn{2}{|c|}{$\mathrm{D}_{2} \mathrm{O}$} & $(\mathrm{HOD})_{2}$ & \multicolumn{3}{|c|}{ HOD } \\
\hline & & Scaling Factor & Absorbance $e^{a, b}$ & Absorbance ${ }^{a}$ & Scaling & Factor & Absorbance ${ }^{a}$ \\
\hline
\end{tabular}

$5 / 15 / 82$

\section{$\underline{\underline{135 \mathrm{~K}}}$}

Doped $\mathrm{D}_{2} \mathrm{O}$ absorbance $=10.70 \quad$ Fully converted HOD absorbance $=38.00$

\begin{tabular}{|c|c|c|c|c|c|}
\hline 0.1 & 1.29 & 14.148 & 2.65 & 0.327 & 12.426 \\
\hline 3.0 & 1.27 & 13.806 & 2.79 & 0.329 & 12.502 \\
\hline 6.0 & 1.25 & 13.681 & 2.92 & 0.331 & 12.578 \\
\hline 9.0 & 1.23 & 13.356 & 3.15 & 0.733 & 12.654 \\
\hline 24.0 & 1.15 & 12.635 & 3.7 & 0.34 & 12.92 \\
\hline 34.0 & 1.09 & 12.093 & 4.1 & 0.345 & 13.11 \\
\hline 84.0 & 0.91 & 10.397 & 5.1 & 0.37 & 14.06 \\
\hline 104.0 & 0.88 & 9.906 & 5.3 & 0.38 & 14.44 \\
\hline 124.0 & 0.85 & 9.573 & 5.46 & 0.39 & 14.82 \\
\hline 144.0 & 0.82 & 9.134 & 5.7 & 0.40 & 15.2 \\
\hline 174.0 & 0.78 & 8.721 & 5.65 & 0.42 & 15.96 \\
\hline
\end{tabular}

$5 / 26 / 82$

Doped $\mathrm{D}_{2} \mathrm{O}$ absorbance $=10.70$

Ful1y converted HOD absorbance $=23.65$

\begin{tabular}{|c|c|c|c|c|c|}
\hline $\begin{array}{l}0.0 \\
6.0\end{array}$ & $\begin{array}{l}0.74 \\
0.725\end{array}$ & $\begin{array}{l}8.155 \\
7.918\end{array}$ & $\begin{array}{l}1.49 \\
1.6\end{array}$ & $\begin{array}{l}0.356 \\
0.359\end{array}$ & $\begin{array}{l}8.419 \\
8.490\end{array}$ \\
\hline 16.0 & 0.695 & 7.471 & 1.88 & 0.365 & 8.632 \\
\hline 35.0 & 0.65 & 7.049 & 2.18 & 0.375 & 8.869 \\
\hline 55.0 & 0.60 & 6.536 & 2.42 & 0.39 & 9.224 \\
\hline
\end{tabular}


TABLE II (Continued)

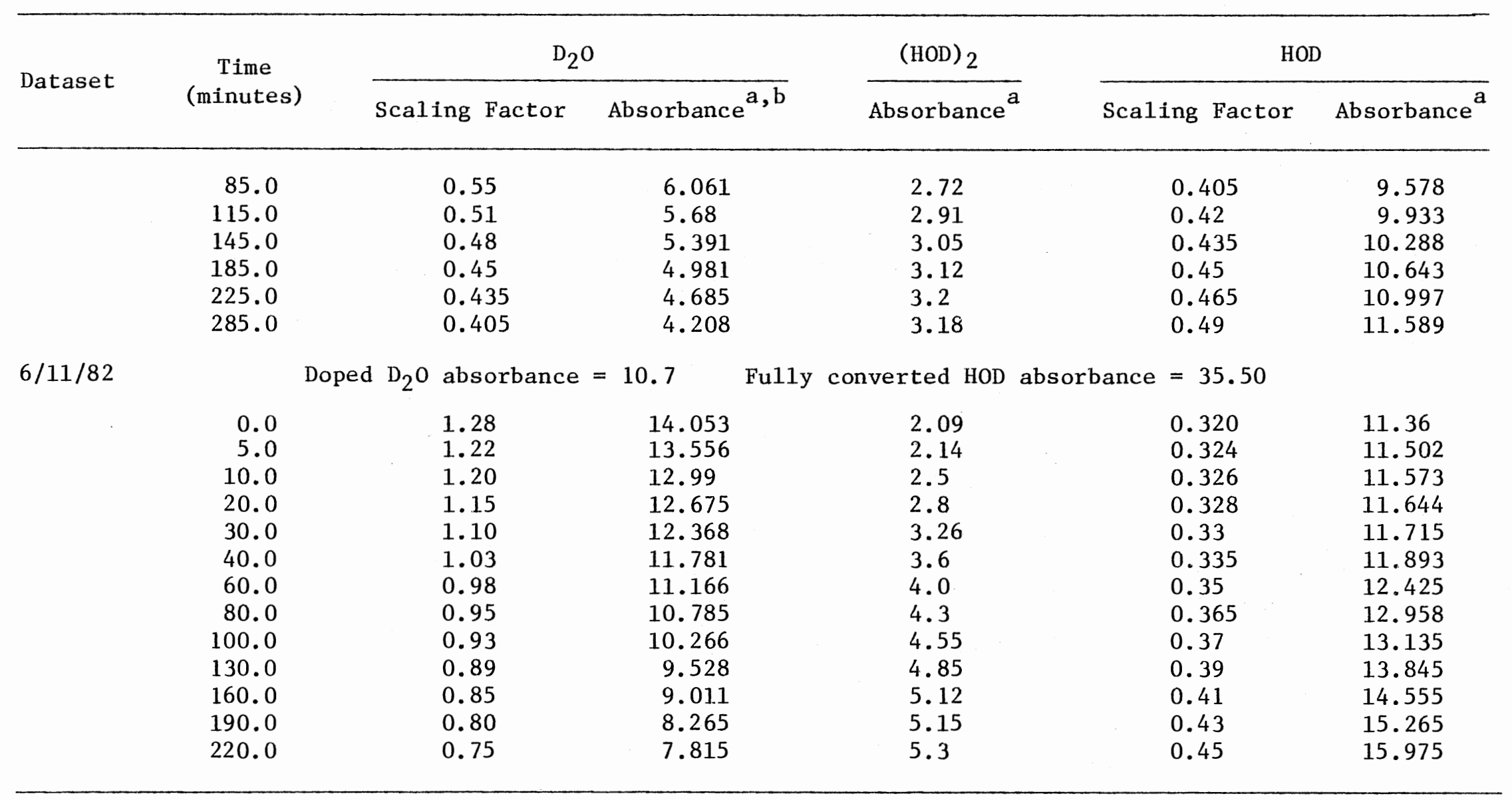

Digilab arbitrary absorbance units.

${ }^{\mathrm{b}}$ Corrected $\mathrm{D}_{2} \mathrm{O}$ concentrations as described in text.

${ }_{\mathrm{d}} \mathrm{D}_{2} \mathrm{O}$ spectra obtained from glass cell ice deposits.

Final converted HOD spectrum obtained at the end of each kinetic run.

Data is accurate to 2 to 3 significant figures. 
of the time interval was spent collecting data during which the $\mathrm{D}_{2} \mathrm{O}$ absorbance was decreasing slightly. Since the ten scans are averaged, the interferometer would obtain a measured absorbance slightly lower for the 2 minute mark where the data collection began, than the true absorbance one would obtain for an instantaneous measurement at the 2 minute mark. If a linear decrease for the absorbance is assumed over the 25 second time interval, then an approximate average inteferometer measured absorbance would be measured at about 13 seconds into the time interval, or at 2.23 minutes instead of 2 minutes. Since the absorbance changes by 2.484 (Digilab arbitrary absorbance units) over the 2 minute interval, then over 13 seconds the absorbance should change by approximately 0.31 absorbance units. This gives rise to approximately a $2.5 \%$ relative error in the two minute absorbance measurement of 12.639. In view of this small error, that decreases dramatically as the time intervals increase and rate of absorbance change decreases, the sampling error was ignored.

\section{Determination of Relative Molar \\ Absorptivities}

Kinetic analysis is based on concentrations changes of chemical species. Therefore some method must be found for converting the absorbance measurements into concentration units before a kinetic mechanism may be proposed for isotopic exchange in cubic ice. To accomplish this, Beer's law is assumed to hold over the dynamic range of all kinetic absorbance measurements. All absorbance measurements, though recorded in arbitrary absorbance units, fell between 0.10 and 0.5 absorbance on a true absorbance scale; a range where Beer's law deviations are not 
severe.

Due to the thin layer nature of the ice deposits and the method used in their preparation it is very difficult if not impossible to determine thickness, thickness uniformity, and absolute concentrations of the various isotopic species. Thus there was no means available for preparing standard Beer's law plots of each isotopic specie isolated in $\mathrm{H}_{2} \mathrm{O}$ cubic ice. Neither does the chemical literature contain reports of absorptivities of $\mathrm{D}_{2} \mathrm{O}$, $\mathrm{HOD}$, or (HOD) 2 isolated in a cubic ice lattice at the necessary frequencies. But fortunately since first order rate constants are dependent on the change in concentrations rather than absolute concentrations, relative concentrations and hence relative molar absorptivities are sufficient. If the relative magnitudes of the absorptivities are found, then the relative concentrations can be found from the absorbance data.

The kinetic expression of the isotopic exchange is

$$
\left[\mathrm{D}_{2} \mathrm{O}\right] \underset{\mathrm{k}-1}{\stackrel{\mathrm{k}_{1}}{\rightleftharpoons}}\left[(\mathrm{HOD})_{2}\right] \underset{\mathrm{k}-2}{\stackrel{\mathrm{k}_{2}}{\rightleftharpoons}} 2[\mathrm{HOD}]
$$

where $\left[\mathrm{D}_{2} \mathrm{O}\right]$ is the $\mathrm{D}_{2} \mathrm{O}$ concentration in moles/liter of the ice deposit, [(HOD) ${ }_{2}$ ] the coupled HOD dimer concentration, and [HOD] the uncoupled HOD concentration. From experimental data, $(46,47)$ it is known that the uncoupled HOD units in the cubic ice lattice eventually migrate apart. Therefore the equilibrium situation proposed in equation (3.1) is constantly perturbed until after an infinite period of time, essentially all the $\mathrm{D}_{2} \mathrm{O}$ and (HOD) 2 have converted to HOD. Thus at any time a material balance yields

$$
\left[\mathrm{D}_{2} \mathrm{O}\right]+\left[(\mathrm{HOD})_{2}\right]=\frac{1}{2}\left[\mathrm{HOD}_{\infty}\right]-\frac{1}{2}[\mathrm{HOD}]
$$


where [HODळ] is the uncoupled HOD concentration after an infinite amount of time and the other concentrations at some lesser time. Rearranging equation (3.2) gives

$$
2\left[\mathrm{D}_{2} \mathrm{O}\right]+2\left[(\mathrm{HOD})_{2}\right]+[\mathrm{HOD}]-\left[\mathrm{HOD}_{\infty}\right]=0
$$

assuming Beer's law holds where $[\mathrm{X}]=$ peak absorbance of $\mathrm{X} / \varepsilon_{\mathrm{x}} \mathrm{b}, \varepsilon_{\mathrm{X}}$ is the molar absorptivity of component $X$ and $b$ the pathlength traversed in penetrating the sample medium then

$$
\begin{aligned}
& \frac{2 \mathrm{D}_{2} \mathrm{O}}{\varepsilon_{\mathrm{D}_{2} \mathrm{O}^{\mathrm{b}}}}+\frac{2 \mathrm{~A}(\mathrm{HOD})_{2}}{\varepsilon_{(\mathrm{HOD})_{2}{ }^{\mathrm{b}}}}+\frac{\mathrm{A}_{\mathrm{HOD}}}{\varepsilon_{\mathrm{HOD}}{ }^{\mathrm{b}}}-\frac{\mathrm{A}_{\mathrm{HOD}_{\infty}}}{\varepsilon_{\text {HOD }}^{\mathrm{b}}}=0 \\
& \frac{2 \mathrm{D}_{2} \mathrm{O}}{\varepsilon_{\mathrm{D}_{2} \mathrm{O}}}+\frac{2 \mathrm{~A}(\mathrm{HOD})_{2}}{\varepsilon_{(\mathrm{HOD})_{2}}}+\frac{\mathrm{A}_{\mathrm{HOD}}-\mathrm{A}_{\mathrm{HOD}_{\infty}}}{\varepsilon_{\mathrm{HOD}}}=0
\end{aligned}
$$

By inserting absorbance data from three different time intervals three different equations may be constructed to solve for the three molar absorptivities. However these equations would form a homogeneous set of equations for which no unique solution exists; only a relational one. Thus to find the relational solution it is assumed that $\varepsilon_{\mathrm{HOD}}=$ 1.0 , and $a=\frac{2}{\varepsilon_{\mathrm{D}_{2} \mathrm{O}}}$, and $\mathrm{b}=\frac{2}{\varepsilon_{(\mathrm{HOD})_{2}}}$. Rewriting, we obtain

$$
\mathrm{aA}_{2} \mathrm{O}+\mathrm{bA}_{(\mathrm{HOD})_{2}}=\mathrm{A}_{\mathrm{HOD}_{\infty}}-\mathrm{A}_{\mathrm{HOD}}
$$

Then with absorbance data from two different time intervals of a particular kinetic run the relative molar absorptivities of $D_{2} 0$, (HOD) $_{2}$, and HOD may be found. Alternatively $\varepsilon_{(\mathrm{HOD})_{2}}$ or $\varepsilon_{\mathrm{D}_{2} \mathrm{O}}$ could be set equal to some constant and the relational solution then found.

REMOLE is a fortran program written to ascertain the relative molar absorptivities of cubic ice-isolated $\mathrm{D}_{2} \mathrm{O},(\mathrm{HOD})_{2}$, and HOD. The program uses equation 3.6 and the equivalent equation found by setting $\varepsilon_{\text {HOD }}=$ 
1.0 plus inputted absorbance data for $\mathrm{D}_{2} \mathrm{O},(\mathrm{HOD})_{2}$, and HOD to determine the best average relative molar absorptivities for each. A program listing with sample data and output is included in Appendix A.

Figure 24 shows a $150 \mathrm{~K}$ set of kinetic observations. REMOLE required that the observations of a dataset be numbered consecutively with integers starting from one. For example, observation 1 would contain the absorbances (Digilab arbitrary absorbance units) of $\mathrm{D}_{2} \mathrm{O}$, (HOD) 2 , and HOD at time $=0$ and observation 2 the absorbances at time $=2$ minutes. Then by inputting the starting and ending observation numbers REMOLE would calculate the average relative molar absorptivities for all unique binary combinations of observations between and including the starting and ending observations using simultaneous equations from equation (3.6). As a check, equation (3.6) was solved with both $\varepsilon_{H O D}=$ 1.0 ; and its appropriate variant equation where $\varepsilon_{(\mathrm{HOD})_{2}}=1.0$. The relative molar absorptivities obtained from setting $\varepsilon_{(\mathrm{HOD})_{2}}=1.0$ could be multiplied by a scaling factor for direct comparison with the molar absorptivities obtained from equation (3.6) with $\varepsilon_{\text {HOD }}=1.0$. As illustrated in Figure 24 observation 10 is at the end of the dataset where the arbitrary absorbance values of HOD are high and the values of $\mathrm{D}_{2} \mathrm{O}$ and (HOD) $)_{2}$ quite low. Thus a 0.5 arbitrary absorbance error would be about a 15-20\% error at observation 10 for $\mathrm{D}_{2} \mathrm{O}$ and (HOD) 2 but only about a $5 \%$ error for $\mathrm{D}_{2} \mathrm{O}$ at lower observations. Therefore it is expected that binary combinations of lower numbered observations should give more reliable consistent absorptivities. REMOLE prints out the relative absorptivities for each binary combination of absorbances used in the simultaneous equation solution so that visual 


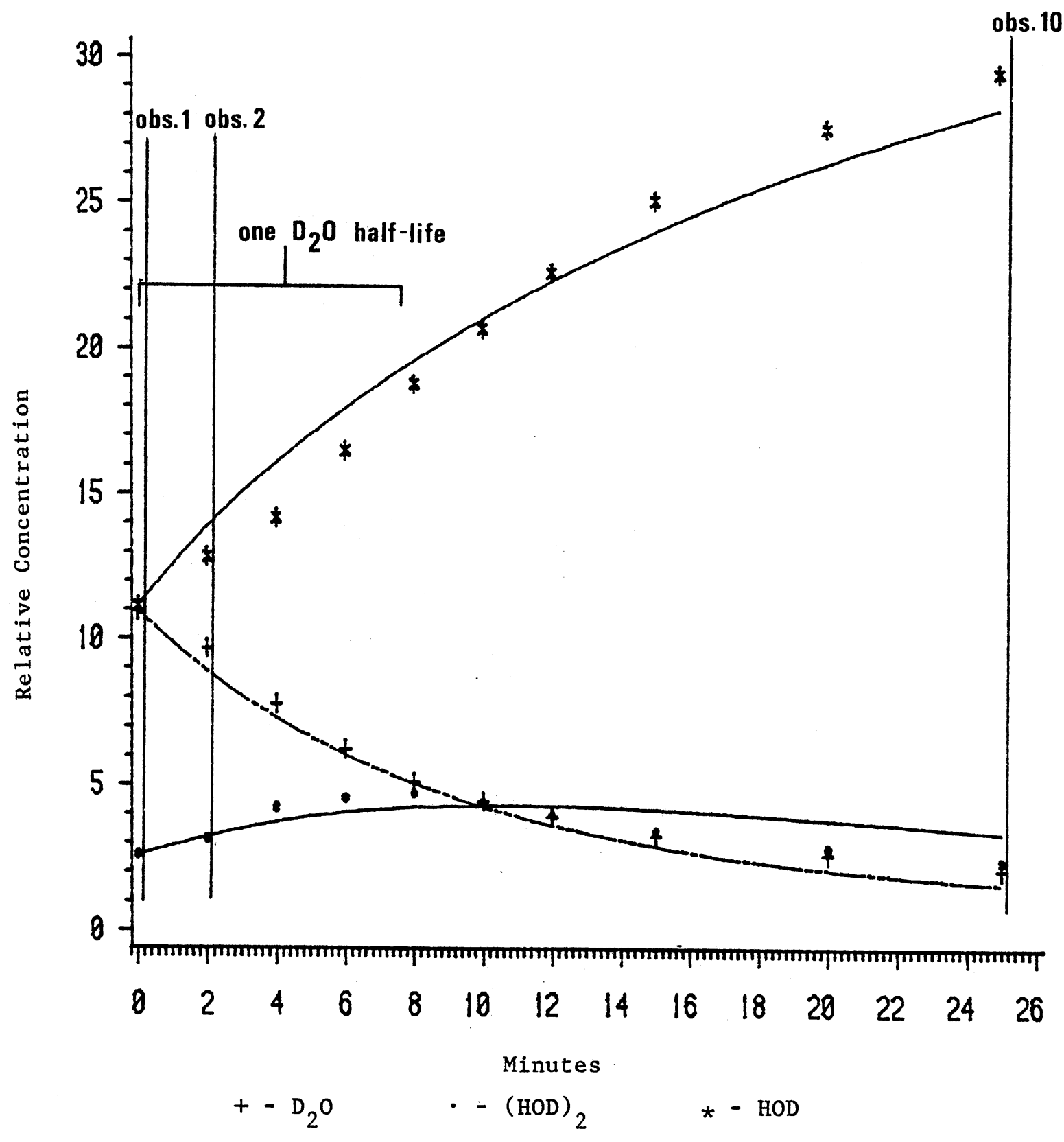

Figure 24. REMOLE Dataset Coverage and Analysis 
inspection of the individual computed absorptivities was possible. An additional feature of REMOLE was to decrement the stopping observation by one and then recompute the average relative molar absorptivities. This process was repeated until only the starting and starting plus one observation absorbances were left for finding the relative molar absorptivities. By appropriate selection of starting and stopping observation numbers it is possible to confine the calculation to the most reliable part of the dataset. From calculations using REMOLE the best absorbances to use for relative-molarabsorptivity calculations were those within the first 1.5 half-lives of the $\mathrm{D}_{2} \mathrm{O}$ absorbance.

Table III shows the results of these calculations for each dataset at each temperature. Included are the relative molar absorptivities for each dataset for calculations with $\varepsilon_{\text {HOD }}$ set equal to 1.0 and also for $\varepsilon^{\prime}$ (HOD) 2 set equal to 1.0 . Unless the $\varepsilon^{\prime}$ values are multiplied by a $\varepsilon_{H O D}$ scaling factor, the two calculations cannot be directly compared. The average relative molar absorptivities for datasets and temperatures with their associated sigmas is shown at the bottom of Table III. The primed average absorptivities have been scaled by $\varepsilon_{(H O D)_{2}}=1.222$ so that the different calculations may be compared for the extent of data induced error. No noticeable temperature dependent trend is observed in the relative molar absorptivities. This should be no problem since the calculated first order rate constants are not dependent on the magnitude of the concentrations just their rate of change. Table IV lists the relative concentration values calculated for each temperature and run-time using Beer's law and the final calculated average relative molar absorptivities of Table III. 
TABLE III

RELATIVE MOLAR ABSORPTIVITIES

\begin{tabular}{|c|c|c|c|c|c|c|}
\hline \multirow[t]{2}{*}{ Dataset } & \multicolumn{3}{|c|}{$\begin{array}{l}\text { Relative Absorptivities } \\
\qquad \varepsilon_{\text {HOD }}=1.0\end{array}$} & \multicolumn{3}{|c|}{$\begin{array}{l}\text { Relative Absorptivities } \\
\qquad \varepsilon_{(\mathrm{HOD})_{2}}=1.0\end{array}$} \\
\hline & $\varepsilon_{D_{2}} 0$ & ${ }^{\varepsilon}(\mathrm{HOD}) 2$ & $\varepsilon_{\text {HOD }}$ & $\varepsilon^{\prime} \mathrm{D}_{2} \mathrm{O}$ & $\varepsilon^{\prime}(\mathrm{HOD})_{2}$ & $\varepsilon_{\text {HOD }}^{\prime}$ \\
\hline \multicolumn{7}{|l|}{$150 \mathrm{~K}$} \\
\hline $\begin{array}{l}2 / 2 / 82 \\
6 / 7 / 82 \\
6 / 9 / 82\end{array}$ & $\begin{array}{l}1.292 \\
1.289 \\
1.422\end{array}$ & $\begin{array}{l}1.113 \\
1.247 \\
1.338\end{array}$ & $\begin{array}{l}1.0 \\
1.0 \\
1.0\end{array}$ & $\begin{array}{l}1.172 \\
1.042 \\
1.148\end{array}$ & $\begin{array}{l}1.0 \\
1.0 \\
1.0\end{array}$ & $\begin{array}{l}0.9027 \\
0.8063 \\
0.7942\end{array}$ \\
\hline \multicolumn{7}{|l|}{$145 \mathrm{~K}$} \\
\hline $\begin{array}{l}1 / 29 / 82 \\
5 / 10 / 82 \\
5 / 24 / 82 \\
6 / 3 / 82\end{array}$ & $\begin{array}{l}1.327 \\
1.214 \\
1.277 \\
1.277\end{array}$ & $\begin{array}{l}1.171 \\
1.141 \\
0.9053 \\
1.295\end{array}$ & $\begin{array}{l}1.0 \\
1.0 \\
1.0 \\
1.0\end{array}$ & $\begin{array}{l}1.152 \\
.9669 \\
1.434 \\
1.003\end{array}$ & $\begin{array}{l}1.0 \\
1.0 \\
1.0 \\
1.0\end{array}$ & $\begin{array}{l}0.8603 \\
1.101 \\
1.111 \\
0.7817\end{array}$ \\
\hline \multicolumn{7}{|l|}{$140 \mathrm{~K}$} \\
\hline $\begin{array}{l}5 / 11 / 82 \\
5 / 25 / 82\end{array}$ & $\begin{array}{l}1.377 \\
-----o n\end{array}$ & $\begin{array}{l}1.303 \\
\text { itted due }\end{array}$ & $\begin{array}{l}1.0 \\
\text { inco }\end{array}$ & $\begin{array}{l}1.097 \\
\text { istent fir }\end{array}$ & $\begin{array}{l}1.0 \\
\text { data po }\end{array}$ & $\begin{array}{r}0.7803 \\
\text { ats- }\end{array}$ \\
\hline \multicolumn{7}{|l|}{$135 \mathrm{~K}$} \\
\hline $\begin{array}{l}5 / 15 / 82 \\
5 / 26 / 82 \\
6 / 11 / 82\end{array}$ & $\begin{array}{l}1.307 \\
1.284 \\
1.311\end{array}$ & $\begin{array}{l}1.285 \\
1.202 \\
1.441\end{array}$ & $\begin{array}{l}1.0 \\
1.0 \\
1.0\end{array}$ & $\begin{array}{l}1.032 \\
1.099 \\
1.021\end{array}$ & $\begin{array}{l}1.0 \\
1.0 \\
1.0\end{array}$ & $\begin{array}{l}0.7863 \\
0.8481 \\
0.7469\end{array}$ \\
\hline $\begin{array}{l}\text { Average } \\
\text { Value }\end{array}$ & 1.307 & 1.222 & 1.0 & 1.106 & 1.0 & 0.8653 \\
\hline$\sigma$ & 0.05228 & 0.1347 & 0.0 & 0.1216 & 0.0 & 0.1209 \\
\hline $\begin{array}{l}90 \% \text { Confidence } \\
\text { Interval }\end{array}$ & \pm 0.026 & \pm 0.067 & - & \pm 0.060 & - & \pm 0.060 \\
\hline$\varepsilon^{\prime}$ & $\begin{array}{l}\varepsilon^{\prime} \mathrm{D}_{2} \mathrm{O}^{\cdot \varepsilon} \\
(\mathrm{HOD})_{2} \cdot \varepsilon \\
\varepsilon_{\mathrm{HOD}}^{\prime} \cdot \varepsilon\end{array}$ & $\begin{array}{l}(\mathrm{HOD})_{2}= \\
(\mathrm{HOD})_{2}= \\
(\mathrm{HOD})_{2}=\end{array}$ & $\begin{array}{l}352 \\
222\end{array}$ & $\begin{aligned} \varepsilon_{\mathrm{D}_{2} \mathrm{O}} & = \\
\varepsilon_{(\mathrm{HOD})_{2}} & = \\
\varepsilon_{\mathrm{HOD}} & =\end{aligned}$ & $\begin{array}{r}.307 \\
.222 \\
.000\end{array}$ & \\
\hline
\end{tabular}


TABLE IV

RELATIVE CONCENTRATIONS DETERMINED FROM ABSORBANCE DATA

\begin{tabular}{|c|c|c|c|c|}
\hline Dataset & Time (minutes) & {$\left[D_{2} \mathrm{O}\right]$} & {$\left[(\mathrm{HOD})_{2}\right]$} & {$[2 \mathrm{HOD}]^{a}$} \\
\hline \multicolumn{5}{|l|}{$150 \mathrm{~K}$} \\
\hline $2 / 2 / 82$ & $\begin{array}{r}0.0 \\
2.0 \\
4.0 \\
6.0 \\
9.5 \\
12.5 \\
15.5 \\
20.5\end{array}$ & $\begin{array}{l}9.08 \\
7.10 \\
5.54 \\
4.33 \\
2.97 \\
2.33 \\
1.82 \\
1.43\end{array}$ & $\begin{array}{l}2.82 \\
4.13 \\
4.58 \\
4.46 \\
3.81 \\
3.15 \\
2.58 \\
1.84\end{array}$ & $\begin{array}{r}5.67 \\
6.41 \\
7.69 \\
8.97 \\
10.98 \\
12.26 \\
13.36 \\
14.46\end{array}$ \\
\hline $6 / 7 / 82$ & $\begin{array}{r}0.0 \\
2.0 \\
4.0 \\
6.0 \\
8.0 \\
10.0 \\
12.0 \\
15.0 \\
20.0 \\
25.0\end{array}$ & $\begin{array}{r}10.94 \\
9.67 \\
7.77 \\
6.22 \\
5.09 \\
4.45 \\
3.92 \\
3.25 \\
2.61 \\
2.08\end{array}$ & $\begin{array}{l}2.58 \\
3.13 \\
4.21 \\
4.54 \\
4.70 \\
4.38 \\
3.95 \\
3.40 \\
2.82 \\
2.37\end{array}$ & $\begin{array}{r}5.55 \\
6.42 \\
7.09 \\
8.24 \\
9.38 \\
10.34 \\
11.30 \\
12.54 \\
13.79 \\
14.75\end{array}$ \\
\hline $6 / 9 / 82$ & $\begin{array}{r}0.0 \\
1.0 \\
2.0 \\
3.0 \\
4.0 \\
5.0 \\
6.0 \\
8.0 \\
10.0 \\
12.0 \\
15.0 \\
20.0\end{array}$ & $\begin{array}{r}10.47 \\
9.82 \\
9.49 \\
9.02 \\
8.47 \\
7.71 \\
7.18 \\
6.57 \\
5.91 \\
5.23 \\
4.53 \\
3.61\end{array}$ & $\begin{array}{l}1.72 \\
1.80 \\
2.13 \\
2.29 \\
2.62 \\
2.99 \\
3.36 \\
3.36 \\
3.27 \\
3.27 \\
2.78 \\
2.41\end{array}$ & $\begin{array}{r}6.03 \\
6.42 \\
6.51 \\
6.70 \\
6.89 \\
7.47 \\
7.85 \\
8.62 \\
9.38 \\
10.15 \\
11.59 \\
12.93\end{array}$ \\
\hline \multicolumn{5}{|l|}{$145 \mathrm{~K}$} \\
\hline $1 / 29 / 82$ & $\begin{array}{r}0.0 \\
3.0 \\
6.0 \\
9.0 \\
12.0 \\
17.0 \\
21.7 \\
27.0 \\
32.0\end{array}$ & $\begin{array}{r}10.50 \\
8.84 \\
7.29 \\
6.44 \\
5.67 \\
4.71 \\
3.95 \\
3.35 \\
2.92\end{array}$ & $\begin{array}{l}2.54 \\
3.68 \\
4.42 \\
4.87 \\
5.03 \\
4.82 \\
4.54 \\
4.21 \\
3.85\end{array}$ & $\begin{array}{r}5.70 \\
6.27 \\
7.03 \\
7.60 \\
8.17 \\
9.12 \\
10.26 \\
11.21 \\
11.97\end{array}$ \\
\hline
\end{tabular}


TABLE IV (Continued)

\begin{tabular}{|c|c|c|c|c|}
\hline Dataset & Time (minutes) & {$\left[D_{2} 0\right]$} & {$\left[(\mathrm{HOD})_{2}\right]$} & {$[2 \mathrm{HOD}]^{\mathrm{a}}$} \\
\hline & $\begin{array}{l}42.0 \\
52.0 \\
62.0 \\
72.0\end{array}$ & $\begin{array}{l}2.35 \\
1.98 \\
1.71 \\
1.63\end{array}$ & $\begin{array}{l}3.19 \\
2.78 \\
2.29 \\
2.09\end{array}$ & $\begin{array}{l}13.11 \\
13.87 \\
14.63 \\
15.01\end{array}$ \\
\hline $5 / 10 / 82$ & $\begin{array}{r}0.0 \\
3.0 \\
6.0 \\
9.0 \\
12.0 \\
17.0 \\
22.0 \\
27.0 \\
32.0 \\
47.0 \\
62.0 \\
77.0\end{array}$ & $\begin{array}{l}7.93 \\
7.30 \\
6.74 \\
6.08 \\
5.87 \\
5.05 \\
4.55 \\
4.16 \\
3.69 \\
2.73 \\
2.22 \\
1.72\end{array}$ & $\begin{array}{l}3.02 \\
3.35 \\
3.60 \\
3.81 \\
3.68 \\
3.79 \\
3.71 \\
3.48 \\
3.33 \\
2.72 \\
2.29 \\
1.92\end{array}$ & $\begin{array}{r}6.44 \\
6.80 \\
7.16 \\
7.70 \\
7.97 \\
8.68 \\
9.31 \\
9.93 \\
10.56 \\
11.99 \\
12.89 \\
13.78\end{array}$ \\
\hline $5 / 24 / 82$ & $\begin{array}{r}0.0 \\
3.0 \\
6.0 \\
9.0 \\
12.0 \\
17.0 \\
22.0 \\
27.0 \\
37.0 \\
47.0\end{array}$ & $\begin{array}{l}7.08 \\
6.21 \\
5.18 \\
4.53 \\
3.86 \\
2.91 \\
2.40 \\
2.29 \\
1.74 \\
1.48\end{array}$ & $\begin{array}{l}2.86 \\
3.18 \\
3.74 \\
3.81 \\
3.94 \\
3.95 \\
3.74 \\
3.39 \\
2.84 \\
2.50\end{array}$ & $\begin{array}{r}5.32 \\
5.65 \\
6.15 \\
6.65 \\
7.32 \\
8.31 \\
8.98 \\
9.48 \\
10.64 \\
11.39\end{array}$ \\
\hline $6 / 3 / 82$ & $\begin{array}{c}0.0 \\
3.0 \\
6.0 \\
9.0 \\
12.0 \\
17.0 \\
22.0 \\
27.0 \\
32.0 \\
37.0 \\
47.0 \\
62.0 \\
82.0 \\
102.25 \\
132.0\end{array}$ & $\begin{array}{l}9.28 \\
8.02 \\
7.24 \\
6.69 \\
6.23 \\
5.60 \\
5.09 \\
4.41 \\
4.07 \\
7.93 \\
7.50 \\
6.67 \\
5.81 \\
5.22 \\
4.47\end{array}$ & $\begin{array}{l}1.51 \\
2.19 \\
2.88 \\
3.01 \\
3.26 \\
3.36 \\
3.29 \\
3.30 \\
3.93 \\
3.90 \\
4.02 \\
4.17 \\
4.21 \\
4.09 \\
3.90\end{array}$ & $\begin{array}{r}6.21 \\
6.55 \\
6.89 \\
7.23 \\
7.57 \\
8.08 \\
8.67 \\
9.35 \\
9.95 \\
7.52 \\
7.90 \\
8.46 \\
9.21 \\
9.96 \\
10.72\end{array}$ \\
\hline \multicolumn{5}{|l|}{$135 \mathrm{~K}$} \\
\hline $5 / 15 / 82$ & $\begin{array}{l}0.1 \\
3.0\end{array}$ & $\begin{array}{l}10.82 \\
10.56\end{array}$ & $\begin{array}{l}2.17 \\
2.28\end{array}$ & $\begin{array}{l}6.21 \\
6.25\end{array}$ \\
\hline
\end{tabular}


TABLE IV (Continued)

\begin{tabular}{|c|c|c|c|c|}
\hline Dataset & Time (minutes) & {$\left[\mathrm{D}_{2} \mathrm{O}\right]$} & {$\left[(\mathrm{HOD})_{2}\right]$} & {$[2 \mathrm{HOD}]^{\mathrm{a}}$} \\
\hline & $\begin{array}{r}6.0 \\
9.0 \\
14.0 \\
24.0 \\
34.0 \\
49.1 \\
64.0 \\
84.0 \\
104.0 \\
124.0 \\
144.0 \\
174.0\end{array}$ & $\begin{array}{r}10.47 \\
10.22 \\
10.06 \\
9.67 \\
9.25 \\
8.55 \\
8.33 \\
7.96 \\
7.58 \\
7.32 \\
6.99 \\
6.67\end{array}$ & $\begin{array}{l}2.39 \\
2.58 \\
2.73 \\
3.03 \\
3.36 \\
3.69 \\
3.93 \\
4.17 \\
4.34 \\
4.47 \\
4.66 \\
4.62\end{array}$ & $\begin{array}{l}6.29 \\
6.33 \\
6.37 \\
6.46 \\
6.56 \\
6.65 \\
6.84 \\
7.03 \\
7.22 \\
7.41 \\
7.60 \\
7.98\end{array}$ \\
\hline $5 / 26 / 82$ & $\begin{array}{r}0.0 \\
6.0 \\
11.0 \\
16.0 \\
25.0 \\
35.0 \\
55.0 \\
85.0 \\
115.0 \\
145.0 \\
185.0 \\
225.0 \\
285.0\end{array}$ & $\begin{array}{l}6.24 \\
6.06 \\
5.90 \\
5.72 \\
5.56 \\
5.39 \\
5.00 \\
4.64 \\
4.35 \\
4.13 \\
3.81 \\
3.59 \\
3.22\end{array}$ & $\begin{array}{l}1.22 \\
1.31 \\
1.38 \\
1.54 \\
1.74 \\
1.78 \\
1.98 \\
2.23 \\
2.38 \\
2.50 \\
2.55 \\
2.62 \\
2.60\end{array}$ & $\begin{array}{l}4.21 \\
4.25 \\
4.28 \\
4.32 \\
4.35 \\
4.43 \\
4.61 \\
4.79 \\
4.97 \\
5.14 \\
5.32 \\
5.50 \\
5.79\end{array}$ \\
\hline $6 / 11 / 82$ & $\begin{array}{r}0.0 \\
5.0 \\
10.0 \\
20.0 \\
30.0 \\
40.0 \\
60.0 \\
80.0 \\
100.0 \\
130.0 \\
160.0 \\
190.0 \\
220.0\end{array}$ & $\begin{array}{r}10.75 \\
10.37 \\
9.94 \\
9.70 \\
9.46 \\
9.01 \\
8.54 \\
8.25 \\
7.86 \\
7.29 \\
6.89 \\
6.32 \\
5.98\end{array}$ & $\begin{array}{l}1.71 \\
1.75 \\
2.05 \\
2.29 \\
2.67 \\
2.95 \\
3.27 \\
3.52 \\
3.72 \\
3.97 \\
4.19 \\
4.21 \\
4.34\end{array}$ & $\begin{array}{l}5.68 \\
5.75 \\
5.79 \\
5.82 \\
5.86 \\
5.95 \\
6.21 \\
6.48 \\
6.57 \\
6.92 \\
7.28 \\
7.63 \\
7.99\end{array}$ \\
\hline
\end{tabular}

${ }^{a}$ Concentration of two HOD units, thus $[2 \mathrm{HOD}]=\frac{1}{2} \cdot[\mathrm{HOD}]$. 
Mode1 Development

One goal of this study was to find the proton transfer and rotational rates and their respective activation energies. To accomplish this goal a model must be developed that relates $k_{t}$, the rate constant for transfer of protons via an ionic defect migration, and $k_{r}$, the rate constant for migration via a $D$ or $L$ Bjerrum defect migration, to the kinetics spectroscopically observed.

Since all the oxygens in a cubic ice lattice are tetrahedrally linked one to another then any migration path of deuterons along these linkages can be represented as a chain of $\mathrm{OH}$ groups as shown in Figure 25a.

If the deuterons are examined in Figure $25 \mathrm{a}$ it can be seen that with proton transfer alone, only 3 unique positions of the deuterons in the $\mathrm{OH}$ chain are possible as shown and labeled in Figure 25b. If a Bjerrum $D$ or $L$ defect migrates through or along the chain then a proton or deuterium rotation may follow that leaves the two deuterons separated by two oxygen atoms instead of one. However, this separation of the deuterons will affect the positions of the deuterons relative to each other only if they are in positions 2 or 3 (i.e. after a transfer), and the defect approaches in such a manner that both defects are not rotated together thus preserving their orientation and translating that particular deuteron configuration through the crystal lattice. So if the number of oxygens between the two deuterons are counted and their position index as defined in Figure $25 \mathrm{~b}$ noted, any particular configuration of deuterons with respect to successive rotations and transfers can be represented by using two subscripts 


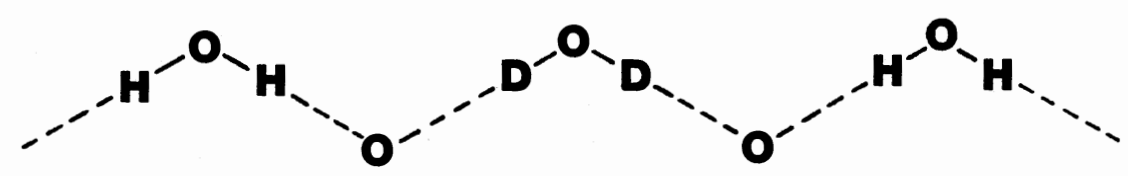

Figure 25a. Hydrogen Bonded Chain in Cubic Ice

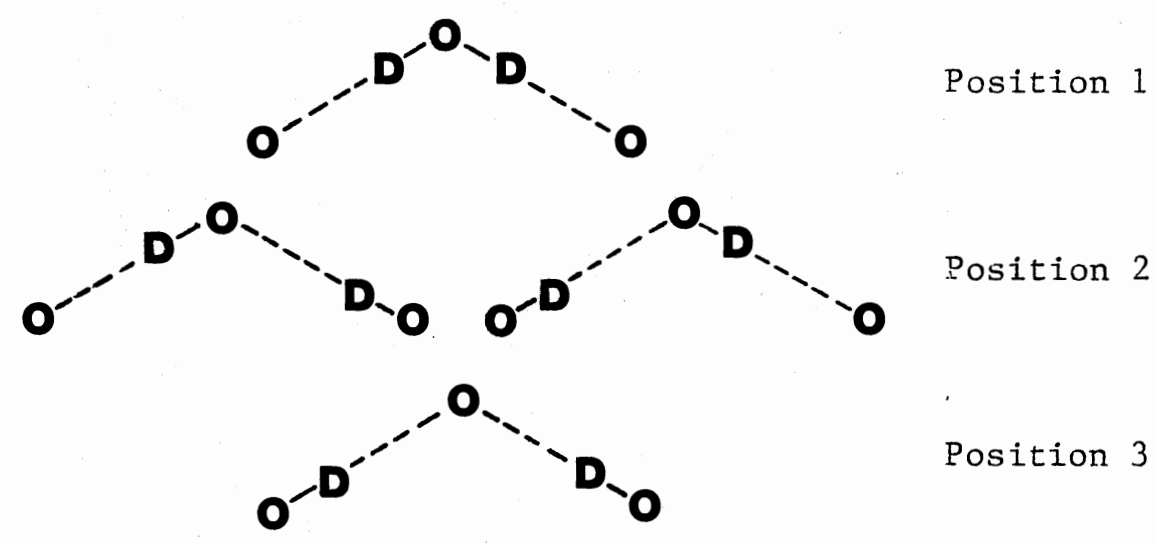

Figure 25b. Possible Proton Transfer Positions
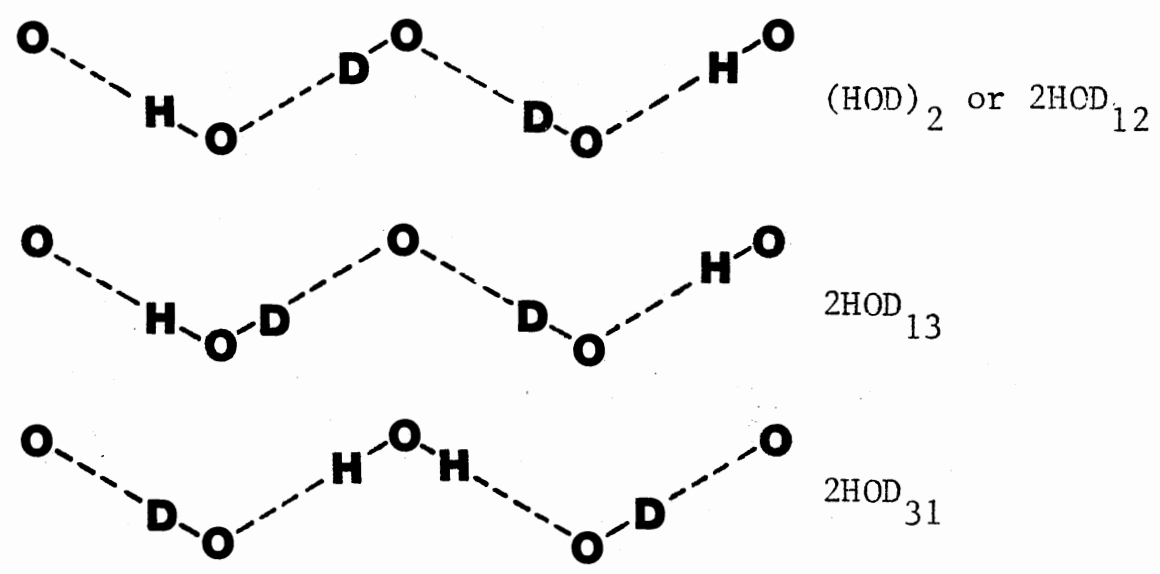

Figure 25c. Example $2 \mathrm{HOD}_{\mathrm{nm}}$ Configurations 
as shown in Figure 25c.

The next question presented is how does a $D_{2} \mathrm{O}$ unit in a crystalline ice lattice convert to two HODs which then migrate away from each other. $\mathrm{A} \mathrm{D}_{2} \mathrm{O}$ unit can be represented by $\mathrm{D}_{2} \mathrm{O}_{11}$ as shown in Figure 26. If an ion defect encounters $\mathrm{D}_{2} \mathrm{O}_{11}$ then a deuteron transfer is possible leaving behind "coupled HOD" or $2 \mathrm{HOD}_{12}$. At this point another ion pair defect could migrate through the $2 \mathrm{HOD}_{12}$ site transferring or shifting the other deuteron to form $2 \mathrm{HOD}_{13}$ or "pseudocoupled HOD". Alternately a D or L Bjerrum defect could migrate through the coupled $\mathrm{HOD}$, or $2 \mathrm{HOD}_{12}$. site leaving behind a $2 \mathrm{HOD}_{21}$ or "separated HOD". At this point "pseudo-coupled HOD", or $2 \mathrm{HOD}_{13}$, must meet a $D$ or $L$ defect to proceed further to $2 \mathrm{HOD}_{22}$ or "fully separated HOD". Likewise separated HOD or $2 \mathrm{HOD}_{21}$ cannot migrate further unless an ion pair defect is encountered to leave $2 \mathrm{HOD}_{22}$ or fully separated HOD behind. Thus the two divergent migration paths reunite back at $2 \mathrm{HOD}_{22}$ where either a transfer or rotation can occur to the $2 \mathrm{HOD}_{31}$ "position 1 form" or $2 \mathrm{HOD}_{23}$ "position 3 form". These forms then migrate to a "position 2 form" and the sequence can repeat continually. But if deuterons can migrate apart from each other via a tunneling transfer or thermally activated rotation they can also migrate together. Figure 26 illustrates this aspect with double arrows and uses $t$ or $r$ to indicate whether the step is a transfer or rotation. $D_{2}{ }_{11}$ and ${ }^{2} \mathrm{HOD}_{12}$ are spectroscopically distinguishable. However according to the experimental evidence to date, the other $2 \mathrm{HOD}_{\mathrm{nm}}$ are perceived spectroscopically as uncoupled HOD.

To relate this model to the measured $\mathrm{D}_{2} \mathrm{O}$, (HOD) 2 , and HOD absorbances some approximation must be incorporated to terminate the 


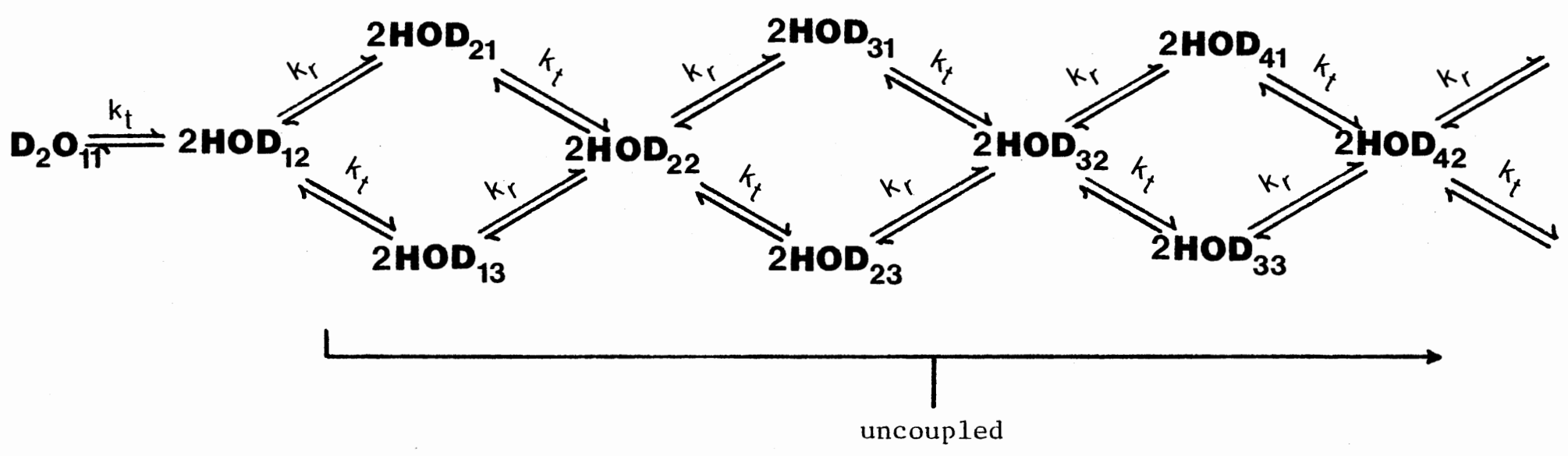

Figure 26. $\mathrm{D}_{2} \mathrm{O}_{11}$ to $2 \mathrm{HOD}_{\mathrm{nm}}$ Migration Mechanism 
number of steps and make any least square fitting technique practical. The first approximation suggested is that the exchange sequence terminates at $2 \mathrm{HOD}_{21}$ and $2 \mathrm{HOD}_{13}$, the pseudo-coupled and separated forms of HOD. In addition there is no back reaction of $2 \mathrm{HOD}_{21}$ or $2 \mathrm{HOD}_{13}$ to ${ }^{2} \mathrm{HOD}_{12}$. This would give

$$
\mathrm{D}_{2} \mathrm{O} \underset{\mathrm{k}_{\mathrm{t}}^{\prime}}{\stackrel{\mathrm{k}_{t}}{\rightleftharpoons}} \text { (HOD) } 2 \stackrel{\mathrm{k}_{t}^{\prime \prime}+\mathrm{k}_{\mathrm{r}}}{\longrightarrow} 2 \mathrm{HOD}_{\text {uncoupled }}
$$

The lack of a back reaction from $2 \mathrm{HOD}_{\text {uncoupled }}$ to (HOD) 2 could be justified by the probable small concentrations of $2 \mathrm{HOD}_{21}$ and $2 \mathrm{HOD}{ }_{13}$ relative to $2 \mathrm{HOD}_{12}$ or $(\mathrm{HOD})_{2}$, due to the forward reactions of $2 \mathrm{HOD}_{21}$ and $2 \mathrm{HOD}_{13}$ that would tend to distribute the newly separated deuterons further apart in the ice lattice. This single equilibrium approximation can be expanded to a double equilibrium model provided an additional unknown parameter is introduced into the model, the $2 \mathrm{HOD}_{21}$ concentration. If the $2 \mathrm{HOD}_{12}$ to $2 \mathrm{HOD}_{13}$ to $2 \mathrm{HOD}_{22}$ forward and back pathways are ignored on the basis of rate constant magnitudes, (to be discussed later), then the following model approximation may be written.

$\mathrm{D}_{2} \mathrm{O} \underset{\mathrm{t}}{\frac{\mathrm{k}_{t}}{\mathrm{k}_{t}}}(\mathrm{HOD})_{2} \stackrel{\mathrm{k}_{r}}{\frac{\mathrm{k}_{\mathrm{r}}^{\prime}}{\longrightarrow}} 2 \mathrm{HOD}$ separated $\stackrel{\mathrm{k}_{t}^{\prime \prime}}{\longrightarrow} 2 \mathrm{HOD}$ uncoupled

Here the back reaction of $2 \mathrm{HOD}_{\text {uncoupled }}$ or $2 \mathrm{HOD}_{22}$ to $2 \mathrm{HOD}$ separated or $2 \mathrm{HOD}_{21}$ is ignored on the basis of the small concentration of $2 \mathrm{HOD}_{22}$ due to the $2 \mathrm{HOD}_{22}$ to $2 \mathrm{HOD}_{31}$ or $2 \mathrm{HOD}_{23}$ forward reactions and the position of $2 \mathrm{HOD}_{22}$ configuration in the migration pathway. The latter is suggested since the further two deuteriums migrate apart, the more options there are for different migration paths leading to different configurations. Hence the further two deuterons move apart the less 
chance there is for the migration path to reverse to the original starting $\mathrm{D}_{2} \mathrm{O}$ unit. The only remaining hurdle is to find the relationship between the various $k_{t} s$ and $k_{r} s$ before the models may be used.

\section{Determining Rate Constant Relationships}

In the gas or liquid phase, reaction rates are determined from collision frequencies, orientation factors, reaction cross sections, energy states populations, transition probabilities, and other factors. Mono and bi-molecular reactions can be expressed with first and second order kinetic rate equations. But reactions in the solid phase can be more complex and indeterminate. Orientations may be fixed, and two body collisions are almost nonexistent.

For a transfer or rotational movement of a deuteron to occur, a migrating ice defect must encounter a $\mathrm{D}_{2} \mathrm{O}$ or HOD configuration. This suggests a second order process. But at a given temperature the concentration and rate of migration of the defects is constant. Furthermore, the defect is not consumed in the reaction so that its concentration still stays constant. Thus all the transfer rate constants $\left(k_{t}\right)$ and rotational rate constants $\left(k_{r}\right)$ expressed in Equation (3.7), (3.8), and Figure 26 are first order with respect to the $\mathrm{D}_{2} \mathrm{O}$ or $2 \mathrm{HOD} \mathrm{nm}_{\mathrm{m}}$ configuration concentrations. The transfer rates between configurations should be equal except for the effect that the different number of approaches and subsequent conversion possibilities arising from different configurations should produce on the transfer rates. A similar situation exists for the rotational rates. The next logical step is to determine what different defect approaches and reacting pathways are possible for different deuteron configurations. 
Figure 27 and Table $\mathrm{V}$ show a brief representation and resulting mathematical formulation for the $\mathrm{D}_{2} \mathrm{O}_{11} \rightarrow 2 \mathrm{HOD}{ }_{12}$ exchange reaction. Reaction I Figure 27 shows three sequential steps labeled the attack, transfer, and leaving factors. If the relative probability of occurrence for each step is determined for each reaction then a comparison between different $k_{t} s$ may be made. For the attack step a hydronium ionic defect moves to the $\mathrm{D}_{2} \mathrm{O}$ site. There are two different hydrogen bonds on which the attacking hydrogen can tunnel. Then the attack factor is written as $2 \nu_{\mathrm{H}}$ where $\nu_{\mathrm{H}}$ is the tunneling frequency of the attacking proton (see Table V). On the transfer step either the proton can tunnel back to its original oxygen at a frequency of $\nu_{H}$ or one of the two deuterons may tunnel at a frequency of $\nu_{D}$ to another oxygen to yield $2 \mathrm{HOD}_{12}$ or coupled HOD. The total tunneling frequency would be $v_{H}+2 v_{D}$ and the tunneling frequency for the desired reaction would be $2 v_{D}$. Then a probability of occurrence for the desired event could be defined as $2 \nu_{D} /\left(\nu_{H}+2 \nu_{D}\right)$. To assure that the transfer step, which leaves a hydronium ion defect at the $\mathrm{HOD}_{12}$ site, does not back exchange to $\mathrm{D}_{2} \mathrm{O}_{11}$ a leaving factor is included using the same logic as for the transfer step. Using these three factors a relative probability of reaction can be assigned to reaction I through VI by

$$
\mathrm{P}_{\mathrm{R}_{\mathrm{X}}}=\text { (attack factor } \mathrm{R}_{\mathrm{X}} \text { ) (transfer factor } \mathrm{R}_{\mathrm{X}} \text { ) (1eaving factor } \mathrm{R}_{\mathrm{X}} \text { ) }
$$

The relationship between any given transfer reaction can be written as

$$
\begin{aligned}
k_{t}^{\prime}= & \frac{\left(\text { attack factor } k_{t}^{\prime}\right)\left(\text { transfer factor } k_{t}{ }^{\prime}\right)\left(\text { leaving factor } k_{t}{ }^{\prime}\right)}{\left.\left.\left(\text { attack factor } k_{t}\right) \text { (transfer factor } k_{t}\right) \text { (leaving factor } k_{t}\right)} k_{t}(3.10) \\
& \text { Table V lists the transfer factors found for Figure } 27 \text { and } 28 \text { for }
\end{aligned}
$$
the forward and back transfer exchange reactions between $\mathrm{D}_{2} \mathrm{O}_{11},{ }_{2} \mathrm{HOD}_{12}$, 
I. $\mathrm{D}_{2} \mathrm{O}_{11} \longrightarrow 2 \mathrm{HOD}_{12}$

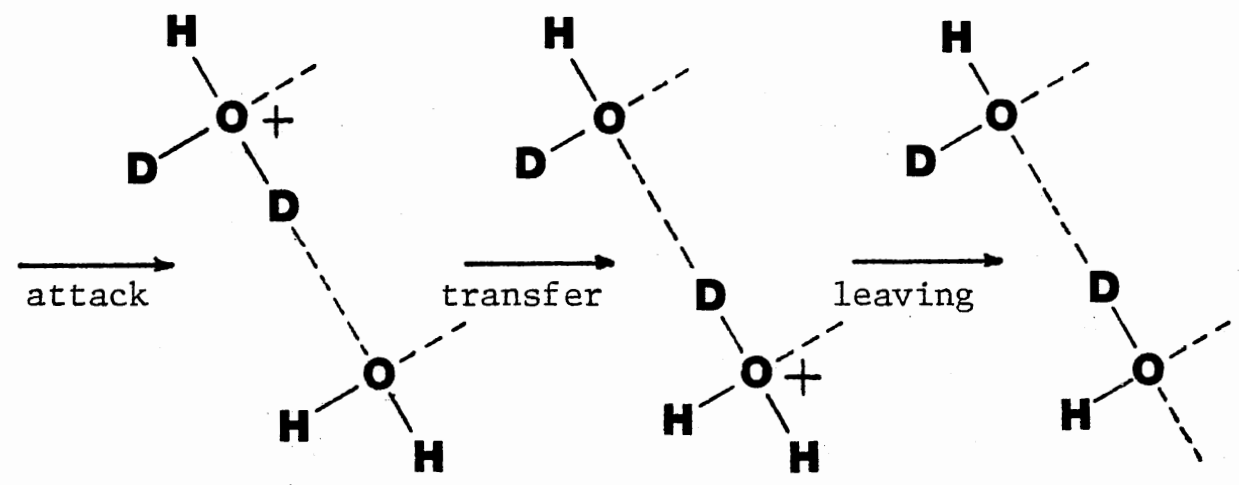

II. $2 \mathrm{HOD}_{12} \rightarrow \mathrm{D}_{2} \mathrm{O}_{11}$

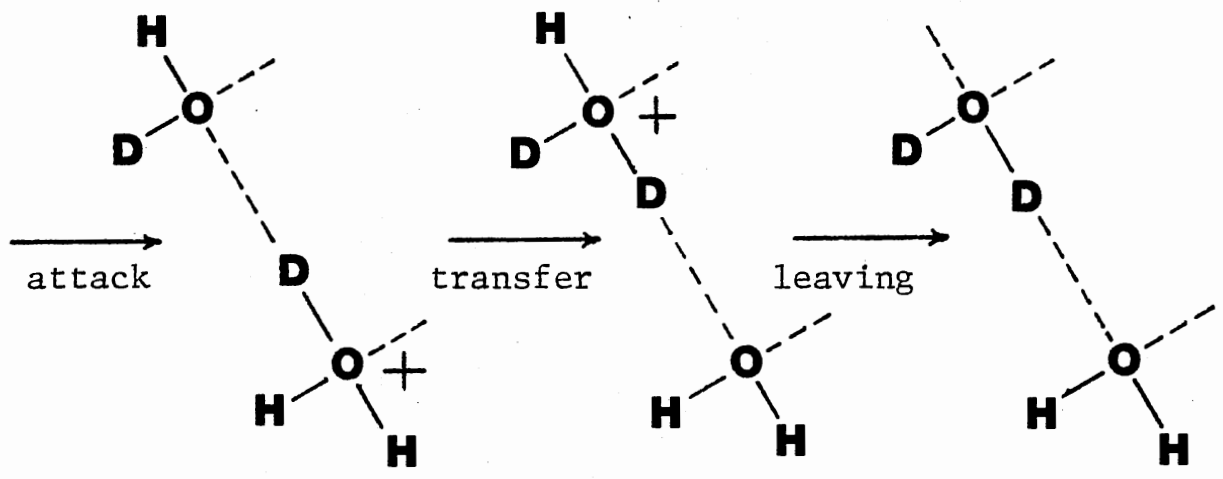

III. $2 \mathrm{HOD}_{12} \longrightarrow 2^{\mathrm{HOD}}{ }_{13}$

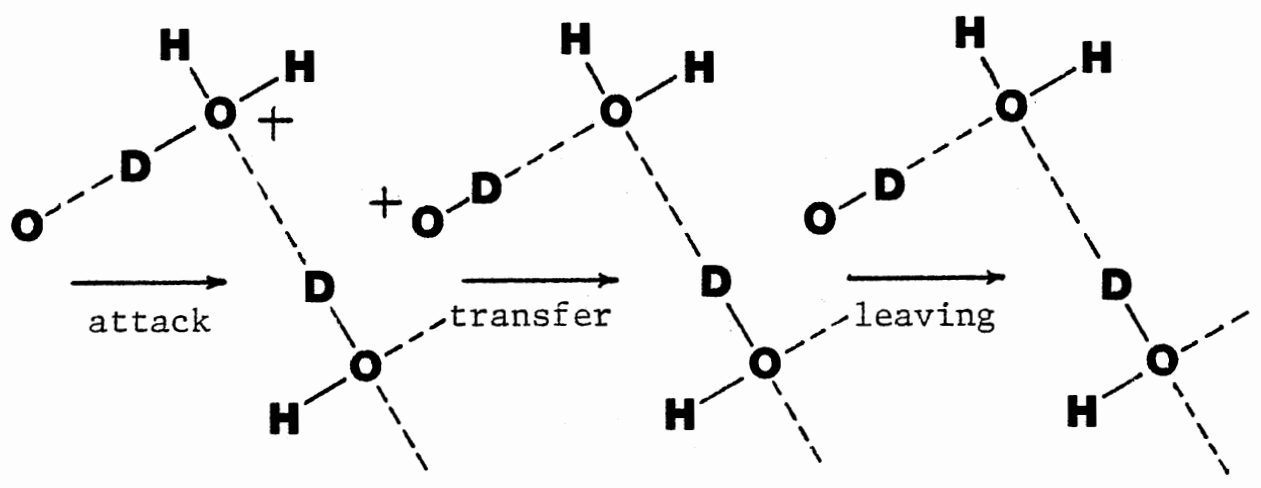

Figure 27. Proton Transfer Steps for Deuterium Migration 
TABLE V

RELATIVE PROBABILITY FACTORS FOR TRANSFER MIGRATION

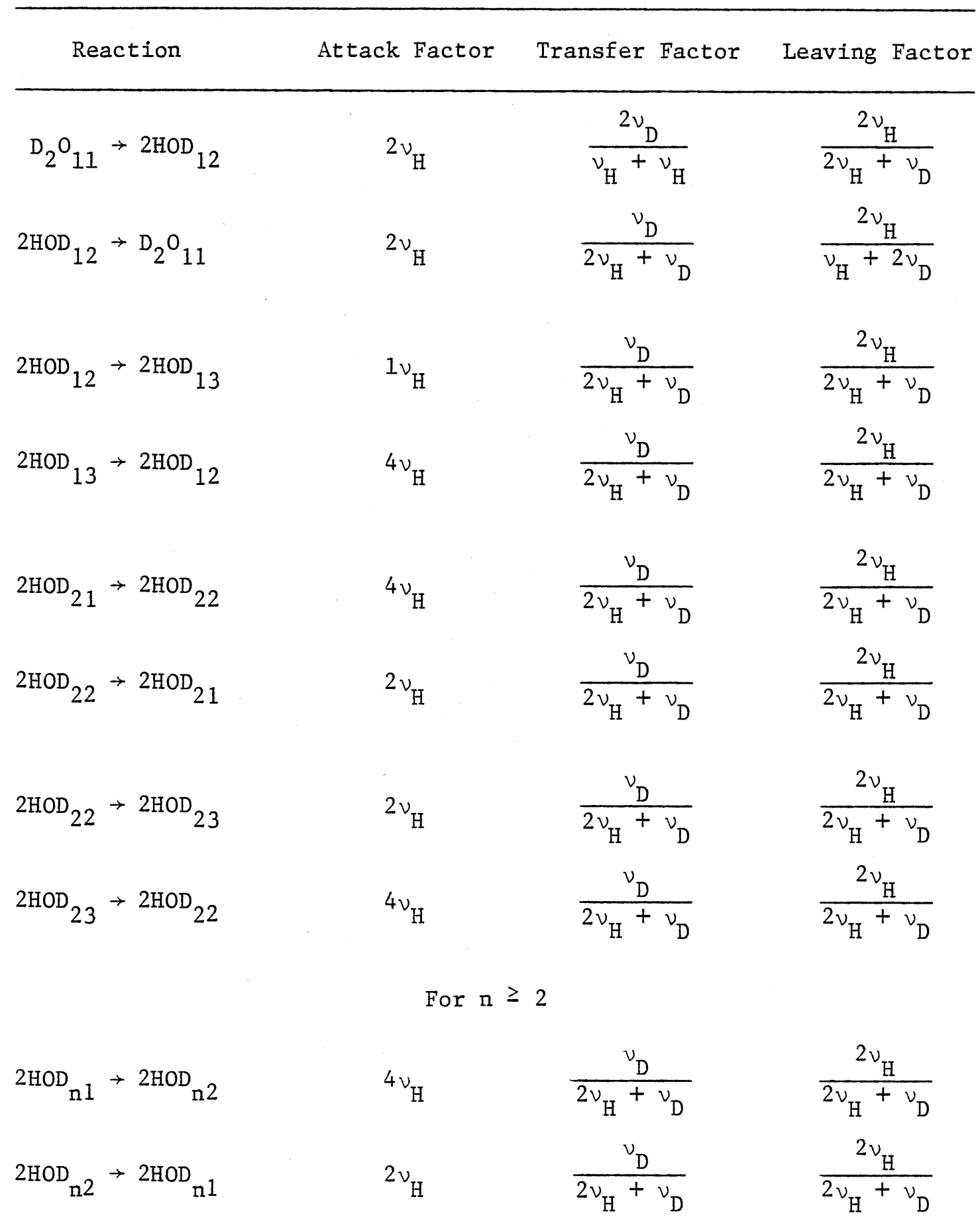


TABLE V (Continued)

\begin{tabular}{|c|c|c|c|}
\hline Reaction & Attack Factor & Transfer Factor & Leaving Factor \\
\hline & & $v_{D}$ & $2 \nu_{H}$ \\
\hline $2 \mathrm{HOD}_{\mathrm{n} 2} \rightarrow 2 \mathrm{HOD}_{\mathrm{n} 3}$ & $2 \nu_{H}$ & $\overline{2 v_{H}+v_{D}}$ & $\overline{2 v_{H}+v_{D}}$ \\
\hline $2 \mathrm{HOD} \rightarrow 2 \mathrm{HOD}$ & $4 v_{T T}-v_{2}$ & $\nu_{D}$ & ${ }^{2 V_{H}}$ \\
\hline n3 n2 & ${ }_{\mathrm{H}}$ & $2 \nu_{H}+v_{D}$ & $2 \nu_{H}+\nu_{D}$ \\
\hline
\end{tabular}


IV. $2 \mathrm{HOD}_{13} \longrightarrow 2 \mathrm{HOD}_{12}$<smiles>CCC(C)(Cl)Cl</smiles>

V. $2 \mathrm{HOD}_{21} \longrightarrow 2 \mathrm{HOD} 22$

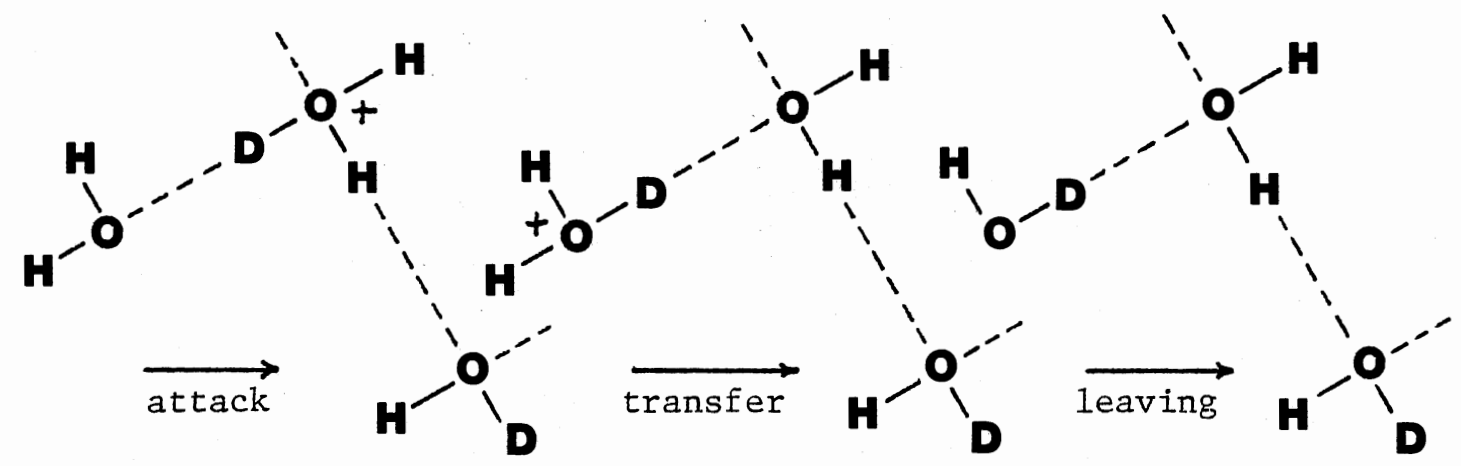

VI. $2 \mathrm{HOD}_{22} \longrightarrow 2 \mathrm{HOD}_{21}$<smiles>CC(C)(Cl)Cl</smiles>

Figure 28. Proton Transfer Steps for Deuterium Migration 
$2 \mathrm{HOD}_{13}, 2 \mathrm{HOD}_{21}$, and $2 \mathrm{HOD}_{22}$ the $\mathrm{D}_{2} \mathrm{O}_{1}$ coupled HOD, pseudo HOD, separated HOD, and fully separated HOD molecular units of cubic ice. It should be noted that the hydroxide ionic defect does not appear to play a significant part in the $\mathrm{D}_{2} \mathrm{O}$ isotopic exchange reaction $(46,47)$.

Examining Table VI and Figures 29 and 30 reveals a similar formulation for the rotational step or a Bjerrum $D$ or $L$ defect migrating through a $2 \mathrm{HOD}_{\mathrm{nm}}$ site. Reaction I the $2 \mathrm{HOD}_{12} \rightarrow 2 \mathrm{HOD}{ }_{21}$ reaction in Figure 29 shows how an $\mathrm{L}$ defect can migrate through the $2 \mathrm{HOD}_{12}$ unit to change it to $2 \mathrm{HOD}_{21}$. The $\mathrm{L}$ defect may enter the $2 \mathrm{HOD}{ }_{23}$ along 3 hydrogen bonded paths, shown by dotted lines. However, the top hydrogen bond pathway does not change the configuration. Thus there are only two attack paths. This gives an attack factor of 2 for the $\mathrm{L}$ defect (see Table VI). In the transfer step the $\mathrm{L}$ defect moves to the oxygen-oxygen linkage between' the two HODs as a result of the deuteron rotating down to the lower 0-0 1inkage. In the bottom 0-0 linkage, there are four different protons that can rotate into the $\mathrm{L}$ defect, as will always be the case of an L defect migrating through a perfect Bernard-Fowler ice crystal. If the bottom protons rotates in, the $L$ defect will move backwards thus not initiating the transfer step. If the deuteron rotates in, the $\mathrm{L}$ defect moves up the hydroxyl chain to the middle position shown in the transfer step. However, if the proton on the bottom HOD unit rotated in, the $L$ defect would simply shift to another attack position identical to the position shown in the attack step. Thus of four possible proton or deuteron rotations only three change the $\mathrm{L}$ defect with respect to the reaction pathway, and only one of these three, namely the deuteron rotation, initiates the transfer step. Therefore the relative probability for the transfer 
TABLE VI

RELATIVE PROBABILITY FACTORS FOR ROTATIONAL MIGRATION

\begin{tabular}{|c|c|c|c|c|}
\hline Reaction & $\begin{array}{l}\text { Attach } \\
\text { Factor }\end{array}$ & $\begin{array}{c}\text { Transfer } \\
\text { Factor }\end{array}$ & $\begin{array}{l}\text { Leaving } \\
\text { Factor }\end{array}$ & Total \\
\hline \multicolumn{5}{|c|}{ L Defect } \\
\hline $2 \mathrm{HOD}_{12} \rightarrow 2 \mathrm{HOD}_{21}$ & 2 & $\frac{1}{3}$ & $\frac{1}{2}$ & $\frac{1}{3}$ \\
\hline $2 \mathrm{HOD}_{21} \rightarrow 2 \mathrm{HOD}_{12}$ & 2 & $\frac{1}{3}$ & $\frac{1}{2}$ & $\frac{1}{3}$ \\
\hline $2 \mathrm{HOD}_{13} \rightarrow 2 \mathrm{HOD}_{22}$ & 4 & $\frac{1}{3}$ & $\frac{3}{4}$ & 1 \\
\hline
\end{tabular}

Sequence A

$2 \mathrm{HOD}_{22} \rightarrow{ }^{2 \mathrm{HOD}} 13 \quad \frac{1}{3} \quad 2 \quad \frac{1}{4} \quad \frac{1}{6}$

Sequence B

$2 \mathrm{HOD}_{22} \rightarrow{ }^{2 \mathrm{HOD}_{13}} \quad 1 \quad \frac{1}{3} \quad \frac{1}{4} \quad \frac{1}{12}$

Total

$2 \mathrm{HOD}_{22} \rightarrow 2 \mathrm{HOD}_{13} \quad \frac{1}{3}$ (Sequence $\left.\mathrm{A}\right)+\frac{2}{3}$ (Sequence $\left.\mathrm{B}\right)=\frac{1}{9}$

$\underline{\text { D Defect }}$

$\begin{array}{rrrrr}2 \mathrm{HOD}_{12} \rightarrow 2 \mathrm{HOD}_{21} & 1 & \frac{1}{3} & \frac{1}{2} & \frac{1}{6} \\ 2 \mathrm{HOD}_{21} \rightarrow 2 \mathrm{HOD}_{12} & 1 & \frac{1}{3} & \frac{1}{2} & \frac{1}{6}\end{array}$

$\begin{array}{rrrrr}2 \mathrm{HOD}_{13} \rightarrow 2 \mathrm{HOD}_{22} & 2 & \frac{1}{2} & \frac{2}{3} & \frac{2}{3} \\ 2 \mathrm{HOD}_{22} \rightarrow 2 \mathrm{HOD}_{13} & 1 & \frac{1}{3} & \frac{1}{3} & \frac{1}{9}\end{array}$


I. $2 \mathrm{HOD}{ }_{12} \longrightarrow 2 \mathrm{HOD}_{21}$

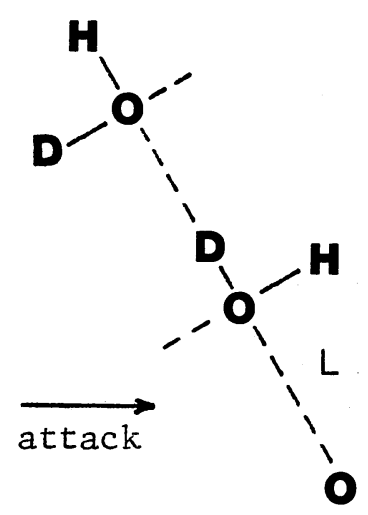

II. $2 \mathrm{HOD}_{21} \longrightarrow 2 \mathrm{HOD}_{12}$

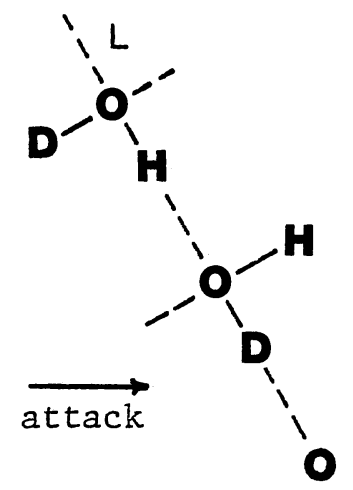

III. $2 \mathrm{HOD}_{13} \longrightarrow 2 \mathrm{HOD}_{22}$ sequence $\mathrm{A}$
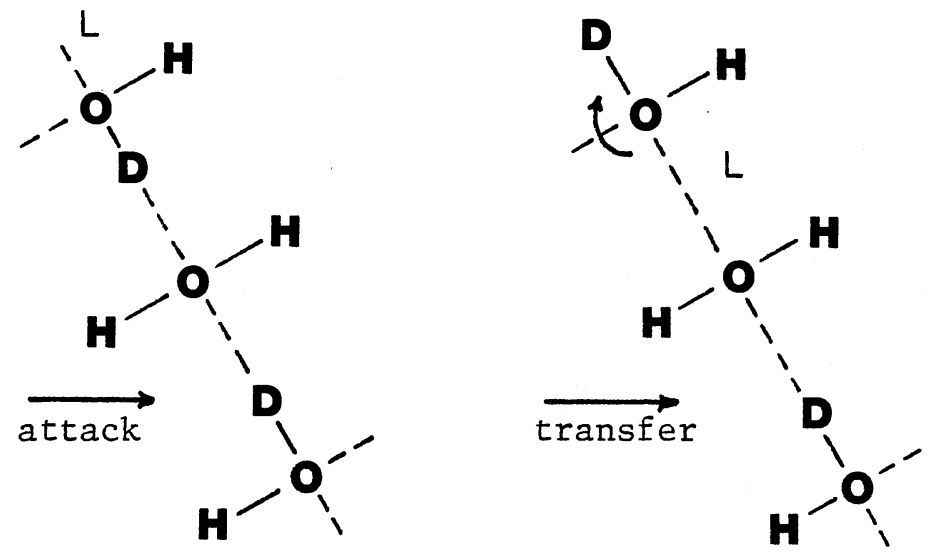

Figure 29. Proton Rotational Steps for Deuteron Migration 
IV. $2 \mathrm{HOD}_{13} \longrightarrow 2 \mathrm{HOD}_{22}$ sequence $\mathrm{B}$
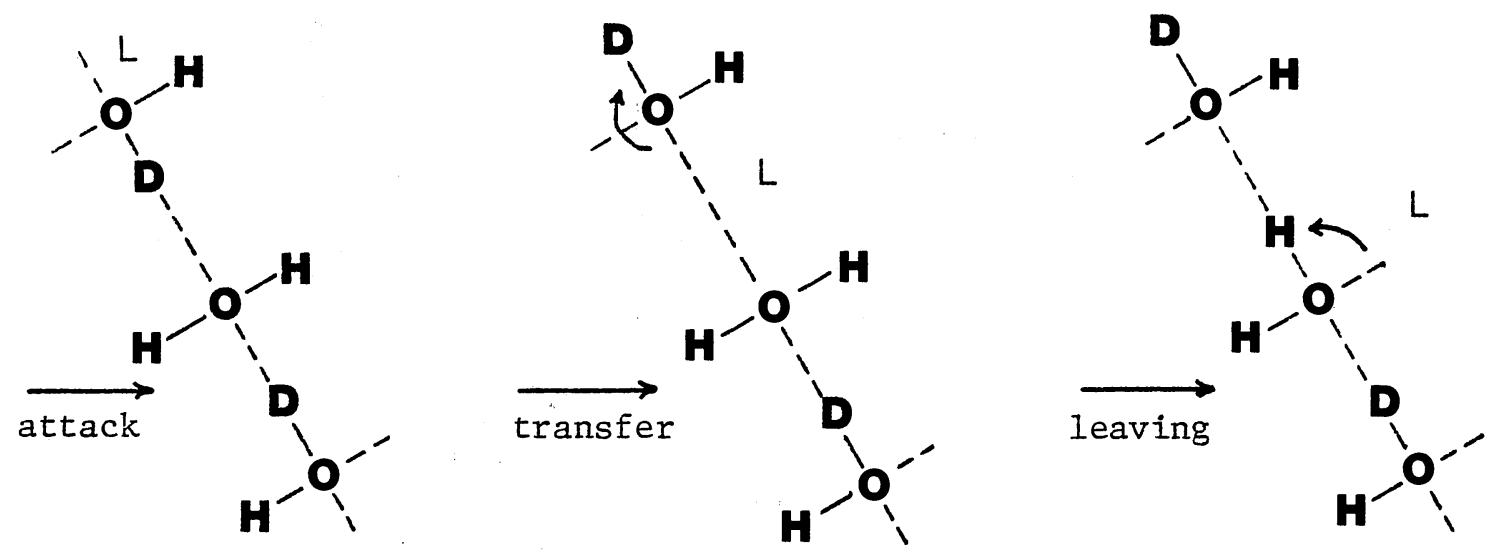

V. $2 \mathrm{HOD}_{22} \longrightarrow 2 \mathrm{HOD}_{13}$ sequence A result
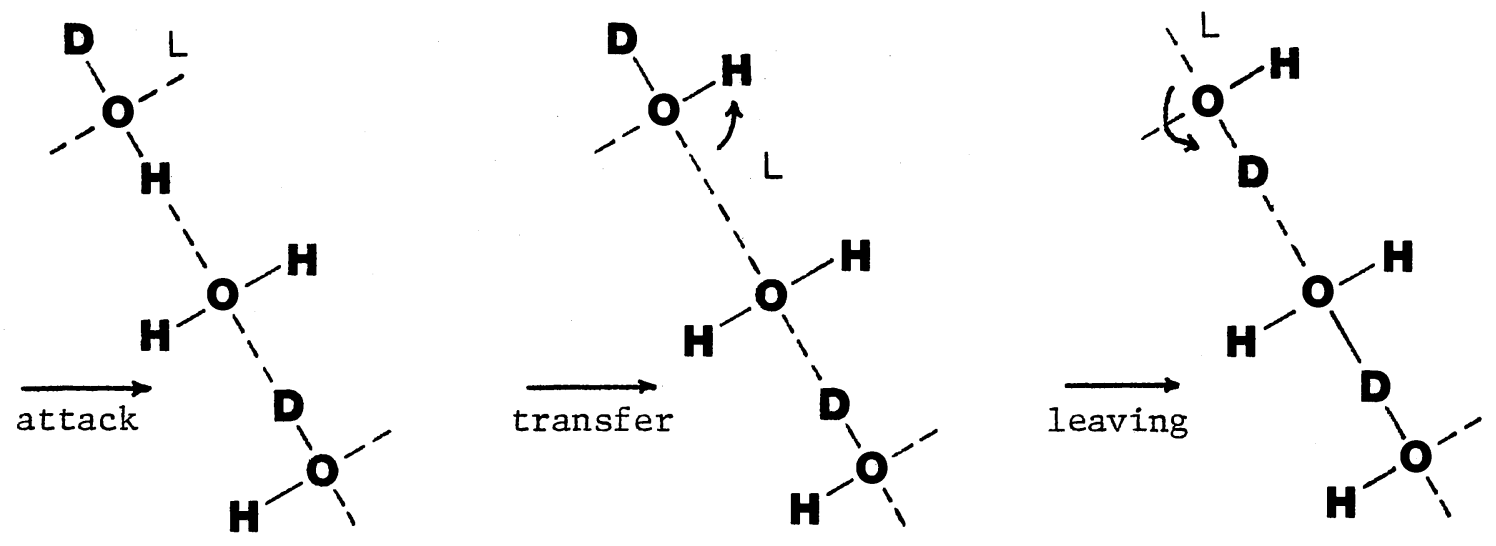

VI. $2 \mathrm{HOD}_{22} \longrightarrow 2 \mathrm{HOD}$

sequence $B$ result
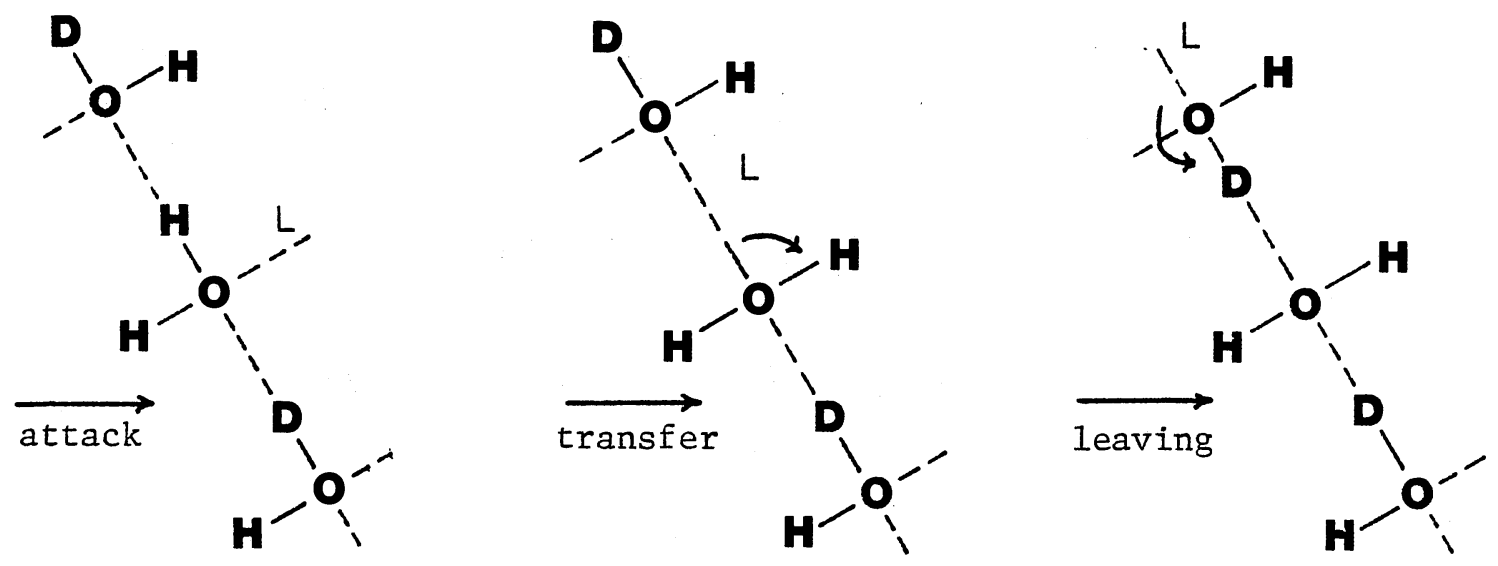

Figure 30. Proton Rotational Steps for Deuteron Migration 
step is $\frac{1}{3}$. For the leaving step all four proton or deuterons will change the $L$ defect with respect to the reaction pathway. Two of these (the protons rotating in) leave the $2 \mathrm{HOD}_{21}$ intact as the $\mathrm{L}$ defect moves on. But if either of the two deuterons rotates in then the $\mathrm{L}$ defect movement leaves a $2 \mathrm{HOD}_{12}$ configuration behind and a $\mathrm{L}$ defect position identical to the position shown in the attack step. Thus for the leaving step there is a $\frac{2}{4}$ or $\frac{1}{2}$ probability that the desired reaction or step occurs. The total relative probability is now found by multiplying these factors together to yield $\frac{1}{3}$ as shown in Table VI. The relative probability for the back reaction $2 \mathrm{HOD}_{21}$ $\rightarrow 2 \mathrm{HOD}_{12}$ is likewise determined.

The $2 \mathrm{HOD}_{13} \rightarrow 2 \mathrm{HOD}_{22}$ (pseudo to fully separated $\mathrm{HOD}$ ) reaction is slightly more complex. As shown in reaction III Figure 29 and reaction IV Figure 30, there are two different sequences to convert $2 \mathrm{HOD}_{13}$ to $2 \mathrm{HOD}_{22}$, each leaving a different configured $2 \mathrm{HOD}_{22}$. Sequence A or reaction III leaves a $2 \mathrm{HOD}_{22}$ product with the end HOD group providing the rotated proton for the leaving step. Sequence $B$ or reaction IV has the middle $\mathrm{H}_{2} \mathrm{O}$ group providing the proton for the leaving step. Since the middle $\mathrm{H}_{2} \mathrm{O}$ has two protons to rotate into the $\mathrm{L}$ defect but the end HOD group of sequence $A$ has only one proton to rotate into the $L$ defect on the transfer step then sequence $B$ should occur twice as much as sequence $A$. For the forward $2 \mathrm{HOD}_{13} \rightarrow 2 \mathrm{HOD}_{22}$ reaction this should present no problem. But for the reverse $2 \mathrm{HOD}_{22} \rightarrow 2 \mathrm{HOD} 13$ reaction each sequence has different attack factors. So to account for this pathway splitting the sequence A total relative probability is weighted by $\frac{1}{3}$ to account for its share of the probability of $2 \mathrm{HOD}{ }_{13} \rightarrow 2 \mathrm{HOD}_{22}$ occurring. Likewise sequence $\mathrm{B}$ is weighted by $\frac{2}{3}$. 
The total reaction relative probability is given by the sum of the sequence relative probabilities.

Similar relative probability calculations for a $D$ defect migration through a $\mathrm{D}_{2} \mathrm{O}_{11}$ or $2 \mathrm{HOD}$ nm site are also shown in Table VI. As with transfer rate constants the rotational rate constants can be related through

$$
k_{r}^{\prime}=\frac{\left(\text { total relative probability } k_{r}{ }^{\prime}\right)}{\text { (total relative probability } k_{r} \text { ) }} k_{r}
$$

Using (3.10) and (3.11) the relationships between the various $k_{t}$ 's and $k_{r}$ 's (the transfer and rotational rate constants) of equation (3.7) and (3.8) are written in terms of one $k_{t}$ and one $k_{r}$. Figure 26 may be rewritten in terms of the $\mathrm{D}_{2} \mathrm{O}_{11} \rightarrow 2 \mathrm{HOD}{ }_{12} \mathrm{k}_{t}$ and $2 \mathrm{HOD}_{12} \rightarrow 2 \mathrm{HOD}_{21} \mathrm{k}_{r}$ as

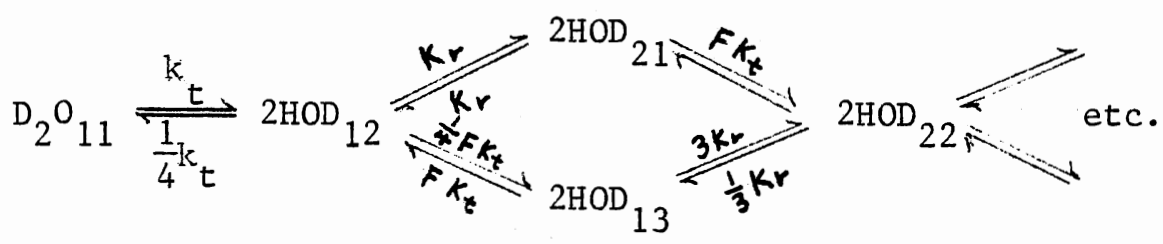

where $F=\left(\frac{v_{H}+2 v_{D}}{2 v_{H}+v_{D}}\right)$ and the $k_{r}$ relationships are calculated using the $\mathrm{L}$ defect factors. If the $\mathrm{D}$ defect factors are used for $\mathrm{k}_{\mathrm{r}}$ then Figure 26 may be written

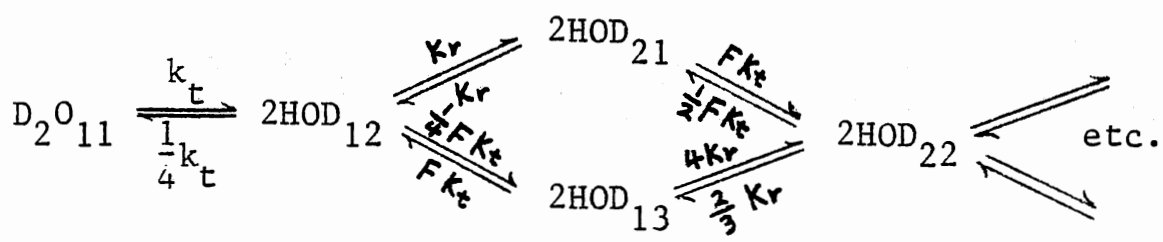

Equation (3.7) the single equilibrium model approximation may be written as

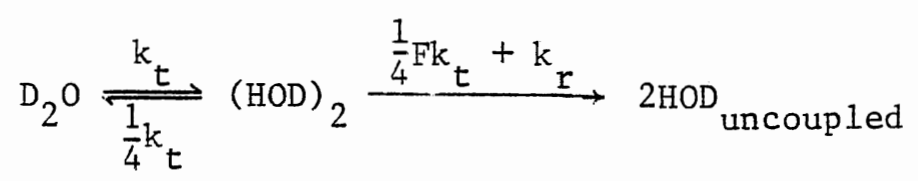

and the double equilibrium model given in Equation (3.7) using either D 
or $\mathrm{L}$ rotational defects as

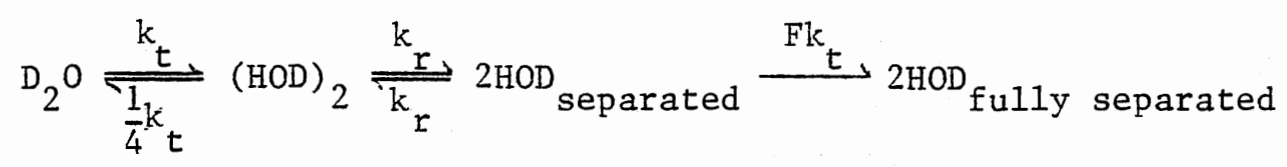

Since the rate constants depleting $2 \mathrm{HOD}_{13}$ in equations (3.12, 3.13) are significantly higher than the feeding rate constants, it is expected that the concentration of $2 \mathrm{HOD}_{13}$ in an exchange process would be small and steady state. Furthermore since the amount of $2 \mathrm{HOD}_{12}$ or coupled HOD being converted to $2 \mathrm{HOD}_{13}$ is small $\left(\frac{1}{4} k_{t}\right)$ compared to the other decoupling rate constants, it is assumed that the deuterons primarily migrate apart through the $2 \mathrm{HOD}_{12}, 2 \mathrm{HOD}_{21}, 2 \mathrm{HOD}_{22}$ pathway, as suggested by the double equilibrium (3.15) model. The single equilibrium (3.14) model assumes that no back reaction of $2 \mathrm{HOD}_{21}$ or $2 \mathrm{HOD}_{13}$ to $2 \mathrm{HOD}_{12}$ occurs. Perusal of these rate constants shows that they are equal or greater in magnitude than the forward rate constants and hence the assumption may not be valid. The double equilibrium (3.15) has this same problem with the $2 \mathrm{HOD}_{21}$ to $2 \mathrm{HOD}_{22}$ forward and back rates. Here, however, the back reaction rate is significantly smaller than the forward ( $F k_{t}$ forward to $\frac{1}{2} F k_{t}$ back) and the concentration of $2 \mathrm{HOD}_{22}$ should be considerably smaller than $2 \mathrm{HOD}_{21}$. In summation the single equilibrium model (3.14) has three unknown parameters $k_{t}$, $k_{r}$, and $F$; and includes no provision for any back exchange into the coupled HOD or $2 \mathrm{HOD}_{12}$ configuration. The double equilibrium model ( 3.15 ) has four unknown parameters $k_{t}, k_{r}, F$, and an initial HOD separated or $2 \mathrm{HOD}_{21}$ concentration. It provides for a $2 \mathrm{HOD}_{21}$ back reaction to $2 \mathrm{HOD} 12$ or coupled HOD, but includes a spectroscopically unobservable species, $2 \mathrm{HOD}_{21}$. Fitting these two models to the experimental data should provide a measure of the importance of the $2 \mathrm{HOD}_{21}$ configuration in the 
isotopic scrambling of $D_{2} \mathrm{O}$ in cubic ice.

Kunst and Warman (48) determined the virtual mobility of protons in ice at $-5^{\circ} \mathrm{C}$ as $6.4 \times 10^{-3} \mathrm{~cm}^{-2} \mathrm{~V}^{-1} \mathrm{sec}^{-1}$ and deuterons in $\mathrm{D}_{2} \mathrm{O}$ ice at $-5^{\circ} \mathrm{C}$ as $2.4 \times 10^{-3} \mathrm{~cm}^{-2} \mathrm{~V}^{-1} \mathrm{sec}^{-1}$. At $-30^{\circ} \mathrm{C}$ they reported that the ratio remained the same though the magnitudes increased. Using these values $F$ is calculated as .736842 . This value was used throughout the calculations and any effects resulting from changing this value are noted.

Determining an initial $2 \mathrm{HOD}_{21}$ or separated $\mathrm{HOD}$ concentration was not straightforward. If an ice deposit of $\mathrm{D}_{2} \mathrm{O}$ isolated in $\mathrm{H}_{2} \mathrm{O}$ with no coupled or uncoupled HOD could be made, then the initial $2 \mathrm{HOD}_{21}$ concentration could be set equal to zero. However, all ice deposits made contained small amounts of coupled HOD initially and some uncoupled HOD in addition. So as a reasonable approximation the initial $2 \mathrm{HOD}_{21}$ concentration was taken as some function of the initial (HOD) $_{2}$ or $2 \mathrm{HOD}_{12}$ concentration. The idea being that whatever processes (limited pre-exchange or deposition contamination) created the initial $2 \mathrm{HOD}_{12}$ concentrations would also create the initial $2 \mathrm{HOD}_{21}$ concentration in the ice deposit. Fractional values of initial $2 \mathrm{HOD}_{12}$ between 0.0 and 1.0 were tried.

Thus with an initial guessed $2 \mathrm{HOD}_{21}$ concentration and the previously calculated $\mathrm{F}$ constant, both the single and double equilibrium models were used to fit the kinetic concentration data. These calculations served to determine the appropriate transfer $\left(k_{t}\right)$ and rotational $\left(k_{r}\right)$ rate constants, for isotopic exchange processes in cubic ice at temperatures ranging from $135-150 \mathrm{~K}$. 
Solution and Data Analysis of the Models

The differential rate equations for the single equilibrium (3.14)

model are

$$
\begin{gathered}
\frac{d\left[D_{2} O\right]}{d t}=\frac{1}{4} k_{t}\left[(H O D)_{2}\right]-k_{t}\left[D_{2} O\right] \\
\frac{d\left[(H O D)_{2}\right]}{d t}=k_{t}\left[D_{2} O\right]-\frac{1}{4}\left[(H O D)_{2}\right]-\left(\frac{1}{4} F k_{t}+k_{r}\right)\left[(H O D)_{2}\right] \\
\frac{d\left[2 \text { HOD }_{\text {uncoup } 1 e d}\right]}{d t}=\left(\frac{1}{4} F k_{t}+k_{r}\right)\left[(H O D)_{2}\right]
\end{gathered}
$$

Likewise for the two equilibrium model (3.15) the differential rate equations are

$$
\begin{aligned}
& \frac{d\left[D_{2} O\right]}{d t}=\frac{1}{4} k_{t}\left[(\mathrm{HOD})_{2}\right]-k_{t}\left[D_{2} O\right] \\
& \frac{d\left[D_{2} O\right]}{d t}=k_{t}\left[D_{2} O\right]-\frac{1}{4} k_{t}\left[(H O D)_{2}\right]-k_{r}\left[(H O D)_{2}\right]+k_{r}[2 H O D \text { separated }] \\
& \frac{d\left[2 \mathrm{HOD}_{\text {separated }}\right]}{\mathrm{dt}}=k_{r}\left[(\mathrm{HOD})_{2}\right]-k_{r}[2 \mathrm{HOD} \text { separated }]-F k_{t}\left[2 \mathrm{HOD}_{\text {separated }}\right] \\
& \frac{d\left[2 \mathrm{HOD}_{\text {fully separated }}\right]}{d t}=F k_{t}\left[2 \mathrm{HOD}_{\text {fully separated }}\right]
\end{aligned}
$$

and $[2 \mathrm{HOD}$ uncoupled $]=[2 \mathrm{HOD}$ separated $]+\left[2 \mathrm{HOD}_{\text {fully separated }}\right]$

Before any model fitting is accomplished these differential equations must be solved. For complex mechanisms two basic approaches are possible. One, find a way to solve the equations analytically, or, two numerically solve them using computer differential equation solvers. Matsen and Franklin (49) have published the general solution to the four component coupled set of first order reactions. The technique sets up the differential equations as a secular determinant similar to a standard eigenvalue problem. Solutions were then found 
from the resulting eigenvalues and eigenvectors. Lewis and Johnson (50) recast the equations into a matrix formulation that is solved by matrix algebra. Unfortunately, these analytical solutions contain many of the problems often encountered in numerical solutions. Therefore, since the differential equations are not stiff; and fast, accurate, easy to use differential equation solvers are available, the numerical solution method was chosen to solve the equations.

A variable order Adams predictor-corrector differential equation solver written by the International Mathematical and Statistical Library group was used to solve all the differential equations of the model simultaneously. Among the features of this routine are variable step sizes, abilities to help handle mildly stiff differential equations, built in user determined relative error bounds, and internal error checking.

The subroutine is named DGEAR and was called from a main Fortran program whenever a solution to the model differential equations was required. DGEAR required that the user supply the differential equations in another subroutine named FCN. FCN required the initial time, $\mathrm{D}_{2} \mathrm{O},(\mathrm{HOD})_{2}$, $\mathrm{HOD}_{\text {separated }} \mathrm{HOD}_{\text {fully separated }}$ concentrations, final time at which the concentration solutions are desired, and various control parameters. DGEAR then outputs the various concentrations at the desired time of reaction along with an error flag indicating the reliability of the answers. Initial step-sizes of 0.00001 and relative error bounds of 0.0001 was found to give the best accuracy and speed. A description of DGEAR along with sample input and output is included in Appendix B. Due to copyright restrictions, a program listing is not included. 
The next problem was to elucidate some method of varying the rate constants until the calculated concentration output is as identical to the experimental concentrations as possible. The method of nonlinear least squares was chosen. Though the methods of nonlinear least squares are legion they all attempt to minimize the square of the error residuals to find the best value of the minimizing parameters. The Marquardt strategy (5]) of nonlinear least squares is one of the most successful and efficient nonlinear routines used. Accordingly, it was used as a subroutine to find the best transfer and rotational rate constants for each dataset at each temperature. NLLSQ1 is a modified Fortran nonlinear least squares program based on the Marquardt strategy. It is composed of a main calling program which reads the data to be fitted, an initial parameter guess, and various control cards. After placing the needed information into array form, NLLSQ1 calls the Marquardt strategy subroutine NLLSQ. The NLLSQ subroutine also required that two additional subroutines DCALC and YCALC be written by the user. YCALC contains the function to be fitted such that at a given call with a chosen set of independent function variables the resulting dependent variables may be calculated and returned to NLLSQ. DCALC may optionally contain the function derivatives or be used as a dummy routine while the subroutine NLLSQ numerically calculated the derivatives. The latter option was used in this work. Once the data is least square fitted, the final optimized parameters (transfer and rotational rate constants), calculated dependent variables $\left(\left[\mathrm{D}_{2} \mathrm{O}\right],\left[(\mathrm{HOD})_{2}\right],[2 \mathrm{HOD}\right.$ uncoupled $\left.]\right)$, and root mean square deviation of $\mathrm{fit}$ is printed. Least squares analysis strives to $f i t$ an equation $Y=f\left(X_{1}, X_{2}, X_{3}, \ldots\right)$ 
to an observed set of $Y, X_{1}, X_{2}, X_{3} \ldots$ data. $Y$ is called the dependent variable, and $x_{i}$ the independent variable. For the single and double equilibrium models the dependent variables are the concentrations of $\mathrm{D}_{2} \mathrm{O}$, (HOD) ${ }_{2}$, and uncoupled HOD. The uncoupled HOD is calculated from the sum of separated HOD and fully separated HOD for the double equilibrium models, and fully separated HOD for the single equilibrium model. The time of reaction $t$ is the independent variable and $k_{t}$ and $\mathrm{k}_{\mathrm{r}}$ the minimizing parameters. The initial concentrations of $\mathrm{D}_{2} \mathrm{O}$, (HOD) 2 , separated HOD, and fully separated HOD were function constants that changed with each dataset analyzed. But since NLLSQ operates on functions with one dependent variable, only one species concentration could be fitted per run, unless the three dependent concentrations are transformed into a single dependent variable. Thus to obtain a consistent fit of the models to all observed concentrations the three concentrations were transformed into a single dependent variable. This was accomplished by including the (HOD) 2 and uncoupled HOD values after the $D_{2} O$ concentration values in the dependent variable array. Thus the first third of the array contained $\mathrm{D}_{2} \mathrm{O}$ concentration values, the second third the (HOD) 2 values, and the last third the uncoupled HOD concentrations values. For the independent or time variable array the reaction time in minutes was repeated three times in the array therefore maintaining a one to one correspondence between the ith observations of the time and concentration arrays. When NLLSQ called the subroutine YCALC, an index of observation requested, present calculated values of $k_{t}$ and $k_{r}$, and concentration and time value arrays were inputted as arguments. YCALC would initialize the needed information required by DGEAR for solving the 
differential kinetic rate equations. Using the time value found at the inputted index of observation DGEAR would solve the rate equations for the concentrations of $\mathrm{D}_{2} \mathrm{O}$, (HOD) ${ }_{2}$, and uncoupled HOD for that observation time. YCALC then determined which third of the concentration and time arrays the observation index referred to and returned either the $\mathrm{D}_{2} \mathrm{O}$, (HOD) 2 , or uncoupled HOD calculated concentration value to the NLLSQ calling subroutine. By calling YCALC for every observation a calculated array of concentrations values was determined for subsequent refinement of the transfer and rotational rate constants.

NLLSQ solved for $k_{t}$ and $k_{r}$ by iterative improvements of the initial guessed $k_{t}$ and $k_{r}$ rate constants. When the iteration failed to yield any significant improvement of $k_{t}$ and $k_{r}$ and specific internal convergence criteria were met, the iteration was stopped and the final computed concentration and time arrays along with the final $k_{t}$ and $k_{r}$ values were printed. By examining the root mean square deviation of fit and comparing the calculated versus observed values a judgement was made on the success of the least square fit for the model being tested. Most of the datasets were fit within 6-8 iterative cycles with good convergence criteria using the double equilibrium model. The single equilibrium model was less successful. To avoid the possibility of having converged on a local minima different initial $k_{t}$ and $k_{r}$ values were tried to see if the final results differed. A copy of NLLSQ with YCALC programmed for the double equilibrium model is included in Appendix C. Also included is sample input, output, and a written description of the NLLSQ nonlinear least square subroutine. 
To determine the activation energies associated with the transfer and rotational rate constants the Arrhenius expression for kinetic rate constant temperature dependence was used.

$$
\ln K=\frac{E}{R T}+\ln A
$$

Here, A, the pre-exponential factor, was assumed to be constant. SAS, the Statistical Analysis System, marketed by the SAS Institute is a system of computer software designed to perform complex or simple statistical analysis of user data. It features a programming language capability, several statistical procedures to perform linear least square analysis, correlation calculations, and line printer or plotter graphing capabilities.

An SAS program ACTIV was written to accomplish the least square analysis of the rate constants versus temperature using equation (3.18). Each least square analysis included the NLLSQ calculated rate constants for all 12 kinetic datasets. A correlation analysis was carried out on the calculated and observed values obtained from the Arrhenius plots. The procedure was then repeated over all 12 kinetic datasets every time the model or a model functional constant was changed. An examination of the Arrhenius plots and calculated correlation values permitted an evaluation on which models gave the best, most consistent activation energies, and what range of error is expected in the activation energy values. A listing of ACTIV is included in Appendix D. 
CHAPTER IV

\section{RESULTS AND CONCLUSIONS}

\section{Spectral and Concentration Data}

One of the by-products of resolving the OD stretch multiplet at 2000-2800 $\mathrm{cm}^{-1}$ was an uncluttered look at the coupled HOD in and out-of-phase modes. Figure 31 illustrates one of the better (HOD) 2 spectrum collected. This particular spectrum was obtained at $145 \mathrm{~K}$ at $17 \mathrm{~min}$ into the exchange reaction. The in-phase component is located at $2404 \mathrm{~cm}^{-1}$ and the out-of-phase component at 2446 $\mathrm{cm}^{-1}$, thus yielding a $42 \mathrm{~cm}^{-1}$ split. The peak absorbance ratio of the two peaks is .70 but the intensity or band areas are almost equal. This is due to the in-phase bandwidth measuring $32 \mathrm{~cm}^{-1}$ while the outof-phase component is $35 \mathrm{~cm}^{-1}$.

This is in excellent agreement with Haas and Hornig's (22) coupled HOD split of $49 \mathrm{~cm}^{-1}$ with frequencies of $2442 \mathrm{~cm}^{-1}$ and $2393 \mathrm{~cm}^{-1}$. However, Haas and Hornig's spectra were obtained at $190 \mathrm{~K}$. Thus allowing for temperature shifts, the agreement is excellent indeed. The peak height ratios of the present work are comparable to those of Haas and Hornig but their predicted 2 to 1 intensity ratio does not agree with the present work. This is probably due to their inability to resolve the HOD couplet and obtain a more quantitative measurement of band areas.

One interesting feature of the (HOD) ${ }_{2}$ doublet is the 35 and 32 


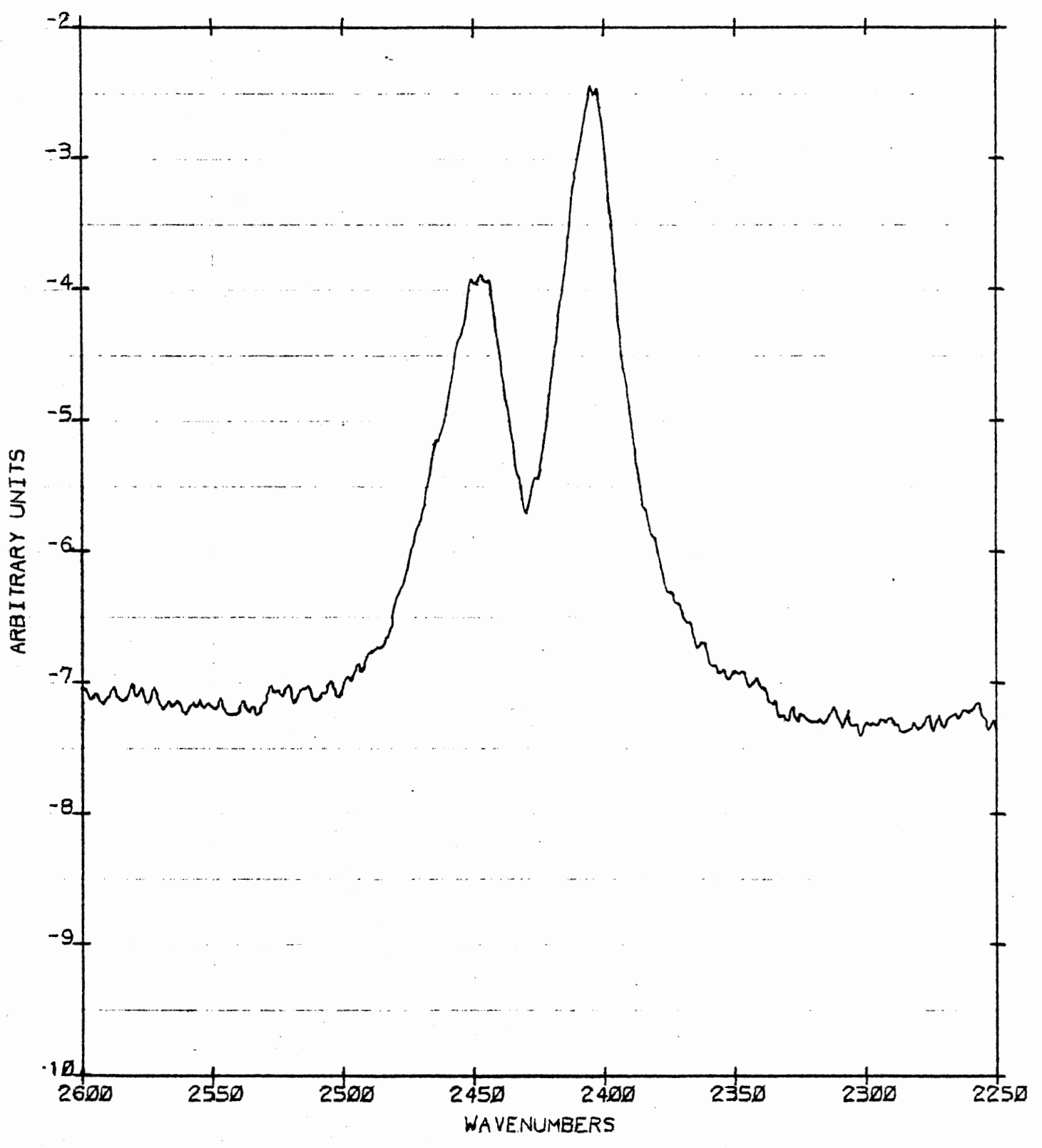

Figure 31. Coupled HOD Absorbance Spectrum of $145 \mathrm{~K}$ 
$\mathrm{cm}^{-1}$ bandwidths which are about $50 \%$ wider than the $\mathrm{D}_{2} \mathrm{O}$ and uncoupled HOD bandwidths. Both the $\mathrm{D}_{2} \mathrm{O}$ and uncoupled HOD oscillators have exactly one possible configuration if the surrounding $\mathrm{H}_{2} \mathrm{O}$ network is ignored. However the (HOD) 2 oscillator has two possible configurations for the hydrogens valence bonded to the two coupled OD oscillators as shown in Figure 32a. This may explain the extra band breadth observed.

Occasionally in some (HOD) 2 spectra an extra wing or band was observed around $2460 \mathrm{~cm}^{-1}$. The intensity would vary from a slight shoulder to an intense peak as shown in Figure 32b. Usually the shoulder would appear in initially collected spectra and quickly disappear as the exchange reaction occurred. A clue to the origin of this shoulder band was discovered when a few ice deposits made at $125 \mathrm{~K}$ instead of $130 \mathrm{~K}$ were more seriously affected by this band. A check of the lower 135 and $140 \mathrm{~K}$ runs revealed that when the band occurred at these temperatures it dissipated less rapidly than at the higher temperature kinetic runs. The $v_{3}$ band of $\mathrm{D}_{2} \mathrm{O}$ is the most intense feature of the initial ice deposit. If the deposit was slighty amorphous the $v_{3}$ band would be slightly amorphous in character, and hence have a slightly greater bandwidth. But since the $\mathrm{D}_{2} \mathrm{O}$ band being subtracted out was fully crystalline, in resolving the (HOD) 2 spectrum any residual amorphous character of $\nu_{3}$ would not be subtracted and show up as a wing or band near the $\nu_{3}$ frequency. As the deposit started to exchange at a higher temperature the ice deposit would quickly anneal and likewise any amorphous character of $\nu_{3}$ would disappear. Therefore this wing was regarded as an amorphous residue and discounted as a spectrally significant feature when it occasionally 

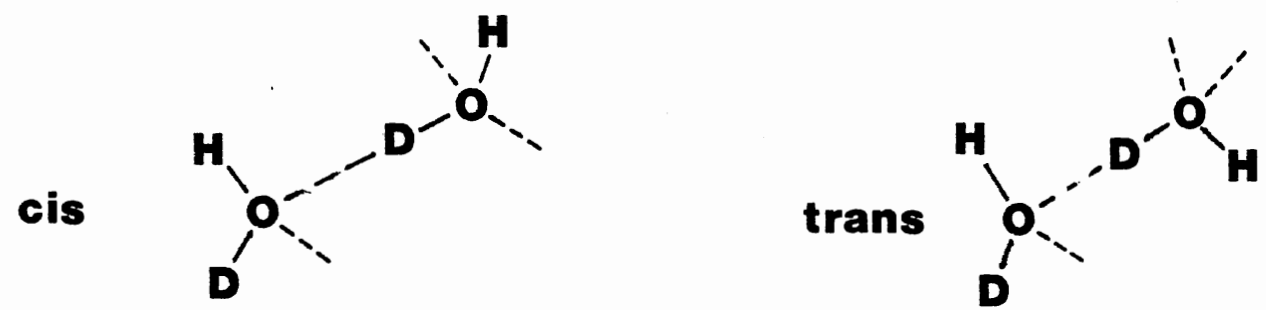

Figure 32a. Possible Coupled Configurations in Cubic Ice Lattice

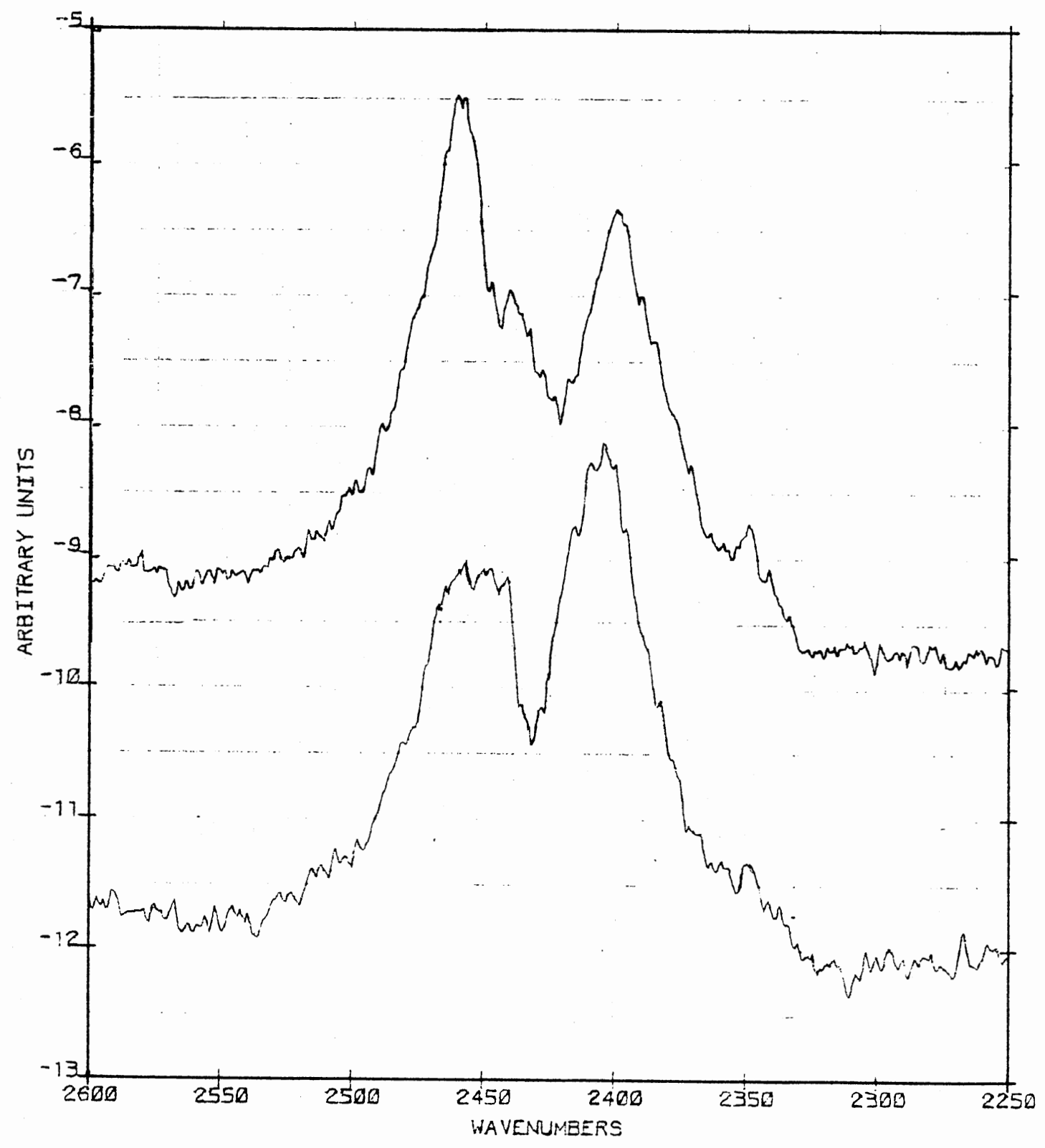

Figure 32b. Amorphous Induced Bands in Coupled HOD Bandshapes 
appeared.

In Table IV the higher temperature (150 K, $145 \mathrm{~K})$ deposits exchanged more completely. Likewise, the error for fitting the kinetic dataset was greatest for $150 \mathrm{~K}$ and $145 \mathrm{~K}$ and least for the $135 \mathrm{~K}$ temperature datasets. In the $150 \mathrm{~K}$ datasets and most of the $145 \mathrm{~K}$ datasets the reaction was followed through at least three halflives of the $D_{2} O$ concentrations. Thus they should provide a fairly rigorous test of the models proposed. The interesting facet of all the datasets is the extensive retardation of the reaction rates after about one to two $\mathrm{D}_{2} \mathrm{O}$ half-lives. The reaction appears to follow an initial first order decay in $\mathrm{D}_{2} \mathrm{O}$ concentration until the concentration level of all species is sufficiently low so that the feedback mechanisms present in the isotopic exchange mechanism becomes important. At that time large concentration changes appear to be stymied by the various back reactions.

\section{Nonlinear Least Square Strategy}

When fitting the one-equilibrium model to the kinetic data, the error became large near the completion of the data. Thus to improve the accuracy of the fit the latter data points of the 150, 145, and $140 \mathrm{~K}$ datasets were deleted. At least $1.5 \mathrm{D}_{2} \mathrm{O}$ concentration halflives worth of data were retained in each dataset. Though a more acceptable fit was obtained, the accuracy of the fit is questionable. Table VII lists the rate constants obtained from this fit and Figure 33 displays the calculated and experimental relative concentration values for the $150 \mathrm{~K} 6 / 7 / 82$ dataset.

As observed in Figure 33 there is difficulty in fitting the 
TABLE VII

LEAST SQUARE CALCULATED RATE CONSTANTS FOR ONE AND TWO EQUILIBRIUM MODELS

\begin{tabular}{|c|c|c|c|c|c|c|c|c|}
\hline \multirow{2}{*}{$\begin{array}{c}\text { Model } \\
\mathrm{F}^{\mathrm{a}} \\
\text { Initial } \mathrm{HOD}_{21} \mathrm{~b} \\
\text { data } \\
\text { Dataset }\end{array}$} & \multicolumn{2}{|c|}{$\begin{array}{c}\text { One equil. } \\
.73684 \\
- \\
\text { shortened }\end{array}$} & \multicolumn{2}{|c|}{$\begin{array}{c}\text { Two equil. } \\
.73684 \\
0.0 \\
\text { ful1 }\end{array}$} & \multicolumn{2}{|c|}{$\begin{array}{c}\text { Two equil. } \\
.73684 \\
0.25 \\
\text { full }\end{array}$} & \multicolumn{2}{|c|}{$\begin{array}{c}\text { Two equil. } \\
.73684 \\
0.5 \\
\text { ful1 }\end{array}$} \\
\hline & $\mathrm{K}_{\text {trans }}$ & $\mathrm{K}_{\text {rot }}$ & $\mathrm{K}_{\text {trans }}$ & $\mathrm{K}_{\text {rot }}$ & $\mathrm{K}_{\text {trans }}$ & $\mathrm{K}_{\text {rot }}$ & $\mathrm{K}_{\text {trans }}$ & $\mathrm{K}_{\text {rot }}$ \\
\hline \multicolumn{9}{|l|}{$150 \mathrm{~K}$} \\
\hline $\begin{array}{l}2 / 2 / 82 \\
\text { RMSD } \\
6 / 7 / 82 \\
\text { RMSD } \\
6 / 9 / 82 \\
\text { RMSD }\end{array}$ & $\begin{array}{r}.21300 \\
1 \\
.13660 \\
.079542 \\
.\end{array}$ & $\begin{array}{l}.21830 \\
.19843 \\
.20734\end{array}$ & $\begin{array}{r}.17495 \\
.11100 \\
.068384 \\
.\end{array}$ & $\begin{array}{l}.28568 \\
.29613 \\
.31804\end{array}$ & $\begin{array}{r}.17496 \\
.11115 \\
.068654 \\
.\end{array}$ & $\begin{array}{l}.36879 \\
.42103 \\
.50200\end{array}$ & $\begin{array}{r}.17430 \\
.11099 \\
.068748 \\
.\end{array}$ & $\begin{array}{r}.52666 \\
.74646 \\
1.4265\end{array}$ \\
\hline \multicolumn{9}{|l|}{$145 \mathrm{~K}$} \\
\hline $\begin{array}{l}1 / 29 / 82 \\
\text { RMSD } \\
5 / 10 / 82 \\
\text { RMSD } \\
5 / 24 / 82 \\
\text { RMSD } \\
6 / 3 / 83 \\
\text { RMSD }\end{array}$ & $\begin{array}{r}.079151 \\
1 \\
.042268 \\
.082043 \\
.042662 \\
.\end{array}$ & $\begin{array}{r}.077733 \\
.061057 \\
.069061 \\
.068473\end{array}$ & $\begin{array}{r}.059852 \\
.033598 \\
.061907 \\
.032988\end{array}$ & $\begin{array}{r}.089019 \\
.075077 \\
.074030 \\
.088568\end{array}$ & $\begin{array}{r}.059440 \\
.034035 \\
.061634 \\
.033011 \\
.\end{array}$ & $\begin{array}{l}7^{10920} \\
.11292 \\
.096254 \\
.11470\end{array}$ & $\begin{array}{r}.058936 \\
.034340^{\circ} \\
.061115^{\circ} \\
.032995^{\circ} \\
.\end{array}$ & $\begin{array}{l}.14205 \\
.23085 \\
.13880 \\
.16417\end{array}$ \\
\hline \multicolumn{9}{|l|}{$140 \mathrm{~K}$} \\
\hline $\begin{array}{l}5 / 11 / 82 \\
\text { RMSD } \\
5 / 25 / 82 \\
\text { RMSD }\end{array}$ & $\begin{array}{r}.018463 \\
.011992 \\
.\end{array}$ & $\begin{array}{r}.023522 \\
.017621\end{array}$ & $\begin{array}{r}.014124 \\
.0092350\end{array}$ & $\begin{array}{r}.023192 \\
.019506\end{array}$ & $\begin{array}{r}.014096 \\
.0092242 \\
.2\end{array}$ & $\begin{array}{l}.028898 \\
.025360\end{array}$ & $\begin{array}{r}.014048 \\
.0092238 \\
.\end{array}$ & $\begin{array}{l}.038439 \\
.036234\end{array}$ \\
\hline
\end{tabular}


TABLE VII (Continued)

\begin{tabular}{|c|c|c|c|c|}
\hline $\begin{array}{c}\text { Mode1 } \\
\mathrm{F}^{\mathrm{a}} \\
\begin{array}{c}\text { Initial } \mathrm{HOD}_{21} \mathrm{~b} \\
\text { data }\end{array}\end{array}$ & $\begin{array}{c}\text { One equil. } \\
, 73684 \\
- \\
\text { shortened }\end{array}$ & $\begin{array}{l}\text { Two equil. } \\
.73684 \\
0.0 \\
\text { ful1 }\end{array}$ & $\begin{array}{c}\text { Two equil. } \\
.73684 \\
0.25 \\
\text { ful1 }\end{array}$ & $\begin{array}{c}\text { Two equil. } \\
.73684 \\
0.5 \\
\text { ful1 }\end{array}$ \\
\hline Dataset & $\mathrm{K}_{\text {trans }} \quad \mathrm{K}_{\text {rot }}$ & $\mathrm{K}_{\text {trans }} \mathrm{K}_{\text {rot }}$ & $\mathrm{K}_{\text {trans }} \quad \mathrm{K}_{\text {rot }}$ & $\mathrm{K}_{\text {trans }} \quad \mathrm{K}_{\text {rot }}$ \\
\hline \multicolumn{5}{|l|}{$135 \mathrm{~K}$} \\
\hline $\begin{array}{l}5 / 15 / 82 \\
\text { RMSD } \\
5 / 26 / 82 \\
\text { RMSD } \\
6 / 11 / 82 \\
\text { RMSD }\end{array}$ & $\begin{array}{c}.0042115 .0040228 \\
.0037345^{3258} .0043476 \\
.0038900^{3059} .0047298\end{array}$ & $\begin{array}{c}.0037078 .1997 .0033044 \\
.00313599^{.1491} .0037833 \\
.0033464{ }_{2068}^{.0039339}\end{array}$ & $\begin{array}{c}.0037055 .0040094 \\
.0031316^{.1961} .0046006 \\
.0033437^{.1489} .0046827\end{array}$ & $\begin{array}{c}.0037008 .0050681 \\
.1926 \\
.0031249 .0058465 \\
.1484 \\
.0033392 .0057573 \\
.1979\end{array}$ \\
\hline
\end{tabular}

$a_{\text {Frequency factor; }} F=\left(\frac{\nu_{H}+2 \nu_{D}}{v_{D}+2 v_{H}}\right)$.

$\mathrm{b}_{\text {Initial }} \mathrm{HOD}_{21}$ determined by $\left[\mathrm{HOD}_{21}\right]_{\text {initial }}=$ (table value shown) $\left[\mathrm{HOD}_{12}\right]_{\text {Initial }}$.

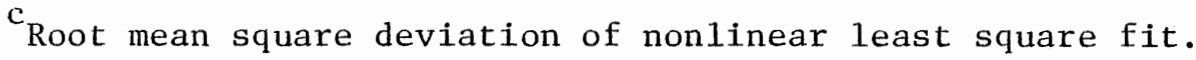




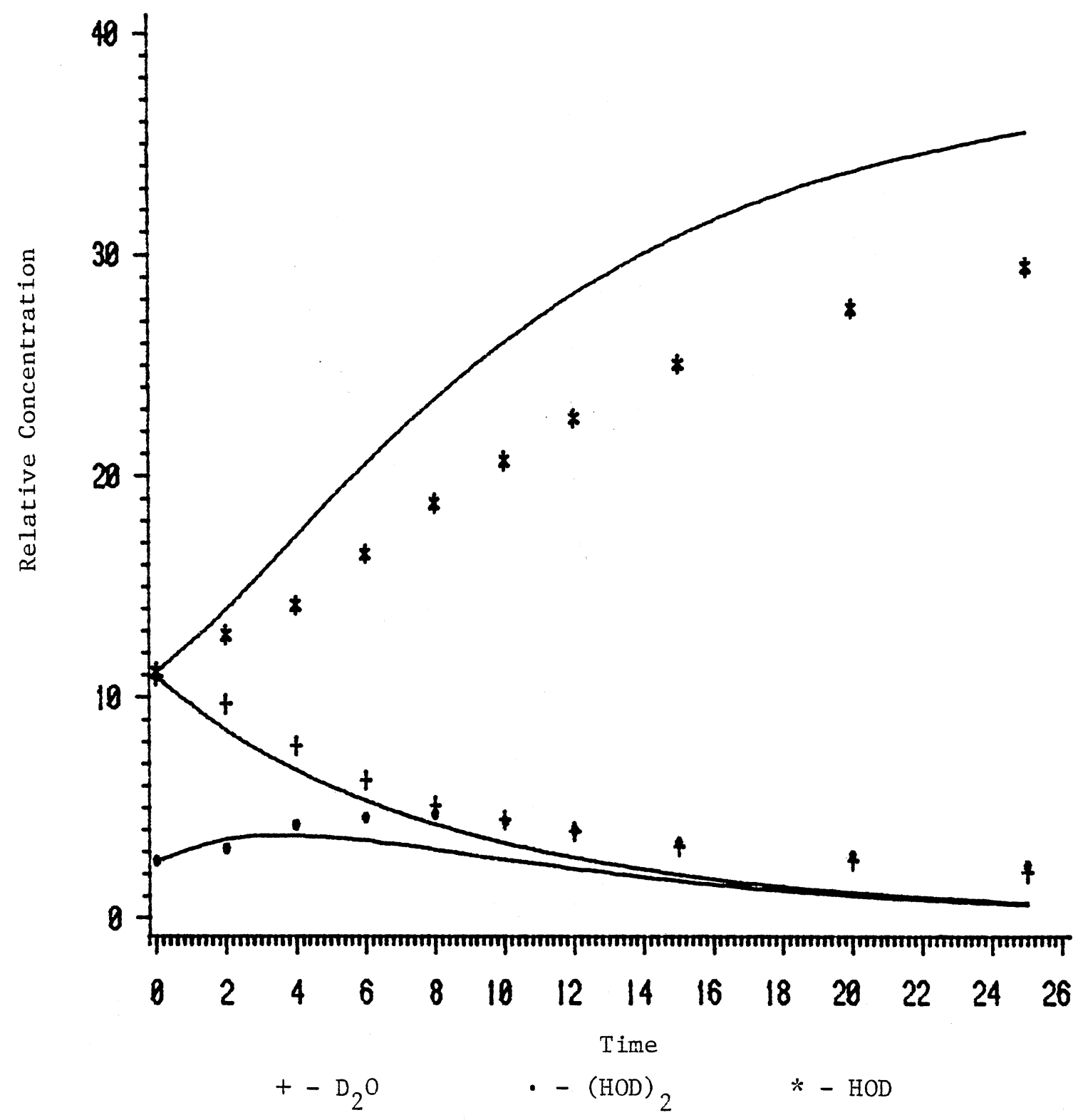

Figure 33. Experimental and One Equilibrium Model Calculated Relative Concentration Curves for 6/7/82 $150 \mathrm{~K}$ Data 
$\left(\mathrm{HOD}_{2}\right.$ ) concentration at the longer time intervals. The lack of back exchange to (HOD) 2 favors a more rapid depletion of (HOD) 2 , thus more quickly eliminating any feedback from (HOD) ${ }_{2}$ to $\mathrm{D}_{2} \mathrm{O}$. As a result both the (HOD) ${ }_{2}$ and $\mathrm{D}_{2} \mathrm{O}$ concentrations fall off too rapidly.

For the two-equilibrium model both the above described shortened datasets and the full datasets were fitted. The full datasets yielded the most consistent results and hence were used for the remainder of the calculations. Several fits were made, each with different initial separated HOD concentrations. Table VII lists the transfer and rotational rate constants found for the three best runs. They are initial separated HOD values of $0.0,0.25 \times$ (HOD $)_{2}$ initial, and $0.5 \times$ (HOD) 2 initial. The root mean square deviation of the fit for each dataset is included beneath each rate constant entry. The $150 \mathrm{~K}$ and $145 \mathrm{~K}$ determined transfer rate constants show the greatest error spread, while the rotational rate constants seem to be more consistent. This is not entirely unexpected. The concentration of hydronium ions in water at $25^{\circ} \mathrm{C}$ is about $1.0 \times 10^{-7}$ moles/liter. So the concentration of ionic defects in ice at $145 \mathrm{~K}$ should be even less. This concentration of defects is less than two parts per billion. It is very difficult to obtain water of this purity. Accordingly the transfer rate constant variance at fixed temperatures is attributed to the ionic defect's sensitivity to small changes in the concentration of impurities in the ice such as arises from normal operation of a vacuum system. So the transfer rate constants 1 isted are assumed to arise from a pure ice deposition situation perturbed by minute contaminations. The fact that the transfer rate constants are so 
sensitive to small contamination changes provides evidence that the ice deposition is pure enough that contamination concentrations are of the same order as the hydronium ion defect concentration. If the contamination was greater, the trapping would be large enough to significantly lower the transfer rates and suppress (HOD) 2 formation as illustrated by Devlin et al. $(46,47)$.

Not surprisingly the rotational rates appear to be more consistent. This may reflect their insensitivity to impurity doping as suggested by Devlin et al. (47).

The transfer rate constants are largely insensitive to the initial separated HOD concentration and corresponding differing rotational rate constants. The rotational rates are affected by the initial separated HOD concentrations as Table VII illustrates. The $.5 \times$ (HOD) 2 initial concentration data has the smallest RMSD of fit but yet this is misleading. The least square analysis showed the .5 calculation to be the least correlated with respect to activation energy plots. In addition for some rate constants the standard error associated with the rotational rate constant was $50 \%$ greater than for the 0.0 , and .25 calculations.

Figures 34-45 show calculated and experimental concentration versus time curves for each dataset. All three two-equilibrium calculations gave practically identical calculated concentration values so the .25 initial $\mathrm{HOD}_{21}, F=.7368$ rate constant calculated concentration values were used. For each graph the symbols represent the experimental data and the lines the corresponding calculated values. Representative extimated error bars are shown for Figure 34 but are omitted from the rest for clarity. 


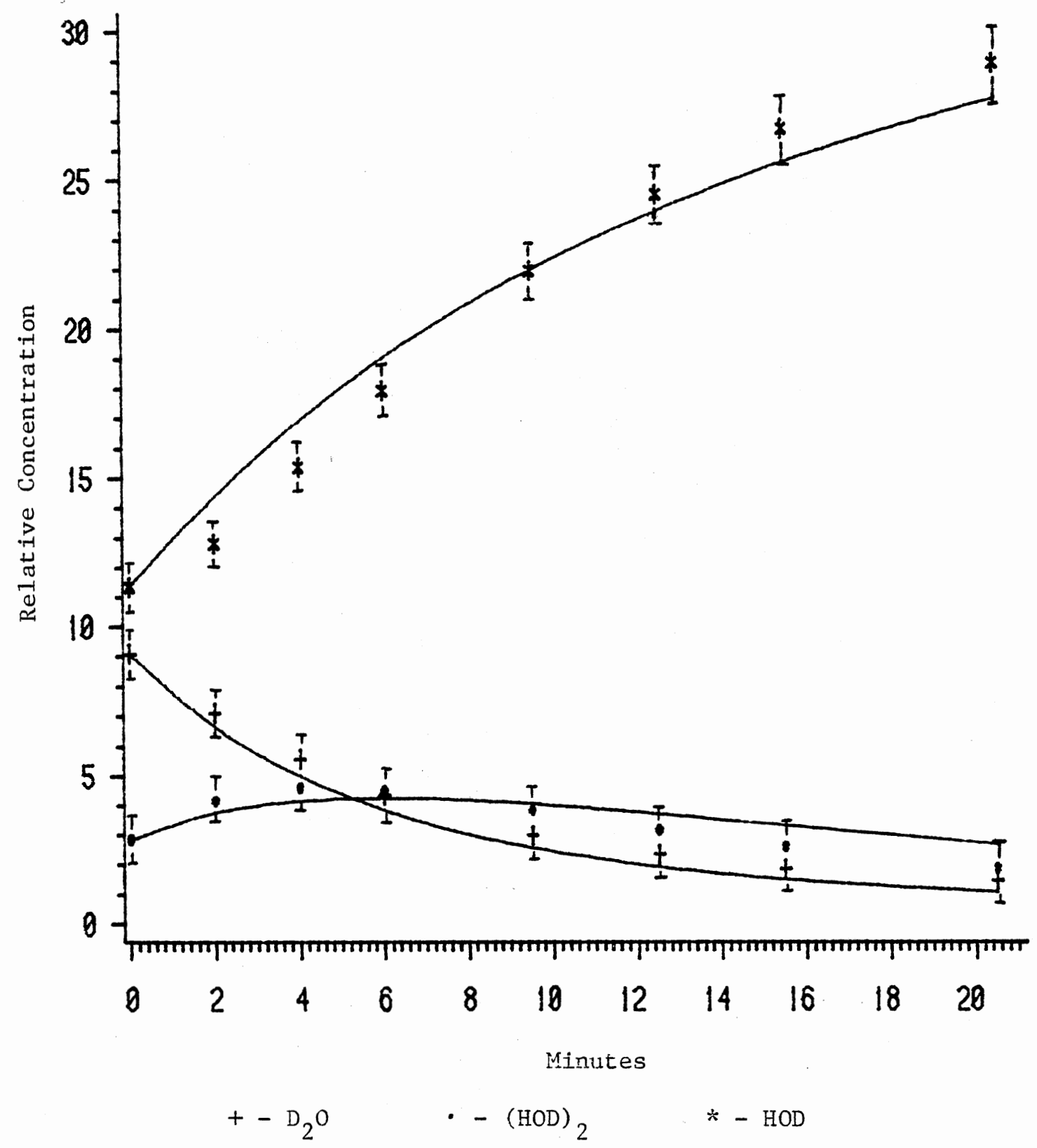

Figure 34. Experimental and Two Equilibrium Model Calculated Relative Concentration Curves for 2/2/82 $150 \mathrm{~K}$ Data 


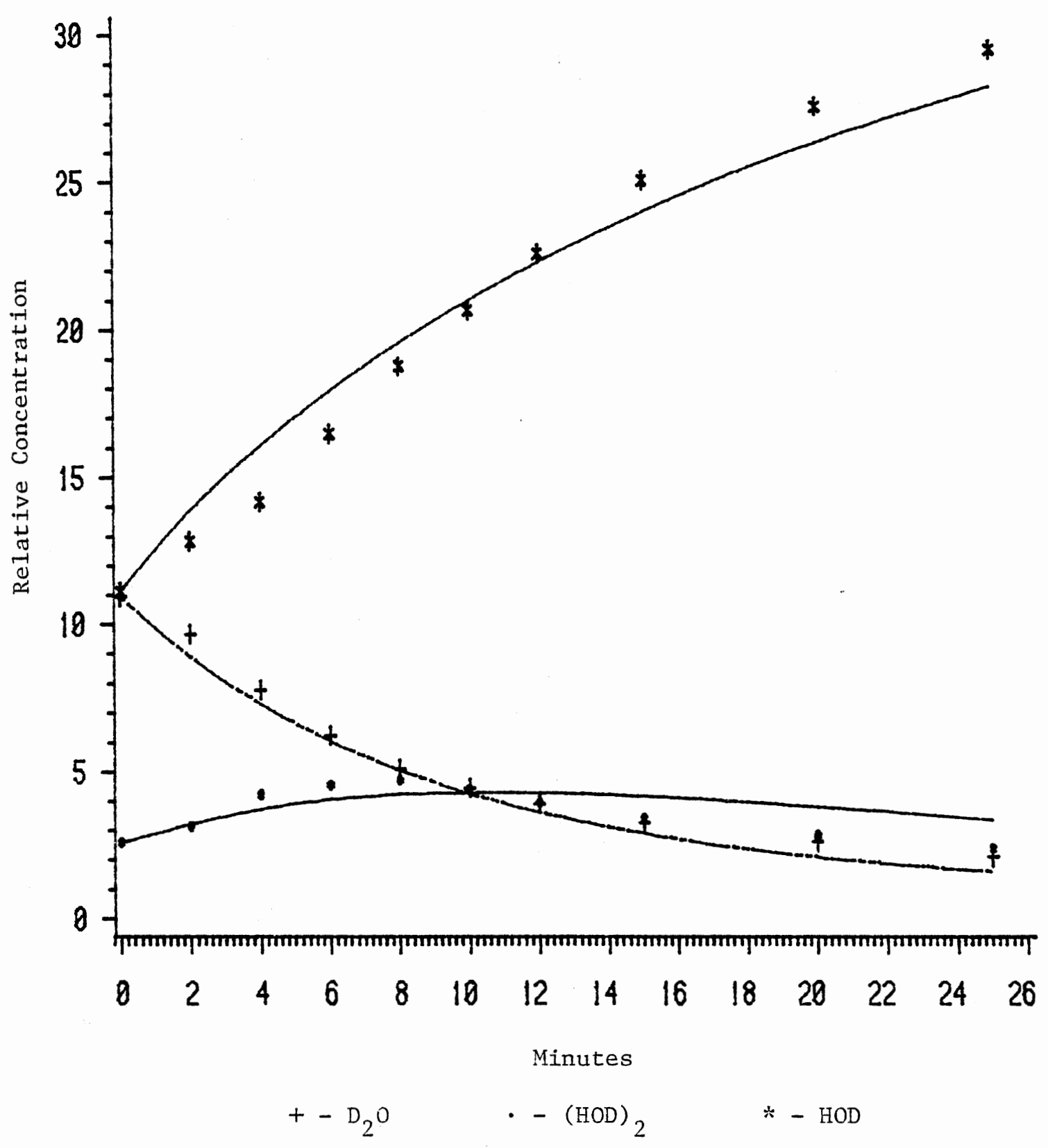

Figure 35. Experimental and Two Equilibrium Model Calculated Relative Concentration Curves for 6/7/82 $150 \mathrm{~K}$ Data 


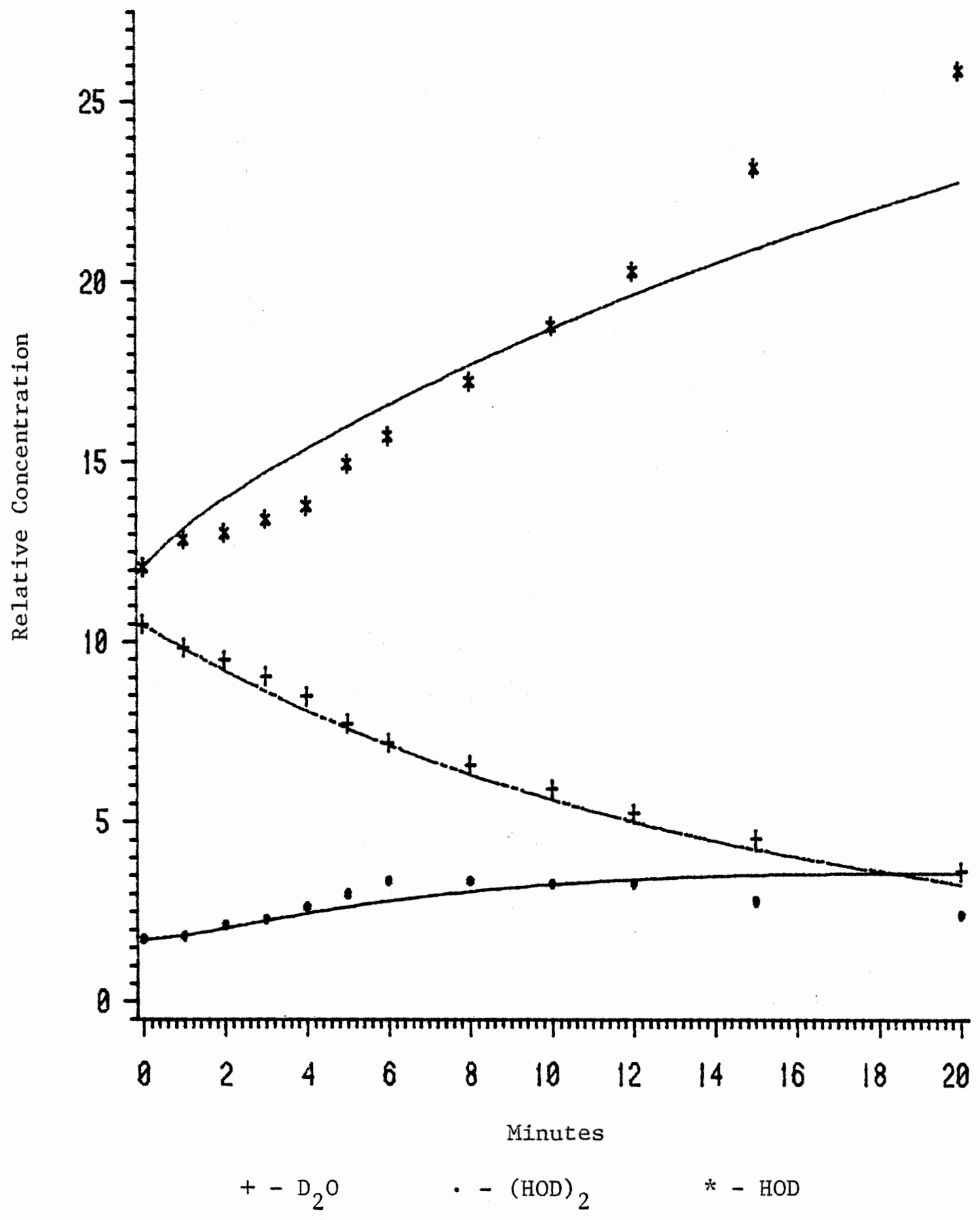

Figure 36. Experimental and Two Equilibrium Model Calculated Relative Concentration Curves for 6/9/82 $150 \mathrm{~K}$ Data 


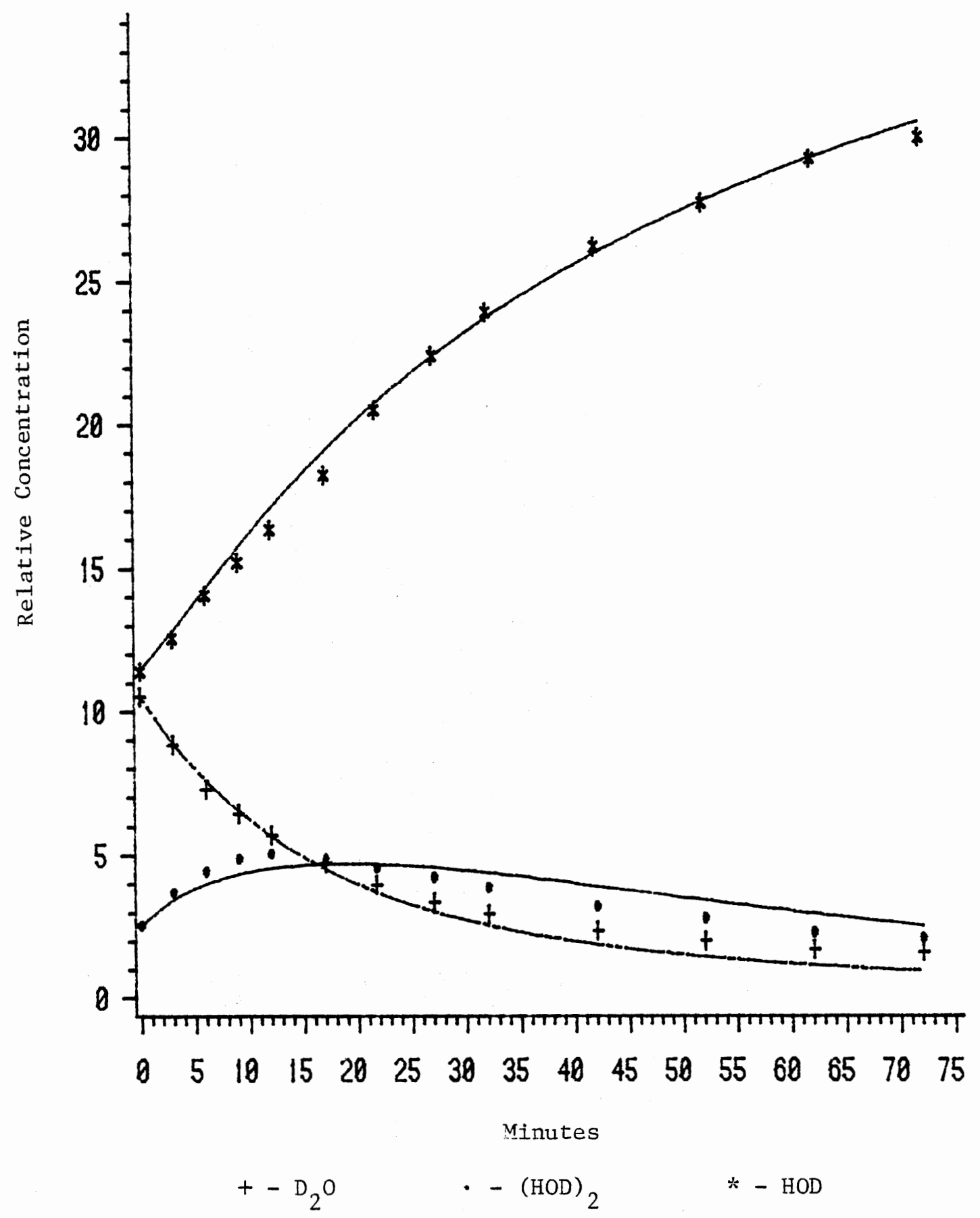

Figure 37. Experimental and Two Equilibrium Model Calculated Relative Concentration Curves for 1/29/82 $145 \mathrm{~K}$ Data 


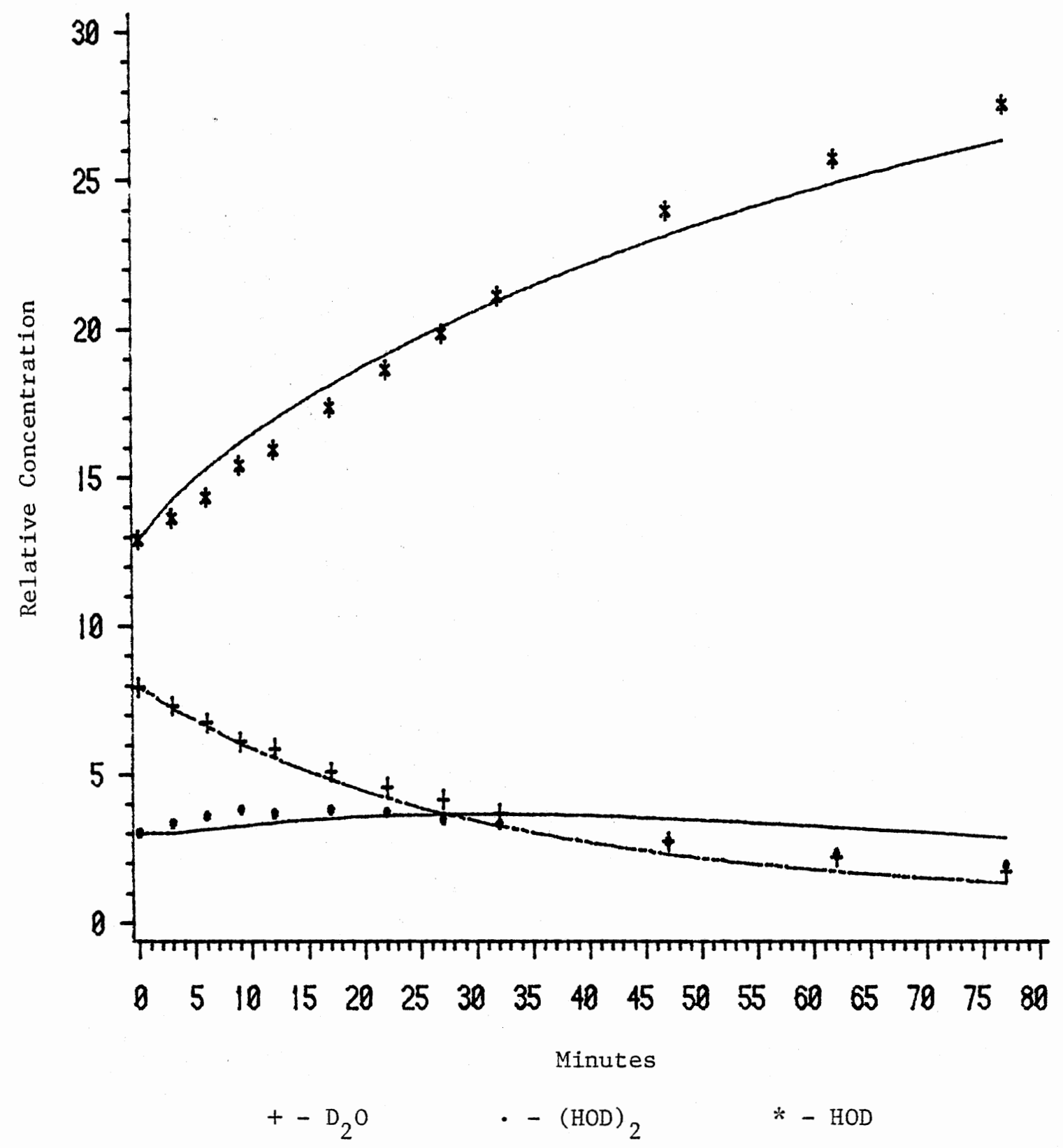

Figure 38. Experimental and Two Equilibrium Model Calculated Relative Concentration Curves for 5/10/82 $145 \mathrm{~K}$ Data 


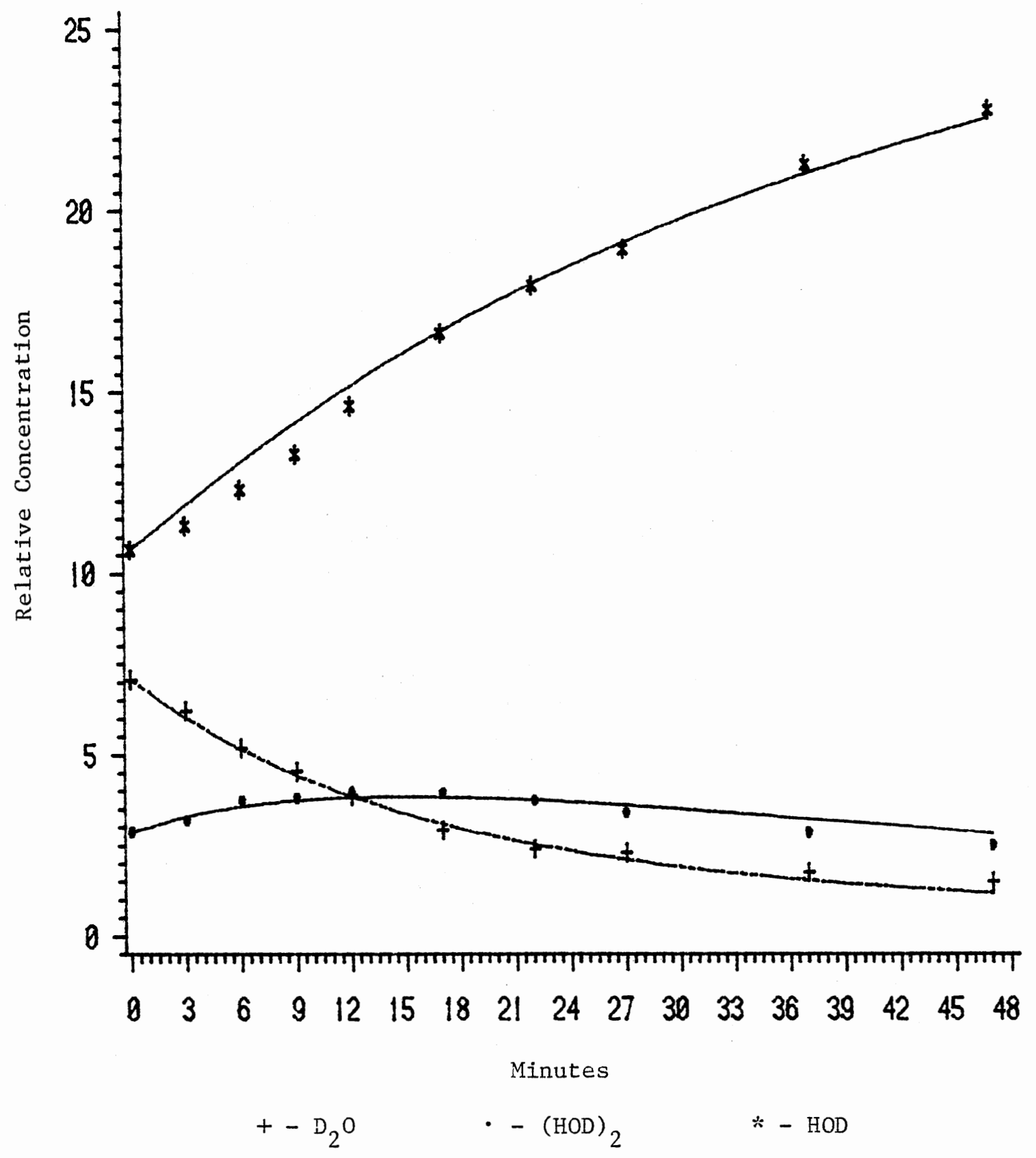

Figure 39. Experimental and Two Equilibrium Model Calculated Relative Concentration Curves for 5/24/82 $145 \mathrm{~K}$ Data 


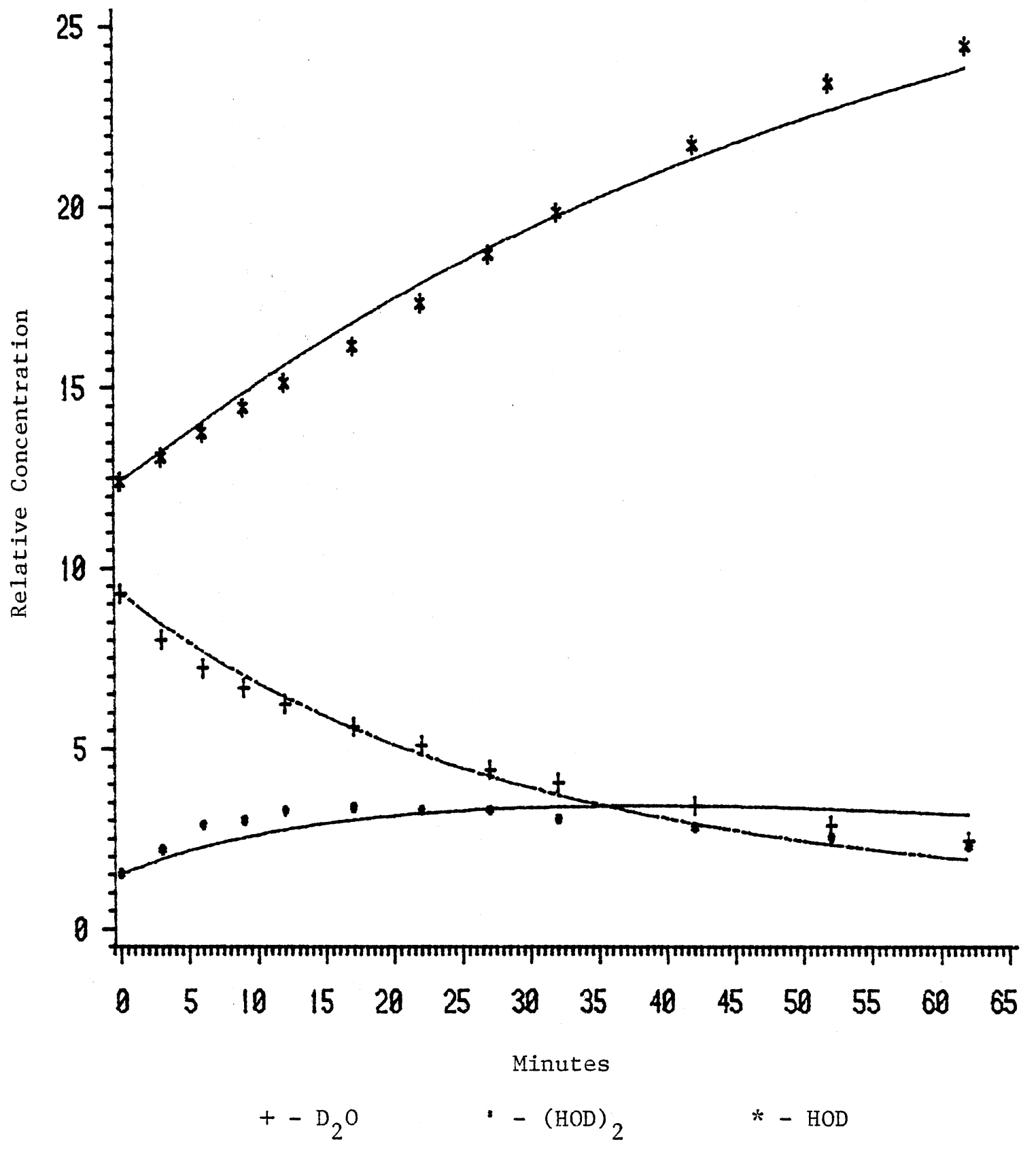

Figure 40. Experimental and Two Equilibrium Model Calculated Relative Concentration Curves for 6/3/82 $145 \mathrm{~K}$ Data 


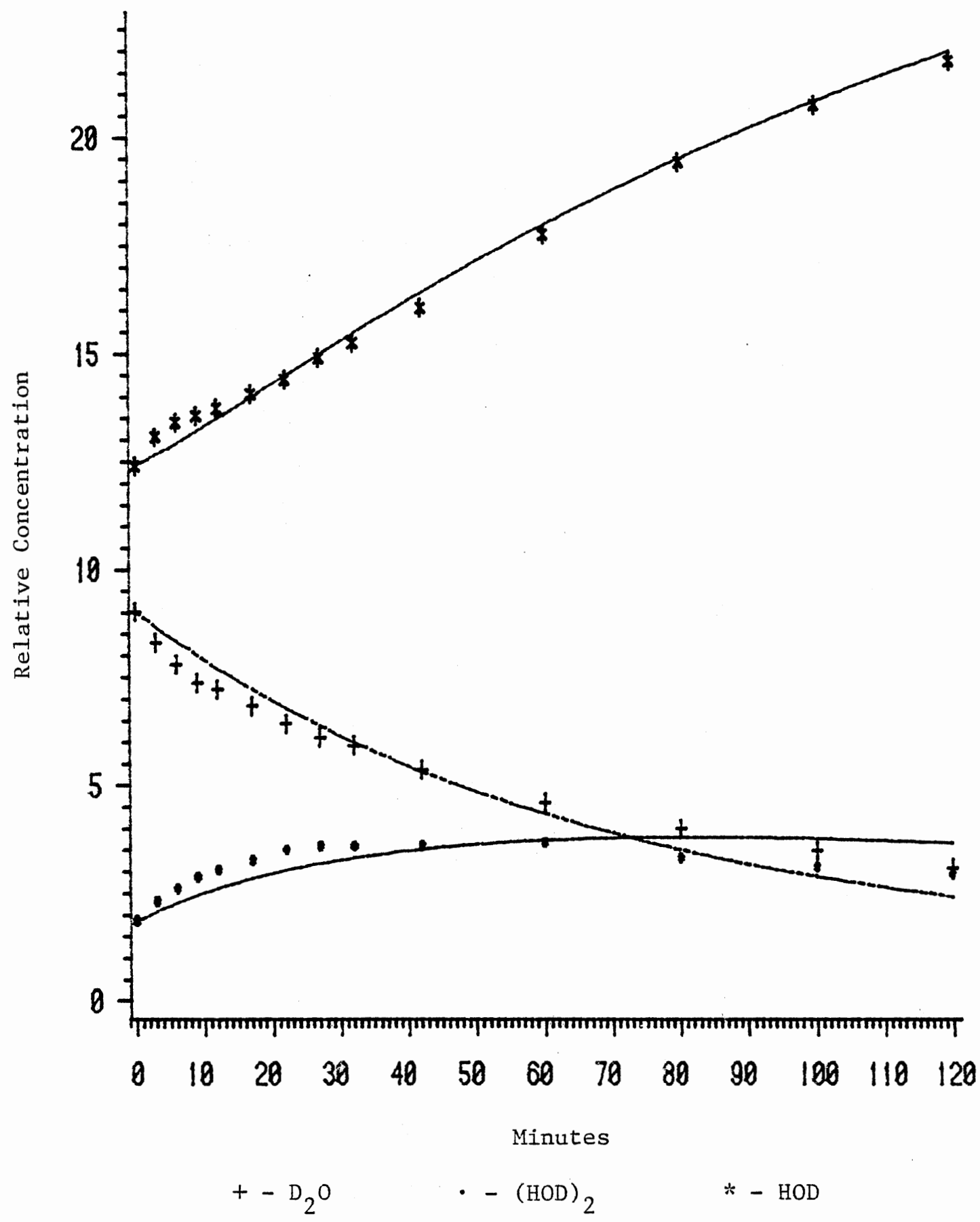

Figure 41. Experimental and Two Equilibrium Model Calculated Relative Concentration Curves for 5/4/82 $140 \mathrm{~K}$ Data 


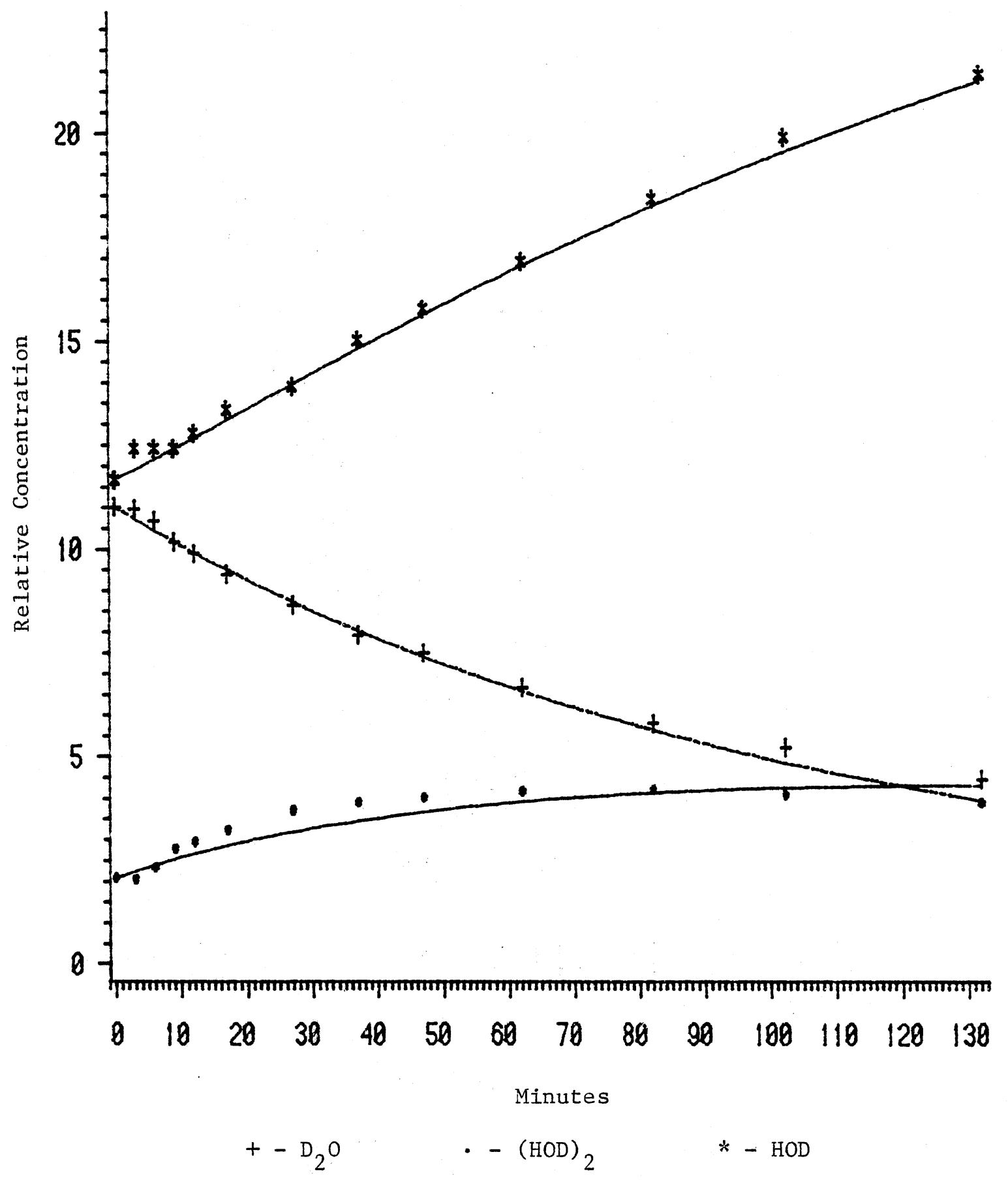

Figure 42. Experimental and Two Equilibrium Model Calculated Relative Concentration Curves for 5/25/82 $140 \mathrm{~K}$ Data 


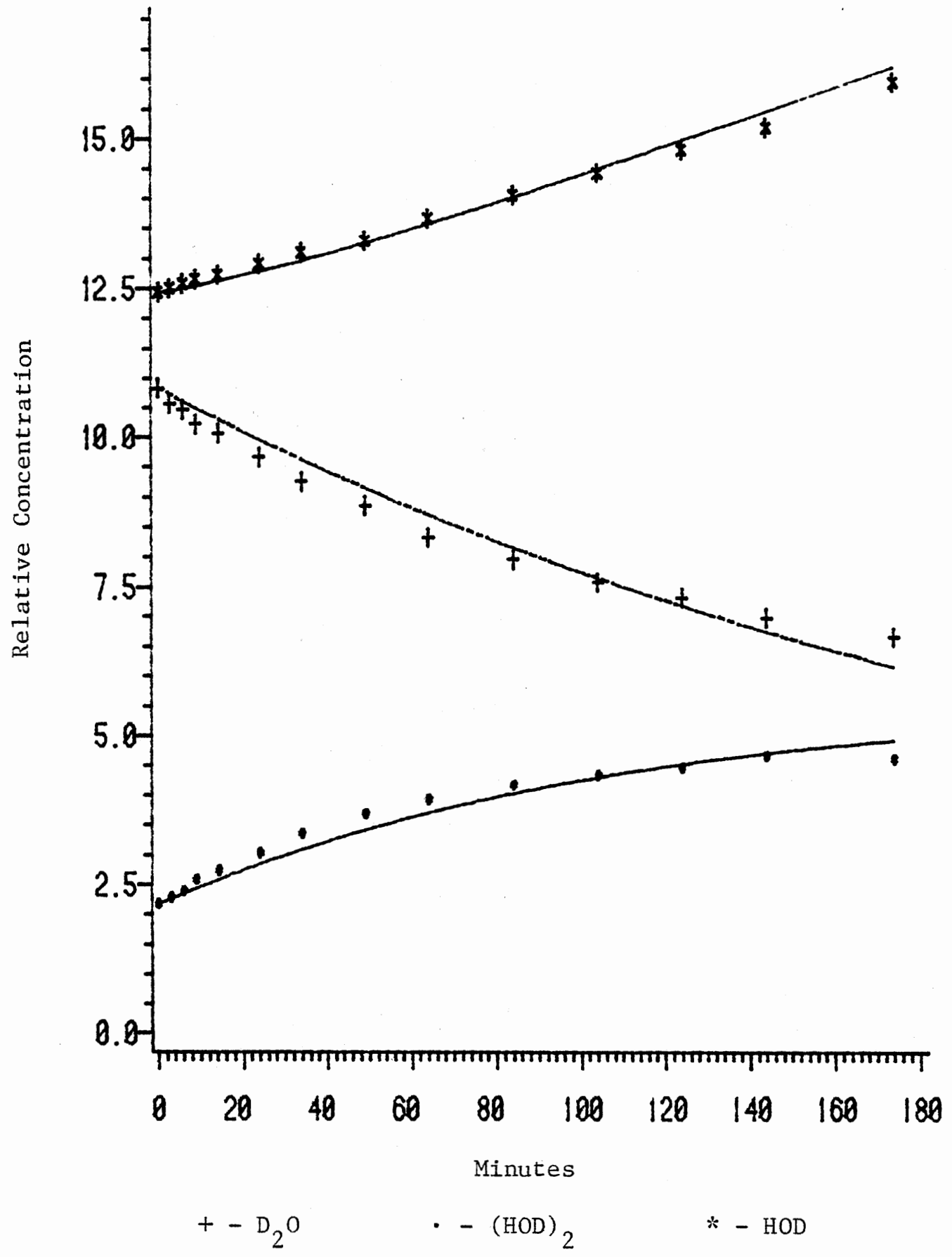

Figure 43. Experimental and Two Equilibrium Model Calculated Relative Concentration Curves for 5/15/83 $135 \mathrm{~K}$ Data 


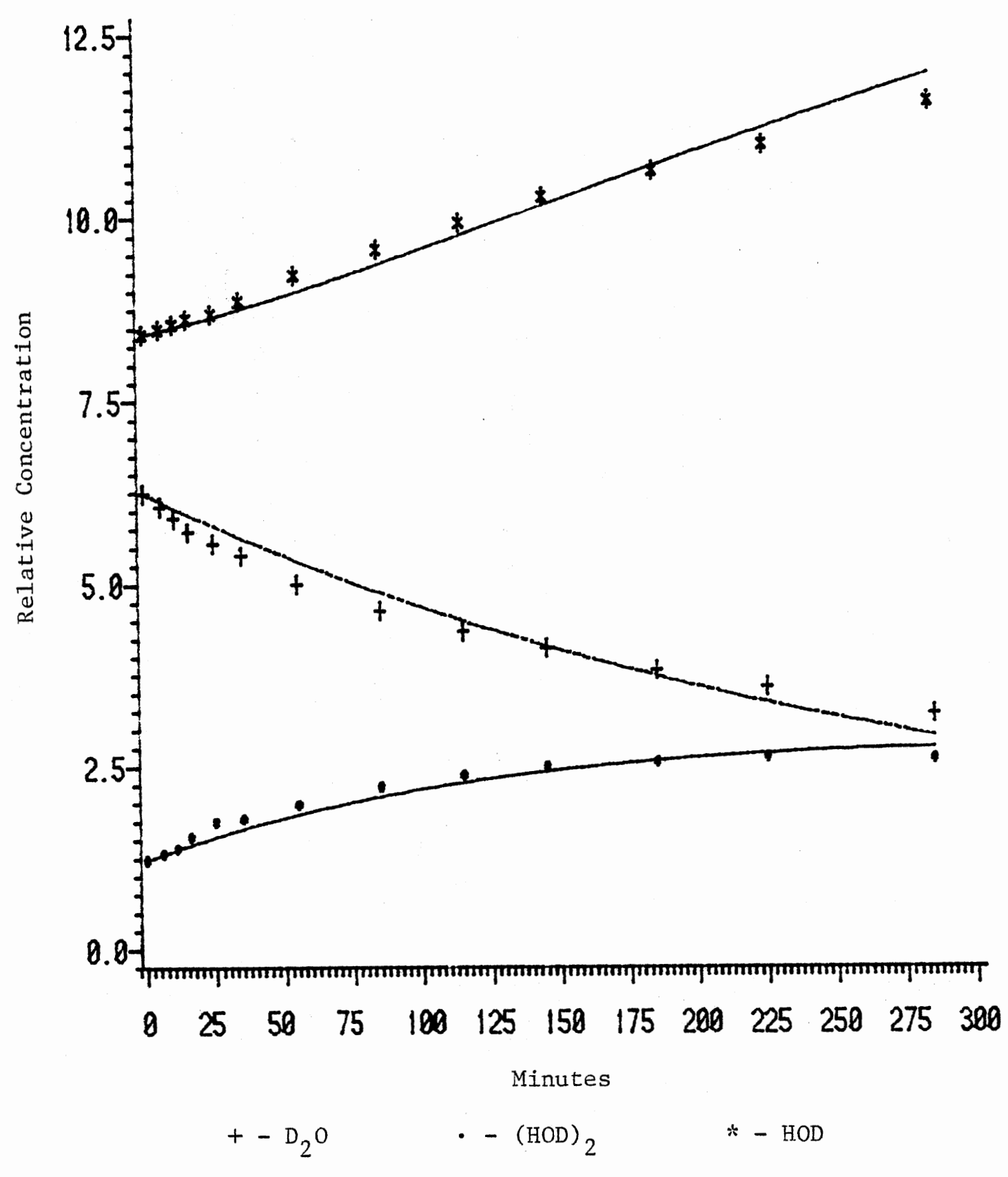

Figure 44. Experimental and Two Equilibrium Model Calculated Relative Concentration Curves for 5/26/82 $135 \mathrm{~K}$ Data 


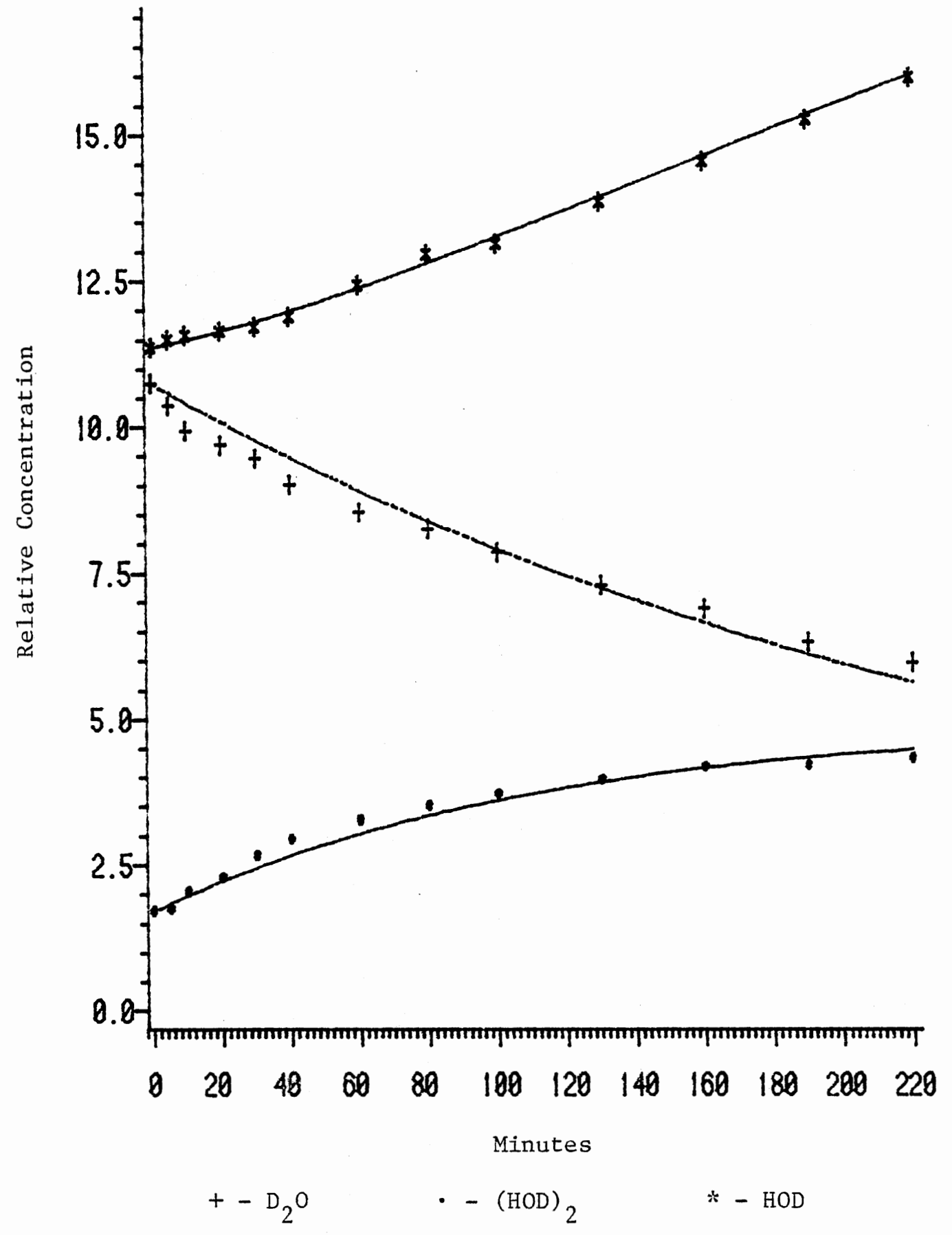

Figure 45. Experimental and Two Equilibrium Model Calculated Relative Concentration Curves for 6/11/82 $135 \mathrm{~K}$ Data 
Figures 46-57 show the calculated $\mathrm{D}_{2} \mathrm{O}_{11}$ and $2 \mathrm{HOD}$ nm configuration concentrations determined from the two-equilibrium model used for Figures $34-45$. The top decaying curve is the $\mathrm{D}_{2} \mathrm{O}$ configuration relative concentration. The increasing curve just below $\mathrm{D}_{2} \mathrm{O}_{11}$ corresponds to the $2 \mathrm{HOD}_{22}$ and higher (fully separated) configuration concentration. Note that the concentration is less than one half the corresponding uncoupled HOD concentrations seen in Figures 34-45. This is because the $2 \mathrm{HOD}_{22}$ concentration includes both HOD units rather than a single HOD unit. Also, the $2 \mathrm{HOD}_{21}$ configuration concentration (separated HOD) is shown separately, rather than added into the $2 \mathrm{HOD}_{22}$ concentration to form the uncoupled HOD shown in Figures 34-45. The lowest intermediary curve in Figures $46-57$ is the $2 \mathrm{HOD}_{21}$ configuration relative concentration (separated HOD). The intermediary curve just above it is the $2 \mathrm{HOD}_{12}$ configuration concentration (coupled HOD). The initial value of $2 \mathrm{HOD}_{21}$ is always one quarter the $2 \mathrm{HOD}_{12}$ concentration as defined in the model. It is interesting to note that the $2 \mathrm{HOD}_{21}$ concentration never exceeds the $2 \mathrm{HOD}_{12}$ concentration in the data shown, but quickly establishes a slightly lower concentration. This is probably due to the equal magnitude of the forward and reverse rotational rate constants between these two configurations.

Compared with the one-equilibrium model, the two-equilibrium model is a significantly better fit, especially at the completion of the exchange reaction. The fit of (HOD) 2 is improved with deviations occurring at two to three $D_{2} O$ half-lives instead of one halflife as in the one-equilibrium model. The two-equilibrium model tends to overestimate the $(\mathrm{HOD})_{2}$ concentration and underestimate the 


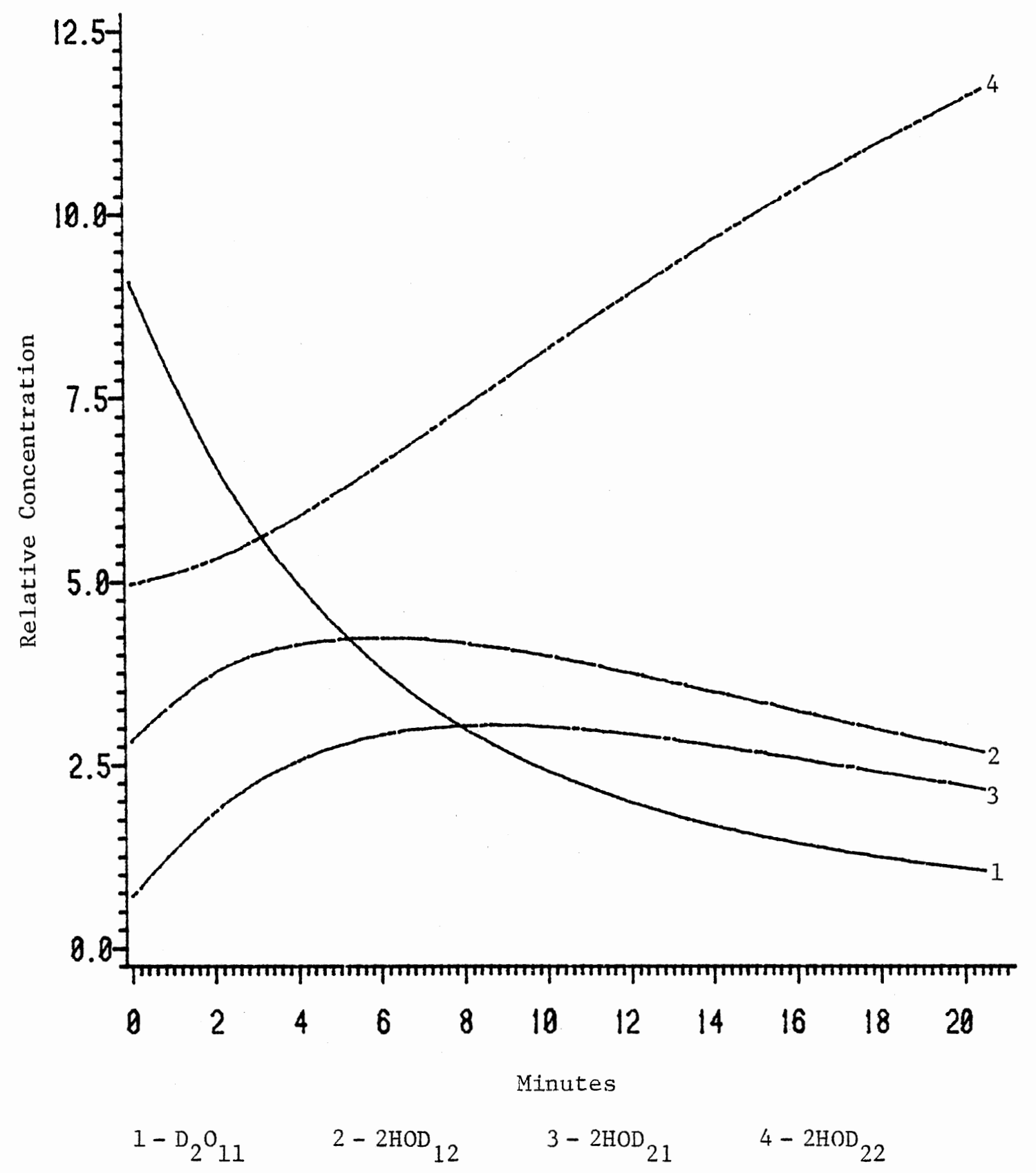

Figure 46. Calculated $\mathrm{D}_{2} \mathrm{O}_{11}$ and $2 \mathrm{HOD}_{\mathrm{nm}}$ Configuration Concentration Curves for $2 / 2 / 82150 \mathrm{~K}$ Data 


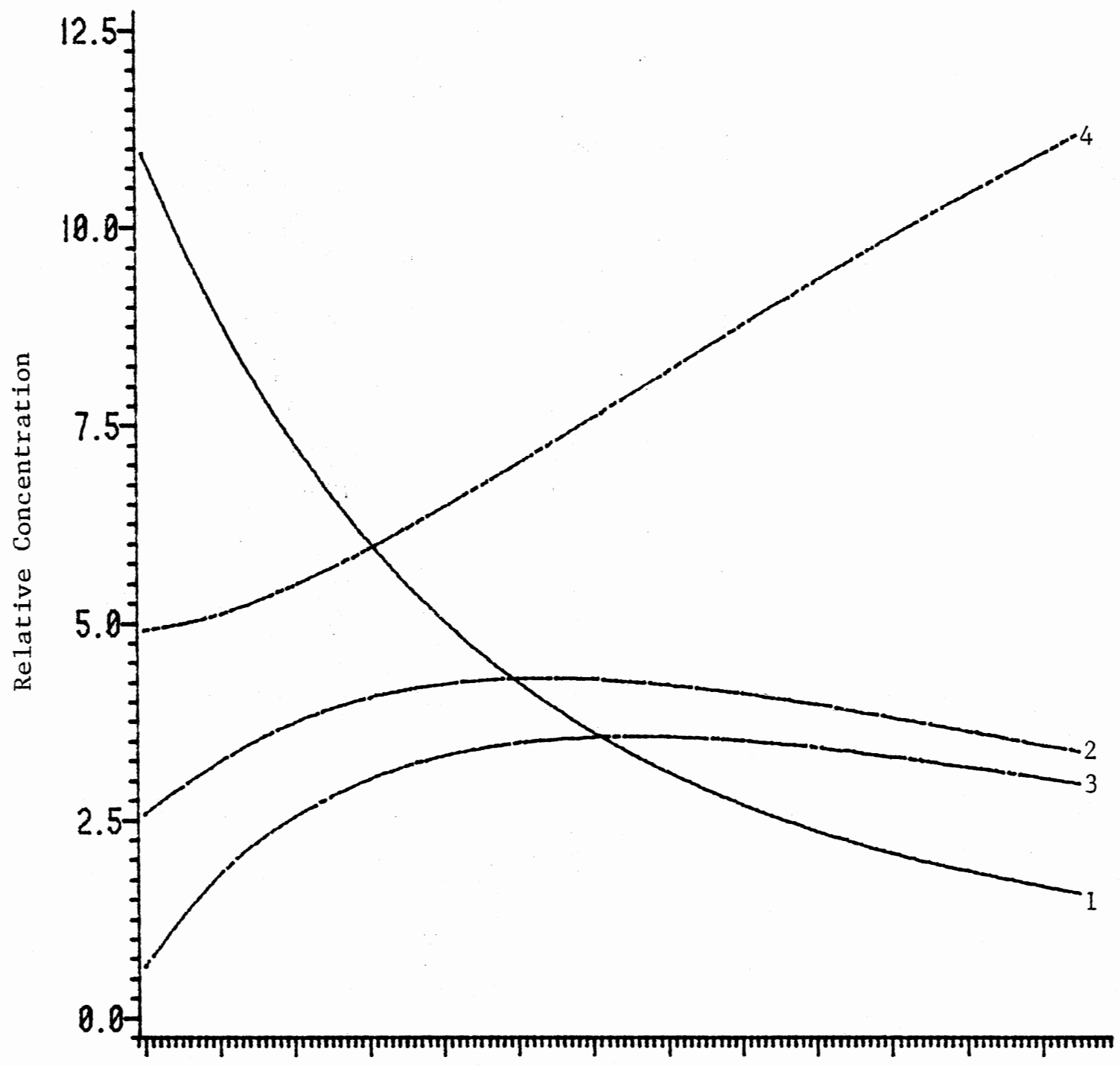

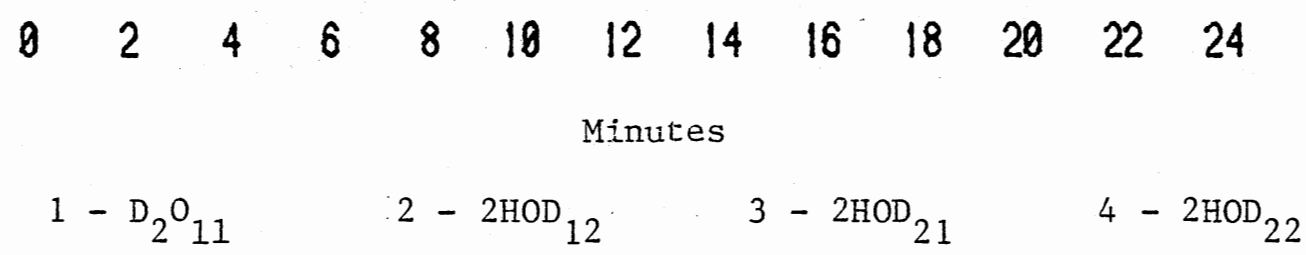

Figure 47. Calculated $\mathrm{D}_{2} \mathrm{O}_{11}$ and $2 \mathrm{HOD}_{\mathrm{nm}}$ Configuration Concentration Curves for $6 / 7 / 82150 \mathrm{~K}$ Data 


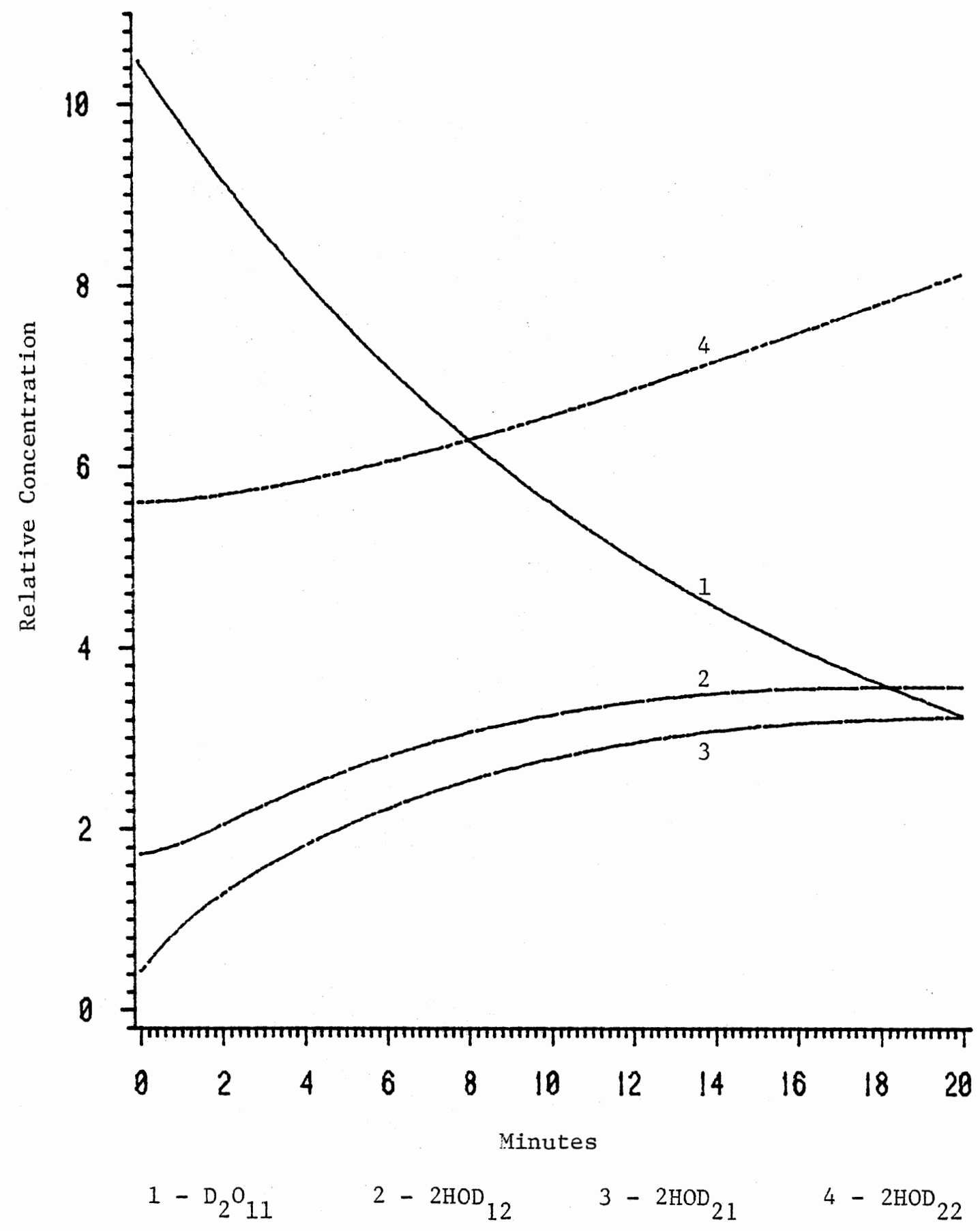

Figure 48. Calculated $\mathrm{D}_{2} \mathrm{O}_{11}$ and $2 \mathrm{HOD}_{\mathrm{nm}}$ Configuration Concentration Curves for $6 / 9 / 82150 \mathrm{~K}$ Data 


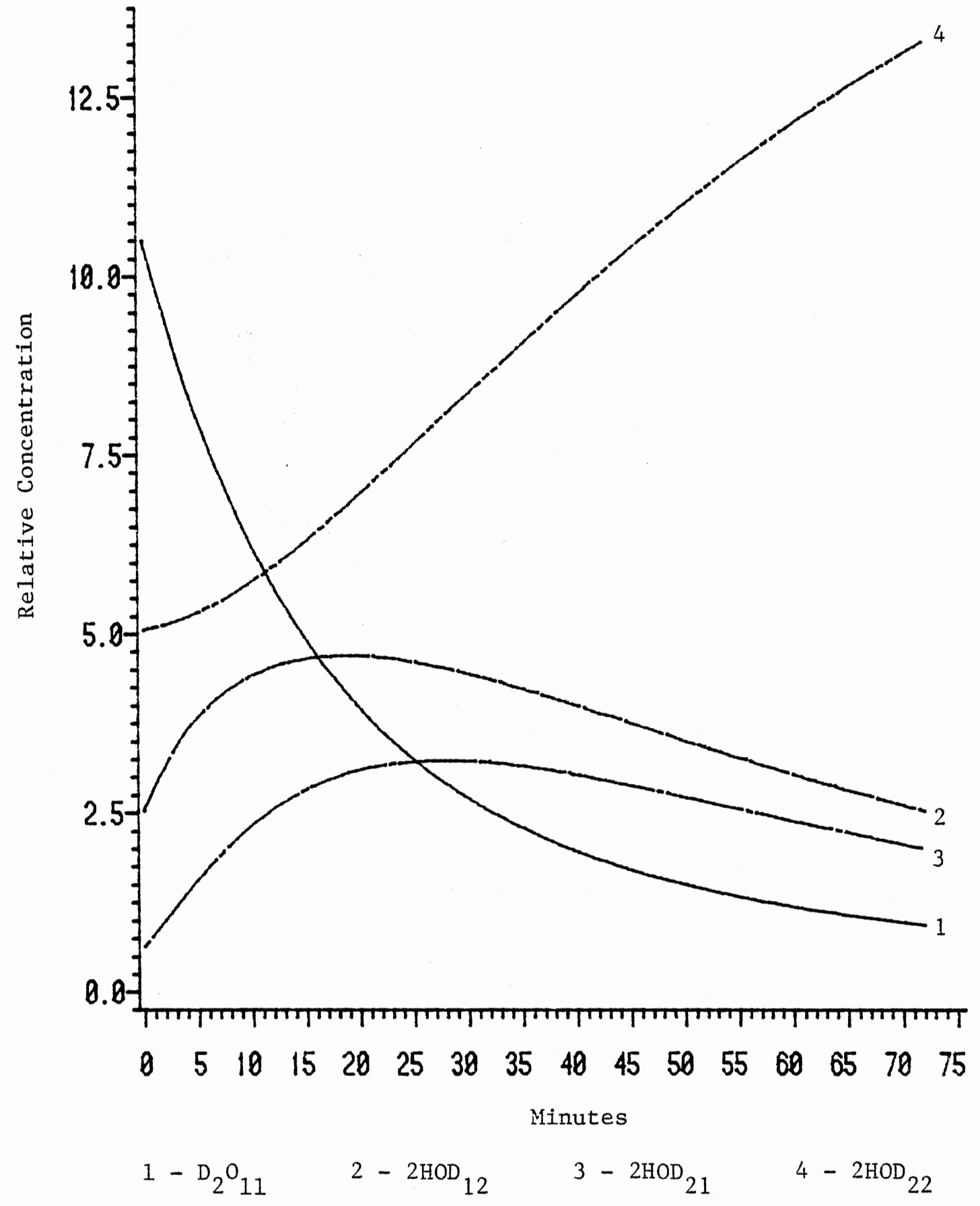

Figure 49. Calculated $\mathrm{D}_{2} \mathrm{O}_{11}$ and $2 \mathrm{HOD}_{\mathrm{nm}}$ Configuration Concentration Curves for $1 / 29 / 82145 \mathrm{~K}$ Data 


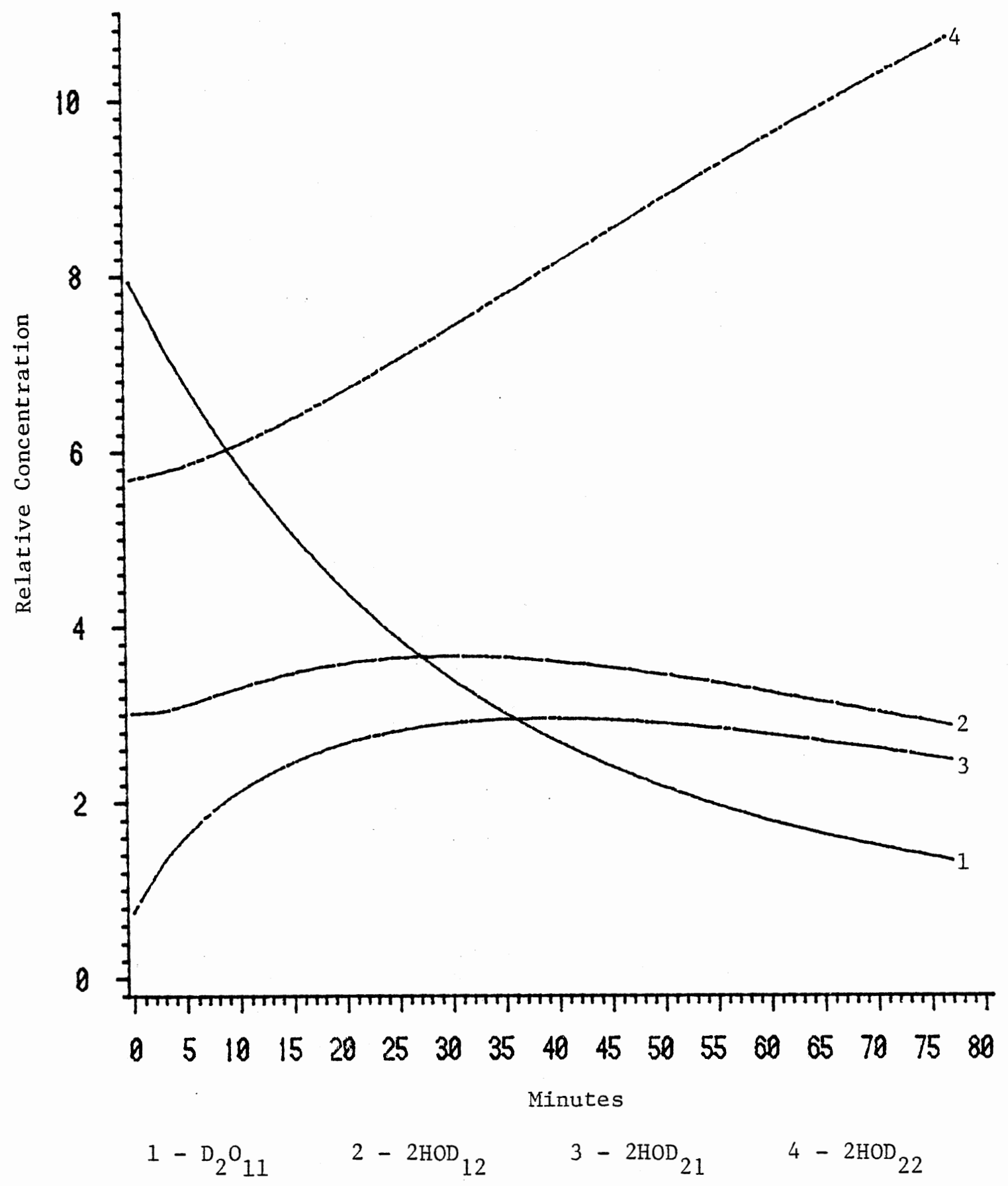

Figure 50. Calculated $\mathrm{D}_{2} \mathrm{O}_{11}$ and $2 \mathrm{HOD}_{\mathrm{nm}}$ "Configuration Concentration Curves for $5 / 10 / 82145 \mathrm{~K}$ Data 


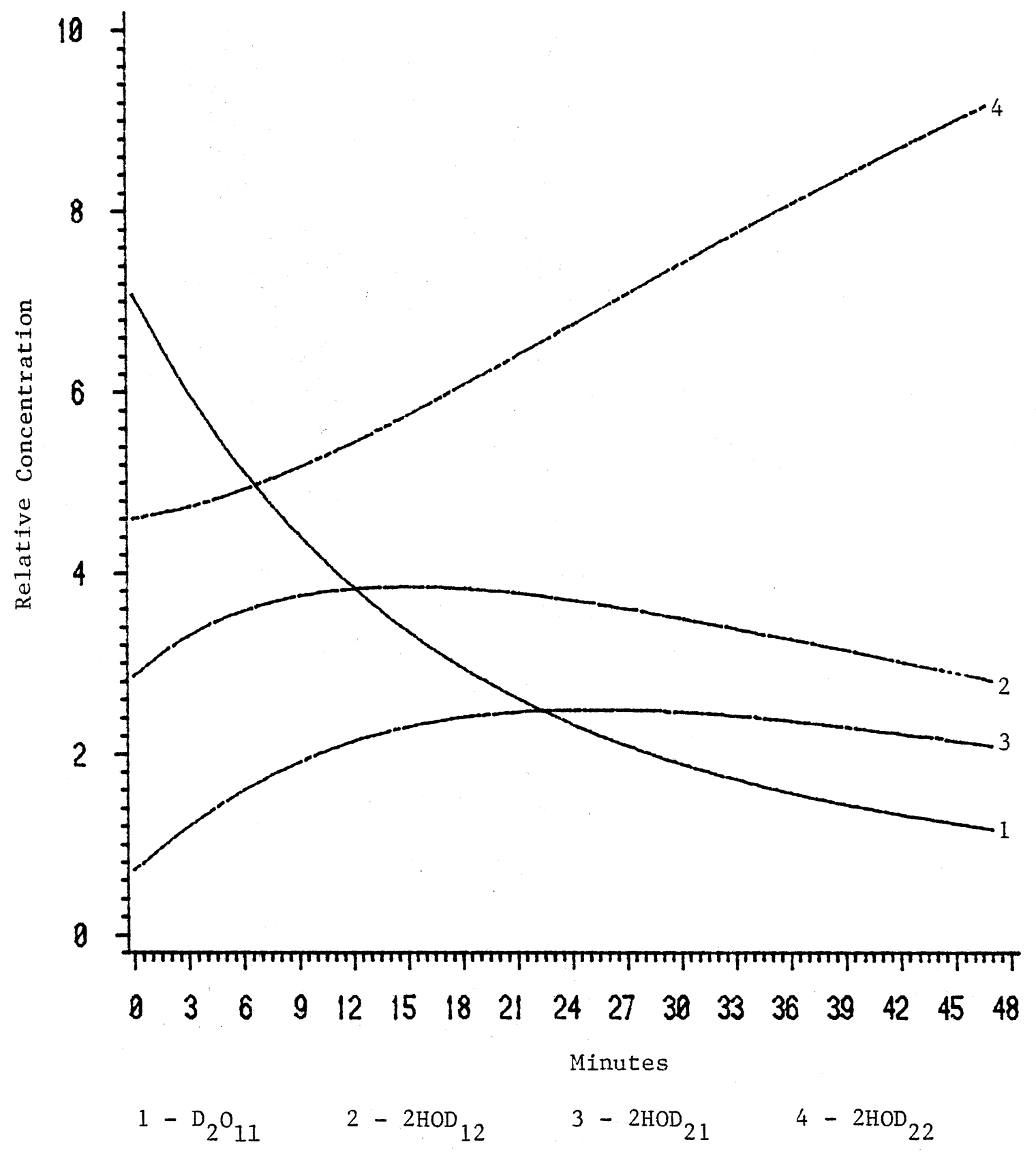

Figure 51. Calculated $\mathrm{D}_{2} \mathrm{O}_{11}$ and $2 \mathrm{HOD}_{\mathrm{nm}}$ Configuration Concentration Curves for 5724/82 $145 \mathrm{~K}$ Data 


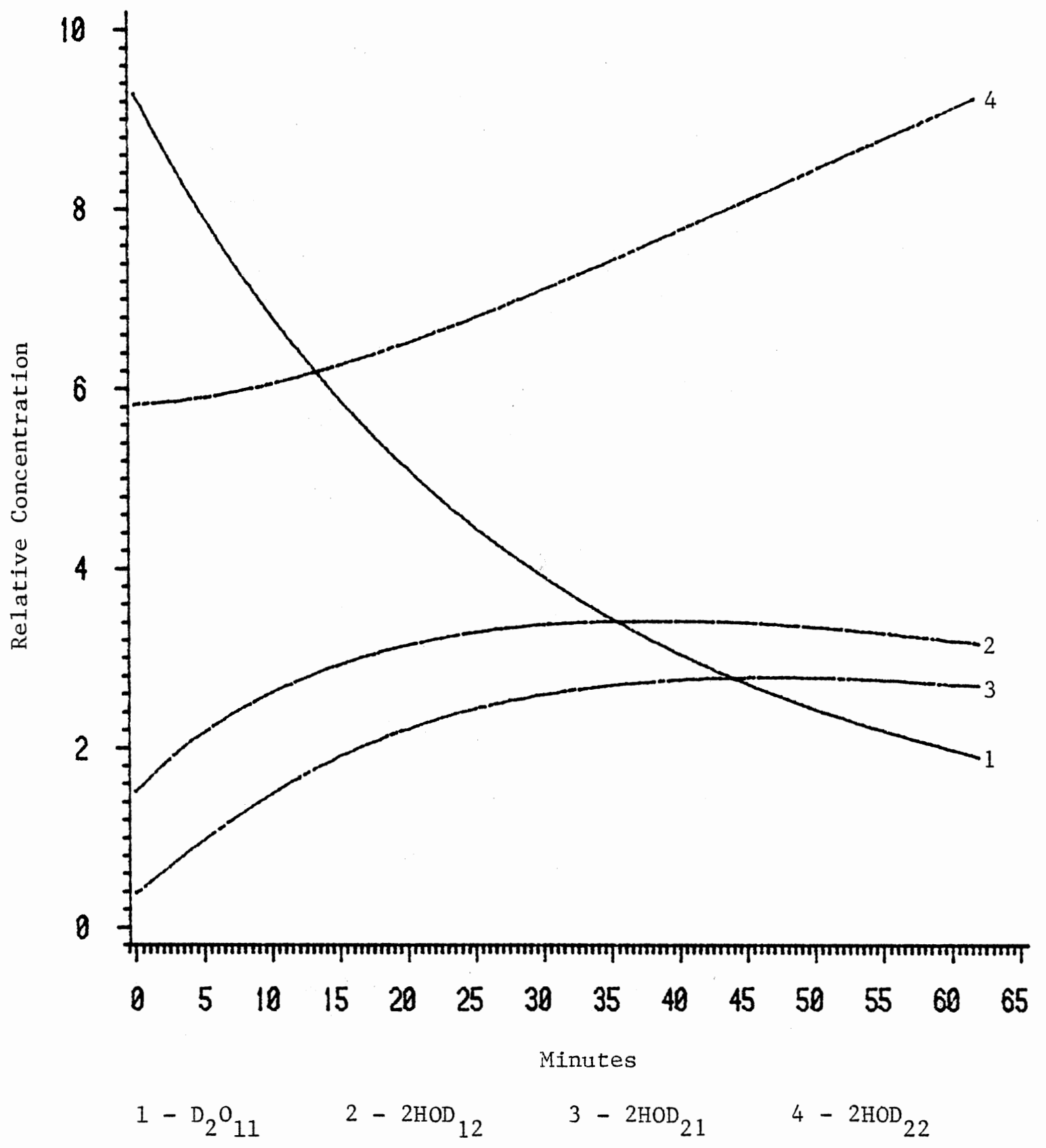

Figure 52. Calculated $\mathrm{D}_{2} \mathrm{O}_{11}$ and $2 \mathrm{HOD}_{\mathrm{nm}}$ Configuration Concentration Curves for $6 / 3 / 82145 \mathrm{~K}$ Data 


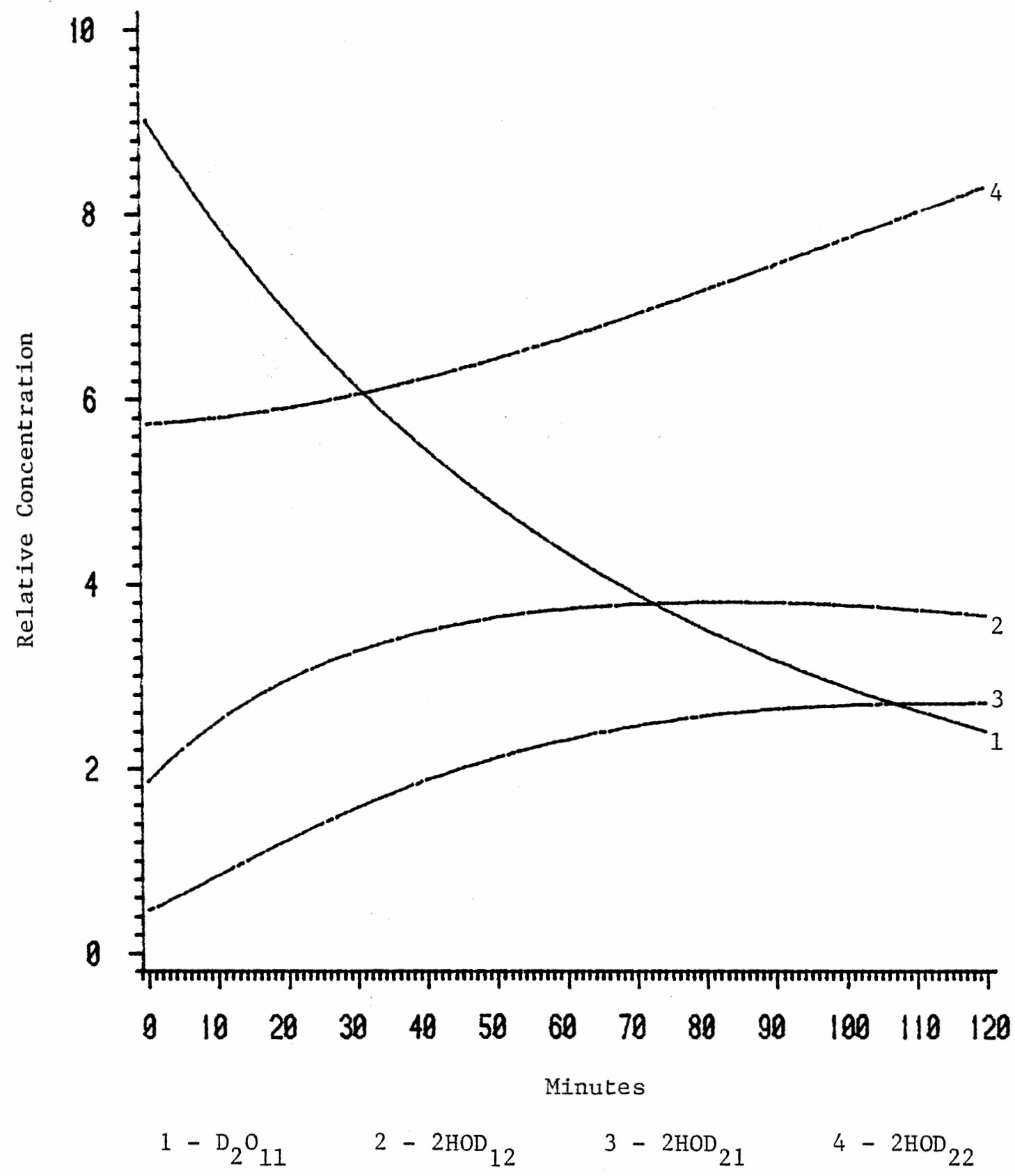

Figure 53. Calculated $\mathrm{D}_{2} \mathrm{O}_{11}$ and $2 \mathrm{HOD}_{\mathrm{nm}}$ Configuration Concentration Curves for $5 / 11 / 82140 \mathrm{~K}$ Data 


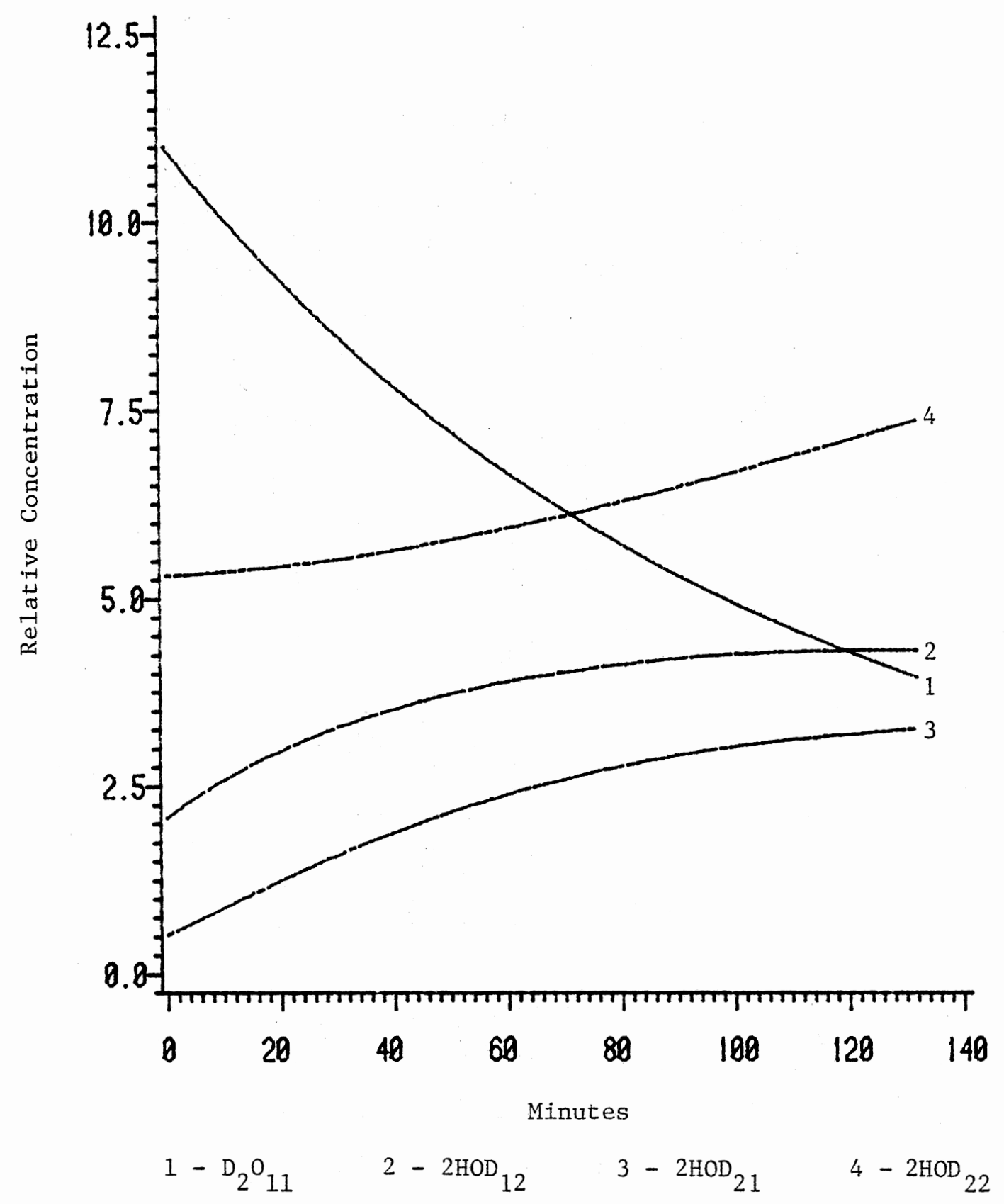

Figure 54. Calculated $\mathrm{D}_{2} \mathrm{O}_{11}$ and $2 \mathrm{HOD}_{\mathrm{nm}}$ Configuration Concentration Curves for $5 / 25 / 82140 \mathrm{~K}$ Data 


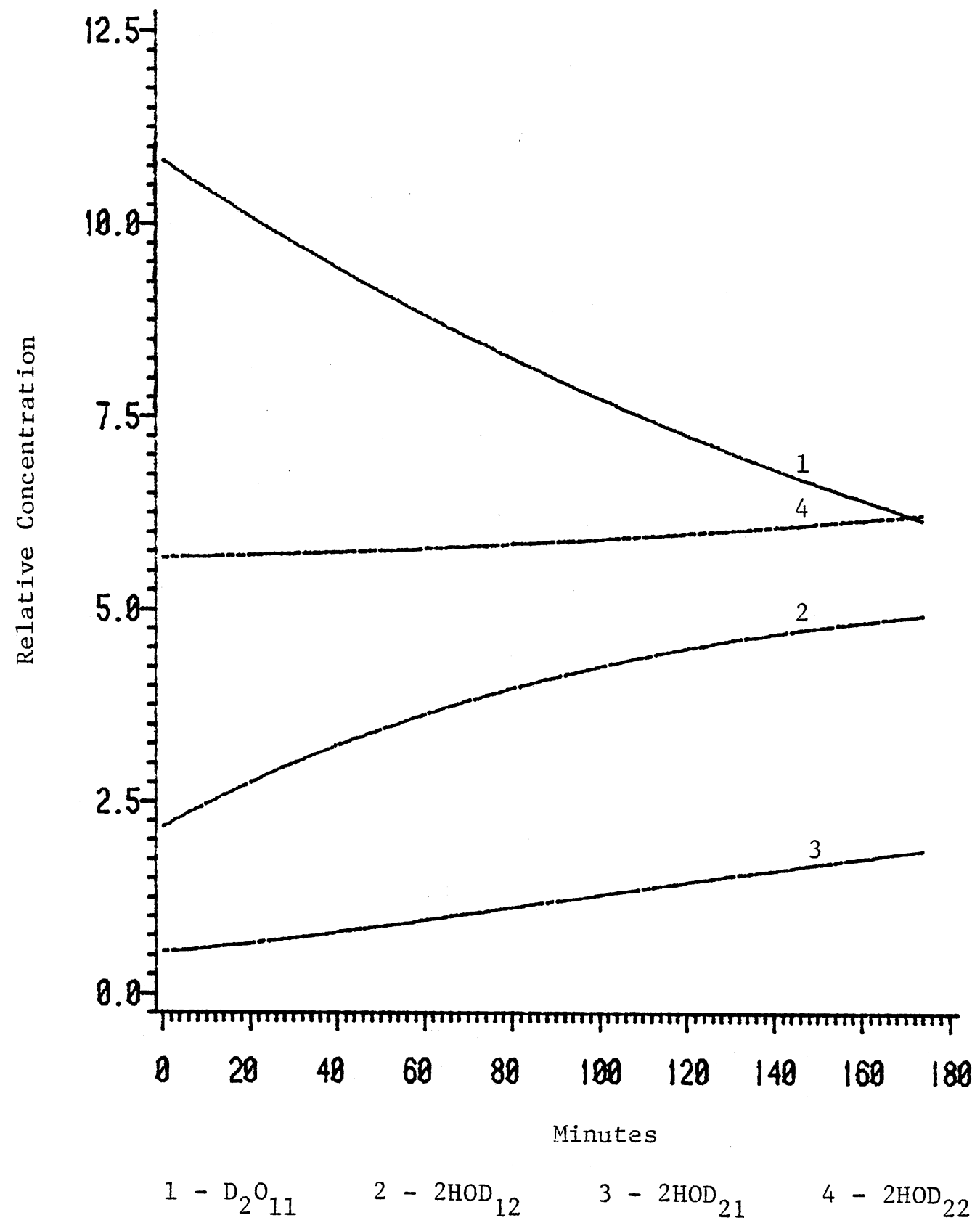

Figure 55. Calculated $\mathrm{D}_{2} \mathrm{O}_{11}$ and $2 \mathrm{HOD}_{\mathrm{nm}}$ Configuration Concentration Curves for 5715/82 $135 \mathrm{~K}$ Data 


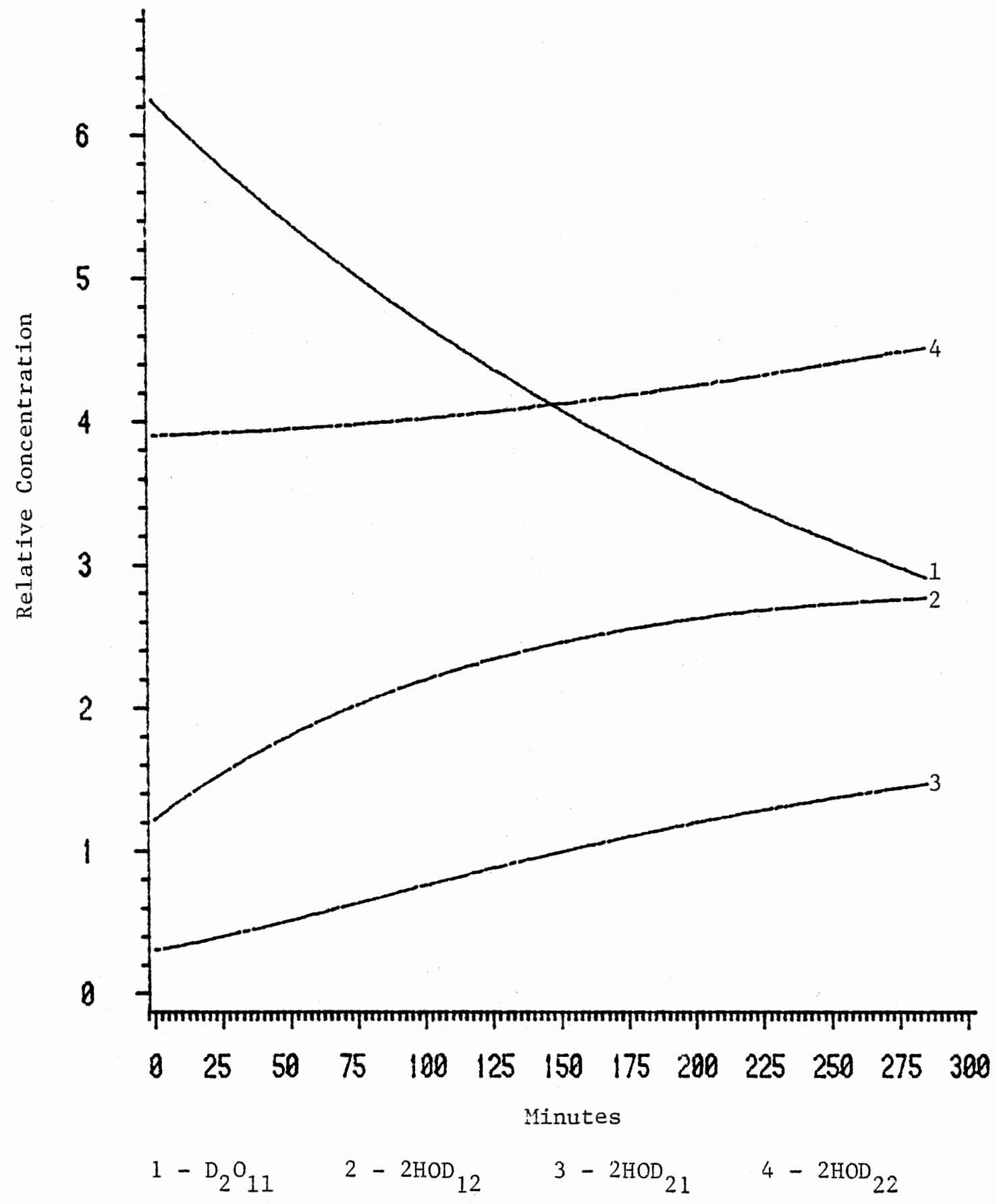

Figure 56. Calculated $\mathrm{D}_{2} \mathrm{O}_{11}$ and $2 \mathrm{HOD}_{\mathrm{nm}}$ Configuration Concentration Curves for 5/28/82 $135 \mathrm{~K}$ Data 


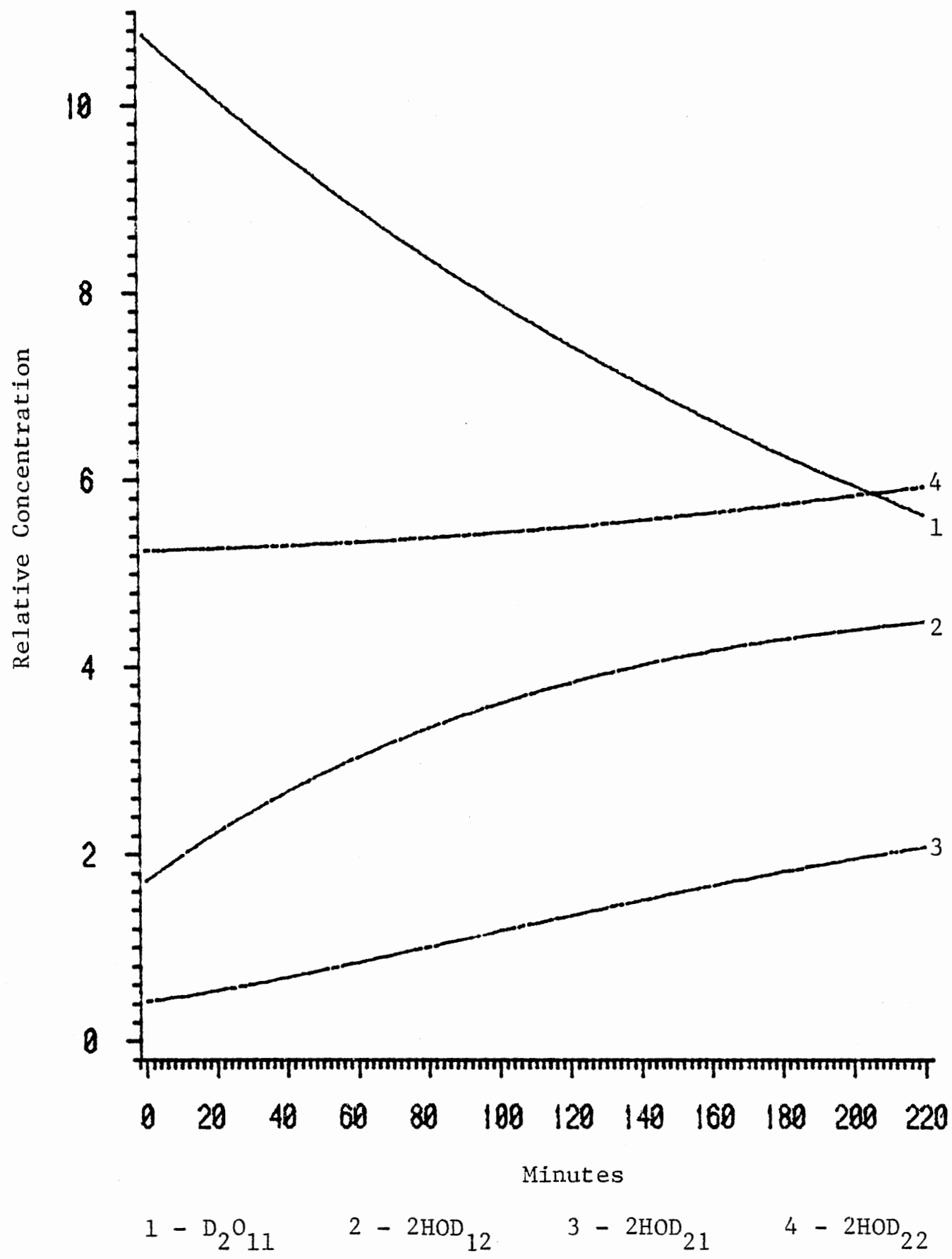

Figure 57. Calculated $\mathrm{D}_{2} \mathrm{O}_{11}$ and $2 \mathrm{HOD}_{\mathrm{nm}}$ Configuration Concentration Curves for $6711 / 82135 \mathrm{~K}$ Data 
$\mathrm{D}_{2} \mathrm{O}$ concentration after several half-lives of the $\mathrm{D}_{2} \mathrm{O}$ concentration. This may be due to the slightly fast depletion of $\mathrm{D}_{2} \mathrm{O}$ which builds up the (HOD) $)_{2}$ too fast. The exclusion of the (HOD) ${ }_{2}$ to pseudo-HOD to separated HOD migration path (see Figure $26,2 \mathrm{HOD}_{12} \leftrightarrow 2 \mathrm{HOD}_{13} \leftrightarrow$ $2 \mathrm{HOD}_{22}$ ) may account for some of the deviations. But attempts to include this pathway in the model failed due to too high a correlation in the rate constants and too many unknowns in the model equation.

Transfer and Rotational Activation Energies

The two-equilibrium model calculated rate constants shown in Table VII were least square fitted to standard Arrhenius plots to find the activation energies predicted for each calculation. Table VIII lists these results.

The correlation factors for the Arrhenius plots tend to support the contention that the 0.0 and .25 calculations are the best fit. For the transfer rate constants the .25 calculation has the best correlation and for the rotational rate constants the 0.0 calculation. In contrast the .5 calculation has the lowest correlation for both the transfer and rotational rate constant plots. A further indication of the poorer fit of the .5 calculation is the .561 standard error which is twice the standard error of the 0.0 and .25 calculations. A .7 calculation not shown gave an even poorer fit. So in summarizing, the 0.0 and .25 calculations gave the best activation energies for the rotational and transfer rate constants. Both calculations give essentially the same rate constants and hence the same activation energies. The upper plot of Figure 58 shows the Arrhenius plot for the transfer rate constants. From this a transfer 
TABLE VIII

TRANSFER AND ROTATIONAL ACTIVATION ENERGIES

\begin{tabular}{lccc}
\hline $\begin{array}{l}\text { Model } \\
\text { initial HoD } 21\end{array}$ & $\begin{array}{c}\text { Two-equilibrium } \\
0.0\end{array}$ & $\begin{array}{c}\text { Two-equilibrium } \\
0.25\end{array}$ & $\begin{array}{c}\text { Two-equilibrium } \\
0.5\end{array}$ \\
\hline $\begin{array}{l}\text { Transfer Activation } \\
\text { Energy (kcal/mole) }\end{array}$ & 9.531 & 9.537 & 9.513 \\
$\begin{array}{l}\text { Standard Error } \\
\begin{array}{l}\text { Least Square } \\
\text { Correlation }\end{array}\end{array}$ & 0.658 & 0.653 & 0.661 \\
$\begin{array}{l}\text { Rotational Activation } \\
\text { Energy (kcal/mole) }\end{array}$ & 11.767 & 0.97736 & 0.97667 \\
$\begin{array}{l}\text { Standard Error } \\
\text { Least Square }\end{array}$ & 0.97697 & 12.199 & 13.296 \\
Correlation & 0.99813 & 0.244 & 0.561 \\
\hline
\end{tabular}




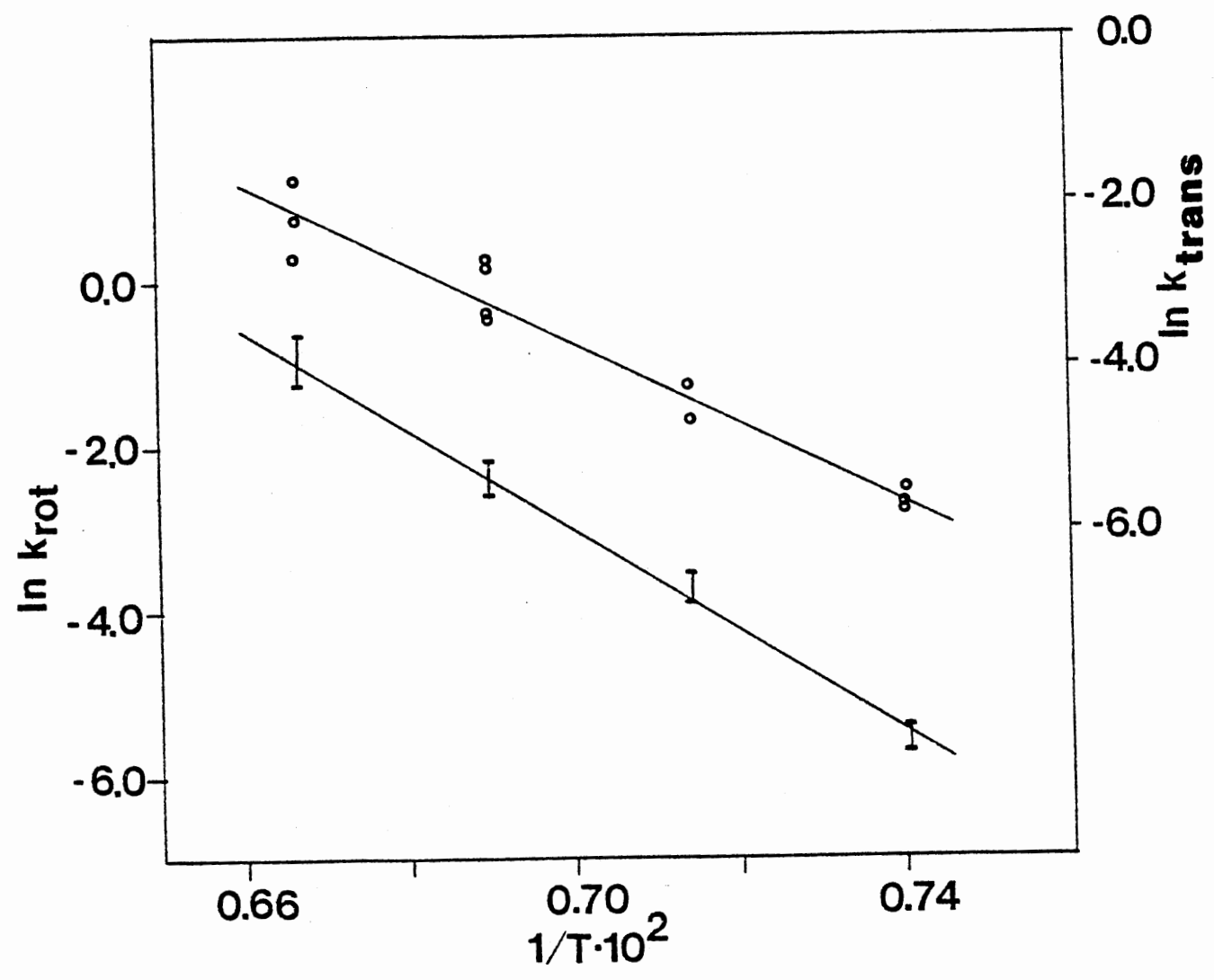

Figure 58. Transfer and Rotational Rate Constants Arrhenius Plots 
rate constant activation energy of $9.5 \pm .7 \mathrm{kcal} / \mathrm{mole}$ with a preexponential factor of $(9.4 \pm .7) \times 10^{12}$ is determined.

The rotational activation energy is not as well determined. Though the standard errors are smaller than those of the transfer rate constant activation energy the 0.0 and .25 calculations still give different activation energies. Unfortunately there is no suitable criteria to determine which value is correct. Thus since the initial separated HOD concentration cannot be determined closer than 0.0 to .25 times the initial (HOD) 2 concentration the 0.0 and .25 calculations should represent acceptable bounds to the rotational rate constant activation energy.

The lower Arrhenius plot of Figure 58 shows the error bars determined from the lowest and highest rate constant from either the 0.0 or . 25 calculations for a given temperature. Thus the upper error bar of the $150 \mathrm{~K}$ data point was determined from the natural $\log$ of .5020 the $150 \mathrm{~K} \mathrm{6/9/82}$ dataset .25 calculated rotational rate constant, and the lower error bar from the $\log$ of .2857 the $150 \mathrm{~K}$ $2 / 2 / 82$ dataset 0.0 claculated rotational rate constant. Then taking the average of the 0.0 calculation 11.8 and .25 calculation 12.2 activation energies and drawing in the resulting straight line plot gives the lower plot shown in Figure 58. So in spute of the initial separated HOD indeterminacy, the rotational activation energy can still be error bounded to an accuracy equal or better than the transfer activation energy. Interestingly, unlike the transfer plot, the rotational plot errors are fairly consistent over the 150 to $135 \mathrm{~K}$ temperature range. This may reflect the possibility that the (HOD) 2 concentrations are less affected by sampling and spectral resolution 
errors in obtaining the coupled HOD absorbances. From the lower plot a rotational rate constant activation energy of $12.0 \pm .5$ $\mathrm{kcal} / \mathrm{mole}$ with a pre-exponential factor of $(1.1 \pm 1.1) \times 10^{17}$ is determined. The error limits were calculated by adding the calculated standard errors to one half the difference between the 0.0 and .25 least square determined activation energies and pre-exponential factors.

\section{Discussion of Activation Energies}

The calculated $9.5 \pm .7 \mathrm{kcal} / \mathrm{mole}$ transfer activation energy is quite close to the $9.3 \mathrm{kcal} / \mathrm{mole}$ value found by Ritzhaupt and Devlin (46) on their studies of doped ice systems. The transfer activation energy reflects an independence of the dopants that drastically affect the transfer rates. This gives further credence to the suggestion that the dopants affect the concentration of ionic defects and hence the rate. Accordingly the activation energy measured represents the ion pair defect formation energy. This ionization is dependent on the temperature, but independent of defect concentration or dopants present in the ice lattice.

A. von Hippel (42) suggested that D and L Bjerrum defects were the only charge carriers in bulk ice conductivity measurements. In view of the magnitudes of the transfer and rotational rate constants and the magnitudes of the $\mathrm{D}_{2} \mathrm{O}$ and (HOD) 2 concentrations, this view is hard to support at $135-150 \mathrm{~K}$ temperatures. Both the ionic and Bjerrum defects appear to be equally active in isotopic scrambling for pure ice systems. But the $12.0 \pm .5 \mathrm{kcal} / \mathrm{mole}$ rotational activation energy does imply that the rotational step may become more 
predominant and the transfer step more rate determining at higher temperatures. Thus conductivity activation energies of pure ice in the 135 to $180 \mathrm{~K}$ region may be hard to relate to a particular defect activation energy. The 9 and $13 \mathrm{kcal} / \mathrm{mole}$ conductivity activation energies at $240-200 \mathrm{~K}$ and $180-170 \mathrm{~K}$, reported by Durand et al. (40) may be a reflection of this problem.

Nagle and Tristram-Nagle (52) have reviewed various models for proton transport in biological membranes. In particular the hydrogen bonded chain mechanisms in which various amino acid hydroxy1 and amine groups hydrogen bond to form a chain capable of transmitting protons via a hop/turn mechanism. For a particular hydrogen bonded chain ( $\mathrm{HBC}$ ) to transmit a proton more than once each hopping or ionic defect migration must be followed by a turn or D, L defect migration through the chain. The model presented in Figure 26 presents a similar situation. Here a particular deuteron cannot move through the ice lattice unless an alternating sequence of transfer and rotational steps is followed. Thus if $\mathrm{D}_{2} \mathrm{O}$ completely scrambles to uncoupled HOD both transfer and rotational defects should be present. But if proton transfer could be induced without a rotational decoupling then a statistical $1: 2: 1$ ratio of $D_{2} O$, coupled HOD, and uncoupled HOD should be produced. This should be identifiable spectroscopically provided the $2 \mathrm{HOD}_{13}$ configuration contributes to the uncoupled HOD band intensity. Laser photoexcitation of the $\mathrm{D}_{2} \mathrm{O}$ OD stretch modes and overtones in a $\mathrm{D}_{2} \mathrm{O} / \mathrm{H}_{2} \mathrm{O}$ deposit cooled below $120 \mathrm{~K}$ may be one method of accomplishing this via a photoionization pathway. 
Summary

The primary goal of this study was to elucidate the kinetics and resulting activation energies for isotopic scrambling in pure cubic ice. Pertinent to this goal was the identification and quantification of mixed isotope vapor deposited ice spectra and development of an experimentally consistent kinetic model to explain the observed spectral changes.

Twelve $\mathrm{D}_{2} \mathrm{O} / \mathrm{H}_{2} \mathrm{O}$ vapor deposited ice samples were made at $130 \mathrm{~K}$ and $125 \mathrm{~K}$ where no isotopic exchange would occur. After warming these samples to $135,140,145$, or $150 \mathrm{~K}$ to initiate exchange, FIIR spectra were collected at various time intervals to monitor the respective spectral changes. To help resolve these spectra into their various components for absorbance and concentration measurements, additional $\mathrm{D}_{2} \mathrm{O} / \mathrm{H}_{2} \mathrm{O}$ ice samples lightly doped with 7-azaindole were made. The IR spectra collected from these ice samples were used to produce pure component $\mathrm{D}_{2} \mathrm{O}$ spectra at the required kinetic temperatures. Using the pure component uncoupled HOD spectra collected at the completion of isotopic exchange, and previously determined pure component $\mathrm{D}_{2} \mathrm{O}$ spectra, the FTIR spectra collected for each ice sample could be resolved into the individual $\mathrm{D}_{2} \mathrm{O}$, and uncoupled HOD spectra. Accordingly absorbances were extracted from these spectra.

Relative concentrations were ascertained from calculated relative molar absorptivities. Using a material balance equation a system of simultaneous equations utilizing the kinetic absorbance data was solved repetitively for the relative molar absorptivities of $\mathrm{D}_{2} \mathrm{O}$, coupled HOD, and uncoupled HOD. 
With the kinetic concentration data in hand, a model was developed relating the various component concentration changes to the migration of ionic and Bjerrum D, L defects. By breaking the interaction of an ionic or Bjerrum $D$, L defect with a $D_{2} O$ or HOD unit in an ice crystal into three steps, the attack factor, the transfer factor, and the leaving factor, it was possible to relate the individual transfer and rotational steps necessary in isotopic scrambling to a common set of transfer and rotation rate constants reflecting the rate of ionic defect migration and $D, L$ defect migration. Approximations yielded both a one- or two-equilibrium model suitable for nonlinear least square fit in the experimental concentration data.

Using an iterative nonlinear least square routine both the oneand two-equilibrium models were fit to the data. The two-equilibrium model with feedback from separated HOD to coupled HOD gave a superior fit. From the rate constants determined with the two equilibrium model Arrhenius plots were constructed and analyzed for the respective transfer and rotational rate activation energies.

As with most investigations, more questions are raised than are answered. One of the interesting prospects raised in this study is what would be the effect of $\mathrm{NH}_{3}$ or $\mathrm{HF}$ doping on the transfer or rotation rates? If rate suppression or enhancement is observed, then possibly the degree of suppression or enhancement could be used as a probe of the proton donicity or affinity of the dopant. A modification of the simultaneous deposit of sample and dopant would be a layered deposit where each layer is a different isotopic or chemical species. Two isotopes could be separated by a third sandwiched 
layer which would have to transport protons for isotopic scrambling to occur. Proton transport across a specifically prepared molecular film could be monitored by this method. Thus there are numerous prospects for further study of proton trnasport in vapor deposited ice samples. 


\section{REFERENCES}

(1) Rinne, F., Math.-Phys. K1, 69, 57, (1917). St. John, A., Proc. Natn. Acad. Sci. U.S.A., 4, (1918).

(2) Bragg, W. H., Proc. Phys. Soc., 34, 98, (1922).

(3) Bril1, R., and Tippe, A., Acta Cryst., 23, 343, (1967).

(4) Barnes, W. H., Proc. R. Soc., A125, 670, (1929).

(5) Bernal, J. D., and Fowler, R. H., J. Chem. Phys., 1, 515, (1933).

(6) Pauling, L., J. Am. Chem. Soc., 57, 2680, (1935).

(7) Bjerrum, W., K. Danshe Vidensk., 27, 1, (1951).

(8) Honjo, G., Kitamura, N., Shimaoka, K., and Mihama, K., J. Phys. Soc. Japan, 11, 527, (1956).

(9) Honjo, G., and Shimaoka, K., Acta Cryst., 10, 710, (1957).

(10) Bertie, J. E., Labbe', H. J., and Whalley, E., J. Chem. Phys., $50,4501,(1969)$.

(11) Hardin, A. H., and Harvey, K. B., Spec. Acta, 29A, 1139, (1973).

(12) Li, P. C., and Devlin, J. P., J. Chem. Phys., 59, 547, (1973).

(13) Narten, A. H., Venkatesh, C. G., and Rice, S. A., J. Chem. Phys., $64,1106,(1976)$.

(14) Whalley, E., Can. J. Chem., 55, 3429, (1977).

(15) Scherer, J. R., and Snyder, R. G., J. Chem. Phys., 67, 4794, (1977).

(16) Bergren, M. S., Schuh, D., Sceats, M. G., and Rice, S. A., J. Chem. Phys., 69, 3468, (1978).

(17) Sivakumar, T. C., Rice, S. A., and Sceats, M. G., J. Chem. Phys., 69,3468 , (1978).

(18) Scherer, J. R., Advances in Infrared and Raman Spectroscopy, (R. J. H. Clark and R. E. Hester, eds.), Vol. 5, Heyden, London, 1978 , p. 149. 
(19) Rhim, W. K., Burum, D. P., and Elleman, D. D., J. Chem. Phys., 71, 3139, (1979).

(20) Hagen, W., Tielens, A. G. G. M., and Greenberg, J. M., Chem. Phys., 56, 367, (1981).

(21) Theil, M. V., Becker, E. D., and Pimentel, G. C., J. Chem. Phys., $27,486,(1957)$.

(22) Haas, C., and Hornig, D. F., J. Chem. Phys., 32, 1763, (1960).

(23) Tursi, A. J., and Nixon, E. R., J. Chem. Phys., 52, 1521, (1970).

(24) Ritzhaupt, G., and Devlin, J. P., J. Chem. Phys., 67, 4779, (1977).

(25) Ritzhaupt, G., Thornton, C., and Devlin, J. P., Chem. Phys. Lett., 59, 420, (1978).

(26) Ritzhaupt, G., Collier, W. B., Thornton, C., and Devlin, J. P., Chem. Phys. Lett., 70, 294, (1980).

(27) Sceats, M. G., Stavola, M., and Rice, S. A., J. Chem. Phys., 71, 983, (1979).

(28) Murby, E. J., and Pullin, A. D. E., Aust. J. Chem., 32, 1167, (1979).

(29) Bentwood, R. M., Barnes, A. J., and Orville-Thomas, W. J., J. Mole. Spec., 84, 391, (1980).

(30) Barnes, A. J., and Suzuki, S., J. Mole. Struct., 70, 301, (1981).

(31) McGraw, R., Madden, W. G., Bergren, M. S., Rice, S. A., and Sceats, M. G., J. Chem. Phys., 69, 3483, (1978).

(32) Madden, W. G., Bergren, M. S., McGraw, W. G., Rice, S. A., and Sceats, M. G., J. Chem. Phys., 69, 3497, (1978).

(33) Sceats, M. G., and Rice, S. A., J. Chem. Phys., 71, 973, (1979).

(34) Sceats, M. G., Stavola, M., and Rice, S. A., J. Chem. Phys., 71, 983, (1979).

(35) Morse, M. D., and Rice, S. A., J. Chem. Phys., 76, 650, (1981).

(36) Matsuoka, O., Clementi, E., and Yoshimine, M... J. Chem. Phys., $64,1351,(1976)$.

(37) Conway, B. E., Bockris, J. O'M., Linton, H., J. Chem. Phys., 24, $834,(1956)$.

(38) Conway, B. E., Bockris, J. O'M., J. Chem. Phys., 28, 354, (1958). 
(39) Kim, D., and Schmidt, V. H., Can. J. Phys., 45, 1507, (1967).

(40) Durand, M., Deleplanque, M., and Kahane, A., Sol. State Comm., $5,759,(1967)$.

(41) Bullemer, B., Eisle, I., Engelhardt, H., Rieh1, N., and Seige, P., Sol. State Comm., 6, 663, (1968).

(42) Hippe1, A. von, Knol1, D. B., Westphal, W. B., J. Chem. Phys., 54, 134, (1971). Hippel, A. von, J. Chem. Phys., 54, 145, (1971). Maidique, M. A., Hippe1, A. von, Westphal, W. B., J. Chem. Phys., 54, 150, (1971).

(43) Jaccard, C., Helv. Phys. Acta, 32, 89, (1959).

(44) Hubmann, M., Z. Physik B, 32, 127, (1979).

(45) Lumpkin, 0., and Dixon, W. T., Chem. Phys. Lett., 62, 139, (1979).

(46) Ritzhaupt, G., and Devlin, J. P., Chem. Phys. Lett., 65, 592, (1979).

(47) Ritzhaupt, G., and Devlin, J. P., J. Chem. Phys., 72, 6807, (1980).

(48) Kunst, M., and Warman, J. M., Nature, 288, 465, (1980).

(49) Matsen, S. A., and Franklin, J. L., J. Am. Chem. Soc., 72, 3337, (1950).

(50) Lewis, E. S., and Johnson, M. D., J. Am. Chem. Soc., 82, 5399, (1960).

(51) Marquardt, D. W., J. Soc. Ind. App1. Math., 11(2), 431, (1963).

(52) Nagle, J. F., and Tristram-Nagle, S., J. Mem. Biol., to be published. 
APPENDIX A

FORTRAN PROGRAM REMOLE 
C OSU BILL COLLIER CHEMISTRV PS2O3 4/27/82

C MAIN PROGRAM TO FIND D2O, (HOD)2, HOD RELATIVE MOLAR ABSORBTIVITIES FROM ABSORBANCE DATA AND MATERIAL BALANCE

C DOUBLE PRECISION USED

$1 M P L I C I T$ REAL $* 8(A-H, O-Z)$

DIMENSION JCARD $(100)$, I (50), A ( 50$), B(50), C(50)$, I TT TLE $(144)$,

1 IMAG4 (5151), RANGE (4), ICHAR ( 10$)$, OUT $(50,3), A A(2,2), B B(2)$, WKAREA $(20)$

DATA IN/5/, IOUT/6/, RANGE/4*0. ODOO/

DATA ICHAR/1HA, IHB, $1 H C, 1 H, 1 H, 1 H, 1 H, 1 H, 1 H, 1 H /$

START DATA SETS LOOP, READ GRAPH

THTLE READ HOD AT T I INF INITY

$A B$ UNITS (CINF), ISTART, ISTOP

$1=0$

READ (IN, 515$)$ ISTART, ISTOP, NNCARD, CINF

IF (ISTART.EQ.9999) STOP

IF (ISTOP.LE. ISTART) GOTO 50

IF (ISTART.GT O) GOTO 15

ISTART = IABS(ISTART)

GOTO 35

15

READ

WRITE (IOUT, 600)

WRITE (IOUT.605) I

DO $20 U=1$, NNCARD

READ $(I N, 520) T(U), A(U), B(U), C(J)$

$C(J)=C(J) * C I N F$
WRITE (IOUT, 610$)$ T (J), A (J), B (J), C (J)

c CONT INUE

PLOT INPUTTEO DATA ON LINE

DO $30 J=1$, NNCARD

$\operatorname{OUT}(U, i)=A(U)$

$\operatorname{OUT}(J, 2)=B(J)$

30

CONTINUE

INC $=1$

NP $=$ NNCARD

$M=3$

IOPT $=1$

IV $=50$

PRINTER RDUTINE AL IGN DATA FILES

CALL USPLTD (T, OUT, IY,NP, M, INC, ITITLE, RANGE, ICHAR, IOPT, IMAG4, 
35
COMB INATIONS OF OBSERVATIONS (TIMES) ISTART TO ISTOP

WRITE (IOUT,615)

SUME $1=0.0000$

SUME $2=0.0000$

SUME $3=0.0000$

SUMEE $1=0.0000$

SUMEE $2=0.0000$

SUMEE $3=0.0 D O O$

NMIN1 = ISTOP-1

ICOUNT $=0$

DO 40 J ISTART, NMINI

NPLUS $1=J+i$

DO $45 K=N P L U S 1$, I STOP

SET UP AA MATRIX AND BB VECTOR

FOR E1, E2, E 3 SOLUT tONS, SET E3

EQUAL TO 1.O AND SOLVE TWO MATERIAL

BALANCE EQUATIONS FOR E1 AND E2 WHERE $2 A / E 1+2 B / E 2=C I N F-C$

\section{$A A(1,1)=A(J)$}

$A A(1,2)=B(U)$

$A A(2,1)=A(K)$

$B B(1)=C I N F-C(J)$

$B B(2)=C I N F-C(K)$

CAL LEQT IF (AA, $1,2,2, B B, 2$, WKAREA, IER)

$E 1=2.0000 / \mathrm{BB}(\mathrm{t})$

$E_{2}=2.0000 / \mathrm{BB}(2)$

$E 2=2.0000$
$E 3=1.0000$

SUME $1=$ SUME $1+E 1$

SUME1 $1=$ SUME $1+E 1$
SUME2 2 SUME $2+E 2$

SUME $3=$ SUME $3+E 3$

SET UP AA MATRIX ANO BB VECTOR

FOR E1, E2, E3 SOLUTIONS, SET E2

EQUAL TO 1.O AND SOLVE TWO MATERIAL

BALANCE EQUATIONS FOR E1 AND E3 WHERE

CINF $G / 2 E 3-A / E I=B$

$A A(1,1)=\operatorname{CINF}-C(J)$

$A A(1.2)=-A(J)$

$A A(2,1)=C I N F-C(K)$

$A A(2,2)=-A(K)$

$B B(1)=B(U)$

$\mathrm{BB}(2)=\mathrm{B}(\mathrm{K})$

CALU LEOT IF (AA, 1,2,2, BB, 2, WKAREA, IER)

$\mathrm{EE} 1=1.0 \mathrm{ODO} / \mathrm{BB}(2)$

$E E 2=1.0000$

$E E 3=0.5000 / B B(1)$

SUMEE 1 - SUMEE 1+EE

SUMEE2 - SUMEE $2+E E 2$

SUMEEO - SUMEE $3+E E$

ICOUNT $=$ I COUNT +1

WRITE (IOUT,620) J,K,T(J),T(K),E1,E2,E3,EE1,EE2,EE3 


\section{FIND AVERAGE E'S AND PRINT RESULTS}

COUNTS - DFLOAT (ICQUNT)

AVEEI $=$ SUME 1/COUNTS

AVEE2 = SUME 2 coUNTS

AVEE3 $=$ SUME3/COUNTS

AVEEE 1 = SUMEE $1 /$ COUNTS

AVEEE 1 = SUMEE $1 /$ COUNTS
AVEEE2 $=$ SUMEE2/COUNTS

AVEEE 3 - SUMEE 3 \% COUNTS

WRITE ( IOUT, 625) AVEE 1, AVEE2, AVEE3, AVEEE 1, AVEEE 2, AVEEE

008

0083

0083

0085

0086

OO\&

0088

0089

0090 GOTO 10

$5 O$ WRITE (IOUT, 630) ISTART, ISTOP

STOP

510 FORMAT (72A1)

515 FORMAT (315, F10,4

520 FORMAT $(4 F 10,4)$

600 FORMAT ( 1 \%, PS2O3 BILL COLLIER CHEMISTRY $1 \%, 0^{\prime}$, RELAT TVE MOLAR A

1BSORBTIVITIES BY SIMULTANEOUS EQUATIONS', //)

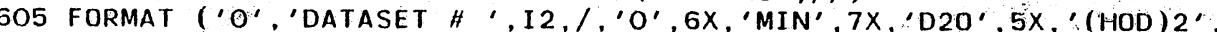

$16 \mathrm{x}$, 'HOD', 1$)$

0091

0092

0093

0094

0095

0096

(10 4 )

615 FÖRMAT $(1 \%$, CALCULATED MOLAR ABSORETIVITIES AT EACH STEP,, 0 ,

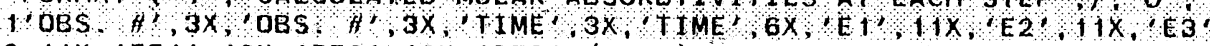
2,11X, 'EE1', 10X,'EE2', 10X, 'EE3', /,',')

620 FORMA $(14,5 X, 14,4 X, F 5,1,2 X, F 5.1,6013.5)$

25 F IERAGE EE 1, 2X, AVERAGE EE2, $2 X$, AVERAGE, EE $3,1 \%, 1,6013,5$ )

630 FORMAT ( 0 ', ERRRER I START $=1,13$, IS GREATER THAN IS TOP = 1,13 ) END 
PS203 BILL COLLIER CHEMISTRY

RELATIVE MOLAR ABSORBTIVITIES BY SIMULTANEOUS EOUATIONS

DATASET \# 1

MIN ODO (HOD)2 HOO

$\begin{array}{llll}0.0 & 13.5000 & 3.1000 & 11.4000 \\ 3.0000 & 11.4000 & 4.5000 & 12.5400 \\ 6.0000 & 9.4000 & 5.4000 & 14.0600 \\ 9.0000 & 8.1500 & 5.9500 & 15.2000 \\ 12.0000 & 7.2500 & 6.1500 & 16.3400 \\ 17.0000 & 6.1500 & 5.9000 & 18.2400 \\ 21.7000 & 4.8000 & 5.5500 & 20.5200 \\ 27.0000 & 4.1000 & 5.1500 & 22.4200 \\ 32.0000 & 3.5000 & 4.7000 & 23.9400 \\ 42.0000 & 2.8500 & 3.9000 & 26.2200 \\ 52.0000 & 2.5000 & 3.4000 & 27.7400 \\ 62.0000 & 2.1000 & 2.8000 & 29.2600 \\ 72.0000 & 1.7000 & 2.5500 & 30.0200\end{array}$


D2O ISOLATED IN H2O $1 / 29 / 82$ RUN $145 K$ UNCORRECTED D2O VALUES

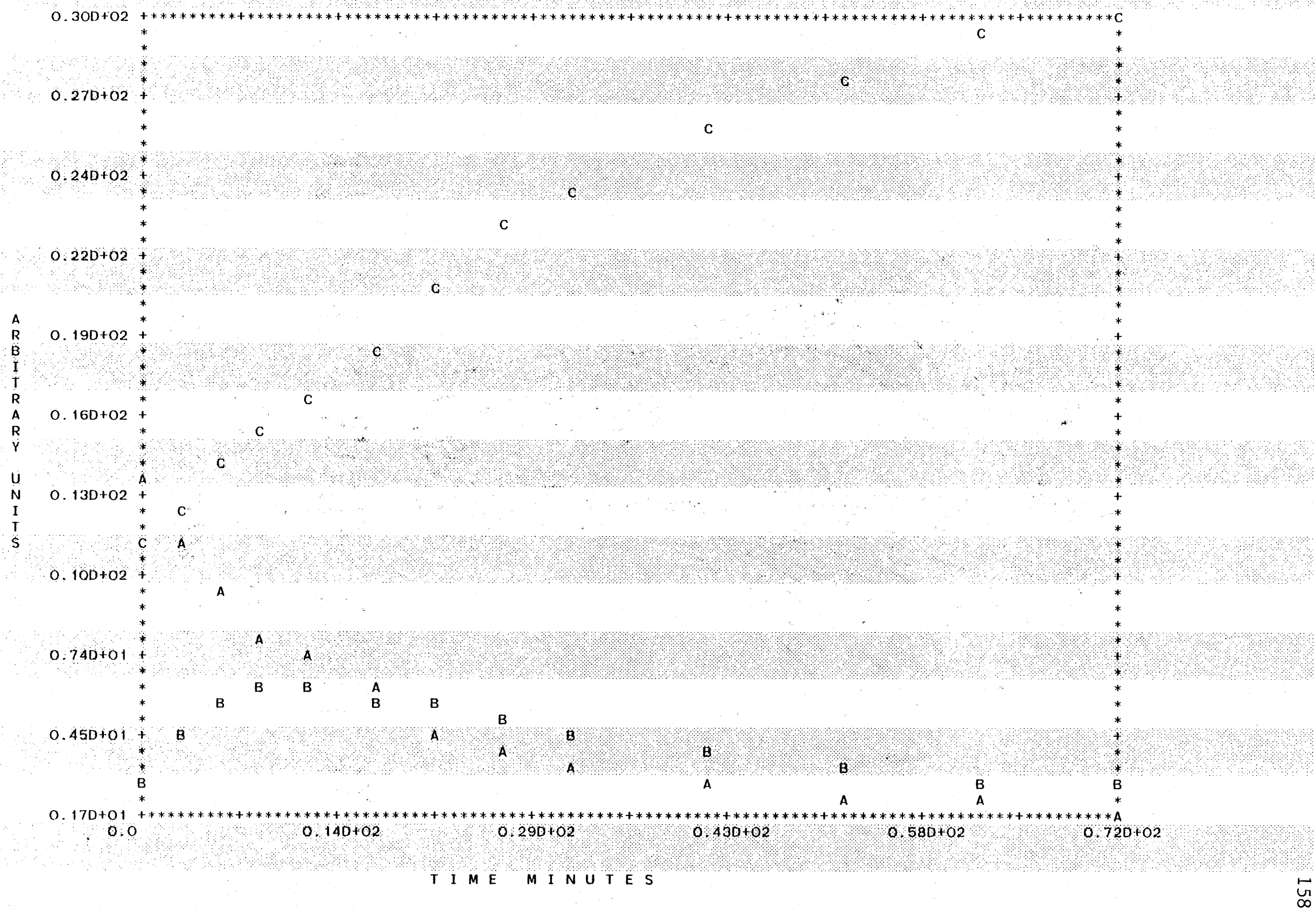


$0.110890+010.10000 D+0$ $\begin{array}{llll}27.0 & 0.12812 D+01 & 0.11220 D+01 & 0.10000 D+01 \\ 32.0 & 0.129180+01 & 0.10878 D+01 & 0.10000 D+01\end{array}$

$0.1000000+0$

$17.0 \quad 0.129160+01 \quad 0.115270+01 \quad 0 \quad 100000+0$

21. 7 0.133040+01 0. $108140+01$ o. $100000+0$

$\begin{array}{llll}27.0 & 0.13198 \mathrm{D}+01 & 0.10996 \mathrm{D}+01 & 0.1000 \mathrm{D}+0 \\ 32.0 & 0.13417 \mathrm{D}+01 & 0.10630 \mathrm{D}+01 & 0.10000 \mathrm{D}+0\end{array}$

$\begin{array}{llll}32.0 & 0.13417 D+01 & 0.10630 D+01 & 0.10000 D+01 \\ 42.0 & 0.13670 D+01 & 0.10249 D+01 & 0.10000 D+01\end{array}$

$62.00 .140620+0$

$973360+00$

$72.0 .0 .147660+01$

$0.80000+0$

$9.00 .123380+0$

$0.100000+0$

$12.0 \quad 0.123300+0$

$.124110+01$

$21.70 .136450+0$

$0.100000+0$

$27.0 \quad 0.134170+01$

$0.115550+010.10000 D+0$

$32.0 .0 .138160+01$

. $106280+01$

$0.100000+0$

$104520+0$

$0.100000+0$

$42.0 \quad 0.14297 D+01$

62.0 0. $15104 \mathrm{D}+01$

$100090+01$

$0.100000+01$

$100890+01$

$0.10000 D+01$

$72.0 \quad 0.164750+01 \quad 0.86204 \mathrm{D}+00 \quad 0.10000 \mathrm{D}+01$

$93972 D+00$

$0.10000 D+01$

$\begin{array}{lllll}12.0 & 0.123160+01 & 0,124410+01 & 0,100000+0 \\ 17.0 & 0.135620+01 & 0.110380+01 & 0.100000+0\end{array}$

17.0 0. $135620+010.110380+0$

27.0 0.142220+01

$10098 D+0$

(48750+01

$0.10495 D+01$

$0.100000+01$
$0.10000 D+01$

$42.0 \quad 0.157500+01$

$0.955780+00$

$0.10000 D+01$

$52.0 \quad 0.1558300+01$

$0.964350+00$

$0.100000+0$

$62.0 \quad 0.174450+01$

$0.884330+00$

$0.100000+0$

$\begin{array}{ll}72.0 & 0.20016 \mathrm{D}+01 \\ 17.0 & 0.15797 \mathrm{D}+01\end{array}$

$0.811930+00$

$0.100000+0$

$21.7 \quad 0.168630+01$

$0.100000+0$

12.0

$27.0 .0 .154110+01$

$100400+0$

$10000 D+01$

$32.0 \quad 0.163700+01$

$0.960770+00$

$0.1000000+0$

$52.00 .175910+01$

$.907960+00$

0. $100000+01$

$10000 D+0$

$12.0 \quad 62.0 \quad 0.21415 \mathrm{D}+01$

$72.0 \quad 0.26096 \mathrm{D}+01$

$.826110+00$

$0 D+01 \quad 0.763800+00$

$0.100000+0$

12.0

$21.7 \quad 0.177860+0$

$0.918680+00$

$0.100000+0$

$\begin{array}{llll}0.152050+01 & 0.101110+01 & 0.100000+0\end{array}$

$0.953840+00$ 0. $100000+0$

52.0 0. $185260+01$

17.0

17.0

52.0 $0.185260+01$

$0.899340+00$

$0.10000 D+01$

$62.0 \quad 0.256780+0$

$0.788250+00$

$0.100000+01$

27.0 0. $110610+01$

$0.126120+01$

$0.100000+0$

$0.100000+0$

$0.100000+0$

.

$\begin{array}{lll}0.11418 D+01 & 0.10000 D+01 & 0.89123 D+00 \\ 0.11876 D+01 & 0.10000 D+01 & 0.91930 D+00\end{array}$

$0.123800+01 \quad 0.100000+01 \quad 0.949670+00$

$.122810+010,100000+010.943770+00$

$131+10+01 \quad 0.100000+01 \quad 0.992810+00$

$.14506 D+010.10000 D+01 \quad 0.10720 D+01$

$\begin{array}{llll}11290 D+01 & 0.10000 D+01 & 0.87207 D+00\end{array}$

$0.105460+01$ 1 $0.1000000+01 \quad 0.841290+00$

$0.112060+010.100000+010.867560+00$

$0.123020+01 \quad 0.100000+01 \quad 0.924690+00$

$\begin{array}{llll}0.12002 D+01 & 0.10000 D+01 & 0.90941 D+00\end{array}$

$\begin{array}{lll}12621 D+01 & 0.10000 D+01 & 0.94071 D+00\end{array}$

$.13337 \mathrm{D}+01 \quad 0.10000 \mathrm{D}+010.97568 \mathrm{D}+00$

$0.131980+010.00000+010.968990+00$

$0.14447 D+010,10000 D+010.102740+01$

$0.164370+01 \quad 0.100000+01 \quad 0.111320+01$

$\begin{array}{lll}0.99410 D+00 & 0.10000 D+01 & 0.80575 D+00 \\ 0.99247 D+00 & 0.10000 D+01 & 0.80490 D+00\end{array}$

$\begin{array}{lll}0.11150 D+01 & 0.10000 D+01 & 0.86546 D+00\end{array}$

$0.128400+010.100000+010.940950+00$

$0.123340+010,100000+01,0.919260100$

$\begin{array}{lll}0.142850+01 & 0.100000+01 & 0.95676 D+00 \\ 0.140790+01 & 0.100000+01 & 0.999130+00\end{array}$

$\begin{array}{lll}0.14079 D+01 & 0.10000 D+01 & 0.99117 D+00\end{array}$

$0.16073 D+01 \quad 0.10000 D+01 \quad 0.106420+01$

$0.191110+01 \% 0.100000+010.116000+01$

$0.989950+00 \quad 0.100000+01 \quad 0.803790+00$

$.122870+010.100000+01 \quad 0.905980+00$

$\begin{array}{llll}0.14654 D+01 & 0.10000 D+01 & 0.99031 D+00\end{array}$

$0.135510+010.10000 D+010.952840+00$

$164780+010,100000+01$ 0. $104630+01$

$0.161590+010.100000+010.103700+01$

$0.19727 D+01 \quad 0.100000+010.113080+01$

$\begin{array}{lll}.24652 D+01 & 0.10000 D+01 & 0.123160+01\end{array}$

$\begin{array}{lll}0.16030 D+01 & 0.10000 D+01 & 0.10147 D+01 \\ 0.17907 D+01 & 0.100000+01 & 0.106190+01\end{array}$

$0.153500+010.100000+01,0.996040+00$

$0.170380+010.10000 D+01$ o. $104080+01$

. $196840+0100100000+01$ o. $110140+01$

$0.191890+010.100000+01 \quad 0.109080+01$

$\begin{array}{llll}0.25923 D+01 & 0.10000 D+01 & 0.12105 D+01\end{array}$

$0.341670+01 \quad 0.100000+01$ o. $130920+01$

$0.193600+010100000+010.108850+01$

. $150390+010.100000101 \quad 0.989040+00$

$174520+010.100000+01 \quad 0.104840+01$

$\begin{array}{lll}213320+01 & 0.100000+01 & 0.112490+01\end{array}$

$206000+01 \quad 0.10000 D+01 \quad 0.111190+01$

$325760+010.100000+010.126860+01$

$0.468390+010.100000+010.136970+01$

$0.877010+00 \quad 0.100000+01,0.792880+00$ 


\begin{tabular}{|c|c|c|c|c|c|c|c|}
\hline & & & & & 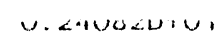 & & \\
\hline .7 & 52.0 & o. $196160+01$ & $0.88140 D+00$ & $0.100000+01$ & $0.222900+01$ & $0.100000+01$ & 0 \\
\hline 21.7 & 62.0 & $0.81693 D+01$ & $0.680780+00$ & $0.100000+01$ & $0.120000+02$ & $0.100000+01$ & $0.146890+$ \\
\hline 21.7 & 72.0 & $0.196840+02$ & $0.653240+00$ & $0.100000+01$ & $0.301330+02$ & $0.100000+01$ & $0.153080+01$ \\
\hline 27.0 & 32.0 & $0.304770+01$ & $0.799100+00$ & $0.100000+01$ & $0.381400+01$ & 0,100000101 & $0.125140+01$ \\
\hline 27.0 & 42.0 & $0.276320+02$ & $0.673940+00$ & $0,10000 \mathrm{D}+01$ & $0.410000+02$ & $0,100000+01$ & $0.148380+01$ \\
\hline 27.0 & 52.0 & $0.16015 D+02$ & $0.683570+00$ & $0.100000+01$ & $0.234290+02$ & $0.100000+01$ & o. 146290+01 \\
\hline 27.0 & 62.0 & $-0.958900+00$ & $0.426830+00$ & $0.100000+01$ & $-0.22466 \mathrm{D}+01$ & $0.100000+01$ & 0.23 \\
\hline 27.0 & 72.0 & $-0.248540+01$ & $0.545570+00$ & $0.100000+01$ & $-0.455560+01$ & $0.10000 D+01$ & $0.183290+01$ \\
\hline 32.0 & 42,0 & $-0.958650+00$ & $0.440030+00$ & $\mathrm{D}+01$ & $0.217860+01$ & $0.100000+01$ & $0.227250+01$ \\
\hline 32.0 & 52.0 & $-0.717700+00$ & $0.394740+00$ & $6+01$ & $0,181820+01$ & $20+01$ & $0.253330+01$ \\
\hline 32.0 & 62.0 & $0.818710-01$ & $-0.131580+00$ & $00+01$ & $0.62222 \mathrm{D}+00$ & $0000+01$ & $-0.760000+01$ \\
\hline 32.0 & 72.0 & $-0.113130+01$ & $0.464250+00$ & $0.10000 D+01$ & $-0.24368 D+01$ & $0.100000+01$ & $O D+O 1$ \\
\hline 42.0 & 52.0 & $-0.31579 D+01$ & $0.574160+00$ & +01 & -0.55 & $O D+01$ & $417 D+01$ \\
\hline 42.0 & 62.0 & $0.381130+00$ & $-0.24561 D+01$ & $0.100000+01$ & $-0.155170+00$ & $0.100000+01$ & $-0.407140+00$ \\
\hline 42.0 & 72.0 & $-0.117730+01$ & $0.46927 D+00$ & 0,10 & 01 & 0.1 & \\
\hline 520 & 62.0 & $0.283400+00$ & $0.921050+00$ & $0,100000+01$ & $-0.307690+00$ & $0.100000+01$ & $0,108570+01$ \\
\hline 52.0 & 72.0 & $0.122810+01$ & $0.474480+00$ & $0,100000+01$ & $0.258820+01$ & $0,100000+01$ & \\
\hline 62.0 & 72.0 & $-0.208770+02$ & $0.62632 \mathrm{D}+00$ & $0.10000 D+01$ & $-0.33333 D+02$ & $0.100000+01$ & $0.15966 \mathrm{D}+01$ \\
\hline
\end{tabular}

AVERAGE E1 AVERAGE E2 AVERAGE E3 AVERAGE EE1 AVERAGE EE2 AVERAGE EE3

$0.175100+01 \quad 0.857130+00 \quad 0,100000+01 \quad 0,190070+01 \quad 0,100000+01 \quad 0,992470+00$ 
$0.110890+01$

$27.0-0.12812 \mathrm{D}+01$

. $11289 \mathrm{D}+0$

$\begin{array}{lll}10000 D+01 & 0.11590 D+01\end{array}$

$32.00 .129180+01$

o. $108780+0$

$.10000 D+01 \quad 0.11418 \mathrm{D}+01$ $42.0 \quad 0.130360+0$

$105300+0$

$0.178760+01$ $6.0129460+01$

0. $105960+01$

$00+0$

$0.123800+0$

0.

$10000 \mathrm{~B}+01$

$0.122810+0$

o. $11886 \mathrm{D}+0$

$12.0 \quad 0.12683 D+01$

$0.12026 D+01$

. 1000OD+01

$0.107230+0$

$17.0 \quad 0.129160+01$

o. $11527 \mathrm{D}+0$

. $100000+01$

$21.70 .133040+0$

$0.108140+0$

, $100000+0$

0. $10546 \mathrm{D}+0$

$27.0 \quad 0.131980+0$

$0.109960+0$

0. $100000+0$

$0.123020+0$

$42.00 .136700+0$

$10249 D+0$

. $100000+0$

$0.120020+0$

52.0 0. $136210+01$

$0.10320 D+01$

$0.10000 D+01$

$9.0 \quad 0.12338 \mathrm{D}+01$

O. $12411 \mathrm{D}+01$

o. $10000 D+0$

o. $13337 \mathrm{D}+0$

$0.13198 \mathrm{D}+01$

$12.0 \quad 0.123300+0$

$0.115550+0$

$100000+0$

$0.99410 D+00$

$21.70 .136450+01$ o $106280+0$

27.0 0.134170+01

0. $106280+0$

. $100000+0$

$32.00 .138160+01$

$10878 D+0$

. $10000 \mathrm{~B}+0$

$0.992470+00$

$0.128400+0$

32.0 0. $13816 \mathrm{D}+0$

0. $10009 D+0$

o. $10000 D+01$

o. $123340+0$ 52.0 0. $142040+0$ $1200123160+0$

$0.100800+01$

o. $13219 D+0$

01 o.

$0.100000+0$

$21.7 \quad 0.14798 \mathrm{D}+01$

. $110380+0$

- $10000 \mathrm{D}+01$

$27.0 \quad 0.142220+01$

$0.104950+01$

$0.10000 D+01$

$989950+0$

$0.122870+0$

$32.0 \quad 0.14875 \mathrm{D}+0$

$0.10049 D+0$

$0.10000 D+0$

$0.135510+01$

$42.0 \quad 0.157500+01$

$0.964350+0$

o. $100000+0$

o. $14802 \mathrm{D}+\mathrm{O}$

$17.0 \quad 0.157970+0$

$0.985470+00$

$0.100000+0$

$0.164780+0$

$21.7 \quad 0.168630+01$

$0.941700+00$ 0. $10000 D+0$

$0.161590+0$

$27.0 \quad 0.154110+01$

$0.100400+01$

$0.100000+01$

$0.17907 D+0$

32.0 . $163700+0$

$0.96077 \mathrm{D}+00$

o. $100000+01$

$0.15350 D+01$

$0.916730+00$

$0.170380+01$

52.0 0. $17591 \mathrm{D}+0$

$21.7 \quad 0.177860+0$

$32.0 \quad 0.16647 \mathrm{D}+01$

$0.918680+00$

$100000+01$

. $101110+0$

$10000 \mathrm{D}+0$

o. $196840+0$

$\begin{array}{llll}0 & 0.100000+01 & 0.193600+0 \\ 1 & 0.10000 D+01 & 0.15039 D+0\end{array}$

$42.0 \quad 0.189630+0$

$0.888970+00$

$100000+01$

$52.00 .18526 \mathrm{D}+0$

$27.0 \quad 0.110610+0$

0

$0.17452 D+0$

0. $126120+01$

. $100000+0$

O. $21332 \mathrm{D}+01$

o.83581D+00

$0.826460+00$

$10000 D+01 \quad 0.822130+00$

$.100000+010.851450+00$

$\begin{array}{ll}.10000 D+01 & 0.90182 D+00\end{array}$

$\begin{array}{ll}10000 D+01 & 0.891230+00\end{array}$

$10000 D+010.91930 D+00$

$100000+01 \quad 0.949670+00$

. $100000+01$ o $943770+00$

$100000+010.872070+00$

$10000 D+01 \quad 0.841290+00$

$0.10000 D+01 \quad 0.83152 D+00$

$0.10000 D+01 \quad 0.86756 \mathrm{D}+00$

$0.100000+01 \quad 0.924690+00$

$0.100000+01 \quad 0.909410+00$

.

. $10000 \mathrm{D}+010.97568 \mathrm{D}+00$

$0.10000 D+010.96899 D+00$

$0.10000 D+010.80575 D+00$

$100000+01 \quad 0.804900+00$

$0,100000+01 \quad 0.865460+00$

. $100000+01 \quad 0.94095 \mathrm{D}+00$

$0.10000 D+01 \quad 0.91926 \mathrm{D}+00$

$\begin{array}{ll}0.10000 D+01 & 0.95676 D+00\end{array}$

$10000 D+010.99913 D+00$

$100000+0110.99117 \mathrm{D}+00$

$100000+01,0.803790+00$

0. $100000+01 \quad 0.905980+00$

$.10000 D+010.99031 D+00$

$\begin{array}{ll}10000 D+01 & 0.95284 D+00\end{array}$

$0.10000 \mathrm{D}+01 \quad 0.99511 \mathrm{D}+00$

$0.100000+01<0 \cdot 104630+0$

. $0000+010.10370 D+01$

. 100000 01 0.10147D+0

$\begin{array}{ll}.10000 D+01 & 0.106190+0\end{array}$

. $10000 D+010.99604 D+00$

. $100000+010.10408 D+01$

$100000+010.110140+01$

$0.100000+010.109080+0$

$0.10000 D+01 \quad 0.108850+01$

$\begin{array}{ll}10000 D+01 & 0.98904 D+00\end{array}$

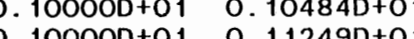

10001 . $112490+01$

0.00000

$0.10000+01$.

$\begin{array}{lllllllll}32.0 & 0.15207 D+01 & 0.99398 D+00 & 0.10000 D+01 & 0.15300 D+01 & 0.10000 D+01 & 0.10061 D+01 \\ 42.0 & 0.20784 D+01 & 0.86307 D+00 & 0.10000 D+01 & 0.24082 D+01 & 0.10000 D+01 & 0.11587 D+01 \\ 52.0 & 0.19646 D+01 & 0.88140 D+00 & 0.10000 D+01 & 0.22290 D+01 & 0.10000 D+01 & 0.11346 D+01\end{array}$

$\begin{array}{llllllll}42.0 & 0.20784 D+01 & 0.86307 D+00 & 0.10000 D+01 & 0.24082 D+01 & 0.10000 D+01 & 0.11587 D+01 \\ 52.0 & 0.19646 D+01 & 0.88140 D+00 & 0.10000 D+01 & 0.22290 D+01 & 0.10000 D+01 & 0.11346 D+01\end{array}$

$\begin{array}{llllllll}52.0 & 0.19646 \mathrm{D}+01 & 0.88140 \mathrm{D}+00 & 0.1000 \mathrm{D}+01 & 0.22290 D+01 & 0.10000 D+01 & 0.11346 \mathrm{D}+01 \\ 32.0 & 0.30477 \mathrm{D}+01 & 0.79910 \mathrm{D}+00 & 0.10000 \mathrm{D}+01 & 0.38140 D+01 & 0.10000 \mathrm{D}+01 & 0.12514 \mathrm{D}+01\end{array}$

$42.0 \quad 0.276320+02 \quad 0.673940+00 \quad 0.100000+01 \quad 0.410000+02 \quad 0.100000+01 \quad 0.148380+0$ $52.0 \quad 0.16015 \mathrm{D}+02 \quad 0.683570+00 \quad 0,100000+01 \quad 0.234290+02 \quad 0 \quad 10000 \mathrm{D}+01 \quad 0.146290+0$ $42.0-0.958650+00 \quad 0.440030+00 \quad 0.100000+01 \quad 0.217860+01 \quad 0.100000+01 \quad 0.227250+0$ $\begin{array}{llllllll}52.0 & -0.71770 D+00 & 0.39474 D+00 & 0.10000 D+01 & -0.18182 D+01 & 0.10000 D+01 & 0.25333 D+0\end{array}$

$\begin{array}{lllllll}52.0 & -0.31579 D+01 & 0.57416 D+00 & 0.10000 D+01 & -0.550000+01 & 0.100000+01 & 0.17417 D+01\end{array}$ 
CALGULATED MOLAR ABSORBTIVITIES AT EACH STEP

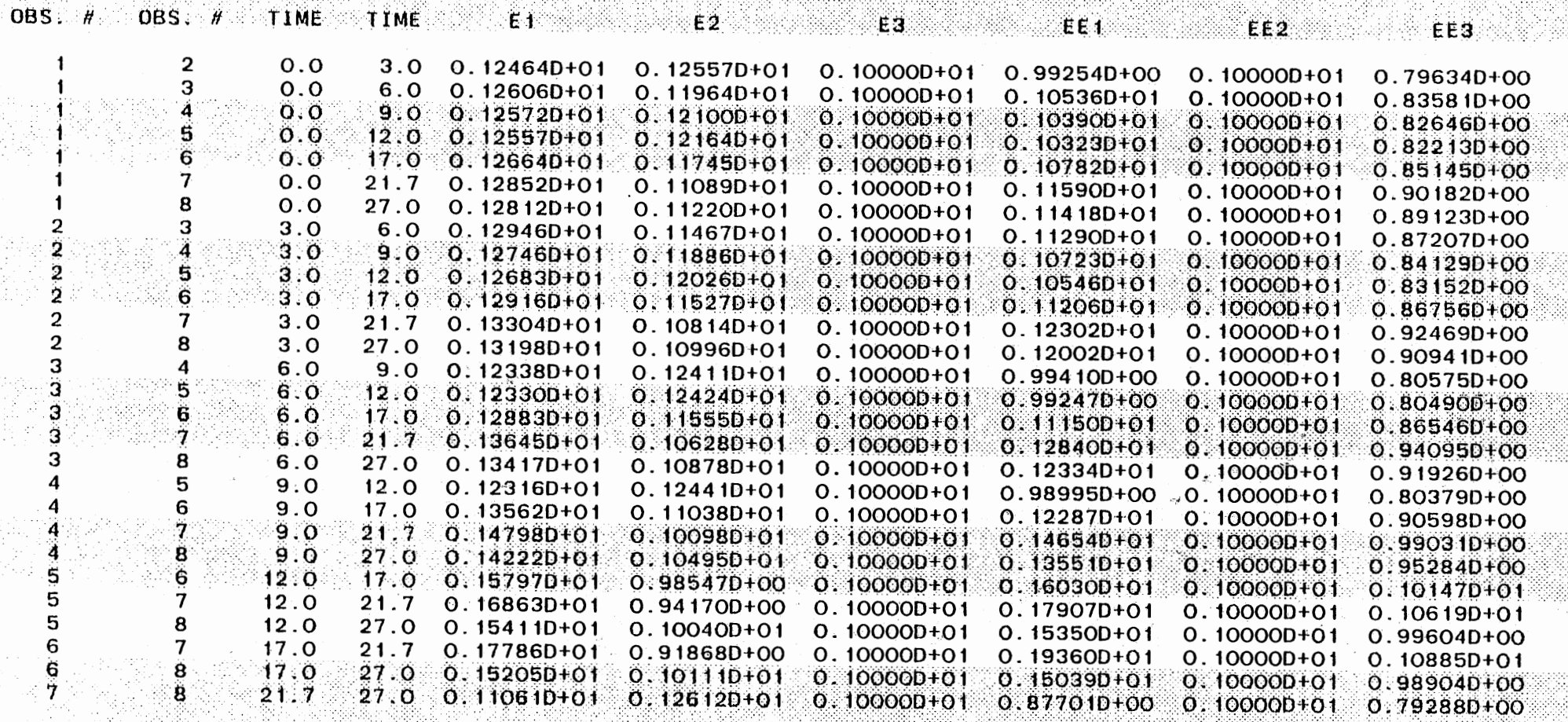

AVERAGE E1 AVERAGE E2 AVERAGE E3 AVERAGE EE 1 AVERAGE EE2 AVERAGE EE 3

$\begin{array}{lllllll}0.13498 D+01 & 0.112410+01 & 0.10000 D+01 & 0.12217 D+01 & 0.10000 D+01 & 0.89658 D+00\end{array}$ 
CALCULATED MOLAR ABSORBTIVITIES AT EACH STEP
TIME
TIME
E 1

E 2

$\mathrm{Ea}$

EE1

EE 2

EE 3

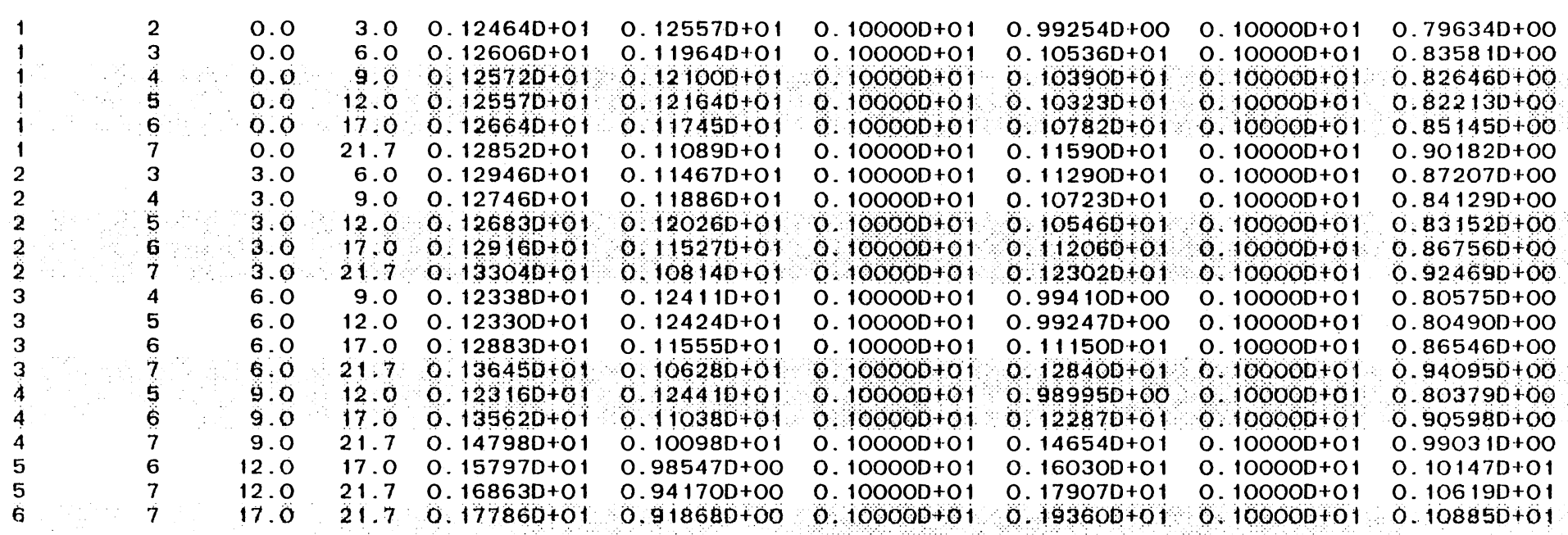

AVERAGE EI AVERAGE E

AVERAGE E3.

$0.100000+01$

$0.13458 D+01 \quad 0.11352 D+01 \quad 0.10000 D+01 \quad 0.12077 D+01 \quad 0.10000 D+01 \quad 0.88826 D+00$ 
CALCULATED MOLAR ABSORBTIVITIES AT EACH STEP

TIME TIME EI

E2

$\mathrm{E} 3$

EE

EF

$\mathrm{EE} 3$

$\begin{array}{ll}2 & 0.0 \\ 3 & 0.0 \\ 4 & 0.0 \\ 5 & 0.0 \\ 6 & 0.0 \\ 3 & 3.0 \\ 4 & 3.0 \\ 5 & 3.0 \\ 6 & 3.0 \\ 4 & 6.0 \\ 5 & 6.0 \\ 6 & 6.0 \\ 5 & 9.0 \\ 6 & 9.0 \\ 6 & 12.0\end{array}$

$3.0 \quad 0.124640+01$ . 0 0.12606D+01 0.12557D+O . $126060+01$

12.0 0.125570+01 o. $121640+0$

o. $119640+01$

0. $10000 D+01$

O. $99254 \mathrm{D}+00$

0. $10000 D+0$

0. $796340+00$

(0000+01

$0.10536 \mathrm{D}+01$

$0.10000 D+0$

$0.835810+00$

$17.0 \quad 0.126640+01$

$0.121640+01$

$0.10000+0$

$0.103900+01$

$\begin{array}{lll}0.100000+01 & 0.826460+00\end{array}$

$0.826460+00$

$\begin{array}{lll}6.0 & 0.12946 D+01 & 0.11467 D+01 \\ 9.0 & 0.12746 D+01 & 0.11886 D+01\end{array}$

$0.117450+01$
$0.11467 D+01$

$0,100000+01$ o. $107820+0$

$0.10000 D+01 \quad 0.11290 D+01$

$0.10000 D+0$

$0.851450+00$

$12.0 \quad 0.12683 D+01 \quad 0.12026 D+0$

$0.10000 D+01 \quad 0.10723 D+01$

$0.10000 D+01 \quad 0.87207 \mathrm{D}+00$

$17.00 .129160+010.115270+0$

9. $0012338 \mathrm{D}+01$

$0.115270+01$

. $10000+010.10546 D+01$

$0.100000+010.841290+00$

12.00 123300+01 0124240101

10000D+01 0.112060+0

$0.100000+010.867560+00$

$17.00 .128830+010.115550+0$

$0.100000+01 \quad 0,994100+00$

$0,100000+0$

$0.867560+00$

$12.00 .123160+010.124410+01$

0. $100000+01$ 0.992470+00

$0.100000+01$

$0.805750+00$

$0.124410+0$

$0.10000 D+01 \quad 0.111500+01$

0. $100000+01$

$0.804900+00$

17.0 0. $135620+010.110380+0$

$\begin{array}{ll}.10000 D+01 & 0.98995 D+00\end{array}$

$0.10000 D+01$

$0.86546 \mathrm{D}+00$

$\begin{array}{llll}0.12287 D+01 & 0.10000 D+01 & 0.90598 D+00\end{array}$

$12.1700157970+0+0$ o $175470+00010000+010160300+010100000+010101470101$

AVERAGE E1 AVERAGE E 2 AVERAGE E3 AVERAGE EE 1 AVERAGE EE 2 AVERAGE EE3
$0.128920+01$
$0.100000+01$
0. 10997D+01
0. $10000 D+01$
$0.849680+00$

$0.118110+01$

\begin{abstract}
$\therefore(\cdots \cdots \cdots$
\end{abstract}

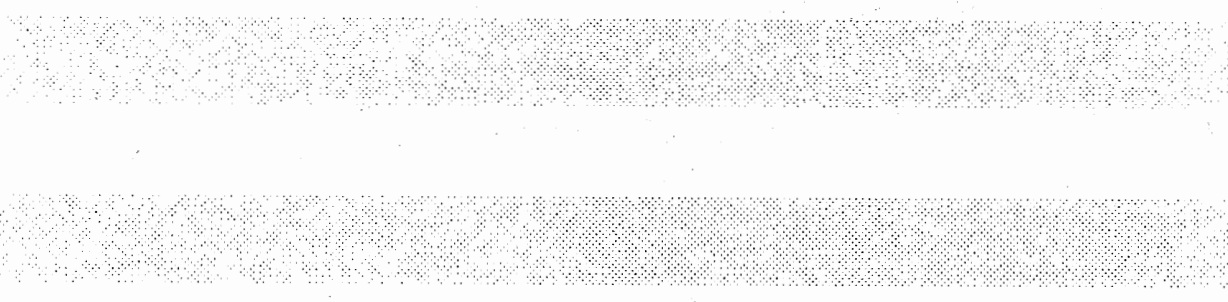


APPENDIX B

INPUT INSTRUCTIONS TO FORTRAN SUBROUTINE DGEAR 
IMSL ROUTINE NAHE

PURPOSE

USAGE

ARGUMENTS N

ECN

FCNJ

$x$
- DGEAR

- DIFFERENTIAL EQUATION SOLVER - VARIABLE ORDER ADAMS PREDICTOR CORRECTOR I.ETHCD OR GEARS METHOD

- CALI DGEAR (N, FCN, FCNJ, $X, H, Y, X E N D$, TOL, INETH, MITER, INDEX, IWR, IWR, IER)

- INPUT NUMBER OF FIRST-ORDER DIFFERENTIAL EQUATIONS. N CAN BE REDUCED, EUT NOVER INCREASED, DURING A PROBLEM. N WUST BE GREATER THAN ZERO.

- NAME OF SUBROUTINE FOR EVALUATIING FUNCTIONS. (INPUT)

THE SUBROUTINE ITSEIF MUST ALSO BE PROVIDED BY THE USER AND IT SHOULD BE OF THE FOLLOWING FORM SUBROUTINE FCN (N,X,Y,YPRIME) REAI $Y(N)$, YPRIME (N)

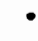

FCN SHOULD EVALUATE YPRIME (I), .., YPRIME (N) GIVEN $N, X$, AND $Y(1), \ldots, Y(N)$. YPRIME (I) IS THE FIRST DERIVATIVE OF $Y(I)$ WITH RESPECT TO $\mathrm{X}$.

FCN MUST APPEAR IN AN EXTERNAL STATEMENT IN THE CAIIING PROGRAM AND $U, X, Y(1), \ldots, Y(N)$ MUST NOT BE ALTERED BY FCN.

- NAME OF THE SUBROUTINE FOR COMPUTING THE N BY N JACOBIAN MATRIX OF PARTIAL DERIVATIVES. (INPUT)

THE SUBROUTINE ITSELF MUST ALSO BE PROVIDED BY THE USER AND IT SHOULD BE OF THE FOLIOWING FORM SUBROUTIINE ECNJ (N, X,Y,PD) REAI $Y(N), P D(N, N)$

FCNJ SHOUID COMPUTE PD(I,J) WHICS IS THE PARTIAL DERIVATIVE OF YPRIME(I) WITH RESPECT TO $Y(J)$.

FCNJ MUST APPEAR IN AN EXTERNAL STATEMENT IN THE CALLING PROGRAM AND $N, X, Y(I), \ldots, Y(N)$ MUST NCT BE ALTERED BY FCNJ.

FCNJ IS CALLED ONLY IF MITER IS EQUAL TO ONE. OTHERIISE A DUMMY ROUTINE CAN BE SUBSTITUTED. SEE REMARKS.

- INDEPENDEINT VARIABIE. (INPUT AIND OUTPUT)

ON INPUT, $X$ SUPPLIES THE INITIAL VALUE AND AND IS USED ONLY CN THE FIRST CAIL. ON OUTPUT, $X$ IS REPLACED WITH THE CURRENT VALUE OF THE INDEPENDENT VARIABLE AT WHICH INTEGRATION HAS BEEN COMPLETED. 
- INPUT/OUTPUT.

ON INPUT, H CONTAINS THE NEXT STEP SIZE IN

$X$. H IS USED ONLY ON THE FIRST CALL.

ON OUTPUT, H CONTAINS THE STEP SIZE USED

LAST, WHETHER SUCCESSEULIY OR NOT.

$Y$

- DEPENDENT VARIABLES, VECTOR OF LEIVGTH N. (INPUT AND OUTPUT)

ON INPUT, $Y(1), \ldots, Y(N)$ SUPPLY INITIAI VALUES.

ON OUTPUT, Y(I), ..,Y(N) ARE REPLACED WITH

A COMPUTED VALUE AT XEND.

XEND - INPUT VALUE OF X AT WHICH SOLUTION IS DESIRED NEXT. INTEGRATION WILI NORMALIY GO SIIGHTLY BEYOND XEND AND THE ROUTINE WILI INTERPOLATE TO $X=X E N D$.

NOTE THAT (X-XEND) *H MUST BE LESS THAN ZERO ( $X$ AND H AS SPECIFIED ON INPLT).

TOI - INPUT REIATIVE ERROR BOUND. TOI NUST BE GREATER THAN ZERO. TOL IS USED ONLY ON THE FIRST CALL UNLESS INDEX IS EQUAL TO - 1 . TOL SHOULD BE AT LEAST AN ORDER OF MAGNITUDE IARGER THAIN THE UNIT ROUNDOFF BUT GENERALIY IOT LARGER THAN .OOI. SINGLE STEP ERROR ESTIMATES DIVIDED BY YMAX(I) WILL BE KEPT LESS THAN TOL IN ROOT-WEAN-SSUARE NORM (EUCIIDEAIN NORH DIVIDED BY SORT(N)). THE VECTOR YMAX OF WEIGHTS IS CONPUTED INTERNALIY AND STORED IN WORK VECTOR WK. INITIAILY YMAX(I) IS THE ABSOLUTE VALUE OF $Y(I)$, WITH A DEFAULT VALUE OF ONE IF $Y$ (I) IS EQUAL TO ZERO. THEREAFTER, YMAX(I) IS THE LARGEST VALUE OF THE ABSOLUTE VALUE OE $Y(I)$ SEEN SO FAR, OR THE INITIAL VALUE OF YMAX(I) IF THAT IS LARGER.

METH - INPUT BASIC METHOD INDICATOR. USED ONLY ON THE FIRST CALL UNLESS INDEX IS EQUAL TO -1 .

METH $=1$, IMPLIES THAT THE ADAMS METHOD IS TO BE USED.

$M E T H=2$, IMPLIES THAT THE STIFF VETHODS OF GEAR, OR THE BACKWARD DIFFERENTIATIOIY FORMULAE ARE TO BE USED.

MITER - INPUT ITERATION IETHOD INDICATOR.

MITER $=0$, IMPIIES THAT EUNCTIONAL ITERATION IS USED. NO PARTIAL DERIVATIVES ARE NEEDED. A DUISYY FCIJJ CAN BE USED.

MITER $=1$, IMPLIES THAT THE CHORD METHOD IS USED WITH AN ANALYTIC JACOBIAN. FOR THIS NETHOD, THE USER SUPPIIES SUBROUTINE FCNJ.

MITER $=2$, IMPIIES THAT THE CHORD METHOD IS USED WITH THE JACOBIAN CALCULATED INTERNALLY BY FINITE DIFFEREMCES. A DUMMY FCNJ CAI BE USED. 
MITER $=3$, IMPLIES THAT THE CHORD METHOD

IS USED WITH THE JACOBIAN REPLACED BY

A DIAGONAL APQROXIMATION BASED ON A

- DIRECTIONAL DERIVATIVE.

A DUMMY ECNJ CAN BE USED.

INDEX - INPUT AND OUTPUT PARAMETER USED TO INDICATE

THE TYPE OF CALL TO THE SUBROUTINE.

ON INPUT, INDEX $=1$, IMPLIES THAT THIS IS THE

FIRST CALL FOR THIS PROBLEM. ON OUTPUT INDEX IS RESET TO $O$ IF INTEGRATION INAS SUCCESSFUI. OTHERWISE, TUE VALUE CF INDEX IS UNCHANGED.

ON INPUT, INDEX $=0$, IMPIIES THAT THIS IS NOT THE FIRST CALL FOR THIS PROBLEM. INDEX IS UNCHANGED ON OUTPUT.

ON INPUT, INDEX $=-1$, IMPLIES THAT THIS IS NOT THE FIRST CAIL FOR THIS PROBLEM, AND THE USER HAS RESET TOL. ON OUTPUT INDEX IS RESET TO $O$ IF INTEGRATION WAS SUCCESSEUI. OTHERWISE THE VAIUE OF INDEX IS UNCHANGED. ON INPUT, INDEX $=2$, IMPIIES THAT THIS IS NOT THE FIRST CAIL FOR THIS PROBIEM. INTEGRATION IS TO CONTINUE AND XEND IS TO BE HIT EXACTIY (NO INTERPOLATION IS DONE) . TEIS VALUE OF INDEX ASSUMES THAT XEND IS BEYOND TEE CURRENT VALUE OF $X$. INDEX IS UNCHANGED ON OUTPUT.

ON INPUT, INDEX $=3$, IMPIIES THAT THIS IS NOT THE FIRST CAIL FOR THIS PROBIEM. INTEGRATION IS TO CONTINUE AND CONTROL IS TO SE RETURNED TO THE CALIING PROGRAM AFTER ONE STEP. XEND IS IGNORED. INDEX IS UNCHANGED ON OUTPUT.

IWK - INTEGER WORK VECTOR OF LENGTH $N$. USED ONLY IF MITER IS EQUAL TO 1 OR 2 .

WK - REAL WORK VECTOR OF LENGTH 4 *N+NMETH+NMITER. THE VAIUE OF NMETH DEPENDS ON THE VALUE OF METH. IF METH IS EQUAL TO 1, NMETH IS EQUAI TO $\mathrm{N} * 13$. IF METH IS EQUAL TO 2, NMETH IS EQUAL TO $\mathrm{N} * 6$. THE VALUE OF NMITER DEPENDS ON THE VALUE OF MITER.

IF MITER IS EQUAL TO 1 OR 2, NMITER IS EQUAI TO $\mathrm{N}^{*}(\mathrm{~N}+\mathrm{I})$. IF MITER IS EQUAL TO 3 , NMITER IS EQUAL TO N. IF MITER IS EQUAL TO 0 , NMITER IS EQUAL TO 1.

WK MUST REMAIN UNCHANGED BETWEEN SUCCESSIVE CALIS DURING INTEGRATION.

IER - ERROR PARAMETER. (OUTPUT)

WARNING ERROR

IER $=33$, IMPIIES THAT $X+H$ WIIL EQUAL $X$ ON THE NEXT STEP. THIS CONDITION DOES NOT FORCE THE ROUTINE TO HALT. HOWEVER, IT DOES INDICATE ONE OF TWO CONDITIONS. 
THE USER MIGHT BE REQUIRING TOO MUCH ACCURACY VIA THE INPUT PARAMETER TOI.

IN THIS CASE THE USER SHOULD CONSIDER INCREASING THE VALUE OE TOL. THE OTHER CONDITION WHICH MIGHT GIVE RISE TO THIS ERROR MESSAGE IS TEAT THE SYSTEM OF DIFFERENTIAL EQUATIONS BEING SOLVED IS STIFF (EITHER IN GENERAI OR OVER THE SUBINTERVAL OF THE PROBLEM BEING SOLVED AT THE TIME OE THE ERROR). IN THIS CASE THE USER SHOULD CONSIDFR USING A NONZERO VAIUE FOR THE INPUT PARAMETER MITER.

WARNING WITH FIX ERROR

IER $=66$, IMPLIES THAT THE ERROR TEST FAILED. H WAS REDUCED BY . I ONE OR MORE TIMES AND THE STEP WAS TRIED AGAIN SUCCESSFULLY.

IER $=67$, IMPIIES THAT CORRECTOR CONVERGENCE COULD NOT BE ACHIEVED. H WAS REDUCED BY . I ONE OR MORE TIMES AND THE STEP WAS TRIED AGAIN SUCCESSFULIY. TERMINAI ERROR

IER $=132$, IMPIIES THE INTEGRAIION WAS HAITED AFTER FAILING TO PASS THE ERROR TEST EVEN AFTER REDUCING H BY A FACTOR OF 1.OEIO FROM ITS INITIAI VALUE. SEE REMARKS.

IER $=133$, IMPLIES THE INTEGRATION WAS HALTED AFTER FAIIING TO ACHIEVE CORRECTOR CONVERGENCE EVEN AFTER REDUCING H BY A FACTOR OF 1.OE10 FROM ITS INITIAI VAIUE. SEE REMARKS.

IER $=134$, IMPLIES THAT AFTER SOME INITIAI SUCCESS, THE INTEGRATION WAS HALTED EITHER BY REPEATED ERROR TEST FAIIURES OR BY A TEST ON TOL. SEE REMARKS.

IER $=135$, IMPLIES THAT ONE OF THE INPUT PARAMETERS $N, X, H, X E N D, T O L, M E T H, M I T E R, ~ O R$ INDEX WAS SPECIFIED INCORRECTIY.

IER $=136$, IMPIIES THAT INDEX HAD A VALUE OF - I ON INPUT, BUT THE DESIRED CHANGES OF PARAMETERS WERE NOT IMPLEMENTEED BECAUSE KEND WAS NOT BEYOND $X$. INTERPOLATION TO $X=X E N D$ WAS PERFORMED. TO TRY AGAIN, SIMPIY CAII AGAIN WITH INDEX EQUAL TO - I AND A NEW VAIUE FOR XEND.

PRECISION/HARDWARE - SINGLE AND DOUBLE/H32

- SINGLE/H36,H48,H60

REQD. IMSI ROUTINES - DGRCS, DGRIN, DGRPS, DGRST, LUDATE, LUEIMF, UERTST, UGETIO 
NOTATION

- INFORMATION ON SPECIAI NOTATION AND

170

CONVENTIONS IS AVAILABLE IN THE MANUAL INTRODUCTION OR THROUGH IMSI ROUTINE UHELP

REMARKS 1. THE EXTERNAL SUBROUTINE FCNJ IS USED ONLY WHEN

INPUT PARAMETER MITER IS EQUAL TO 1. OTHERWISE, A

DUMMY FUNCTION CAN BE USED. THE DUMMY SUBROUTINE

SHOULD BE OF THE FOLIOWING FORM

SUBROUTINE FCNJ (N,X,Y,PD)

INTEGER N

REAL $Y(N), P D(N, N), X$

RETURN

END

2. AFTER THE INITIAI CALL, IF A NORMAL RETURN OCCURRED

(IER=0) AND A NORMAL CONTINUATION IS DESIRED, SIMPIY

RESET XEND AND CALL DGEAR AGAIN. ALL OTHER

PARAMETERS WIII BE READY FOR THE NEXT CALL. A CHANGE

OF PARAMETERS WITH INDEX EQUAI TO - I CAN BE MADE

AFTER EITHER A SUCCESSFUL OR AN UNSUCCESSFUL RETURN.

3. THE COMMON BIOCK /GEAR/ USED IN DGEAR NEEDS TO BE

PRESERVED BETWEEN CAIIS TO DGEAR. IF IT IS NECESSARY

FOR THE COMMON BIOCK TO EXIST IN THE CAIIING PROGRAM

THE FOLIOWING STATEMENT SHOUID BE INCIUDED COMMON /GEAR/ DUMMY (48), SDUMMY (4), IDUMMY (38)

WHERE DUMMY, SDUMMY, AND IDUMMY ARE VARIABLE NAMES NOT USED ELSEWHERE IN THE CALIING PROGRAM. (FOR DOUBIE PRECISION DUMMY IS TYPE DOUBIE AND SDUMMY IS TYPE REAL)

4. THE CHOICE OF VALUES FOR METH AND MITER MAY REQUIRE SOME EXPERIMENTATION, AIND ALSO SOME CONSIDERATION OF THE NATURE OF THE PROBLEM AND OF STORAGE REQUIREMENTS. THE PRIIE CONSIDERATION IS STIFFNESS. IE

THE PROBLEM IS NOT STIEF, THE BEST CHOICE IS PROBABLY METH $=1$ WITH MITER $=0$. IF THE PROBLEM IS STIFE TO A SIGNIFICANT DEGREE, THEN METH SHOULD BE 2 AND MITER SHOULD BE 1, 2, OR 3. IF THE USER HAS NO KNOWLEDGE OE THE INHERENT TIME CONSTANTS OF THE PROBLEM, WITH

WHICH TO PREDICT ITS STIEENESS, ONE WAY TO DETERMINE THIS IS TO TRY METH $=1$ AND MITER = O FIRST, AND LOOK AT THE BEHAVIOR OF THE SOLUTION COMPUTED AND THE STEP SIZES USED. IF THE TYPICAI VAIUES OF H ARE MUCH SMALLER THAN THE SOLUTION BEHAVIOR WOULD SEEM TO REQUIRE (THAT IS, MORE THAN 100 STEPS ARE TAKEN OVER AN INTERVAL IN. WHICH THE SOIUTIONS CHANGE BY LESS THAN ONE PERCENT), THEN THE PROBLEM IS PROBABLY STIFF AND THE DEGREE OF STIFENESS CAN BE ESTIMATED FROM THE VALUES OF H USED AND THE SMOOTHNESS OF THE SOLUTION. IF THE DEGREE OF STIEFNESS IS ONLY SIIGHT, IT MAY BE THAT METH $=1$ IS MORE EFFICIENT THAN METH $=2$. EXPERIMENTATION WOUID BE REQUIRED TO DETERMINE THIS. REGARDLESS OF METH, THE LEAST EEFECTIVE VALUE OF MITER IS 0, AND THE MOST EFEECTIVE IS I OR 2. MITER $=3$ IS GENERALLY SOMEINHERE IN BETWEEN. SINCE THE STORAGE REQUIREMENTS GO UP IN THE SAME ORDER AS EFFECTIVENESS, TRADE-OFE CONSIDERATIONS ARE NECESSARY. FOR REASONS OF ACCURACY AND SPEED, THE CHOICE OF MITER $=1$ IS GENERAILY PREFERRED TO MITER $=2$, UNLESS THE SYSTEM IS FAIRLY COMPEICATED 
(AND FCNJ IS THUS NOT FEASIBLE TO CODE). THE

ACCURACY OF THE FCINJ CALCULATION CAN BE CHECKED BY COMPARISON OF THE JACOBIAN WITH THAT GENERATED WITH MITER $=2 \%$ IF THE JACOBIAN MATRIX IS SIGNIFICANTLY DIAGONAILY DOMINANT, THEN THE OPIION MITER $=3$ IS LIKELY TO BE INEARIY AS EFEECTIVE AS MITER = 1 OR 2, AND WILI SAVE CONSIDERABLE STORAGE AND RUN TIME. IT IS POSSIBLE, AND POTENTIAELY QUITE DESIRABLE, TO USE DIEFERENT VALUES OF METH AND MITER IN DIFFERENT SUBINTERVALS OF THE PROBLEM. FOR EXAMPLE, IF THE PROBLEM IS NON-STIEL INITIALLY AND STIFE LATER, METH $=1$ AND MITER $=0$ MIGHT BE SET INITIALIY, AND METH $=2$ AND MITER = 1 LATER.

5. THE INITIAL VALUE OF THE STEP SIZE, $H$, SHOUID BE CHOSEN CONSIDERABLY SMALIER THAN THE AVERAGE VALUE EXPECTED FOR THE DROBLEM, AS THE FIRST-ORDER METHOD WITH WHICH DGEAR BEGINS IS NOT GENEFALIY THE MOST EFFICIEIT ONE. HOWEVER, EOR THE FIRST STEP, AS EOR EVERY STEP, DGEAR TESTS FOR THE POSSIBIIITY THAT THE STEP SIZE WAS TOO LARGE TO PASS THE ERROR TEST (BASED ON TOL), AND IF SO ADJUSTS THE STEP SIZE DOWN AUTOMATICALIY. THIS DOWNWARD ADJUSTIENT, IF ANY, IS NOTED BY IER HAVING THE VAIUES 66 OR 67, AND SUBSEQUENT RUNS ON THE SAME OR SIMILAR PROBLEM SHOULD BE STARTED WITH AN APPROPRIATELY SMAIIER VALUE OF $H$.

6. SOME OF THE VALUES OF INTEREST LOCATED IN THE COMION BLOCK /GEAR/ ARE

A. HUSED, THE STEP SIZE H LAST USED SUCCESSFUIIY (DUMIYY (8) )

B. NQUSED, THE ORDER LAST USED SUCCESSFULIY (IDUMMY (6))

C. NSTEP, THE CUMULATIVE NUMBER OF STEPS TAKEN (IDUMMY (7))

D. NEE, THE CUMULATIVE NUMBER OF FCN EVALUATIONS (IDUMMY (8))

E. NJE, THE CUMULATIVE NUMBER OF JACOBIAN EVALUATIONS, AND HENCE ALSE OF MATRIX LU DECOMPOSITIONS (IDUMMY (9))

7. THE NORMAL USAGE OF DGEAR MAY BE SUMMARIZED AS FOLIOWS A. SET THE INITIAL VALUES IN Y.

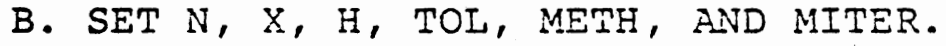

C. SET XEND TO THE FIRST OUTPUT POINT, AND INDEX TO 1.

D. CALI DGEAR.

E. EXIT IF IER IS GREATER THAN 128.

F. OTHERWISE, DO DESIRED OUTPUT OF $Y$.

G. EXIT IF THE PROBLEM IS EINISHED.

H. OTHERWISE, RESET XEND TO THE NEXT OUTPUT POINT, AND RETURN TO STEP D.

8. THE ERROR WHICH IS CONTROLLED BY WAY OF THE PARAMETER TOL IS AN ESTIMATE OF THE LOCAL TRUNCATION ERROR, THAT IS, THE ERROR CONIITTED ON TAKING A SINGLE STEP WITH THE METHOD, STARTING WITH DATA REGARDED AS EXACT. THIS IS TO BE DISTINGUISHED EROM THE GLOBAL TRUNCATION ERROR, WHICH IS THE ERROR IN ANY GIVEN COMPUTED VRILUE OF $Y(X)$ AS A RESULT OF THE LOCAL TRUNCATION ERRORS FROM AIL STEPS TAKEN TO OBTAIN $Y(X)$. THE LATTER ERROR 
ACCUMULATES IN A NON-TRIVIAL WAY FROM THE LOCAL

ERRORS, AND IS NEITHER ESTINATED NOR CONTROLLED BY 172

THE ROUTINE. SINCE IT IS USUALLY THE GLOBAL ERROR THAT

A USER WANTS TO HAVE UNDER CONTROL, SOME

EXPERILENTATION MAY BE NECESSARY TO GET THE RIGHT

VALUE OF TOL TO ACHIEVE THE USERS NEEDS. IF THE

PROBLEM IS MATHEMATICALIY STABLE, AND THE METHOD USED

IS APPROPRIATELY STABLE, THEN THE GLOBAL ERROR AT A

GIVEN X SHOULD VARY SMOOTHLY WITH TOL IN A MONOTONE

INCREASING MANNER.

9. IF THE ROUTINE RETURNS WITH IER VALUES OF 132. 133,

OR 134, THE USER SHOULD CHECK TO SEE IF TOO MUCH

ACCURACY IS BEING REQUIRED. THE USER MAY WISH TO

SET TOL TO A LARGER VALUE AND CONTINUE. ANOTHER

POSSIBLE CAUSE OE THESE ERROR CONDITIONS IS AN

ERROR IN THE CODING OF THE EXTERNAL FUNCTIONS FCN

OR FCNJ. IE NO ERRORS ARE FOUND, IT MAY BE NECESSARY

TO MONITOR INTERMEDIATE QUANTITIES GENERATED BY THE

ROUTINE. THESE QUAITTITIES ARE STORED IN THE WORK VECTOR

WK AND INDEXED BY SPECIEIC ELEMENTS IN THE COMION BLOCK

/GEAR/. IF IER IS 132 OR 134, THE COMPONENTS CAUSIAG

THE ERROR TEST FAILURE CAN BE IDENTIFIED FROM LARGE

VALUES OF TUE QUANTITY

WK (IDUMMY (II) +I) /WK (I), FOR I=I, . ., N.

ONE CAUSE OE THIS MAY BE A VERY SMALL BUT NONZERO

INITIAL VALUE OF ABS ( $Y(I))$.

IF IER IS 133, SEVERAI POSSIBILITIES EXIST.

IT MAY BE INSTRUCTIVE TO TRY DIFFERENT VAIUES OF MITER.

ALTERNATIVEIY, THE USER MIGHT MONITOR SUCCESSIVE

CORRECTOR ITERATES CONTAINED IN WK(IDUMMY (I2)+I), FOR

$I=1, \ldots, N$. ANOTHER POSSIBILITY MIGHT BE TO MONITOR

THE JACOBIAN MATRIX, IE ONE IS USED, STORED, BY

COLUMN, IN WK(IDUMMY $(I 0)+I)$, FOR I=I, .., N*N IF

MITER IS EQUAL TO 1 OR 2 , OR FOR $I=1, \ldots, N$ IF

MITER IS EQUAI TO 3.

Algorithm

DGEAR finds approximations to the solution of a system of first order

ordinary differential equations of the form $y^{\prime}=f(x, y)$ with initial

conditions. The basic methods used for the solution are of implicit linear multistep type. There are two classes of such methods available to the user. The first is the implicit Adams methods (up to order twelve), and the second is the backward differentiation formula (BDF) methods (up to order Iive), also called Gear's stiff methods. In either case the implicitness of the basic formula requires that an algebraic system of equations be solved at each step. A variety of corrector iteration methods is available for this.

DGEAR and the associated nuclei are adaptations of a package designed by A. C. Hindmarsh based on C. W. Gear's subroutine DIFSUB.

See references:

1. Hindmarsh, A.C., "GEAR: Ordinary Differential Equation System Solver", Lawrence Livermore Laboratory, Report UCID-3000I, Revision 3, December, 1974. 
2. Gear, C.w., Numerical Initial Value problems in Ordinary Differential Equations, Prentice-iali, Englewood Cliffs, New Jersey, 1971.

\section{Example}

This example illustrates the basic usage of DGEAR. A table of solution values for $x=1.0,2.0, \ldots, 10.0$ is obtained for the predator-prey problem:

$$
\begin{array}{ll}
y_{1}^{\prime}=2 y_{1}\left(1-y_{2}\right) & y_{1}=1 \\
y_{2}^{\prime}=y_{2}\left(y_{1}-1\right) & y_{2}=3
\end{array} \text { at } x=0
$$

\section{Input:}

$\begin{array}{ll}\text { INTEGER } & \text { N, METH, MITER, INDEX, INK (2), IER, K } \\ \text { REAL } & Y(2), \text { WK (35), X, TOL, XEND, H }\end{array}$

\section{EXTERNAL FCN, FCNJ}

$\mathrm{N}=2$

$\mathrm{X}=0.0$

$Y(1)=1.0$

$Y(2)=3.0$

TOI $=.00001$

$\mathrm{H}=.00001$

$\mathrm{METH}=1$

MITER $=0$

INDEX $=1$

DO $10 \mathrm{~K}=1,10$

$X E N D=F I O A T(K)$

CALI DGEAR (N, FCN, FCNJ , X, H, Y, XEND, TOL, METH, MITER, INDEX, IWK, WK , IER)

C IF(IER.GT.I28) GO TO 20

10 CONTINUE

$Y(1)$ and $Y(2)$ are current solution values at $X$.

C

20 CONTINUE

C

Handle IER.GT.128

Items that may help diagnose the problem should be output here.

C
STOP
END
INTEGER N
REAL $Y(N), Y P R I M E(N), X$
$\operatorname{YPRIME}(1)=2.0 * Y(1) *(1.0-Y(2))$
YPRIME $(2)=Y(2) *(Y(1)-1.0)$
RETUR.N
END
SUBROUTINE FCNJ (N, X,Y,PD)
INTEGER
REAL
RETURN
$\mathrm{N}$
EIND

TOL, N, Y (I), ..., Y(N), XEND, H, X, METH , MITER, AND INDEX.

SUBROUTINE $\quad F C N(N, X, Y, Y P R I M E)$ 


\section{output:}

$I E R=0$

$\begin{array}{cll}X & Y(1) & Y(2) \\ 1 . & 0.08 & 1.46 \\ 2 . & 0.035 & 0.58 \\ 3 . & 0.29 & .25 \\ 4 . & 1.45 & 0.19 \\ 5 . & 4.05 & 1.44 \\ 6 . & 0.18 & 2.26 \\ 7 . & 0.07 & 0.91 \\ 8 . & 0.15 & 0.37 \\ 9 . & 0.65 & 0.19 \\ 10 . & 3.15 & 0.35\end{array}$


APPENDIX C

FORTRAN PROGRAM NLLSQ1 
LEVEL 130 O MAY 1983$)$

REQUESTED OPTIONS (EXEGUTE), NODEGR NOL TST, OPT (O)

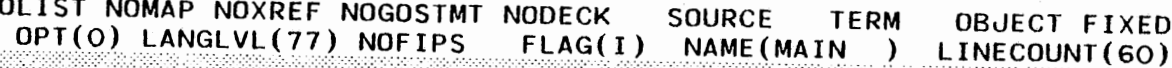

NOTEST NOTRMFLG CHARLEN(500)

SRCFLG NOSYM SDUMP

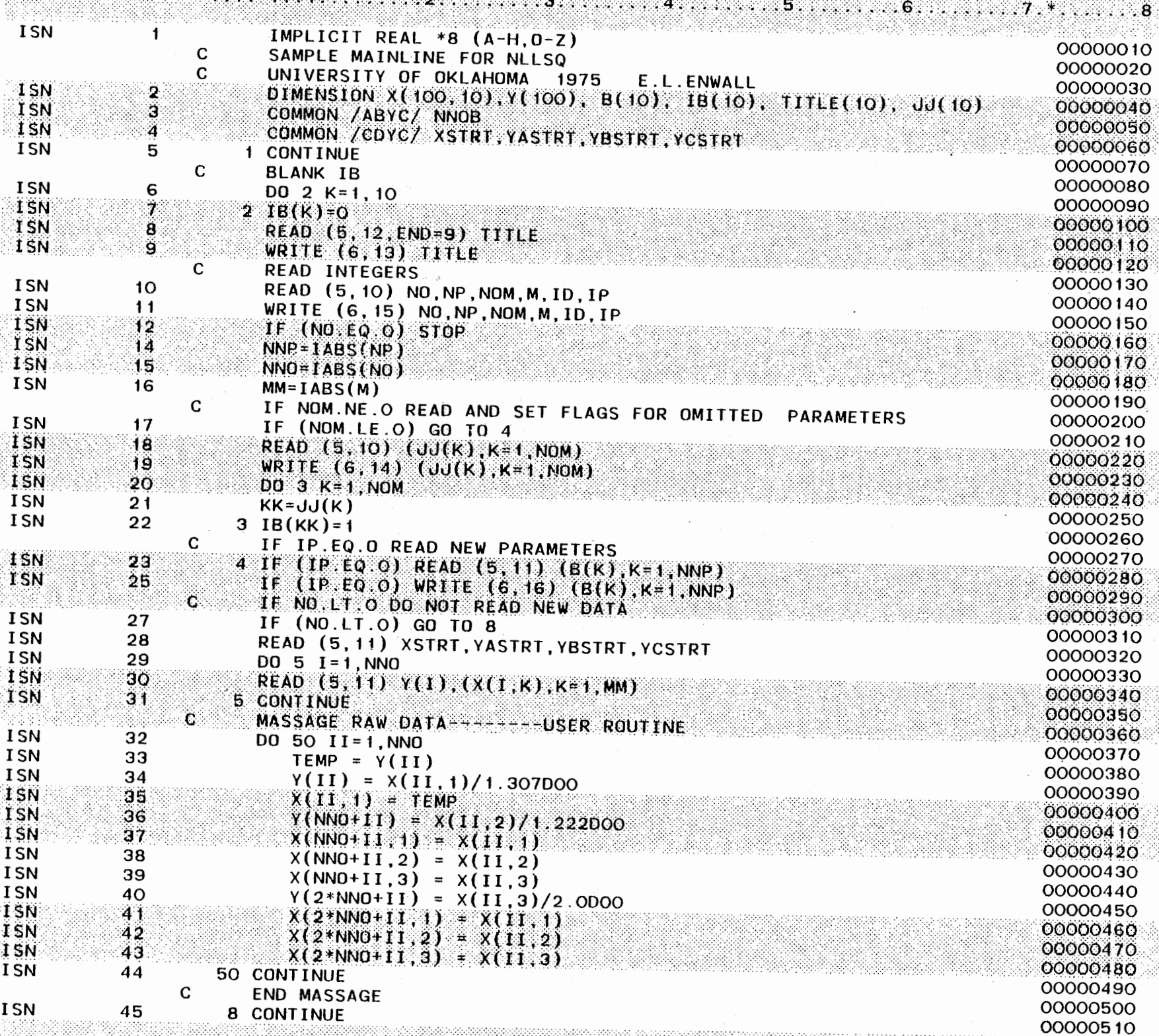




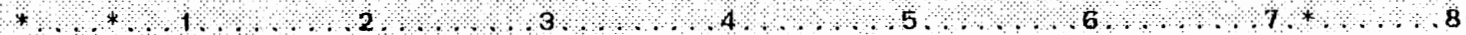

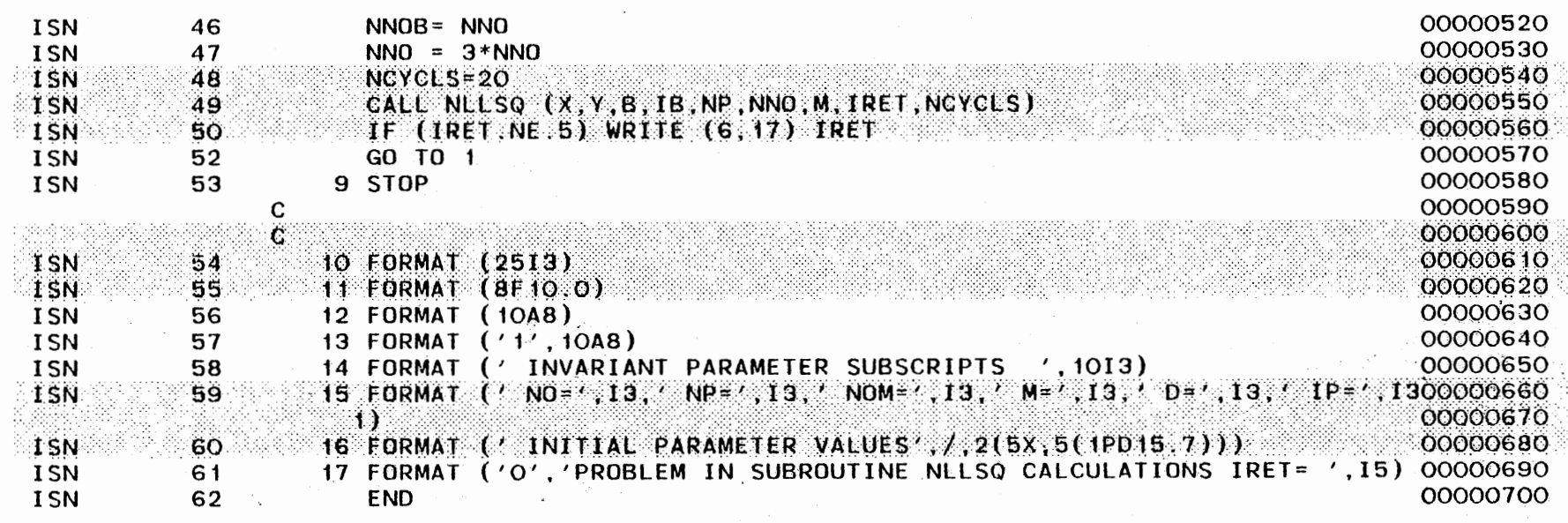

*** VS FORTRAN ERROR MESSAGES $* * *$

IF $\times 0030 \mathrm{I}$ CNTL $0(\mathrm{t})$ TRMF L HAS BEEN SPECTFIEB BUT SYSTERM IS NOT A TERMHNAL. TRMFLG CANCELEO

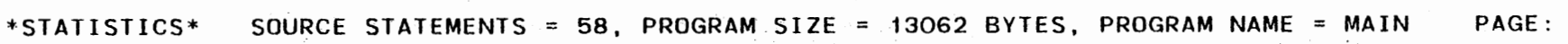

* STATISTICS* D DLAGNOSTIC GENERATEO SEVERTTY COBE $1 S O$

****** END OF COMPILATION 1 ***** 
LEVEL 1.3.0 (MAY 1983)

OPTIONS IN EFFECT:

NOLISI NUMAP NOXREF NOGOSIMI OPT (O) I.ANGL VL (77) NOFIPS

TERM

OBUECT FIXED

NOTESI NOTRMFLG CHARI.EN(50O)

SRCFLG NOSYM

SDUMP

\begin{tabular}{|c|c|c|c|}
\hline \multirow{4}{*}{$\begin{array}{l}\text { I SN } \\
\text { I SN } \\
\text { I SN }\end{array}$} & 1 & STUBROUYINE OCALC $(X, \gamma, B, D, N P, I)$ & 00000710 \\
\hline & 2 & IMPLICIT REAL $\$ 8(A-H, 0-2)$ & 00000720 \\
\hline & $\mathbf{3}$ & DIMENSION $\times(100,10), \gamma(100), B(10), D(10)$ & 00000730 \\
\hline & c & D CALC ROUTINE SPECIFIC TO RUN OR DUMMY & 00000740 \\
\hline I SN & 4 & RE TURN & 00000750 \\
\hline $1 \mathrm{SN}$ & 5 & END & 00000760 \\
\hline
\end{tabular}

SOURCE STATEMENTS 5 P PROGRAM SIZE -432 GYTES PROGRAM NAME = DCALC

-STATISTICS* NO DIAGNOSTICS GENERATED

***** END OF COMPILATION $2 * * * * * *$ 
OPTIONS IN EFFECT NOU IST NOMAP NOXREF NOGOSTMT NODECK SOURGE TERM OBUECT EIXED OPT (O) LANGLVL(77) NOFIPS FLAG(I) NAME(MAIN;) LINECOUNT (6O)

EST NOTRMFLG CHARLEN (500)
SRCFLG NOSYM SDUMP

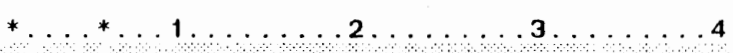

SUBROUT INE YCALC $(X, Y, B, Y C$, WDEL, 1$)$
IMPLICIT REAL $(A-O, O Z)$

DIMENSION $X(100,10), Y(100), B(10), Y Y(4)$, WK $(400)$

COMMON XKT, XKR, F

COMMON /ABYC/ NNOB

COMMON /COYC/ XSTRT YASTRT YESTRT YCSTRT

EXTERNAL FCN FCNO

$\mathrm{N}=4$

METH $=1$

MITER =

INDEX $=1$

KKT

$X K R=B(1)$

$X X=X S T R T$

$Y Y(1)=Y A S T R T / 1.307 D 00$

$Y Y(2)=Y B S T R T / 1.22 D O O$

$Y Y(3)=Y B S T R T=0.0000$

$Y Y(4)=Y$ STRT $/ 2$, ODOO - YY (3)

$\mathrm{H}=1.0 \mathrm{D}-05$

$\mathrm{TOL}=1 . \mathrm{OD}-04$

IF (I.GT.(2*NNOB)) GOTO 20

$6 \ldots \ldots \ldots 7 * \ldots \ldots 8$

IF (I GT NNOB) GDTO

CALL BGEAR (N, FCN, FONJ, XX, H, YY XEND, TOL, METH, MITER, INDEX, IWK, WK, (IER)

$Y C=Y Y(1)$

$X(1,4)=\operatorname{Yr}(1)$

$X(1,5)=Y Y(3)$

RETURN

10 CALL BGEAR (N, FCN, FCNU, XX, H, YY, XEND, TOL, METH, MITER, INDEX, I WK, WK, (IER)

$Y C=Y Y(2)$

$X(1,4)=Y Y(2)$

$x(1,5)=Y Y Y(3$

WBEL $=Y(1)-Y C$

RETURN

20 CALL DGEAR ( $N, F C N, F C N J, X X, H, Y Y, X E N D, T O L, M E T H, M I T E R$, INDEX, IWK, WK, 1IER)

$Y C=Y Y(3)+Y Y(4)$

$x(1,4)=x(1)$

$X(1,5)=$ Yr $(4)$

WDEL $=Y(1)-Y C$

RETURN

END

SOURCE STATEMENTS = 43, PROGRAM SIZE $=5752$ BYTES, PROGRAM NAME \& YCALC

NO DIAGNOSTICS GENERATED
00000770

00000780

00000790

00000800

00000810

00000820

00000830

0000830

000850

0000060

00870

0

0

00000890

00000900

00000910

00000920

00000930

00000940

00000945

00000950

00000960

00000970

00000980

00000990

00001000

00001010

00001020

0001030

0001040

000

-

00001070

00001080

00001090

00001100

00001110

00001120

00001130

00001140

00001150

00001160

00001170

00001180

00001190

00001200

001210

PAGE:

4.

* STATISTICS*

END OF COMPILATION $3 * * * * * *$ 
OPIIONS IN EFFECT: NOLIST NOMAP NOXREF NOGOSTMT NODECK SOURCE TERM OBJECT FIXED NOTEST NOTRMFLG OPI(O) I.ANGIVL(77) NOFIPS FIAG(I) NAME(MAIN, LINECOUNT(60)

\begin{tabular}{|c|c|c|c|}
\hline ISN & 1 & SUBROUTINE FCN (N,X,Y,YPRIME) & 00001220 \\
\hline ISN & 2 & TMPLICIT REAL $* B(A-H, O-Z)$ & 00001230 \\
\hline I SN & 3 & DIMENSION Y $Y(N), Y P R I M E(N), E(10)$ & 00001240 \\
\hline ISN & 4 & COMMON XKI,XKR,F & 00001250 \\
\hline ISN & 5 & $Y \operatorname{PRIME}(1)=0.25000 * X K T * Y(2)-X K K * Y(1)$ & 00001260 \\
\hline ISN & 6 & YPRIME (2) $=X K T * Y(1)-0.25000 * X K T * Y(2)-X K R * Y(2)+X K R * Y(3)$ & 00001270 \\
\hline ISN & 7 & YPRIME $(3)=X K R \div Y(2)-X K R+Y(3)-F * X K T * Y(3)$ & 00001280 \\
\hline ISN & 8 & YPRIME (4) $\approx F * X K T * Y(3)$ & 00001285 \\
\hline I SN & $\mathbf{9}$ & RETURN & 0000129 \\
\hline $1 \mathrm{SN}$ & 10 & END & 00001300 \\
\hline
\end{tabular}

*STATISTICS* SOURCE SIATEMENTS - 10, PRDgRAM SIZE a 1039 BYTES, PROGRAM NAME = FCN

PAGE: 
LEVEL 13,0 (MAY 1983$)$

NOTEST NOTRMFLG CHARLEN (500)

SRCF L G NOSYM SDUMP

$$
* \ldots *^{*} \ldots 1 \ldots \ldots \ldots .2 \ldots \ldots
$$

5

6.

$7 . * \ldots .8$

\begin{tabular}{|c|c|c|c|}
\hline ISN & 1 & SUBROUT INE $F C N U$ (N, $X, Y, P O)$ & 00001310 \\
\hline$I S N$ & 2 & IMPLICIT AEAL $8 \quad(A-H, B-2)$ & 00001320 \\
\hline I SN & 3 & DIMENSION $Y(N), P D(N, N)$ & 00001330 \\
\hline I SN & 4 & RETURN & 00001340 \\
\hline I SN & 5 & END & 00001350 \\
\hline
\end{tabular}

YSTATISTICS* SOURCE STATEMENTS $=5$, PRUGRAM SIZE $=556$ BYTES, PROGRAM NAME $=$ FCNU

PAGE:

*STATISTICS * NO DIAGNOSTICS GENERATED

****** END OF COMPILATION $5 * * * * * *$

END OF COMPILATION $5 * * * * * *$

6

(

(

২

s. 
$+\ldots * \ldots 1 \ldots \ldots \ldots 2 \ldots \ldots \ldots 3 \ldots \ldots \ldots 4 \ldots \ldots+\ldots \ldots$

ISN SUBROUTINE NLLSO ( $X, Y, B, I B, N P, N O$ MM IRET NCYCLS) NON LINEAR I.EAST SOUARES ROUTINE USING MAROUAROT CONVERG STRATEGY OOOO 370 J.SOC. INDUST. APPL.MATH. VOL. II.NO.2. JUNE 1963-D.W.MAROUARDT OOOOI38O DIMENSIONED FOR 10 VARIABLES, IOO OBSERVATIONS, 5 IND. VARIABLES OOOOI390 NP NEGATIVE CALCULATES ESTIMATED DERIVATIVES OOO14OO MM NEGATIVE PRINTS B VALUES ON EVERY CYCLE $\quad$ OOOO1410 WRITTEN U OF OKLA MARCII 1975 E.L.ENWALL. $\quad 00001420$ IMPLICIT REAL. $\$ 8$ (A-H,O-Z) $\quad 00001430$ REAL*8 PHIR, PHI, PHIL 10,PIILB IO,DEN,DARCOS, SUMA 0001440 DIMENSION $X(100,10), Y(100), B(10), D(10), I B(10) \quad 00001450$ DIMENSION Al 10, 10). AS(10,10), S(100), BS(10), DB(10), DDB(10), DGOONO1460 1(10), $V(10), \operatorname{AAS}(10,10), A M(100)$ REAL GAMZRO/4 EEO1/,DDEL/5.E-5/.EPS/2.5E-09/.FEPS/1.E-6/.LAMBDA OOOO148O COMMON XK1, XK4,XK2

DATA $101 /$ B $(\%, 102 /)=\%$.NIP/O/

$0000 \div 490$

OOOO 1500

$\begin{array}{lc}\text { ISN } & 6 \\ \text { ISN } & 7 \\ \text { ISN } & 8 \\ \text { ** ERROR } & 1755(W) * * *\end{array}$

***ERROR $1755(W) * * *$

$\begin{array}{lr}\text { ISN } & 9 \\ \text { ISN } & 11 \\ \text { ISN } & 12 \\ \text { ISN } & 13 \\ \text { ISN } & 14 \\ \text { ISN } & 15 \\ \text { ISN } & 17 \\ \text { ISN } & 19 \\ \text { ISN } & 20 \\ \text { ISN } & 21 \\ \text { ISN } & 22 \\ \text { ISN } & 23 \\ \text { ISN } & 24 \\ \text { ISN } & 25 \\ \text { ISN } & 26 \\ \text { ISN } & \\ \text { ISN } & 27 \\ \text { ISN } & 28 \\ & \\ \text { ISN } & 29 \\ \text { I SN } & 30 \\ \text { ISN } & 31 \\ \text { ISN } & 33 \\ \text { ISN } & 34 \\ \text { ISN } & 35 \\ \text { ISN } & 36 \\ \text { I SN } & 37 \\ \text { ISN } & 38 \\ \text { ISN } & 39 \\ \text { ISN } & 40 \\ \text { ISN } & 41 \\ \text { ISN } & 42 \\ \text { ISN } & 43 \\ \text { ISN } & 44\end{array}$

LIKE TYPE TO AVOID ERROR MESSAGE. CTER CONSTANT HAS BEEN ASSTGNED TO

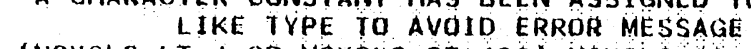

IF (NCYCLS LT I.OR NCYCLS GT 1OO) NCYCIS = 20

$\angle A M B D A=0.01000001$

ND $=1$

NPRT $=1$

IRET $=0$

IF $(N P \text {. LE OO })^{N} \mathrm{ND}=-1$

IF (MM.LE.O) NNPRT $=-1$

$N P=I A B S(N P)$

IF (NP.NE.O) GO ro 101

WRITE $(6,189)$

RETURN

$101 \quad M M=I A B S(M M)$

WRITE $(6,176)$

$\mathrm{NCYC}=\mathrm{O}$

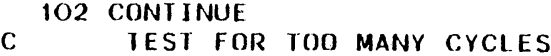

If (NCYC.GT.NCYCLS) GO TO 14

NCYC $=$ NCYC! 1

c BUILU MATRIX

NIP $=0$

Do $103 K=1, N P$

IF $(I B(K) \cdot N E . O) \quad N I P=N I P+1$

$D(K)=0.0$

$V(k)=0.0$

DO $103 \quad L=1$. NP

$A(K, I)=0.0$

103 CONTINUE

PIII $=0.0$

DO $109 \quad I=1$. NO

CALL YCALC (X,Y,B,YC,WDEL, I)

IF (ND.GT O) GO TO IOS

SDEL = WDEL

IF $(1 B(K)$.NE.O) GO ro 10.4

A NON-CHARACTER VARIABLE OR ARRAY INITIALIZE WITH CONSTANT OT

00001510

00001520

00001530

00001540

00001550

00001560

00001570

00001580

00001590

00001600

00001610

00001620

00001630

000016.40

00001650

00001660

$000016 \% 0$

00001680

00001690

00001700

00001710

00001710

00001720

00001740

00001750

0001760

0001760

0001780

00001780

00001790

00001800

00001810

00001820

00001830

00001840 


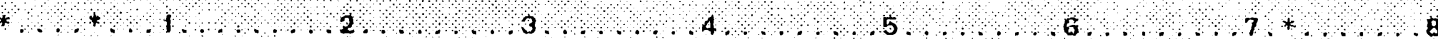

\begin{tabular}{|c|c|}
\hline I SN & 45 \\
\hline I SN & 46 \\
\hline $1 \mathrm{SN}$ & 47 \\
\hline ISN & 48 \\
\hline $1 S N$ & 49 \\
\hline I SN & 50 \\
\hline I SN & 51 \\
\hline I SN & 52 \\
\hline $1 \mathrm{SN}$ & 53 \\
\hline ISN & 54 \\
\hline ISN & 55 \\
\hline I SN & 56 \\
\hline ISN & 57 \\
\hline I SN & 58 \\
\hline $1 \mathrm{SN}$ & 59 \\
\hline ISN & 60 \\
\hline ISN & 61 \\
\hline I SN & 62 \\
\hline I SN & 63 \\
\hline I SN & 64 \\
\hline $1 \mathrm{SN}$ & 65 \\
\hline I SN & 66 \\
\hline I SN & 67 \\
\hline I SN & 69 \\
\hline I SN & 71 \\
\hline ISN & 72 \\
\hline $1 S N$ & 73 \\
\hline I SN & 75 \\
\hline I SN & 76 \\
\hline I SN & 77 \\
\hline$I S N$ & 78 \\
\hline ISN & 79 \\
\hline I SN & 80 \\
\hline I SN & 81 \\
\hline I SN & 82 \\
\hline I SN & 83 \\
\hline I SN & 84 \\
\hline I SN & 85 \\
\hline I SN & 86 \\
\hline$I S N$ & 88 \\
\hline$I S N$ & 89 \\
\hline ISN & 90 \\
\hline I SN & 91 \\
\hline I SN & 92 \\
\hline$I S N$ & 93 \\
\hline I SN & 94 \\
\hline ISN & 95 \\
\hline I SN & 96 \\
\hline I SN & 97 \\
\hline I SN & 38 \\
\hline
\end{tabular}

$B Z=B(K)$

$\mathrm{DD}=\mathrm{BZ} * \mathrm{DDEL}$

CALL YCALC (X, Y,B, YC,WOEL, I)

$O(K)=($ SDEL $-W D E L) / D D$

$B(K)=B Z$

104 CONTINUE

WDEL $=$ SDEL

Go 10106 .

$105 \mathrm{CALL}$ DCALC (X,Y, B, O NP, $)$

106 PHI $=$ PHI + WOEL NWDEL

DO $108 K=1$, NP
IF (IB $(K)$.NE.O) Go To 108

$V(K)=V(K)+D(K) * W D E L$

Do $107 \mathrm{~L}=1 \mathrm{NP}$

IF (1B(L) NE O) GO 10,107

$\mathrm{A}(\mathrm{K}, \mathrm{L})=\mathrm{A}(\mathrm{K}, \mathrm{L})+\mathrm{B}(\mathrm{K}) * \mathrm{~B}(\mathrm{~L})$

107 CONTINUE

108 CONTINUE

109 CONTINUE

c 4 GALE RMSD

RMSD $=($ PHIR $/(N O$ NP + NTP $) * \% 5$

IF (NPRT.LE.O.OR.NCYC.EQ.. 1) WRITE $(6,182)$ NCYC,RMSD, LAMBDA

IF (NPRT.LE.O.OR.NCYC.EQ.1) WRITE $(6,187)(I 01, K, I 02, B(K), K=1, N P)$ $M=0$

C. SAVE DLAGONAL ELEMENTS

$00110 \mathrm{~K}=1, \mathrm{NP}$

tF $(t B(K)$ NE 0$) A(K, K)=1,0$

IF $(A(K, K) L E, O O)$ GO 169

$110 \mathrm{DG}(\mathrm{K})=A(\mathrm{~K}, \mathrm{~K}) * * .5$

DO $111 K=1$. NP

$V(K)=V(K) / B G(K)$

(K) 1 .

C SAVE ORIGINAL MATRTX

$A A S(K, L)=A(K, L)$

SCALE MATRIX

$111 A(K, L)=A(K, L) /(D G(K) * D G(L))$

$C$ SAVE MATRIX, ORIG PARAMS

DO $112 \mathrm{~K}=1 \mathrm{NP}$

$\mathrm{BS}(\mathrm{k})=\mathrm{B}(\mathrm{K})$

DO $112 L=1$, NP

$\operatorname{AS}(K, L)=A(K, L)$

112 IF $(K . E Q . L) \quad A(K, L)=A(K, L)+L A M B D A$

IRET 1

113 GONT INUE

DO $114 K=1 \mathrm{NP}$

$14 \operatorname{DDB}(K)=\mathrm{DB}(K)$

C CHECK FOR CONVERGENCE

$\mathrm{DO} 115 \mathrm{~K}=1 \mathrm{NP}$

$Z=D O B(K) * * 2 /(F E P S+B(K) * * 2)$

IF ( 2 GT EPS) GO ro 116

115 CONTINUE

WRITE $(6,179)$

GO TO 134
00001850

00001860

00001870

00001880

00001890

00001900

00001910

00001920

00001930

00001940

00001950

00001960

OOOO1970

001980

000

on

000

00002010

00002020

00002030

00002040

00002050

00002060

00002070

00002080

00002090

00002100

00002110

00002120

00002130

00002140

002150

002160

00002160

0002170

000280

00002190

00002200

00002210

00002220

00002230

00002240

00002250

00002260

00002270

00002280

00002290

00002300

00002310

0002320

000

002340

0002340

00002350

00002360

00002370

00002380

00002390

00002400 
C CALC PHI (I.AMBOA)

116 PHIL $=0.0$

Do $117 \quad I=1$. NO

$\begin{array}{lr}\text { ISN } & 99 \\ \text { ISN } & 100 \\ \text { ISN } & 101 \\ \text { ISN } & 102 \\ \text { ISN } & 103 \\ \text { ISN } & 104 \\ \text { ISN } & 105 \\ \text { ISN } & 106 \\ \text { ISN } & 107 \\ \text { ISN } & 108 \\ \text { ISN } & 109 \\ \text { ISN } & 110 \\ \text { ISN } & 112 \\ \text { ISN } & 113 \\ \text { ISN } & 114 \\ & \\ \text { ISN } & 115 \\ \text { ISN } & 116 \\ \text { ISN } & 117 \\ \text { ISN } & 118 \\ \text { ISN } & 119 \\ \text { ISN } & 120 \\ \text { ISN } & 121 \\ \text { ISN } & 121 \\ \text { ISN } & 122 \\ \text { ISN } & 123 \\ \text { ISN } & 124 \\ \text { ISN } & 125 \\ \text { ISN } & 126 \\ \text { ISN } & 127 \\ \text { ISN } & 128 \\ \text { ISN } & 129 \\ \text { ISN } & 130 \\ \text { ISN } & 131 \\ \text { ISN } & 132 \\ \text { ISN } & 134 \\ \text { ISN } & 135 \\ \text { ISN } & 136 \\ \text { ISN } & 137 \\ \text { ISN } & 138 \\ \text { ISN } & 139 \\ \text { ISN } & 140 \\ \text { ISN } & 141 \\ \text { ISN } & 142 \\ \text { ISN } & 143 \\ \text { ISN } & 144 \\ \text { ISN } & 145 \\ \text { ISN } & 146 \\ \text { ISN } & 147 \\ \text { ISN } & 148 \\ \text { ISN } & 149\end{array}$

CALL

(X, Y, B, YC, WDELL, I

TEST PIIIL

1 18 CON (PHIL.I.E.PHIR) GO TO 128

$.4 \ldots \ldots 5 \ldots \ldots \ldots \ldots . \ldots \ldots$

IF (LAMBUA.GE.1.O) GO TO 123

LAMBDA

DO $119 \mathrm{~K}=1$, NP

DO $119 \quad 1=1, N P$

$A(K, L)=A S(K, L)$

19 IF $(K, E O L) \dot{A}(K, L)=A(K, L)+L A M B D A$ IRET $=2$

Go TO 149

C CALC PHII (LAMBDA*10)

21 PHIL 1O=0.O

CALL YCALC (X,Y,B, YC, WDEL, 1$)$

122 PHIIL 1O=PHIL 1O +WBEL WDEL

IF (PHILIO GE PPIIR ANDL

NEW (PIHT TO.GE.PHIR) GO TO 118

C NEW LAMBOA

C LARGE LAMBDA. GAMMA TEST

123 CONTINUE

$D T G=0.0$

GTG $=0.0$

$B$ T $B=0.0$

DO $124 \mathrm{~K}=1$. NP

$D T G=D T G+D B(K)+D G(K)$

$G T G=G T G+D G(K) * D G(K)$

$124 B T B=B T B+D B(K) * D B(K)$

$D E N=D I G /((B T B * G T G) * * 5)$

GAM $=(180 . / 3.141592) * D A R C O S(D E N)$

IF (NPRT.LE.O.OR.NCYC.EQ. i) WRITE $(6,177)$ GAM, LAMBDA

IF (GAM.GE.90.O) GO TO 148

If (GAM.GE.GAMZRO) GO TO 102

DO $125 K=1$, NP

DO $125 K=1, N P$
$D B(K)=D B(K) / 2$.

$125 B(K)=B S(K)+D B(K)$

Do $126 \mathrm{~K}=1$. N

$Z \div D B(K) * * 2 /($ FEPS $+B(K) *+2)$

126 CONTINUE

Go $10 \quad 146$

127 GO TO 12

(LAMBDA/ 10)

28 LAMBDA $=L A M B D A / 10$.

PIILB 10 $=0.0$

DO $129 K=1$, NP

DO $129 L=1$.NP

00002410

00002420

00002430

00002440

00002450

00002460

00002470

00002490

00002500

00002510

00002520

00002540

00002550

00002560

00002610

00002630

00002650

00002660

00002670

00002680

00002690

00002700

00002710

00002720

00002730

00002740

00002750

00002760

OOOO2770

00002780

00002790

0000280

000028

00028

00028

0002830

00002840

00002850

00002860

00002870

00002880

00002890

00002900

00002910

00002920

00002930

00002940

00002950

00002960 


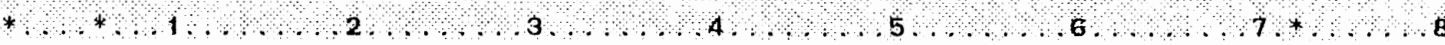

129 IF $(K . E Q . L) \quad A(K, L)=A(K, L)+L A M B D A$ IRE T $=3$

Go to 149

130 CONTINUE

DÖ $131 \mathrm{I}=1, \mathrm{NO}$

CALL YCALC $(X, Y, B, Y C, W D E L, I)$

131 PHLB 10=PHLB 10+WDEL *WDEL

IF (PHLB 1O.GT.PHIR) GO TO 132

$\mathrm{GO} 10102$

C RESTORE START ING VALUE OF LAMBDA

132 LAMBDA $=\angle A M B D A * 10$

DO $133 \mathrm{~K}=1, \mathrm{NP}$

$133 B(K)=B S(K)+D D B(K)$

GO TO 102

C CONVERGENC

134 CONT INUE

C SET UP FOR FINAL MATRIX INVERSION, CALC EST CONDITION NUMBER

00002970

00002980

00002990

00003000

00003010

00003020

00003030

00003040

00003050

00003060

00003070

00030

00030

00030

0003100

00003110

00003120.

00003130

00003140 SAVE SCALED MATRIX IN AS

00003150

$A M I N=1 . E 25$

AMAX $=0.0$

Do $135 \mathrm{~K}=1$, NP

If (AAS $(K, K)$, GI AMAX) AMAX-AAS $(K, K)$

IF $(\operatorname{AAS}(K, K) . L T . A M I N) \quad A M I N=A A S(K, K)$

DO $135 L=1, N P$

$A(K, L)=A A S(K, L) /(D G(K) * D G(L))$

00003170

00003180

00003190

00003200

00003210

00003220

35 AS (K L)

CONONO $A M A X$ /AMIN

CDTTE (6, 185) 60 (N)

IRET $=4$

GO TO 149

c

SCALED INUERSE INA

DO $137 \mathrm{~K}=1$, NP

ISN $\quad 180$

ISN $\quad 183$

I SN

ISN

ISN

$37 \operatorname{AAS}(K, L)=A(K, L) /(D G(K) * D G(L))$

c

00003230

00003230

00003250

0003260

0003260

00003270

00003280

00003290

00003300

00003310

00003320

00003330

00003340

$B(K) B S(k)$,

Do $139 K=1, N P$

$139 D G(K)=A A S(K, K) * * 5$

DO $140 \quad K=1$, NP

$140 \operatorname{AAS}(K, L)=A A S(K, L) /(D G(K) * D G(L))$

\begin{tabular}{ll}
140 AAS $(K, L)=A A S(K, L) /(D G(K) * D G(L))$ & 00003400 \\
\hline & AAS NOW CORRELATION MATRIX
\end{tabular}

00003390

CTO ERROPS IN EAT PARAMETER

DO $14 \mathrm{~K}=1 \mathrm{~N}$ $\mathrm{DB}(K)=\mathrm{DG}(\mathrm{K}) * \mathrm{RMSD}$

IF (IB (K).NE.O) DB(K)=0.0

192

193

141 CONTINUE

WRITE $(6,170)$ (K,BS(K), DB (K) K K 1 , NP)

00003430

00003440

00003450

00003460

00003470

00003480

00003490

WRITE $(6,173)$

00003500

CALL YCALC $(X, Y, B, Y C, W D E L, I)$

WRITE $(6,172) \quad Y(I), Y C, W D E L,(X(I, K), K=1, M M)$

00003520 
142 CONT INUE

OO $143, K=175)$

\begin{tabular}{|c|c|}
\hline I SN & 202 \\
\hline $1 \mathrm{SN}$ & 203 \\
\hline $1 \mathrm{SN}$ & 204 \\
\hline I SN & 205 \\
\hline I SN & 206 \\
\hline $1 \mathrm{SN}$ & 207 \\
\hline I SN & 208 \\
\hline I SN & 209 \\
\hline $1 S N$ & 210 \\
\hline ISN & $21 !$ \\
\hline I SN & 212 \\
\hline I SN & 213 \\
\hline I SN & 214 \\
\hline ISN & 215 \\
\hline ISN & 216 \\
\hline I SN & 217 \\
\hline ISN & 218 \\
\hline ISN & 219 \\
\hline ISN & 220 \\
\hline I SN & 221 \\
\hline ISN & 222 \\
\hline I SN & 223 \\
\hline $1 \mathrm{SN}$ & 224 \\
\hline I SN & 225 \\
\hline$I S N$ & 226 \\
\hline I SN & 227 \\
\hline I SN & 228 \\
\hline ISN & 229 \\
\hline $1 \mathrm{SN}$ & 230 \\
\hline ISN & 231 \\
\hline $1 \mathrm{SN}$ & 232 \\
\hline I SN & 233 \\
\hline I SN & 234 \\
\hline I SN & 235 \\
\hline $1 \mathrm{SN}$ & 236 \\
\hline I SN & 237 \\
\hline I SN & 238 \\
\hline I SN & 239 \\
\hline I SN & 240 \\
\hline I SN & 241 \\
\hline ISN & 242 \\
\hline ISN & 243 \\
\hline ISN & 244 \\
\hline I SN & 245 \\
\hline I SN & 246 \\
\hline I SN & 247 \\
\hline ISN & 248 \\
\hline ISN & 249 \\
\hline $1 \mathrm{SN}$ & 250 \\
\hline ISN & 251 \\
\hline ISN & 252 \\
\hline ISN & 253 \\
\hline
\end{tabular}

DO $144 \quad K=1$.NP

DO $144 \mathrm{~K}=1$. NP

AAS $(K, L)=0.0$ WRit $(0,104)$

DO $145 \mathrm{~K}=1$ NP

IRE T $=5$

C RETUR

C. G L TEST 146 WRITE $(6,180)$

GO TO 134

147 CONI INUE

Go ग0 134

Go To 134

$150 M=M+1$

$$
\begin{aligned}
& M=M+ \\
& K=1
\end{aligned}
$$

GO TO 165

151 DO $158 \quad M=1$, NP

I MAX $=M-1$

DO $157 \mathrm{~L}=\mathrm{M}, \mathrm{NP}$

SUMA $=0.0$

$K L I=L$

$J=N P-I$

$K L I=K L I+U$

$153 \quad K M I=K M I+J$

$A M(K)=D E N O M$

GO TO $15 \%$

$157 K=K+1$

158 CONTINUE

$$
\text { NP }
$$

143 WRITE $(6,174)$ K, (AAS $(K, L), L=1, N P)$

A4 AAS(K, $)=A A S(K, L)+A(K, U) \times A S(U, L)$

C TAA AASTKE DUT PRODUCT OF INVERSE AND STARTING MATRICES

145 WRITE $(6,183) K,(A A S(K, L), L=1, N P)$

C TOO MANY CYCLES

WRI TE $(6,181)$

148 WRITE $(6,186)$ GAM

INTERNAL SUBROUIINE TO INVERT MATRIX CIIOLESKI METIIOD

$$
\begin{aligned}
& M=1 \\
& \text { DO } 150 K=1, N P
\end{aligned}
$$

If (NP.GT.1) GO TO $1 \mathrm{~b}$ !

$A M(I)=1.0 / A M(1)$

If (IMAX) 154,154,152

152 DO $153 \quad 1=1$, IMAX

SUMA = SUMA + AM $(K L 1) * A M(K M I)$

154 TERM $=A M(K)-S U M A$

IF (L-M) $155,155,156$

155 IF (TERM LE. O.O) GN TO 169

DENOM $=$ TERM**.5

$156 \operatorname{AM}(K)=$ TERM/DENOM
00003530 00003540 00003550 00003560 00003570 00003580 00003590 00003600 00003610 00003620 00003630 00003640 00003650 0003650 0003660 00003680 00003680 0003690 00003700 00003710 00003720 00003730 00003740 00003750 00003760 00003770 00003780 00003790 00003800 00003810 00003820 00003830 00003840 00003850 00003860 00003870 0003880 0003890 003 00003910 900 00003920 0003930 00003940 00003950 00003960 00003970 00003980 00003990 000040no 00004010 00004020 00004030 00004040 00004050 00004060 00004070 


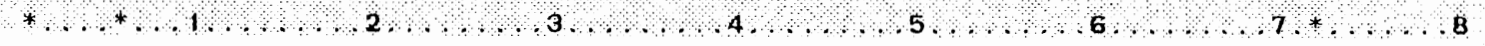

\begin{tabular}{|c|c|c|c|c|}
\hline I SN & 254 & & $\operatorname{AM}(1)=1.0 / \operatorname{AM}(1)$ & 00004090 \\
\hline ISN & 255 & & $K D M=1$ & 00004100 \\
\hline$I \mathrm{SN}$ & 256 & & $00,161,1,2, N$ & 00004110 \\
\hline ISN & 257 & & $\mathrm{KDM}=\mathrm{KBM}+\mathrm{NP}-\mathrm{L}+2$ & 00004120 \\
\hline I SN & 258 & & TERM 1 O/AM(KOM) & 00004130 \\
\hline I SN & 259 & & $A M(K D M)=T E R M$ & 00004140 \\
\hline I SN & 260 & & $K M I=0$ & 00004150 \\
\hline ISN & 261 & & $K L I=L$ & 00004160 \\
\hline $1 \mathrm{SN}$ & 262 & & $\operatorname{IMAX}=\mathrm{L}-1$ & 00004170 \\
\hline ISN & 263 & & $00,160 M=1,1 M A X$ & 00004180 \\
\hline$I N$ & 264 & & $k=k L t$ & 00004190 \\
\hline I SN & 265 & & SUMA $=0.0$ & 00004200 \\
\hline I SN & 266 & & DO $159 I=M, I M A X$ & 00004210 \\
\hline I SN & 267 & & $I I=K M I+I$ & 00004220 \\
\hline $1 \mathrm{SN}$ & 268 & & SUMA SUMA AM(KLI) $\checkmark A M(11)$ & 00004230 \\
\hline ISN & 269 & 159 & $\mathrm{KL} L \mathrm{KL} I+\mathrm{NP}-1$ & 00004240 \\
\hline $1 S N$ & 270 & & $A M(K)=S U M A * T E R M$ & 00004250 \\
\hline I SN & 271 & & $J=N P-M$ & 00004260 \\
\hline I SN & 272 & & $K L I=K+J$ & 00004270 \\
\hline ISN & 273 & 160 & $K M I=K M I+J$ & 00004280 \\
\hline$I S N$ & 274 & 161 & CONT INUE & 00004290 \\
\hline $\mathrm{ISN}$ & 275 & & $k=1$ & 00004300 \\
\hline I SN & 276 & & bo $164 \mathrm{M}=1, \mathrm{NP}$ & 00004310 \\
\hline I SN & 277 & & $K L I=K$ & 00004320 \\
\hline I SN & 278 & & Do $163 \mathrm{~L}=\mathrm{M}, \mathrm{NP}$ & 00004330 \\
\hline I SN & 279 & & $K M I=K$ & 00004340 \\
\hline $1 \mathrm{SN}$ & 280 & & IMAX $=\mathrm{NP}-\mathrm{L}+1$ & 00004350 \\
\hline I SN & 281 & & SUMA $=0.0$ & 00004360 \\
\hline $1 \mathrm{SN}$ & 282 & & $001621=1,1 M A x$ & 00004370 \\
\hline I SN & 283 & & SUMA $=$ SUMA $A M(K L I) * A M(K M I)$ & 00004380 \\
\hline I SN & 284 & & $K L I=K L I+1$ & 00004390 \\
\hline I SN & 285 & 162 & $K M I=K M I+1$ & 00004400 \\
\hline$I \mathrm{SN}$ & 286 & & $A M(K)=S U M A$ & 00004410 \\
\hline ISN & 287 & 163 & $k=k+1$ & 00004420 \\
\hline $1 \mathrm{SN}$ & 288 & 164 & CONT INUE & 00004430 \\
\hline I SN & 289 & 165 & CONT INUE & 00004440 \\
\hline I SN & 290 & & $M=1$ & 00004450 \\
\hline I SN & 291 & & DO $166 \mathrm{~K}=1$, NP & 00004460 \\
\hline ISN & 292 & & $00166 \mathrm{~L}=\mathrm{K}, \mathrm{NP}$ & 00004470 \\
\hline I SN & 293 & & $A(K, L)=A M(M)$ & 00004480 \\
\hline ISN & 294 & & $A(L, K)=A M(M)$ & 00004490 \\
\hline I SN & 295 & 166 & $M=M+1$ & 00004500 \\
\hline I SN & 296 & & DO $168 \mathrm{~K}=1, \mathrm{NP}$ & 00004510 \\
\hline I SN & 297 & & $\mathrm{DB}(\mathrm{K})=0.0$ & 00004520 \\
\hline ISN & 298 & & IF (IB (K) NE O $\quad \mathrm{GO} 10 \quad 168$ & 00004530 \\
\hline$I S N$ & 299 & & DO $167 \quad \mathrm{l}=1, \mathrm{NP}$ & 00004540 \\
\hline I SN & 300 & 167 & $\mathrm{DB}(\mathrm{K})=\mathrm{DB}(\mathrm{K})+\mathrm{A}(\mathrm{K}, \mathrm{L}) * v(\mathrm{~L})$ & 00004550 \\
\hline I SN & 301 & & $D B(K)=D B(k) / D G(K)$ & 00004560 \\
\hline I SN & 302 & 168 & $B(K)=B S(K)+D B(K)$ & 00004570 \\
\hline I SN & 303 & & GO TO $(113,120,130,136)$, IRET & 00004580 \\
\hline $1 \mathrm{SN}$ & 304 & 169 & WRTTE $(6,188)$ M, NCYC,IRET & 00004590 \\
\hline$I S N$ & 305 & & IRET IRET+ $1000 * N C Y C+M * 1000 * 2$ & 00004600 \\
\hline \multirow[t]{3}{*}{ I SN } & 306 & & RETURN & 00004610 \\
\hline & & & & 00004620 \\
\hline & & & & 00004630 \\
\hline ISN & 307 & 170 & FORMAT ('OPARAMETERS AND SIGMAS') & 00004640 \\
\hline
\end{tabular}




\begin{tabular}{|c|c|c|c|c|c|c|}
\hline & & & RMAI & (.OB & & 00004 \\
\hline **+ERRUR & & 112 & FURMA & (1X, 1P3E $11.3,(T 35,5 E 10.3))$ & & 00004660 \\
\hline I SN & 310.4 & 173 & FORMAT & $\left(O^{\prime}, 5 \mathrm{x}, \mathrm{Y}, 10 \mathrm{X}, \mathrm{YC}, 10 \mathrm{X}, \mathrm{DEL}, \mathrm{g}, \mathrm{X}-1 \mathrm{M}\right)$ & Gikuụp & OMMA ASSUM \\
\hline ISN & 3i & 174 & FORMAT & $(15.5 \times, 10+7.3)$ & & $\begin{array}{l}00004670 \\
00004680\end{array}$ \\
\hline I SN & 312 & 175 & FORMA I & (' CORRELAIIION MATRIX') & & 90 \\
\hline ISN & 313 & 176 & FORMAT & (' ONON LINEAR LSO ROUIINE WITH MAROUARDT STRAT & TEGY') & 04700 \\
\hline I SN & 314 & 177 & FORMA! & (' GAMMA LAMBDA TEST GAMMA $=\prime, F 4.0, ' ; \quad$ LAMBDA $=\prime$, & . 1PE 7.0) & 710 \\
\hline I SN & 315 & 178 & FORMAT & 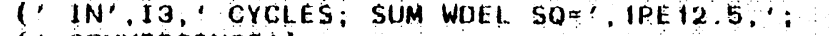 & $R M S D=!, E 12 . E$ & 5) 00004720 \\
\hline I SN & 316 & 179 & FORMAT & (' CONVERGENCE') & & 730 \\
\hline ISN & 317 & 180 & FORMAT & (' GAMMA EPSILON TEST $\rightarrow$ CONVERGENCE') & & 40 \\
\hline I SN & 318 & 181 & FORMAT & (' NCYCLES EXCEEDED') & & \\
\hline I SN & 319 & 182 & FORMAT & (' CYCLE',12,': RMSD=', IPE 12.5,': & E7.1) & 60 \\
\hline ISN & 320 & 183 & FORMAT & $(I 5,5 \times, 5($ PE 13,4$), /, 12 \times, 5 E 13.4)$ & & 70 \\
\hline 15 & $32 !$ & 184 & FORMAT & $B * B$ (NVERSE') & & 180 \\
\hline I SN & 322 & 185 & FORMAT & (. MAIRIX CONDITIION NUMBER & & 30 \\
\hline 1 ISI & 323 & 186 & FORMAT & NO CONVERGENCE GAMMA=!,F4.O) & & 300 \\
\hline ISI & 324 & 187 & FORMAT & $(5 \times, 5(A 3,12, A 2$, IPE 10.3)) & & 00004810 \\
\hline I SN & 325 & 188 & FORMAI & (' MAIRIX INVERSION ERROR $M=\prime, 15 .^{\prime} \quad$ NCYC $=$ ', I5.' & IREI $=$, . I5) & 00004820 \\
\hline ISN & 326 & 189 & FORMA T & NUM OF PARAMETERS $\left.=0^{\prime}\right)$ & & 30 \\
\hline SN & 327 & & & & & 00004840 \\
\hline
\end{tabular}

*** VS FORTRAN ERROR MESSAGES ***

\begin{tabular}{|c|c|c|c|c|c|c|c|c|c|c|c|}
\hline IF $\times 17551$ & DATA & $4(w)$ & 8 & $\begin{array}{l}\text { A CHARACTER } \\
\text { CONSTANT OF }\end{array}$ & $\begin{array}{l}\text { CONSTANT HAS } \\
\text { I.IKE TYPE TO }\end{array}$ & $\begin{array}{l}\text { BEEN ASSIGNED TO A NON-CIIARACTER } \\
\text { AVOID ERROR MESSAGE. }\end{array}$ & VARIABI.E & OR & ARRAY. & INITIALIZE & WIIH \\
\hline If $\times 17551$ & DATA & $4(w)$ & $B$ & $\begin{array}{l}\text { A CIIARACTER } \\
\text { CONSTANT OF }\end{array}$ & $\begin{array}{l}\text { CONSTANT HAS } \\
\text { LIKE TYPE TO }\end{array}$ & $\begin{array}{l}\text { BEEN ASSIGNED TO A NON-CHARACTER } \\
\text { AVOID ERROR MESSAGE. }\end{array}$ & VARIABLE & OR & ARRAY. & INITIALIZE & WITH \\
\hline
\end{tabular}

IFX1264I FORM $4(W)$ 309 SLASH, COLON, OR COMMA EXPECTED AFTER DELIMITER GROUP "2".

*STATISTICS* SOURCE STATEMENTS = 313, PROGRAM SIZE = 227A6 BYTES, PROGRAM NAME = NILLSO PAGE: 7 .

*STATISTICS* 3 DIAGNOSTICS GENERATED. HIGHEST SEVERITY CODE IS 4.

***** END OF COMPILAIION 6 ***** 
APPENDIX D

SAS PROGRAM ACTIV 
SAS PROGRAM ACTIV TO FIND ACTIVATION ENERGIES EROM RATE CONSTANT DATA

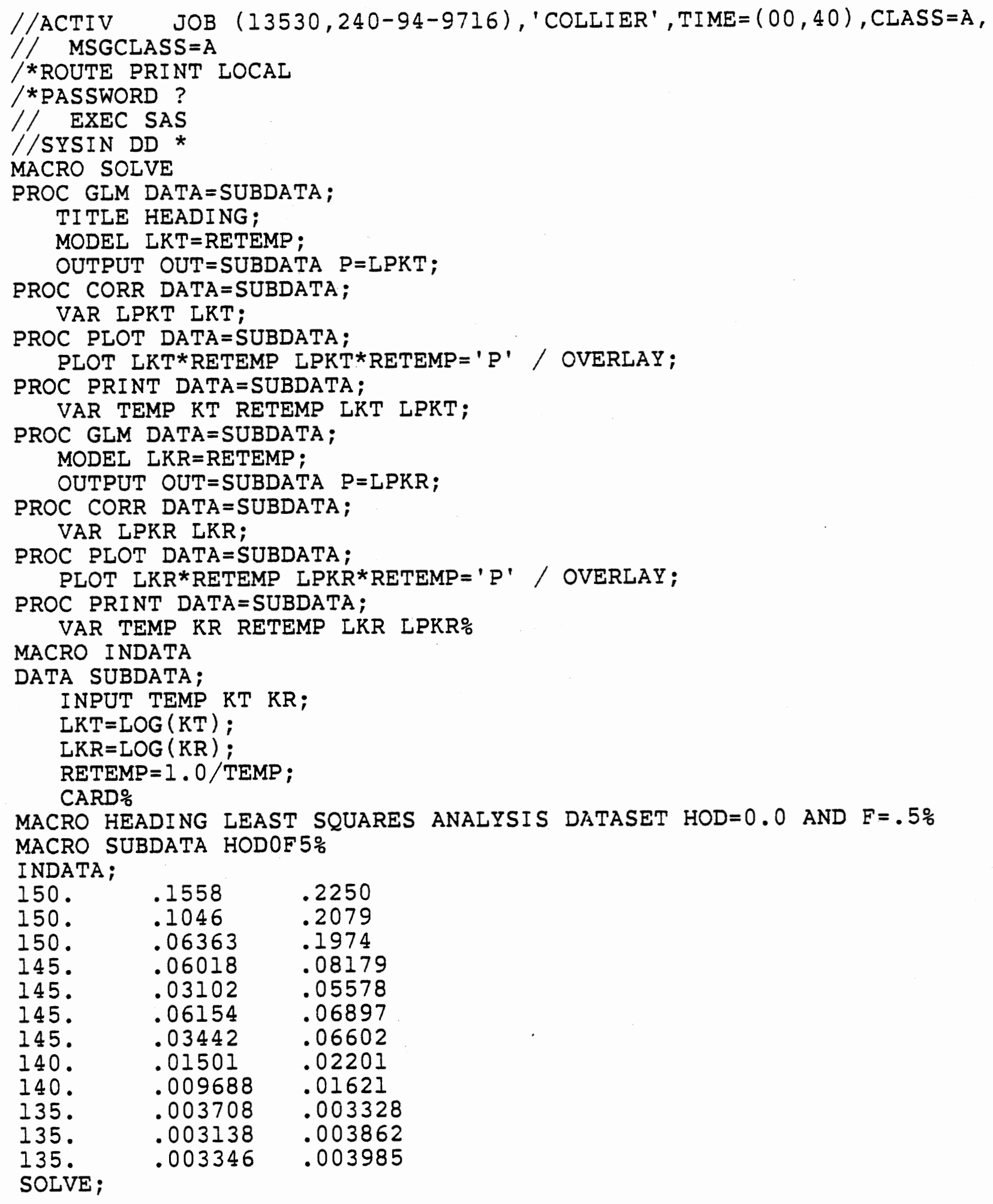


PAGE 2

MACRO HEADING LEAST SQUARES ANALYSIS DATASET HOD $=0.0$ AND $F=.7368 \%$ MACRO SUBDATA HODOF 73\%

INDATA;

$\begin{array}{lll}150 . & .1556 & .2143 \\ 150 . & .1046 & .1974 \\ 150 . & .06366 & .1924 \\ 145 . & .05999 & .07713 \\ 145 . & .03105 & .05444 \\ 145 . & .06144 & .06632 \\ 145 . & .03442 & .06388 \\ 140 . & .01500 & .02135 \\ 140 . & .009688 & .01578 \\ 135 . & .003707 & .003304 \\ 135 . & .003136 & .003783 \\ \text { I35. } & .003346 & .003934 \\ \text { SOLVE; } & & \end{array}$

MACRO HEADING LEAST SQUARES ANALYSIS DATASET HOD $=0.0$ AND $F=1.0 \%$ MACRO SUBDATA HODOFI\%

INDATA;

$\begin{array}{lll}150 . & .1551 & .2041 \\ 150 . & .1045 & .1878 \\ 150 . & .06367 & .1873 \\ 145 . & .05977 & .07297 \\ 145 . & .03105 & .05307 \\ 145 . & .06131 & .06386 \\ 145 . & .03441 & .06178 \\ 140 . & .01498 & .02068 \\ 140 . & .009684 & .01535 \\ 135 . & .003708 & .003280 \\ 135 . & .003134 & .003706 \\ \text { I35. } & .003346 & .003882 \\ \text { SOLVE; } & & \end{array}$

MACRO HEADING LEAST SQUARES ANALYSIS DATASET HOD $=.25$ AND $\mathrm{F}=.5 \%$ MACRO SUBDATA HOD25F5\% INDATA;

$\begin{array}{lll}150 . & .1567 & .3059 \\ 150 . & .1047 & .2927 \\ 150 . & .06367 & .2841 \\ 145 . & .06024 & .1050 \\ 145 . & .03121 & .08420 \\ 145 . & .06168 & .09504 \\ 145 . & .03442 & .08425 \\ 140 . & .01501 & .02809 \\ 140 . & .009691 & .02076 \\ 135 . & .003706 & .004098 \\ 135 . & .003134 & .004810 \\ 135 . & .003344 & .004823 \\ \text { SOLVE; } & & \end{array}$

MACRO HEADING LEAST SQUARES ANALYSIS DATASET HOD $=.25$ AND $F=.7368 \%$ MACRO SUBDATA HOD25F73\% INDATA;

$\begin{array}{lll}150 . & .1559 & .2760 \\ 150 . & .1046 & .2617 \\ 150 . & .06367 & .2674\end{array}$




$$
\begin{gathered}
\text { VITA } \\
\text { William Bridgman Collier } \\
\text { Candidate for the Degree of } \\
\text { Doctor of Philosophy }
\end{gathered}
$$

Thesis: SPECTROSCOPICALLY EVALUATED RATES AND ENERGIES FOR PROTON TRANSFER AND BJERRUM DEFECT MIGRATION IN CUBIC ICE

Major Field: Chemistry

Biographical:

Personal Data: Born in Rocky Mount, North Carolina on October 30,1954 , one of four children of John R. and Carrie M. Collier.

Education: Graduated from Roanoke Rapids High School, Roanoke Rapids, North Carolina, in 1973; received Bachelor of Science degree from Oral Roberts University, Tulsa, Oklahoma with a major in Chemistry in May 1977; received Master of Science degree from Oklahoma State University, Stillwater, Oklahoma with a major in Physical Chemistry in December 1981; and completed requirements for the Doctor of Philosophy degree at Oklahoma State University, December, 1983.

Professional Experience: Undergraduate Research Program Participant, University of Oklahoma, Summer, 1976; Graduate Teaching Assistant, 1977-1978, 1980-1983; Graduate Research Assistant, 1978-1983; Member of American Chemical Society; Member of Phi Lambda Upsilon, Honorary Chemical Society. 